UNIVERSIDADE DE SÃO PAULO

ESCOLA DE ENGENHARIA DE SÃO CARLOS

DEPARTAMENTO DE ENGENHARIA DE PRODUÇÃO

\title{
MODELOS DE REFERÊNCIA PARA O PROCESSO DE DESENVOLVIMENTO DE PRODUTOS: NOVAS POSSIBILIDADES DE REPRESENTAÇÃO
}

Carolina Román Amigo

\begin{abstract}
Dissertação apresentada à Escola de Engenharia de São Carlos da Universidade de São Paulo como requisito parcial para obtenção do título de mestre em Engenharia de Produção

Área de Concentração: Processos e Gestão de Operações

Orientador: Prof. Tit. Henrique Rozenfeld
\end{abstract}


AUTORIZO A REPRODUÇÃO TOTAL OU PARCIAL DESTE TRABALHO, POR QUALQUER MEIO CONVENCIONAL OU ELETRÔNICO, PARA FINS DE ESTUDO E PESQUISA, DESDE QUE CITADA A FONTE.

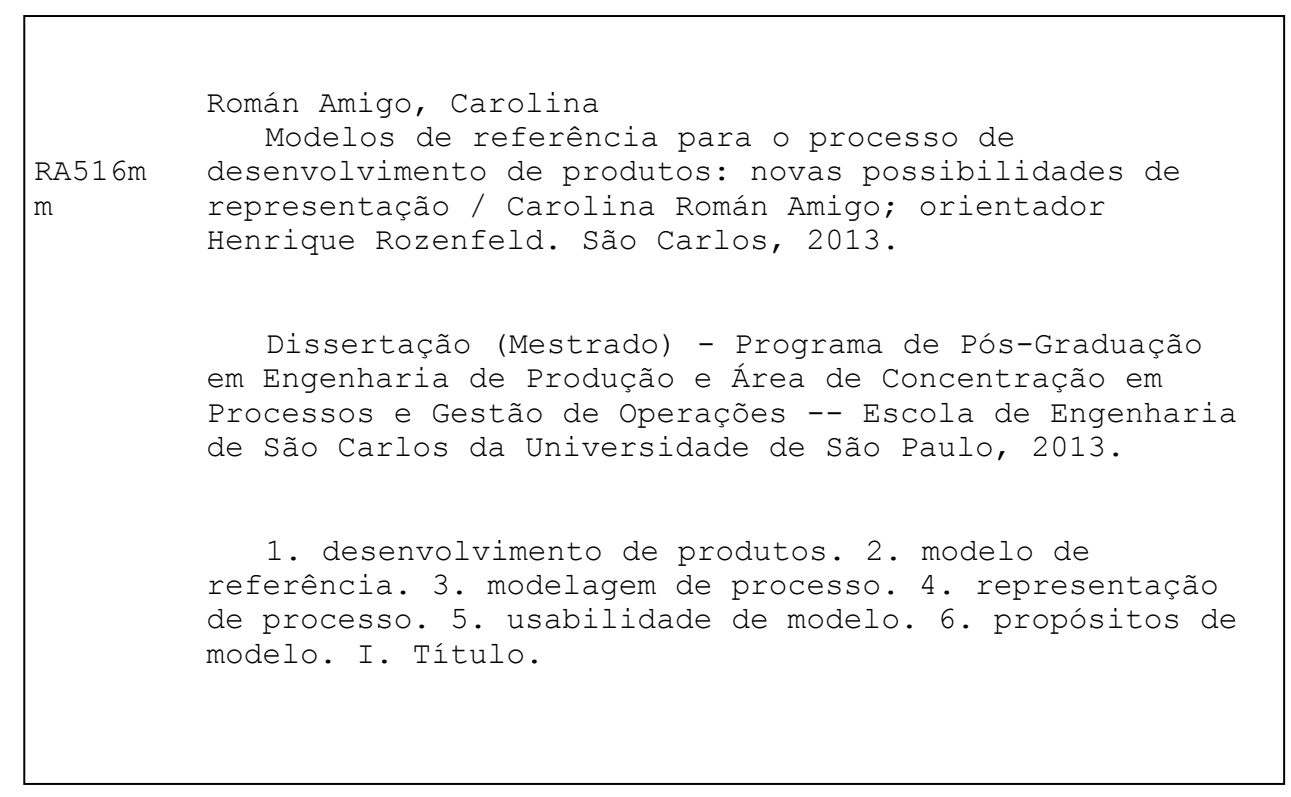




\section{FOLHA DE JULGAMENTO}

Candidata: Arquiteta e Urbanista CAROLINA ROMAN AMIGO.

Título da dissertação: "Modelos de referência para o processo de desenvolvimento de produtos: novas possibilidades de representação".

Data da defesa: 20/06/2013

Comissão Julgadora:

Prof. Titular Henrique Rozenfeld (Orientador)

(Escola de Engenharia de São Carlos/EESC)

Prof. Associado Daniel Capaldo Amaral

(Escola de Engenharia de São Carlos/EESC)
Resultado:
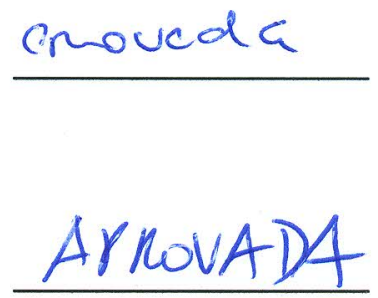

Prof. Dr. Roquemar de Lima Baldam

APROJA DA

(Instituto Federal de Educação, Ciência e Tecnologia do Espírito Santo/IFES)

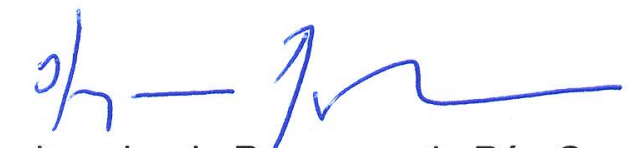

Coordenador do Programa de Pós-Graduação em Engenharia de Produção:

Prof. Titular Henrique Rozenfeld

Presidente da Comissão de Pós-Graduação:

Prof. Titular Denis Vinicius Coury 

Dedico este trabalho a meu pai, minha maior referência, cujo exemplo eu levo comigo para toda a vida 



\section{Agradecimentos}

Ao meu orientador, Prof. Henrique Rozenfeld, pelo excelente ambiente de pesquisa que proporciona a seus alunos e pelo contagiante entusiasmo e energia com que conduz suas pesquisas.

Ao meu irmão Ricardo, pela valiosa ajuda na elaboração do protótipo $\mathrm{A}$, pelas longas horas de ensinamentos sobre base de dados e programação e pelas inspiradoras discussões sobre este mestrado.

Ao Prof. Daniel, pela dedicação e atenção que sempre deu ao meu trabalho, com contribuições que tanto acrescentaram à sua qualidade.

Aos alunos de graduação Bruno e Fernanda, que me ajudaram na elaboração dos protótipos.

Ao meu marido Mateus, pelo companheirismo e dedicação nos meses em que precisei de ajuda para preparar o texto dessa dissertação ao computador.

Aos meus queridos colegas de laboratório, amigos que me acolheram nesta nova cidade e que sempre estavam dispostos a ajudar no desenvolvimento deste trabalho: Ana, Camila, Dani, Diego, Gabi, Gui, Jana, João, Kênia, Luís, Luke, Mateus, Miriã, Edivandro, Maicon, Taís, Vanessa, Vitor, Vitor Macul, Sayuri, Samuel e a todos os demais e não menos importantes amigos integrantes do Departamento de Engenharia de Produção da EESC.

A todos os potenciais usuários dos protótipos que se voluntariaram a participar dos testes de usabilidade; sem a contribuição de vocês, esta pesquisa não teria sido possível.

Ao Wagner, da Klug Solutions $\AA$, que disponibilizou a excelente plataforma de modelagem ARPOß para a modelagem do protótipo $B$ desta pesquisa.

À minha mãe Filomena, à minha irmã Cristina, ao meu cunhado Danilo, à minha tia Enza e à minha Nonna pelas inúmeras visitas e caronas para São Paulo, que encurtaram as distâncias e diminuíram a saudade.

À Comissão de Aperfeiçoamento de Pessoal de Nível Superior (CAPES) e à Fundação de Amparo à Pesquisa do Estado de São Paulo (FAPESP), pelo suporte financeiro que viabilizou minha dedicação exclusiva a este mestrado.

Aos funcionários do Departamento de Engenharia de Produção da EESC pelo apoio e à Universidade de São Paulo, pelo ensino gratuito e de excelência. 



\section{Resumo}

Há um consenso na literatura de que a aderência a um modelo de referência torna a gestão do processo de desenvolvimento de produtos (PDP) mais eficiente, pois estes auxiliam na sua representação, compreensão, elaboração, gestão e melhoria. Apesar de existirem diversos métodos de modelagem de PDP disponíveis, estes métodos são ainda pouco utilizados pela comunidade prática. Uma das possíveis causas deste problema é a dificuldade que as vistas elaboradas por estes métodos de modelagem oferecem para a visualização e compreensão do processo. Não há ainda estudos sobre a modelagem de PDP que considerem a perspectiva do usuário de forma satisfatória. Esta pesquisa tem por objetivo propor novas vistas para modelos de referencia de PDP que sejam mais eficazes, eficientes e satisfatórias no atendimento aos propósitos dos usuários de modelos de referência de PDP, em comparação com as vistas existentes. Para isso foram desenvolvidos dois protótipos de modelos de referência de PDP, um com novas vistas propostas, de caráter analógico, e um com vistas existentes, baseadas em fluxo de atividades com ligações lógicas. Esses protótipos foram submetidos a testes de usabilidade. Os resultados mostram que as vistas propostas foram mais eficazes, eficientes e satisfatórias para a maioria dos propósitos analisados. Conclui-se que vistas analógicas podem ser mais adequadas para a representação de modelos de referência de PDP, em relação às vistas existentes baseadas em fluxo lógico de atividades.

Palavras-chave: desenvolvimento de produtos; modelo de referência; modelagem de processo; representação de processo; usabilidade de modelo; propósitos de modelo. 



\begin{abstract}
There is a consensus in the literature that adherence to a reference model makes product development (PD) process managing more efficient, because reference models support the representation, understanding, design and improvement of these processes. Although a variety of modeling methods are available, they are still not intensively used by the practical community. One of the possible reasons for this problem is the difficulty offered to process visualization and comprehension by views elaborated though these modeling methods. There is still a gap on the literature with respect to studies on PD reference models that consider the user perspective. This research aims to propose new views for PD reference models, which can be more effective, efficient and satisfactory than the existing ones regarding the purposes of PD reference models users. For this end, two reference models prototypes were developed, one of them with new analogic views, and another with existing activity network-based views. These prototypes were tested for usability. The results show that the proposed views were more effective, efficient and satisfactory than the traditional ones for most analyzed purposes. The conclusion is that analogic views can be more suitable to satisfy the purposes of users of PD reference models than activity network-based views.
\end{abstract}

Keywords: product development; reference model; process modeling; process representation; model usability; model purposes. 



\section{Lista de figuras}

Figura 1 - Relação entre modelos de referência genéricos e específicos......27

Figura 2 - Pilares da síntese da bibliografia fundamental .............................35

Figura 3 - Relação entre os conceitos relevantes para modelagem do PDP..38

Figura 4 - Exemplificação dos conceitos relevantes dentro de um exemplo de modelo de PDP

Figura 5 - Relação entre um processo, seus modelos e suas vistas (adaptado de Browning, 2010) 42

Figura 6 - Elementos de um modelo de referência (MUNDIM et al., 2002) ....43

Figura 7 - Técnicas de modelagem de processos de negócio utilizadas pelas organizações (Adaptado de Vergidis, Turner e Tiwari, 2008)................................46

Figura 8 - Exemplo de integração entre as vistas ARIS (AMARAL, 2002).....48

Figura 9 - Construtos para modelagem de empresas disponíveis na plataforma ARPO usando os métodos EPC e BPMN (Fonte: material de apresentação da Klug Solutions, disponível em http://www.klugsolutions.com) .......49

Figura 10 - Exemplos de vistas oferecidas pela plataforma ARPO, usando os métodos EPC e BPMN (Fonte: material de apresentação da Klug Solutions, disponível em http://www.klugsolutions.com) .....................................................50

Figura 11 - Trecho de um processo modelado em EPC, na dimensão processos da plataforma ARPO

Figura 12 - Trecho de um processo modelado em EPC, na dimensão organização e pessoas da plataforma ARPO

Figura 13 - Propriedades "Gerente de projeto" na base de dados do ARPO, onde é possível identificar as vistas com ocorrência desse construto. .52

Figura 14 - Visão geral do processo de desenvolvimento pelo RUP (Fonte: Software RUP® IBM).

Figura 15 - Diferentes vistas oferecidas pelo RUP para a disciplina "Modelagem de Negócios": vista do workflow com conjuntos de atividades (A), vista geral das atividades (B) e vista geral dos artefatos (C) (Fonte: Software RUP® IBM).

Figura 16 - Vista detalhada do conjunto de atividades "Identificar processos de negócios" (Fonte: Software RUP® IBM). .56

Figura 17 - Exemplo da visualização centrada em papéis do RUP (Fonte: Software RUP® IBM)

Figura 18 - Exemplo de painel interativo touchscreen (Fonte: Blog G\&G Comunicação interativa)

Figura 19 - Propósitos e vistas relacionados por meio de tributos (adaptado de Browning, 2010)

Figura 20 - Exemplos de ícones (A), e símbolos (B), para construtos com mesmo significado.

Figura 21 - Síntese do raciocínio empregado no planejamento da pesquisa .70

Figura 22 - Framework para classificação de métodos de pesquisa (adaptado de Meredith et al., 1989)

Figura 23 - Pacotes de trabalho com suas principais entregas e relacionamento entre elas 
Figura 24 - Modelo para condução da revisão bibliográfica sistemática - RBS Roadmap (CONFORTO et al., 2011) ........................................................... 77

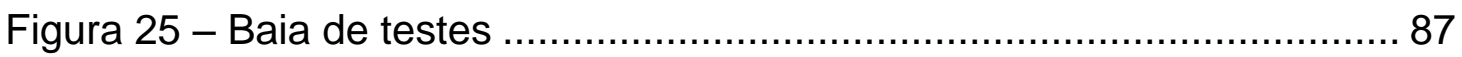
usuário

Figura 26 - Escala utilizada para a coleta de métricas auto-reportadas pelo

Figura 27 - Entregas do pacote de trabalho A............................................ 95

Figura 28 - Aproveitamento da RBS e sobreposição entre as bases de dados

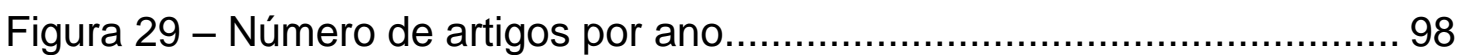

Figura 30 - Modelo de referência para o processo de desenvolvimento de produtos (ROZENFELD et al., 2006).............................................................. 102

Figura 31 - Entregas do pacote de trabalho B....................................... 103

Figura 32 - Relacionamento entre os principais construtos e blocos de

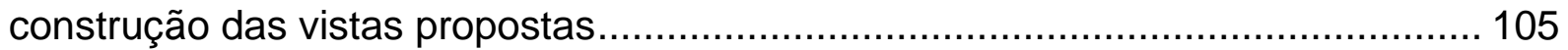

Figura 33 - Diagrama de classes elaborado para a base de dados do protótipo $\mathrm{A}$ 106

Figura 34 - Vista com representação gráfica do modelo navegável (tela inicial) 108

Figura 35 - Vista das fases e gates do processo, com entregas principais. 108

Figura 36 - Vista de tabela, organizada com todos os construtos de uma fase 109

Figura 37 - Vista de órbita de um elemento............................................ 109

Figura 38 - Menu de listas para o construto "Papéis".................................. 110

Figura 39 - Exemplo de vista de órbita centrada em um papel: é possível observar as atividades, entregas, melhores práticas e áreas relacionadas com este papel na fase selecionada.

Figura 40 - Exemplo de vista de órbita centrada em uma entrega: é possível observar as atividades, papéis e áreas relacionadas com essa entrega na fase selecionada.

Figura 41 - Exemplo de vista de órbita centrada em uma atividade: é possível observar os papéis, entregas, melhores práticas e áreas relacionadas com essa atividade na fase selecionada.

Figura 42 - Exemplo de vista de órbita centrada em uma área (neste caso, com o filtro de atividades acionado): é possível observar as entregas e os papéis relacionados com essa área na fase selecionada. 112

Figura 43 - Exemplo de vista de órbita centrada em uma melhor prática: é possível observar as atividades e entregas relacionadas com essa melhor prática na

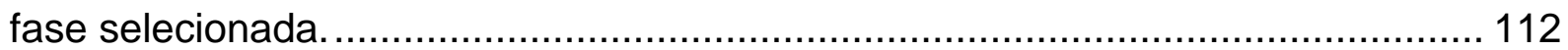

Figura 44 - Principais construtos empregados na modelagem das vistas em EPC 115

Figura 45 - Vista modelada em VAC das macrofases do processo (tela inicial)

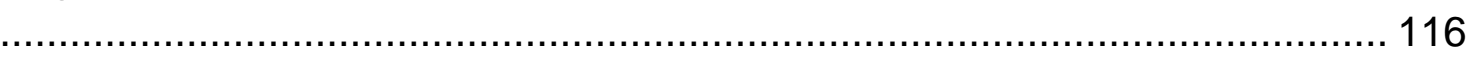

Figura 46 - Vista modelada em VAC das fases e gates do processo .......... 117

Figura 47 - Exemplo de vista de uma fase modelada em eEPC, na dimensão de processos. O fluxo de informações é dado pelos eventos e atividades. 
Figura 48 - Exemplo de vista de uma atividade modelada em eEPC, na dimensão de processos. Construtos que não os de fluxo lógico de atividades são representados nessas vistas.

Figura 49 - Exemplo de vista de propriedades de um elemento do processo. É possível identificar em quais vistas o elemento selecionado ocorre no modelo. .118

Figura 50 - Exemplo de vista de uma área do processo (com seus papéis subordinados), modelada em eEPC, na dimensão organizacional.

Figura 51 - Exemplo de vista de um papel (com suas responsabilidades) modelada em eEPC na dimensão organizacional.

Figura 52 - Entregas do pacote de trabalho C .......................................121

Figura 53 - Eficácia (Sucesso total, Sucesso parcial e Falha) .....................127

Figura 54 - Eficácia detalhada (tipo de estratégia e ajuda)..........................128

Figura 55 - Média de ações por tarefa e número de ações suficientes para realização das tarefas de acordo com a estratégia ideal. 131

Figura 56 - Porcentagem de esforço a mais empregado (ações) pelos usuários para realizar uma tarefa, em relação ao mínimo de ações necessárias de acordo com a estratégia ideal para cada protótipo 132

Figura 57 - Média de segundos por tarefa. 133

Figura 58 - Métricas auto reportadas em relação à facilidade de uso e concordância 135

Figura 59 - Métricas comparativas e combinadas: Eficácia, esforço, tempo e satisfação relativos ( $B$ em relação a $A$ )

Figura 60 - Entregas do pacote de trabalho $D$ 139 



\section{Lista de Tabelas}

Tabela 1 - Exemplos de arquiteturas para modelagem de empresas (adaptado de Vernadat, 1996).

Tabela 2 - Exemplos de linguagens de modelagem de processos de negócios (adaptado de Vergidis, Tiwari e Majeed, 2008) ....................................................37

Tabela 3 - Exemplos de construtos comuns em modelos de PDP ................39

Tabela 4 - Blocos de construção fundamentais de modelos de PDP e alguns de seus atributos (adaptado de Browning, 2010)

Tabela 5 - Categorias de usuários de modelos de processos (adaptada de Browning, 2010)

Tabela 6 - Propósitos de modelos de processos, identificados para o usuário "Dono do processo" (adaptado de Browning, 2010).

Tabela 7 - Etapas do método para obtenção do alinhamento entre propósitos de modelos e métodos de modelagem (Adaptado de Browning, 2010) ....................63

Tabela 8 - Principais atividades dos pacotes de trabalho ……......................75

Tabela 9 - Síntese das etapas do modelo para condução de RBS.................78

Tabela 10 - Etapas e atividades do desenvolvimento dos protótipos .............81

Tabela 11 - Critérios para seleção de usuários para os testes de usabilidade

Tabela 12 - Sequência de atividades para realização dos testes de usabilidade

Tabela 13 - Método para o cálculo do tempo planejando e realizando a tarefa 88

Tabela 14 - Escala utilizada para avaliar a eficácia das tarefas. Fonte: adaptada de Tullis e Albert (2008). 89

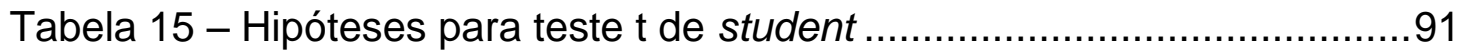

Tabela 16 - Valores numéricos atribuídos à escala likert..............................92

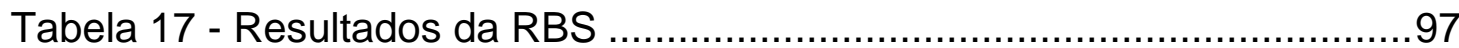

Tabela 18 - Periódico com mais artigos selecionados pela RBS ...................97

Tabela 19 - Número de artigos selecionados por autor ................................98

Tabela 20 - Propósitos de usuários de modelos de referência de PDP..........99

Tabela 21 - Perfil dos usuários selecionados para o teste de usabilidade...121

Tabela 22 - Tarefas do roteiro para os testes de usabilidade .....................124

Tabela 23 - Propósitos para os quais nenhum protótipo testado é eficaz....139

Tabela 24 - Propósitos para os quais não é possível garantir com 95\% de confiança que há diferença em relação à eficiência dos protótipos.

Tabela 25 - Propósito que teve resultados discrepantes para suas tarefas. 141

Tabela 26 - Propósitos para os quais é possível concluir que o protótipo A é mais eficaz, eficiente e satisfatório que o protótipo $B$. 



\section{Lista de Siglas e Abreviaturas}

BOM: Bill of Materials

BPMN: Business Process Model and Notation

CPM: Critical Path Method

CSS: Cascading Style Sheets

DP: Desenvolvimento de Produtos

DSM: Design Structured Matrix

EPC: Event Process Chain

eEPC: Extended Event Process Chain

FMEA: Failure Mode and Effects Analysis

IDEF: Integration Definition for Function Modeling

ISO: International Organization for Standardization

PDP: Processo de Desenvolvimento de Produtos

PDMA: Product Development and Management Association

PERT: Program (or Project) Evaluation and Review Technique

QFD: Quality Function Deployment

RBS: Revisão Bibliográfica Sistemática

SIPOC: Suppliers, Inputs, Process, Outputs, and Customers

SQL: Structured Query Language

VAC: Value Added Chain

WBS: Work Breakdown Structure 



\section{Sumário}

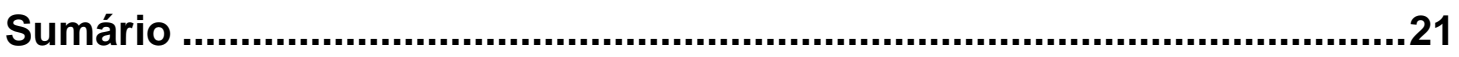

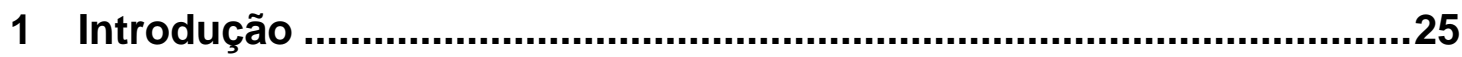

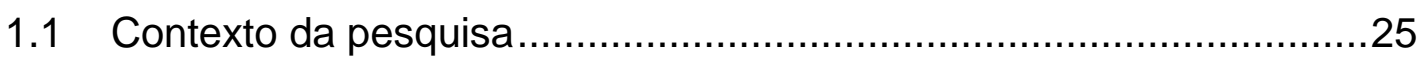

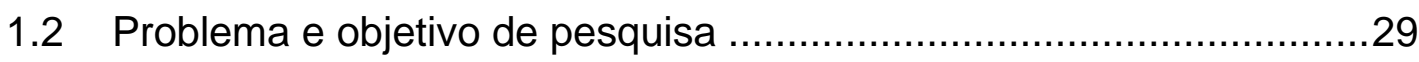

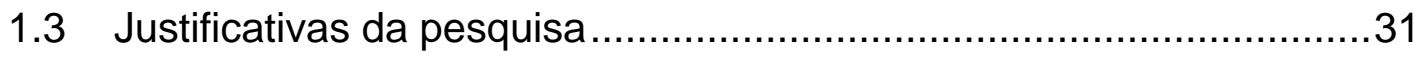

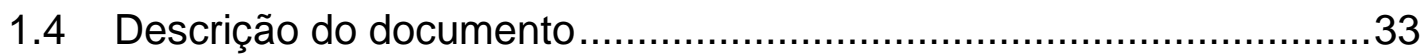

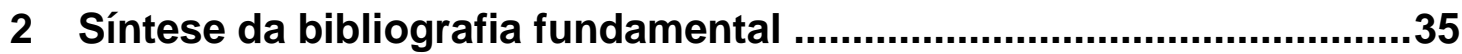

2.1 Modelagem do processo de desenvolvimento de produtos................35

2.1.1 Principais conceitos e definições................................................36

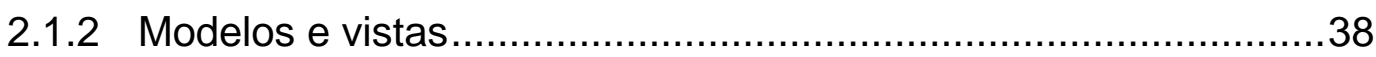

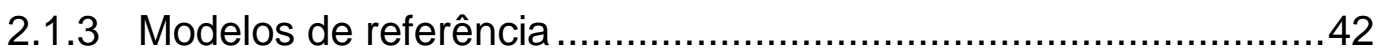

2.1.4 Métodos de modelagem do PDP ...........................................43

2.1.5 Ferramentas computacionais empregadas na representação de

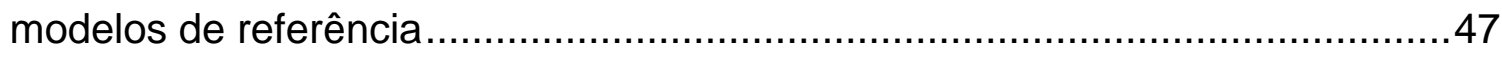

2.1.5.1 Plataformas de modelagem de empresas ..........................47

2.1.5.2 Modelos de referência customizáveis para uma área de conhecimento 53

2.1.5.3 Softwares para modelagem de workflow .............................57

2.1.5.4 Softwares de desenho ou planilhas ......................................58

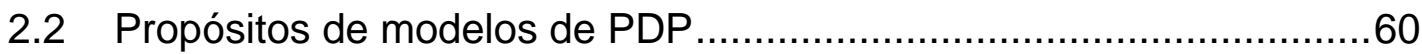

2.3 Interação dos usuários com um modelo de processo ..........................64

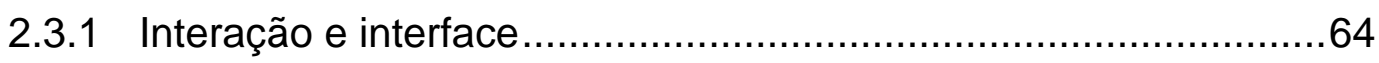

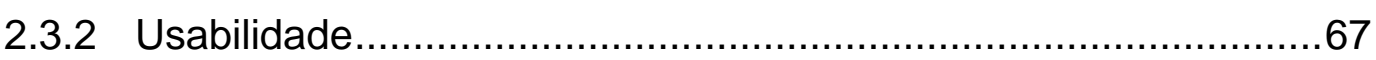

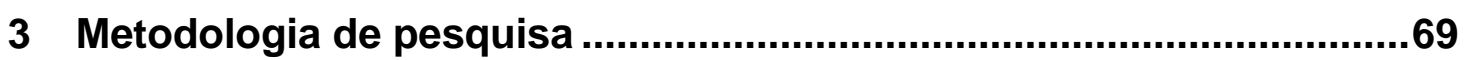

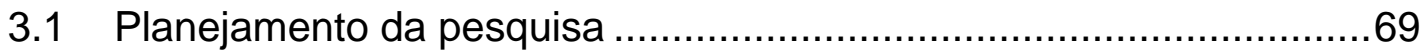

3.2 Pacotes de trabalho, principais entregas e respectivas atividades ....74

3.3 Métodos empregados no pacote de trabalho A: Teoria......................76

3.3.1 Revisão bibliográfica sistemática .............................................76

3.3.2 Definição dos propósitos de modelos de referência de PDP e escolha do método de modelagem ......................................................78

3.4 Métodos empregados no pacote de trabalho B: Desenvolvimento dos protótipos 80 
3.5 Métodos empregados no pacote de trabalho C: Avaliação dos protótipos 82

3.5.1 Seleção dos usuários 83

3.5.2 Testes de usabilidade 85

3.5.3 Procedimentos para extração dos dados dos testes de usabilidade 88

3.6 Métodos empregados no pacote de trabalho D: Análise dos resultados 89

3.6.1 Escala para medir eficácia 89

3.6.2 Estatística descritiva para métricas de eficiência. 90

3.6.3 Teste t de student (eficiência) .90

3.6.4 Escala comparativa (métricas auto-reportadas/satisfação) ......... 91

3.6.5 Índice de Concordância (métricas auto-reportadas) .................... 93

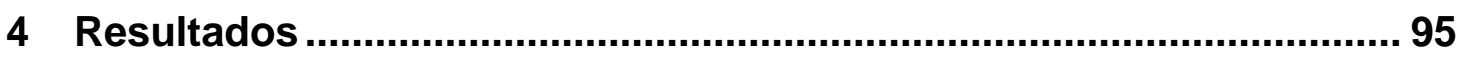

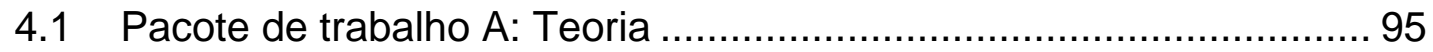

4.1.1 Revisão bibliográfica sistemática sobre métodos de modelagem para o PDP 95

4.1.2 Propósitos de usuários de modelos de referência de PDP e método existente de modelagem selecionado................................................ 99

4.1.3 Modelo de referência genérico selecionado …......................... 100

4.2 Pacote de trabalho B: Desenvolvimento dos protótipos.................... 103

4.2.1 Protótipo A: vistas propostas .................................................... 103

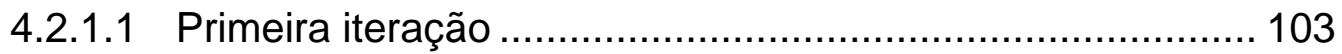

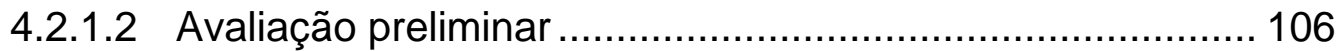

4.2.1.3 Segunda iteração - Vistas finais ...................................... 107

4.2.2 Protótipo B: vistas do método de modelagem eEPC …............. 113

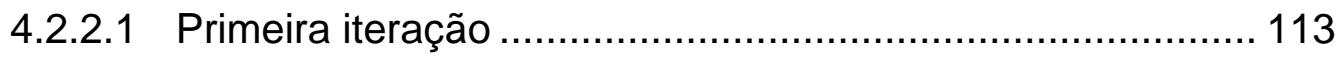

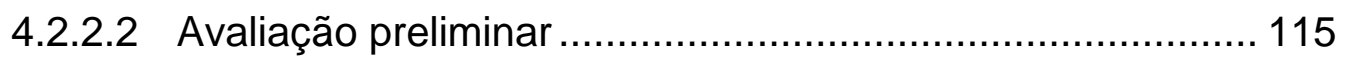

4.2.2.3 Segunda iteração - Vistas finais ...................................... 116

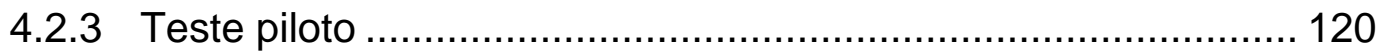

4.3 Pacote de trabalho C: Avaliação dos protótipos ............................. 121

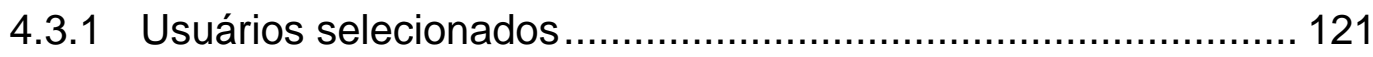

4.3.2 Roteiro de tarefas para testes de usabilidade ........................... 123

4.3.3 Dados coletados nos testes de usabilidade ............................. 125

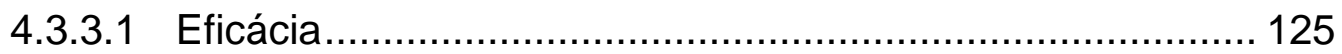

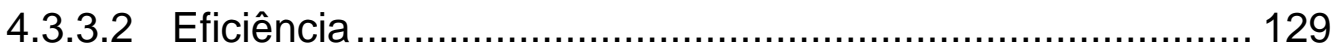


4.3.3.3 Métricas auto-reportadas (Satisfação) ..............................134

4.3.3.4 Métricas comparativas e combinadas .................................136

5 Análise dos resultados e conclusões ............................................139

5.1 Limitações e sugestões de trabalhos futuros .................................143

5.2 Principais contribuições para a área de conhecimento ...................146

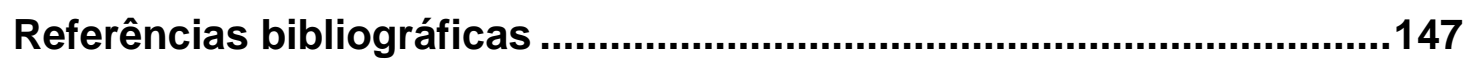

Apêndice A - Definições de termos relevantes para a modelagem de PDP .153

Apêndice B - Protocolo da revisão bibliográfica sistemática ..................157

Apêndice C - Tabela síntese dos métodos de modelagem de PDP.........163

Apêndice D - Artigo: Views of process models suitable for PD reference models purposes. .209

Apêndice E - Questionário Perfil do Usuário..........................................229 usuários

Apêndice F - Exemplo da apresentação do roteiro de tarefas para os

Apêndice G - Gabarito do roteiro de tarefas dos testes de usabilidade .239

Apêndice H - Sequência preferencial de ações necessárias (estratégia

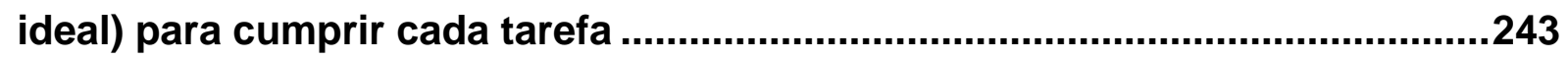

Apêndice I - Termo de consentimento livre e esclarecido .....................247

Apêndice J - Legenda dos ícones do protótipo A...................................249

Apêndice K - Relatório do percurso cognitivo para os protótipos A e B .251

Apêndice $\mathrm{L}$ - Estatistica descritiva e teste $\mathrm{t}$ de student para métricas de eficiência. .255 



\section{Introdução}

\subsection{Contexto da pesquisa}

A capacidade de inovação por meio do desenvolvimento de novos produtos é, dentre as capacidades básicas das organizações, uma das que conferem maior vantagem competitiva por ser de difícil imitação (SLATER, 1996; GRIFFIN, 1997; BESSANT; FRANCIS, 1997). O processo de desenvolvimento de produtos é o processo pelo qual uma organização transforma dados sobre oportunidades de mercado e possibilidades técnicas em informações de valor para a produção comercial (CLARK; FUJIMOTO, 1991). Ele é considerado um processo de negócios com características específicas, pois envolve criatividade e inovação e é não linear e iterativo (KLINE, 1985; COOPER; KLEINSCHMIDT, 1995; BARCZAK et al., 2009).

Um processo de negócio pode ser definido como um conjunto de atividades estruturadas e medidas, com o objetivo de produzir um resultado específico para um mercado ou cliente em particular (DAVENPORT, 1993; VERNADAT, 1996; HARRINGTON et al., 1997; BROWNING et al., 2006). Segundo Jeston e Nelis (2006), a gestão de processos de negócio ${ }^{1}$ consiste na realização dos objetivos de uma organização por meio da melhoria e controle desses processos. A gestão por processos traz diversas vantagens para o processo de desenvolvimento de produtos, como tornar claras as relações dentro da organização e entre a organização e o mercado; facilitar a visão interdisciplinar, aumentando a integração; e alinhar toda a organização em torno de um objetivo comum, pois enfoca as atividades que agregam valor ao processo e não apenas responsabilidades, hierarquias e funções individuais (CLARK; FUJIMOTO, 1991; DESCHAMPS; NAYAK, 1997; ROZENFELD et al., 2006; BARCZAK et al., 2009).

Assim como para outros processos, é possível e útil construir modelos para o processo de desenvolvimento de produtos (SMITH; MORROW, 1999; ENGWALL et al., 2005). Um modelo pode ser definido como "uma representação (com maior ou menor grau de formalidade) de uma abstração da realidade expressa em um tipo específico de formalismo" (VERNADAT, 1996; BROWNING, 2006). Um modelo de

\footnotetext{
${ }^{1}$ Em inglês BPM (Business process management).
} 
processo deve ajudar as pessoas a representar e compreender todas as interações internas ao processo que nem sempre estão evidentes (PARK; CUTKOSKY, 1999).

Um modelo pode ser prescritivo (to-be), informando as pessoas qual 0 trabalho e como ele deve ser realizado; ou descritivos (as-is), descrevendo a realidade como ela é e procurando representar o conhecimento sobre como o trabalho é feito (BROWNING et al., 2006).

Há modelos de referência genéricos e específicos. Modelos de referência genéricos são representações de processos de negócio contendo melhores práticas da área de aplicação. Eles são prescritivos e possuem um conjunto de diretrizes de caráter genérico, que podem ser adaptadas para aplicação em diversos contextos (FETTKE et al., 2006). Usualmente modelos de referência genéricos são elaborados por instituições ou organizações ou resultantes de pesquisas elaboradas por autores consagrados, como Pahl e Beitz (1988); Cooper (2001); Ulrich e Eppinger (2007), entre outros.

Um modelo de referência genérico pode ser adaptado para um determinado contexto, resultando em um modelo de referência específico de caráter prescritivo (to-be), ou seja, uma instância do modelo genérico (VERNADAT, 1996; BROWNING et al., 2006; FETTKE; LOOS, 2006). Esse modelo de referência específico também pode ser resultado da melhoria de um modelo específico de caráter descritivo (asis). Modelos específicos descritivos são úteis para retratar e analisar o processo real de uma organização, tal como ele ocorre. Qualquer que seja sua origem, um modelo de referência específico fornece bases para o planejamento do desenvolvimento de um produto em particular, que é tratado como um projeto (Figura 1). Projetos são definidos pelo PMI (2008) como "empreendimentos temporários realizados para criar um produto, serviço ou resultado único." Modelos específicos também são denominados processos padrão (BROWNING, 2010). 


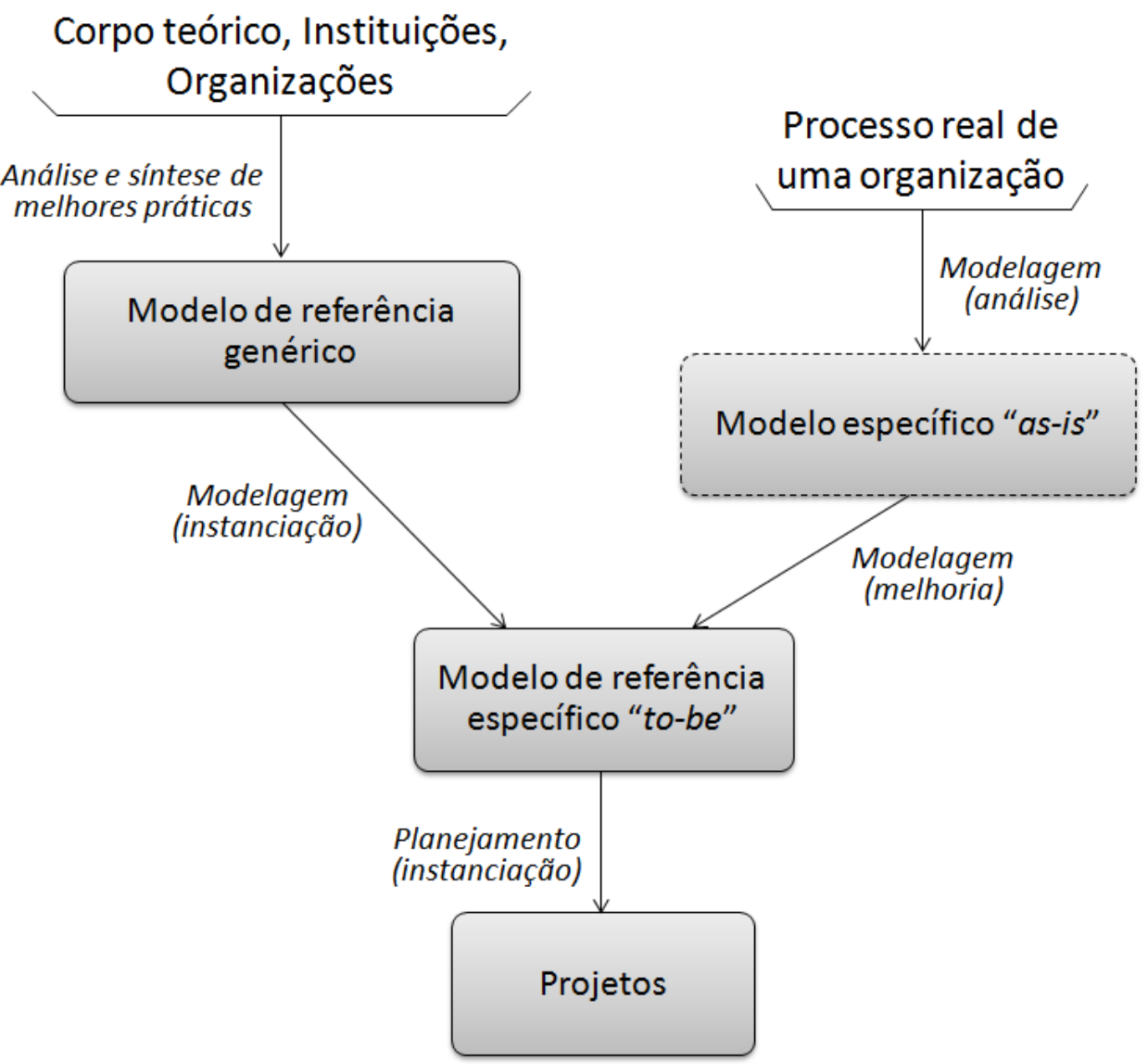

Figura 1 - Relação entre modelos de referência genéricos e específicos.

Um mesmo processo pode ser modelado de várias maneiras diferentes. Existem diversos métodos de modelagem (ou formalismos) ${ }^{2}$ para a representação de um processo disponíveis na literatura. Um método de modelagem é "um conjunto de elementos (construtos e regras de sintaxe) capaz de representar uma parte da realidade, relativa a um subconjunto do domínio do processo/sistema que está sendo modelado"(AMARAL, 2002). Em outras palavras, um método de modelagem fornece os passos e a linguagem para que se possa representar a realidade, ou seja, elaborar o modelo de um processo.

Por sua vez, o modelo de um processo, modelado com um dado formalismo, pode ser visto de diferentes formas pelos seus diferentes usuários. Por exemplo, um processo modelado com o método eEPC (extended event process chain) pode oferecer uma vista para o fluxo de informações entre departamentos da empresa e outra vista para o fluxo de informações entre as atividades do processo, ou ainda uma vista com o organograma de papéis na empresa, entre outras. Segundo Browning (2008), as vistas de um modelo podem ser definidas da seguinte forma:

\footnotetext{
${ }^{2}$ Para mais detalhes sobre os termos empregados, consulte o item 2.1.1.
} 
Ao passo que um modelo de processo inclui todos os atributos ou conjecturas subjacentes consideradas suficientes para descrevê-lo, uma vista é um arranjo de símbolos, uma tabela, ou outra representação escolhida para mostrar um subconjunto selecionado desses atributos ou conjecturas.

Ou seja, uma vista simplifica a visualização de um modelo (que geralmente é complexo), ao selecionar apenas os elementos relevantes para um dado propósito. Por exemplo, um usuário que seja o gestor de projetos consultará um nível de granularidade do modelo (com atividades, responsáveis e cronogramas, por ex.) diferente de um usuário que seja o dono do processo ${ }^{3}$ (com uma visão mais geral das fases do processo e papéis genéricos, por ex.). Dessa forma, cada usuário efetivamente só entra em contato com o modelo por meio das vistas que lhe são disponibilizadas. Por esta razão, nesta pesquisa será utilizado o termo vista de um modelo quando o foco estiver na interação do usuário com um modelo.

A modelagem de processos oferece vários desafios. É difícil representar um processo consistentemente e sem ambiguidades. Um método de modelagem deve ser genérico o suficiente para possibilitar a modelagem de vários tipos de processos, mas ao mesmo tempo específico o suficiente para discernir as possíveis vistas e evitar múltiplas interpretações (ex: um fluxograma serve para modelar praticamente todo o tipo de processo, mas dá margem para múltiplas interpretações). Modelar um processo complexo como o desenvolvimento de um produto em vários níveis de granularidade, a fim de atender às necessidades dos diferentes usuários do modelo também é tarefa árdua (PARK; CUTKOSKY, 1999; BROWNING et al., 2006).

Há ainda o desafio de apresentação das informações no modelo (PARK; CUTKOSKY, 1999). A escolha da forma de representação de um processo é relevante, pois ela pode atuar como um moderador da sua eficácia em atingir seu propósito primordial (BROWNING; RAMASESH, 2007). Isso pode ocorrer, por exemplo, porque o método de modelagem escolhido não representa algumas informações relevantes para o usuário; ou então porque as informações relevantes para determinado propósito de um usuário do modelo estão disponíveis, mas não suficientemente claras ou evidentes na vista fornecida.

Há uma extensa literatura sobre métodos de modelagem de processos de negócio. Autores como Kettinger et al. (1997); Melão e Pidd (2000); Kalpic e Bernus

${ }^{3}$ As definições de usuários do processo que são utilizadas nesta pesquisa são as sugeridas por Browning (2010), e estão disponíveis no item 2.2. 
(2002); Aguilarsaven (2004); Vergidis, Tiwari e Majeed (2008) realizaram revisões sobre os métodos de modelagem existentes. É possível encontrar alguns autores com revisões de literatura específicas sobre a modelagem de processos de desenvolvimento de produtos (SMITH; MORROW, 1999; O'DONOVAN et al., 2005; BROWNING et al., 2006; BROWNING, 2008; JUN; SUH, 2008). Apesar de a literatura oferecer diversos métodos de modelagem de processos para diversos propósitos, a comunidade prática ainda usa técnicas simples e manuais para lidar com processos de negócio (BROWNING; RAMASESH, 2007; VERGIDIS; TURNER; TIWARI, 2008; HEISIG et al., 2009).

Há desafios enfrentados pela indústria no uso e compreensão de modelos de processos que podem ser a razão para esse descompasso significativo entre teoria e prática (HEISIG et al., 2009). Restam lacunas na teoria que poderiam ajudar a solucionar esses desafios, que são detalhadas no item 1.3.

\subsection{Problema e objetivo de pesquisa}

O problema que dá origem a essa pesquisa pode ser definido da seguinte forma: apesar de existirem diversos métodos de modelagem de PDP desenvolvidos no âmbito acadêmico, esses métodos são ainda pouco utilizados pela comunidade prática. Segundo a literatura, uma das possíveis causas deste problema é o fato de que os propósitos dos usuários de um modelo de PDP não são ainda satisfatoriamente atendidos pelas vistas de modelos existentes. Usuários enfrentam desafios como: a dificuldade que essas vistas oferecem para lidar com a flexibilidade do PDP, ou seja, para lidar com mudanças e para comportar as iterações típicas desse processo; e a dificuldade que as vistas oferecem para a visualização e compreensão do processo.

Este trabalho focará apenas em um dos desafios citados: a dificuldade que as vistas oferecem para a visualização e compreensão do processo. $O$ escopo desta pesquisa também é limitado aos propósitos de usuários de modelos de referência de

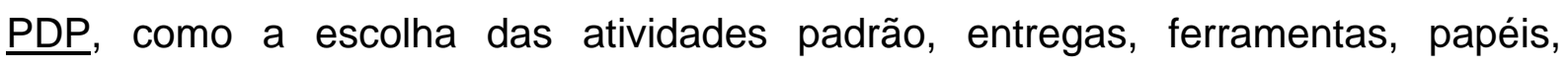
conhecimentos; a aprendizagem organizacional e o treinamento, entre outros (vide item 2.2). O planejamento e a gestão de um projeto de desenvolvimento de produto 
a partir de um modelo de referência específico não faz parte do escopo deste trabalho.

Dessa forma, o objetivo desta pesquisa é propor novas vistas para modelos de referência de PDP que sejam mais eficazes, eficientes e satisfatórias ${ }^{4}$ no atendimento aos propósitos de seus usuários, em comparação com as vistas existentes. Para isso, pretende-se utilizar uma abordagem ainda não encontrada na literatura em relação à modelagem do PDP, aplicando conhecimentos advindos das áreas de design de interação e experiência do usuário. Essa nova abordagem permite:

- a exploração das possibilidades que ambientes interativos computacionais proporcionam aos usuários;

- uso de diferentes perspectivas do processo para o usuário, tanto em relação à complexidade e granularidade da informação disponibilizada quanto em relação ao recorte do processo dados os interesses específicos desses usuários.

Deve-se ressaltar que, apesar da proposição de novas vistas exigir a proposição de um novo método de modelagem para o PDP, não é o objetivo dessa pesquisa definir com rigor a semântica e a sintaxe desse novo método. Esse método tem como objetivo apenas oferecer uma base sobre a qual as novas vistas possam ser desenvolvidas. Caso fosse utilizado um método existente para a proposição das vistas, o desenvolvimento dessas ficaria preso a suas limitações e vícios de apresentação e interface.

${ }^{4}$ Vide item 2.3.2 para melhor compreensão. 


\subsection{Justificativas da pesquisa}

Heisig et al. (2009), a partir de uma série de workshops realizados com membros da academia e indústria envolvidos com a modelagem de processos, destacaram entre as áreas chave de pesquisa futuras em modelagem a área de visualização de processos. Heisig et al. (2009) justificam a escolha dessa área de pesquisa indicando os desafios que são enfrentados pela academia e pela comunidade prática para uso e compreensão de modelos de processos, que são listados a seguir.

Modelos de processos devem ser fáceis e rápidos de entender a fim de serem efetivamente incorporados ao dia a dia das empresas. Em geral, porém, eles trazem muitas informações e são muito complexos, dificultando o seu uso quando mostrados em sua totalidade. A disponibilização de informações no modelo além das que são de interesse imediato do usuário prejudica a sua compreensão (BROWNING, 2008). Por esta razão, os modelos precisam proporcionar vistas considerando as várias perspectivas do processo (entre diferentes unidades, papéis, grupos e indivíduos) e, simultaneamente, criar uma terminologia compartilhada entre elas, o que é um grande desafio (HEISIG et al., 2009). Além disso, modelos elaborados com os métodos de modelagem disponíveis muitas vezes também não são intuitivos o suficiente para proporcionar uma fácil e rápida compreensão aos usuários (HEISIG et al., 2009).

Browning (2010) trata esses desafios indicados por Heisig et al. (2009) como manifestações de um problema mais fundamental: Os modelos não são, em geral, adequados para atender de forma satisfatória a propósitos particulares de seus usuários (dentre eles propósitos relacionados a modelos de referência de PDP, como visualizar o processo, definir entregas padrão, etc.). Browning (2010) chega a essa conclusão ao realizar um estudo em que faz o relacionamento entre os propósitos de modelos de processos e as vistas de modelos de processos mais comuns, por meio dos seus atributos ${ }^{5}$. Dessa forma ele investiga se as vistas de modelos analisadas possuíam informações objetivas que pudessem atender aos diferentes propósitos de seus usuários. Seus resultados mostram que as vistas

\footnotetext{
${ }^{5}$ Este estudo será mais detalhado no item 1.4.
} 
analisadas não atendiam de forma satisfatória a uma parte significativa dos propósitos de seus usuários. Ele argumenta que essa é uma conclusão relevante, pois o alinhamento de uma vista de processo com o propósito a que ela se destina é um critério importante para avaliar a utilidade dessa vista (BROWNING, 2010).

Tanto Browning (2010) quanto Heisig et al. (2009) indicam que estudos sobre a modelagem de processos que considerem a perspectiva do usuário podem trazer contribuições significativas, aumentando a aceitação e uso de modelos pela comunidade prática. Browning (2010) sugere pesquisas futuras que relacionem vistas e propósitos de modelos considerando também aspectos subjetivos da relação entre usuários e modelos como, por exemplo, a forma de disposição do conteúdo e outros aspectos que possam afetar a interação e a facilidade de uso. Ele argumenta que considerar esses aspectos subjetivos é importante porque o modelo pode até possuir o conteúdo relevante para o apoio ao propósito desejado, porém esse conteúdo pode não estar evidente ou não ser de fácil acesso para o usuário. Heisig et al. (2009) reforçam a importância da análise da interação entre usuários e modelos ao indicar a usabilidade de modelos de processos para diferentes propósitos como tema relevante de pesquisa dentro da área de visualização de processos.

Outros autores também destacam a importância da realização de novas pesquisas na área de visualização de processos. Krishnan e Ulrich (2001) indicam o desenvolvimento de esquemas de representação como uma alta prioridade na pesquisa de desenvolvimento de produtos. Melhores representações e vistas têm sido apontadas em pesquisas anteriores como uma chave para melhorar 0 gerenciamento de projetos de desenvolvimento de produtos (KRISHNAN; ULRICH, 2001; BROWNING; RAMASESH, 2007) e sistemas de suporte a decisão em geral (BASU et al., 1997). Reduzindo a complexidade e enfocando os pontos de apoio mais importantes, as representações de modelos podem ser fator importante para a inovação em projetos de sistemas (ALEXANDER, 1964; ZACHMAN, 1986; SIMON, 1996 apud BROWNING, 2008) e em decisões de desenvolvimento de produtos (KRISHNAN; ULRICH, 2001).

Observar esses desafios a partir da ótica de outra área de conhecimento, que ofereça recursos para observar a relação dos usuários com os modelos (como design de interação, experiência do usuário) pode contribuir para a sua solução. A revisão de literatura realizada mostra que não há estudos sobre a modelagem de PDP que considerem a perspectiva do usuário de forma satisfatória. $O$ estudo 
realizado por Browning (2010), que é o que mais se aproxima do escopo desta pesquisa, não tem ênfase em propósitos de modelos de referência de PDP e considera apenas uma pequena parcela do componente representação, que é o fato da informação estar ou não estar disponível no modelo. Ele não considera a forma como essa informação está disponível, nem tampouco observa a interação com o usuário de qualquer maneira. Dessa forma, está configurada uma lacuna que justifica a importância desta pesquisa.

\subsection{Descrição do documento}

Este documento está divido nas seguintes seções:

- Seção 1 - Introdução: descreve o contexto, problema, objetivos e justificativas da pesquisa.

- Seção 2 - Síntese da bibliografia fundamental: apresenta o estado da arte da literatura e os conceitos básicos para a compreensão da pesquisa.

- Seção 3 - Metodologia de pesquisa: expõe o planejamento da pesquisa, descreve os métodos que serão empregados e detalha os pacotes de trabalho.

- Seção 4-Resultados: apresenta os resultados desenvolvidos pela pesquisa.

- Seção 5 - Análise dos resultados e conclusões: discute os resultados obtidos, as limitações da pesquisa, mostra as principais conclusões e indica trabalhos futuros.

- Referências bibliográficas: apresenta as referências bibliográficas usadas no trabalho e citadas no texto.

- Apêndices: reúne os apêndices do documento. 



\section{Síntese da bibliografia fundamental}

A síntese da bibliografia está dividida em três grandes temas: a modelagem do processo de desenvolvimento de produtos; os propósitos de modelos de PDP; e a interação de usuários com modelos de PDP. A Figura 2 sintetiza os pilares da síntese da bibliografia fundamental.

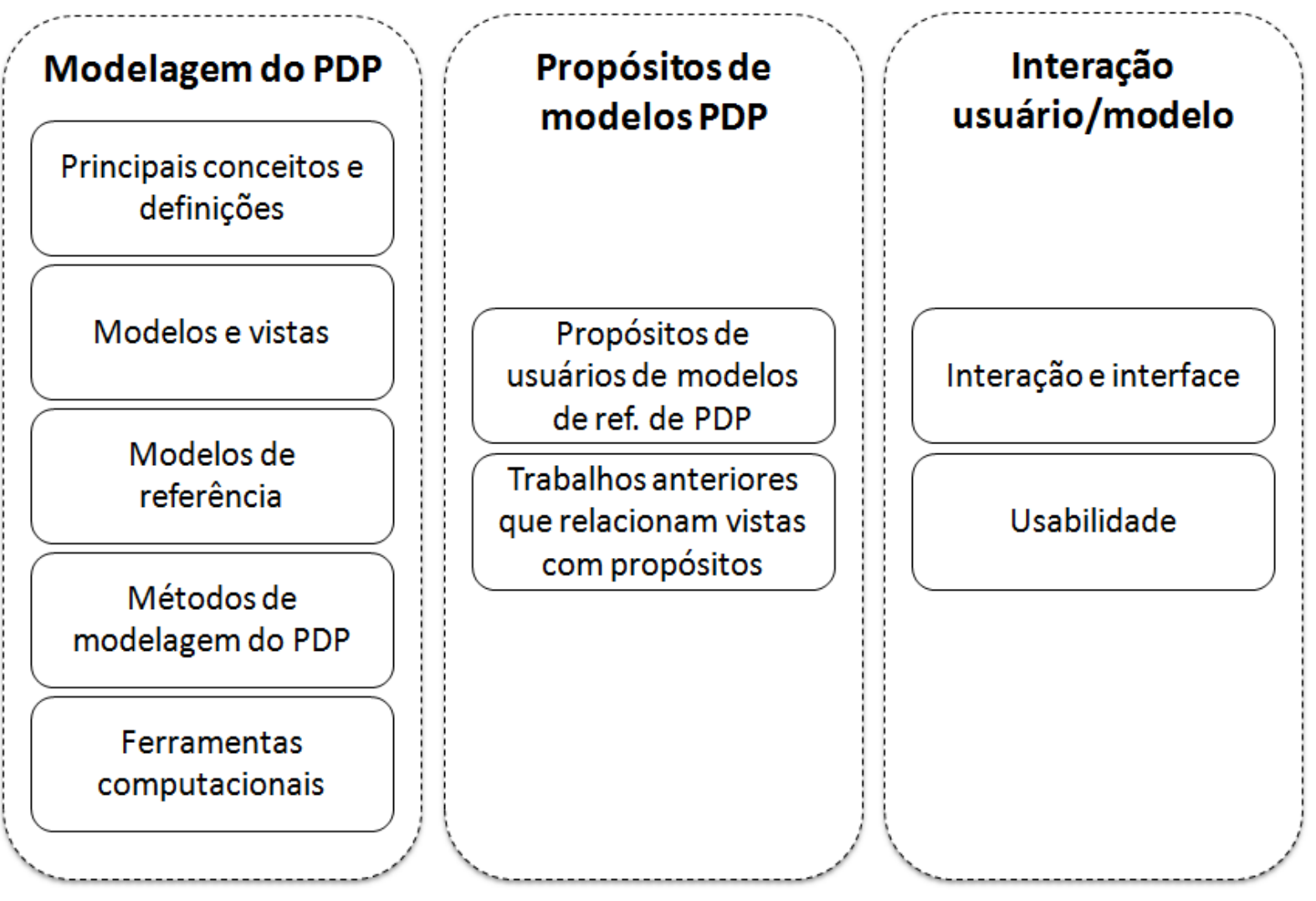

Figura 2 - Pilares da síntese da bibliografia fundamental

\subsection{Modelagem do processo de desenvolvimento de produtos}

Segundo Jeston e Nelis (2006), a modelagem de processos está relacionada com os métodos usados para identificar e conceitualizar processos de negócio (retrato atual, as-is) e processos futuros (retrato futuro, to-be). A modelagem do PDP possui algumas proposições fundamentais (BROWNING et al., 2006): 
- O PDP não pode ser completamente mecanizado, mas, apesar disso, possui uma estrutura que se repete.

- Uma abordagem estruturada facilita a gestão de projetos de DP, principalmente dos mais complexos. Um sistema complexo pode ser mais bem compreendido quando examinado por suas partes constituintes, no caso de um processo, suas atividades e entregas ${ }^{6}$.

- Sempre há um descompasso entre um modelo e a realidade modelada, pois é impossível modelar a realidade em toda sua complexidade. Porém, apesar desse descompasso, modelos podem ser muito úteis.

- Modelos são sempre construídos com um propósito (vide item 2.2) e é fundamental escolher um modelo observando o propósito para o qual se intenciona utilizá-lo (VERNADAT, 1996; AGUILARSAVEN, 2004; BROWNING et al., 2006).

\subsubsection{Principais conceitos e definições}

Durante a pesquisa pelos conceitos fundamentais da modelagem do PDP, muitas vezes mais de uma definição foi encontrada na literatura. Corroborando a constatação de Amaral (2002), pode-se perceber uma falta de consenso sobre 0 significado de termos como método, metodologia, arquitetura, framework e formalismo de modelagem. Por esta razão foi necessário adotar apenas as definições que fossem coerentes entre si e pertinentes aos objetivos desta pesquisa. Os termos e as definições adotadas estão no Apêndice A - Definições de termos relevantes para a modelagem de PDP.

Uma arquitetura ou framework de modelagem "É uma coleção de princípios, formalismos de modelagem, ferramentas e metodologias de modelagem, que sejam relevantes para um dado domínio de aplicação da modelagem (AMARAL, 2002, pág. 107)". Alguns exemplos de arquiteturas de modelagem estão na Tabela 1.

\footnotetext{
${ }^{6}$ BROWNING et al. (2006) denomina isso paradigma da decomposição.
} 
Tabela 1 - Exemplos de arquiteturas para modelagem de empresas (adaptado de Vernadat, 1996)

\begin{tabular}{ll}
\hline Sigla & \\
\hline CEN ENV 40003 & PERA \\
CIMOSA & ARIS \\
GRAI/GIM & GERAM \\
\hline
\end{tabular}

Uma arquitetura de modelagem pode possuir mais de uma metodologia de modelagem, que é um conjunto de métodos a ser utilizado de maneira estruturada para resolver um problema (VERNADAT, 1996). Para o termo métodos de modelagem, não há consenso na literatura; há autores que os denominam de frameworks, técnicas ou até abordagens (VERNADAT, 1996; KETTINGER et al., 1997; AGUILARSAVEN, 2004; O'DONOVAN et al., 2005; BROWNING et al., 2006; JUN; SUH, 2008; BROWNING, 2010). Assim, adota-se para este trabalho a seguinte a definição de Amaral (2002), que considera métodos de modelagem equivalentes a formalismos:

Um formalismo ou método de modelagem é um conjunto de elementos (construtos e regras de sintaxe) capaz de representar uma parte da realidade, relativa a um subconjunto do domínio do processo/sistema que está sendo modelado.

Um formalismo possui uma linguagem de modelagem que fornece uma sintaxe e semântica apropriadas para especificar precisamente os componentes de um processo de negócios (LU; SADIQ, 2007). A semântica se refere à definição dos construtos e suas representações gráficas, ou seja, com que símbolos gráficos ou textuais eles serão expressos; a sintaxe se refere à lógica de relacionamento entre os construtos, de maneira que o resultado final seja um conjunto coerente. A Tabela 2 traz alguns exemplos de linguagens de modelagem.

Tabela 2 - Exemplos de linguagens de modelagem de processos de negócios (adaptado de Vergidis, Tiwari e Majeed, 2008)

\begin{tabular}{ll}
\hline Sigla & Nome \\
\hline BPEL & Business Process Execution Language \\
UML & Unified Modeling Language \\
BPML & Business Process Modeling Language \\
\hline
\end{tabular}


Em geral uma ferramenta, na forma de um software, é empregada para auxiliar na construção do modelo. A ferramenta deve ser escolhida em função do método de modelagem que se pretende adotar. Alguns exemplos de ferramentas estão no item 2.1.5.

A Figura 3 sintetiza a relação entre os conceitos explicados acima.

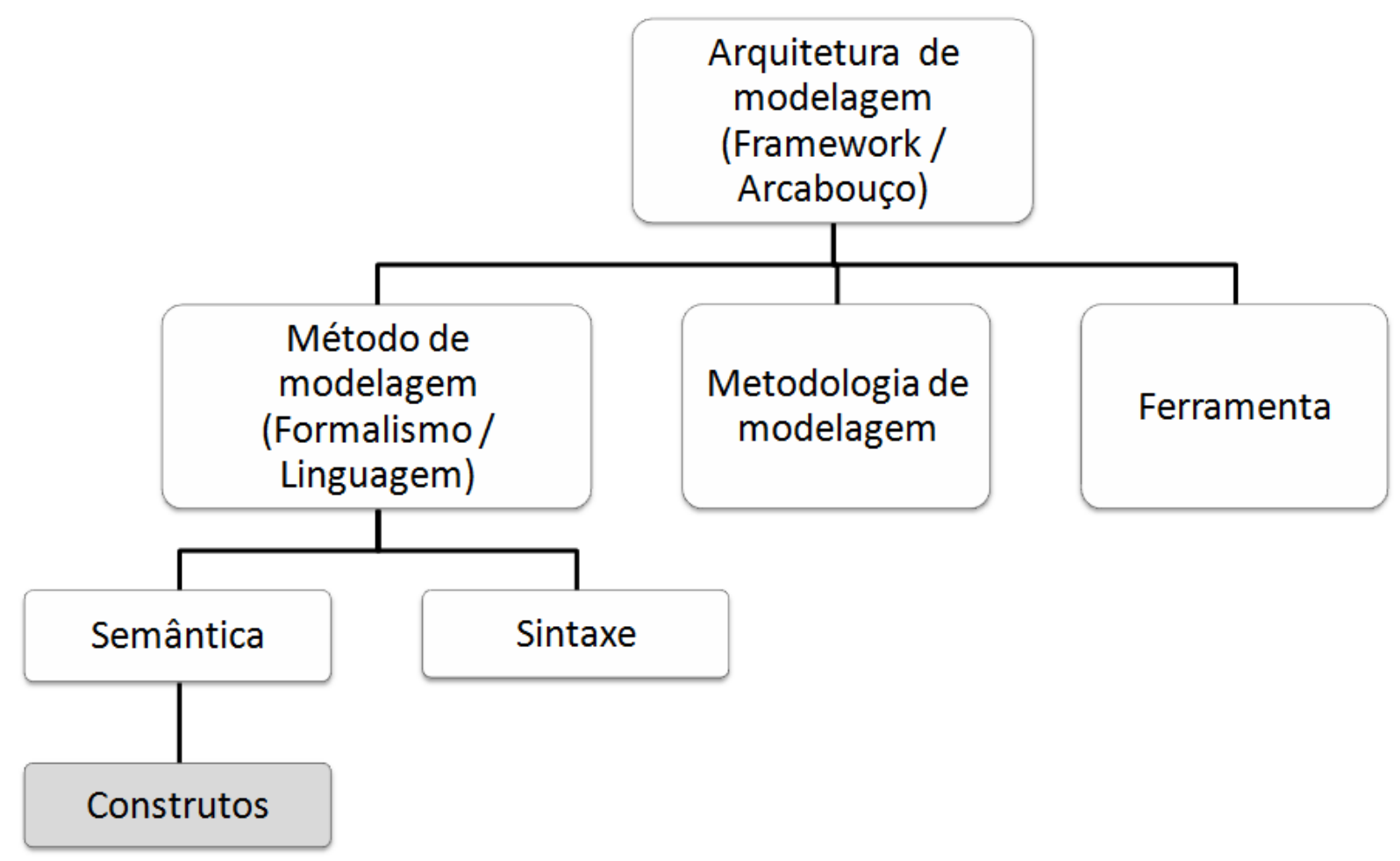

Figura 3 - Relação entre os conceitos relevantes para modelagem do PDP

\subsubsection{Modelos e vistas}

Um modelo é uma representação útil de algum assunto. É uma abstração mais ou menos formal da realidade (ou universo, ou discurso) expressa por meio de algum formalismo definido por construtos de modelagem para o propósito do usuário (DOUMEINGTS et al., 1995; VERNADAT, 1996; STEIGER, 1998; ENGWALL et al., 2005; BROWNING et al., 2006). Um construto de modelagem é um elemento básico de uma linguagem de modelagem definido por sua semântica. Eles podem ser símbolos gráficos, declarações textuais, ou expressões matemáticas e lógicas (VERNADAT, 1996; AMARAL, D.C., 2002). Exemplos clássicos de construtos de 
modelos de PDP são atividades e entregas (BROWNING et al., 2006). Em um fluxograma comum, as atividades são representadas pelas caixas e as entregas pelas setas que ligam as caixas. Estes e outros construtos comuns em modelos de PDP estão descritos na Tabela 3.

Tabela 3 - Exemplos de construtos comuns em modelos de PDP

\begin{tabular}{|c|c|}
\hline Construto & Descrição \\
\hline $\begin{array}{l}\text { Atividade/ } \\
\text { sub-processo }\end{array}$ & $\begin{array}{l}\text { Uma unidade de trabalho definida por seus inputs, outputs, recursos } \\
\text { utilizados e outros atributos potenciais (Tabela 4). Um elemento do } \\
\text { processo, mas também um processo em si mesma. Nomeada como um } \\
\text { verbo (BROWNING et al., 2006). }\end{array}$ \\
\hline Entrega & $\begin{array}{l}\text { Qualquer input ou output de um elemento de processo. Nomeada como um } \\
\text { substantivo (BROWNING et al., 2006). } \\
\text { Qualquer resultado de um projeto que seja mensurável, tangível e que } \\
\text { precise ser produzido para que o produto final do projeto seja alcançado } \\
\text { (ROZENFELD et al., 2006). }\end{array}$ \\
\hline Papel & $\begin{array}{l}\text { Referência genérica a um recurso humano ou grupo de recursos humanos } \\
\text { que realiza o trabalho (executa um elemento do processo) (BROWNING et } \\
\text { al., 2006).Um papel é um conjunto de atribuições e responsabilidades que } \\
\text { podem ser assumidas por um determinado ator do processo (ROZENFELD } \\
\text { et al., 2006). }\end{array}$ \\
\hline Ferramenta & $\begin{array}{l}\text { "Auxiliam na execução de uma tarefa. Definidas como pacotes de software } \\
\text { computacional para oferecer suporte a uma ou mais técnicas." (PALVIA; } \\
\text { NOSEK, } 1993 \text { apud KETTINGER et al., 1997) }\end{array}$ \\
\hline Técnica & $\begin{array}{l}\text { "Um procedimento sistemático definido empregado por um recurso humano } \\
\text { para realizar uma atividade a fim de produzir um produto ou resultado ou } \\
\text { entregar um serviço, e que pode empregar uma ou mais ferramentas." } \\
\text { (PMI, 2008) }\end{array}$ \\
\hline
\end{tabular}

Um modelo de processo normalmente é um conjunto organizado de blocos de construção. Um bloco de construção é um componente de um modelo definido como um conjunto de um ou mais construtos (VERNADAT, 1996). Vernadat (1996) faz um paralelo com a língua escrita que ajuda a esclarecer esses conceitos. Construtos de modelagem de empresas são equivalentes aos elementos básicos da linguagem. Blocos de construção são equivalentes a palavras ou expressões básicas da linguagem. Modelos parciais são sentenças padrão ou pré-definidas da linguagem. Por fim modelos de empresas são conjuntos completos de sentenças de uma linguagem descrevendo um sistema, situação ou fenômeno (VERNADAT, 1996). Exemplos de blocos de construção de um modelo de PDP, relacionados com o construto atividade, são os diferentes tipos de atividades. Por exemplo, atividades de construção e as atividades de avaliação (gates). 
Cada bloco de construção pode ter uma série de atributos. Um atributo descreve uma característica ou propriedade de um objeto (ex. a cor de um carro, o nome de uma pessoa, a data de compra do carro pela pessoa). Um atributo pode ser total (seu valor é sempre definido), ou parcial (seu valor pode permanecer desconhecido). Ele é definido pelo seu nome e toma valores de um conjunto chamado domínio definido sobre um tipo de dado (VERNADAT, 1996; BROWNING, 2008). A caráter exemplar, os atributos mais utilizados para os construtos de atividades e entregas são listados na Tabela 4 (BROWNING et al., 2006).

Tabela 4 - Blocos de construção fundamentais de modelos de PDP e alguns de seus atributos (adaptado de Browning, 2010)

\begin{tabular}{|c|c|}
\hline Atributos de Atividades/Processos & Atributos de Entregas \\
\hline 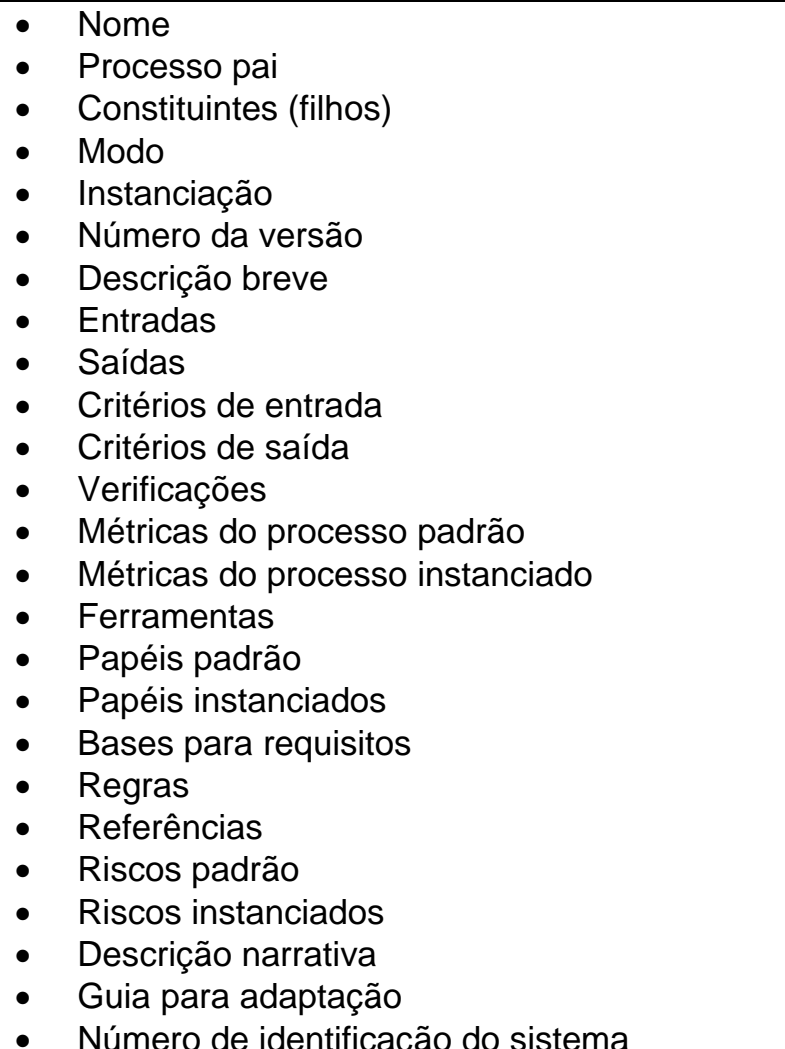 & 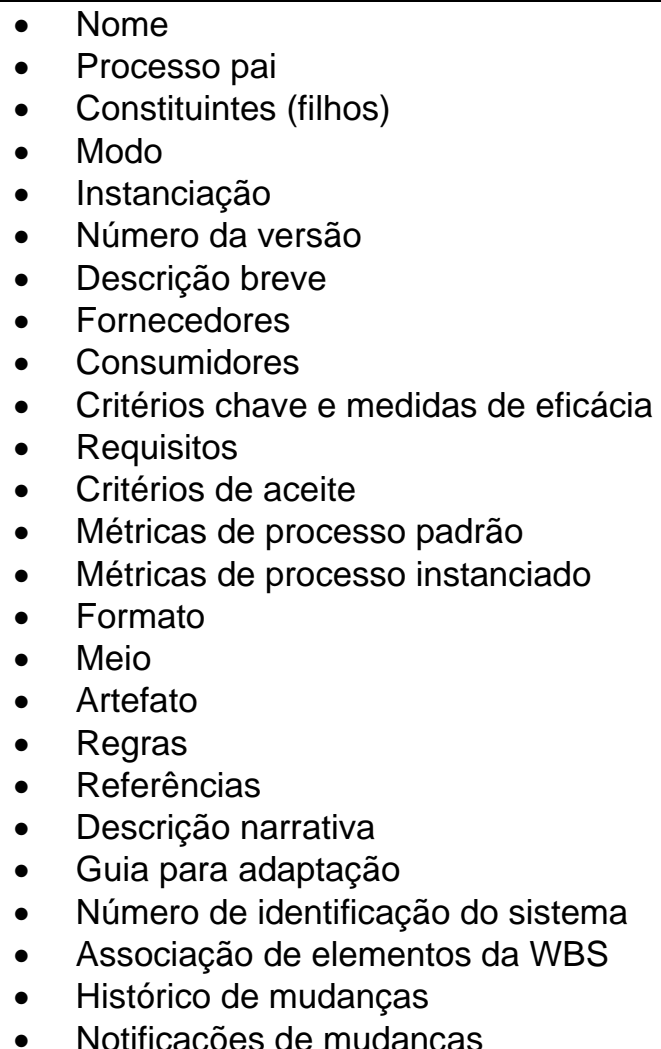 \\
\hline
\end{tabular}

A Figura 4 mostra a relação entre os conceitos explicados dentro de um exemplo de modelo de processo usando a notação de um fluxograma clássico. 


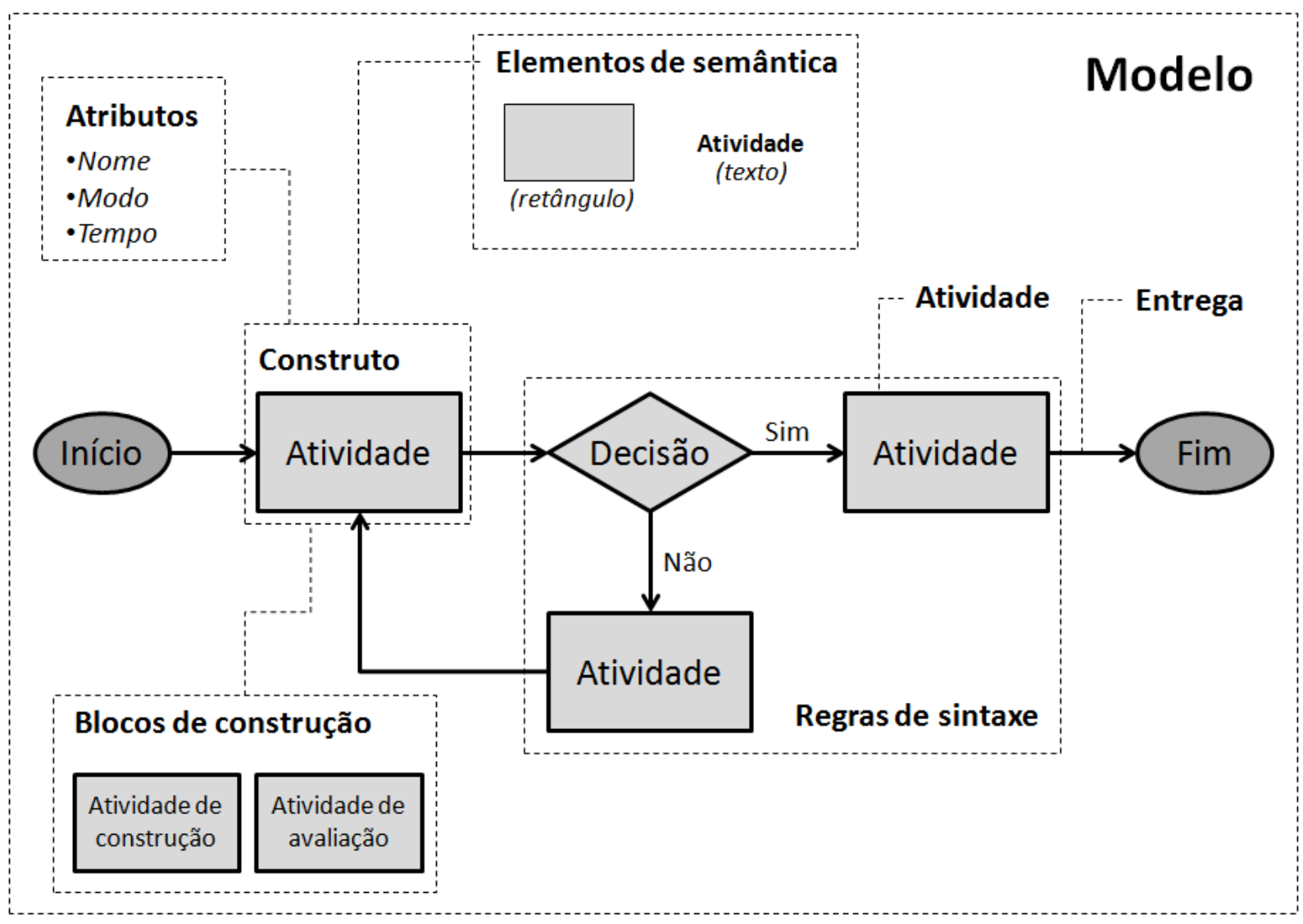

Figura 4 - Exemplificação dos conceitos relevantes dentro de um exemplo de modelo de PDP

Como já explicado anteriormente, um modelo de processo sempre representa a realidade de forma simplificada; é impossível representar toda a complexidade de um processo real. O subconjunto de informações que será selecionado para constituir um modelo pode ser configurado de várias maneiras, dependendo do seu propósito, resultando em diferentes vistas desse modelo. Browning (2008) define as vistas de um modelo da seguinte forma:

Ao passo que um modelo de processo inclui todos os atributos ou conjecturas subjacentes consideradas suficientes para descrevê-lo, uma vista é um arranjo de símbolos, uma tabela, ou outra representação escolhida para mostrar um subconjunto selecionado desses atributos ou conjecturas.

As vistas têm por finalidade simplificar a compreensão de um modelo. São especialmente úteis para a compreensão de modelos complexos. Uma arquitetura de um sistema pode estruturar vistas sincronizadas para um processo, permitindo que cada usuário acesse o mesmo repositório de informações a partir do ponto da vista mais conveniente para ele (KRUCHTEN, 1995; BROWNING, 2008). A Figura 5 
mostra a relação entre um processo, seus possíveis modelos direcionados a diferentes propósitos e as possíveis vistas de um dos modelos.

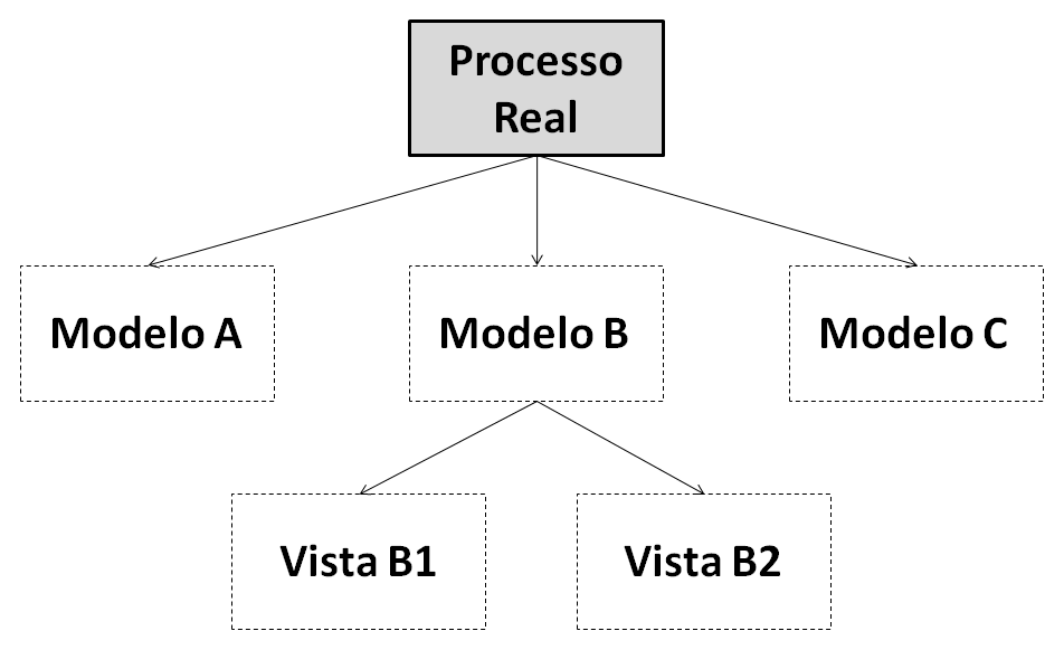

Figura 5 - Relação entre um processo, seus modelos e suas vistas (adaptado de Browning, 2010)

\subsubsection{Modelos de referência}

Modelos de processos podem ser genéricos ou específicos para uma organização (vide item 1.1). Há um consenso na literatura de que a aderência a um modelo torna a gestão do processo de desenvolvimento de produtos mais eficiente (COOPER, 2001; KALPIC; BERNUS, 2002; ENGWALL et al., 2005; FETTKE et al., 2006). Modelos de processos são úteis para: auxiliar o time de desenvolvimento a focar nas atividades que adicionam valor; proporcionar transparência e visibilidade da situação para a força de trabalho; auxiliar no cumprimento de compromissos de uma forma previsível, reprodutível e consistente; indicar as melhores práticas em relação ao processo; auxiliar na prevenção de falhas, baseados em processos anteriores; proporcionar um vocabulário comum para a discussão do trabalho e resultados; proporcionar uma linha base para a gestão, auxiliando na medição de melhorias de processo; proporcionar uma abordagem comum na empresa para times de desenvolvimento de diferentes projetos; permitir a análise de potenciais mudanças de processo; e auxiliar na compreensão e aprendizado de processos complexos, entre outros (BROWNING et al., 2006).

Um modelo de referência de um processo é constituído por ( 
Figura 6): atividades, informações, recursos e organização, embasados por conhecimento constituído por conceitos, métodos, técnicas e ferramentas (MUNDIM et al., 2002). Atividades ocorrem dentro de um processo ou subprocesso, e são normalmente realizadas por pessoas ou departamentos (HARRINGTON et al., 1997). Recursos podem ser equipamentos, serviços, suprimentos, commodities, materiais (entre outros) que servem para a execução das atividades de um processo. Organização refere-se às pessoas (grupos ou equipes) que realizam as atividades, bem como qualquer grupo, corporação, divisão, departamento, planta ou escritório (HARRINGTON et al., 1997) no âmbito do qual o processo ocorre. Informações são as entradas e saídas das atividades de um processo. E conhecimento é informação organizada e analisada (TURBAN; FRENZEL, 1992).

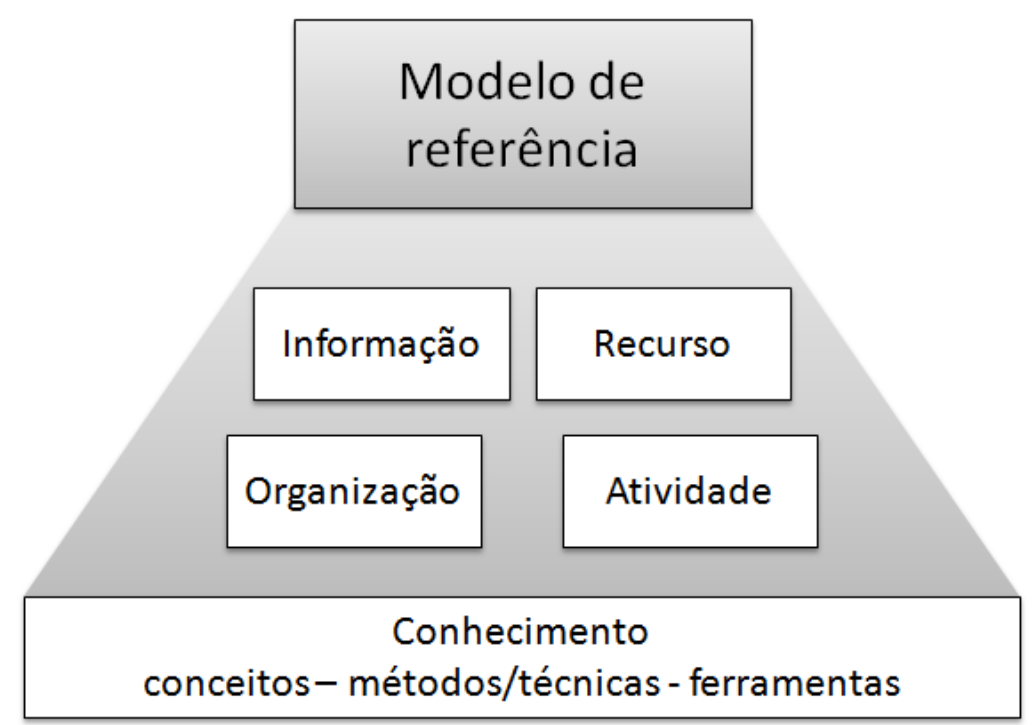

Figura 6 - Elementos de um modelo de referência (MUNDIM et al., 2002)

\subsubsection{Métodos de modelagem do PDP}

É possível encontrar algumas revisões de literatura sobre métodos de modelagem específicos para PDP. Smith e Morrow (1999) utilizam dois critérios na avaliação dos modelos que possuem relação com o seu propósito: o primeiro é se o modelo resultante da aplicação do método de modelagem atende questões gerenciais importantes, que envolvem decisões como agendamento de tarefas, alocação de recursos, lançamento de produtos, especificações meta, entre outras; o segundo é se o modelo é capaz de fornecer informações relevantes no momento 
certo para as tomadas de decisão durante o processo. À medida que descrevem e analisam os modelos, Smith e Morrow (1999) também indicam os pontos fortes e fracos dos métodos de modelagem. Eles concluem que todos os modelos analisados em sua revisão atendem ao critério de importância gerencial.

A análise realizada por O’Donovan et al. (2005) não faz uma avaliação baseada em critérios. Eles enfocam na descrição dos métodos de modelagem, suas origens, suas características e propósitos. Eles concluem que, apesar da grande variedade de arquiteturas de modelagem existentes, os métodos tendem a possuir um núcleo comum, baseado em uma sequência de atividades. Eles veem nesse fato a possibilidade de unificar alguns desses métodos de modelagem em um único método orientado a objetos. Eles identificam um descompasso entre os métodos oferecidos na literatura e os utilizados pela comunidade prática, que ainda se concentra nos mais simples. Indicam ainda uma lacuna no que diz respeito ao apoio oferecido pelos métodos de modelagem à tomada de decisão durante o processo.

Jun e Suh (2008) fazem uma breve revisão sobre os métodos de modelagem de PDP a fim de relacioná-las com as principais características do processo. Eles dividem os métodos em dois grandes grupos: métodos baseados em gráficos (ex: IDEF) e métodos baseados em matriz (ex: DSM). Eles levantam quais características do PDP cada método atende: negociação de iterações, efeito de aprendizagem, plano de projeto incerto e rotas alternativas, reuniões, feedback de iterações, refinamento das informações de projeto, análise, iteração de mudanças de engenharia, sobreposição de atividades e síntese. Eles concluem que os métodos de modelagem são limitados em relação à representação dessas características.

Browning et al. (2006) apresentam uma tabela síntese dos métodos de modelagem do $\mathrm{PDP}^{7}$. Essa tabela agrupa os métodos por tipos (por exemplo, modelos baseados em fases, modelos de rede de atividades, etc.) e dá uma breve descrição dos pontos de vista dos processos, as premissas que os distinguem dos demais, seus propósitos típicos e as principais variáveis-chave e atributos. Ele chama a atenção para o fato de sua revisão não ser exaustiva e abordar apenas os principais métodos. A partir dessa revisão, Browning (2008) elabora uma matriz indicando quais atributos de objetos (atividades e entregas), cada método de

${ }^{7}$ Esta tabela está incorporada na tabela síntese dos métodos de modelagem, no Apêndice $C$ - Tabela síntese dos métodos de modelagem de PDP. 
modelagem representa. O seu objetivo principal é prover bases para a elaboração de uma arquitetura para vistas do processo.

Observa-se que nenhuma destas revisões sobre métodos de modelagem existentes na literatura tem intenção de esgotar o tema. É possível encontrar métodos descritos em uma revisão que não são descritos em outras, e nenhuma agrega todos os métodos descritos nas demais. Outro aspecto que se pode observar é que as revisões mais recentes encontradas já possuem mais de três anos e podem estar desatualizadas.

Dentre outros estudos sobre modelagem de processos encontrados na literatura, é importante destacar uma survey realizada por Vergidis, Turner e Tiwari (2008), com o propósito de identificar as práticas da indústria em relação à modelagem de processos de negócio, que indicou quais os métodos de modelagem de processos são mais utilizados. Os 25 participantes da survey eram oriundos de empresas de serviços como bancos, universidades e consultorias. Eles foram solicitados a indicar, dentre uma lista com os métodos de modelagem mais comuns, quais eles utilizavam e com que frequência. A lista de métodos que foi utilizada como ponto de partida foi elaborada a partir de revisão bibliográfica, que indicou fluxogramas, modelos IDEF, redes de petri e documentação (descrição textual) como as mais comuns. Os resultados, indicados na Figura 7, mostraram que a maioria dos participantes utiliza, com maior frequência, fluxogramas com notação informal para representar seus processos, seguidos por documentação. Por documentação pode-se entender principalmente planilhas e arquivos de texto, que podem servir para listar as atividades a serem realizadas bem como dar detalhes sobre procedimentos, entre outros. 


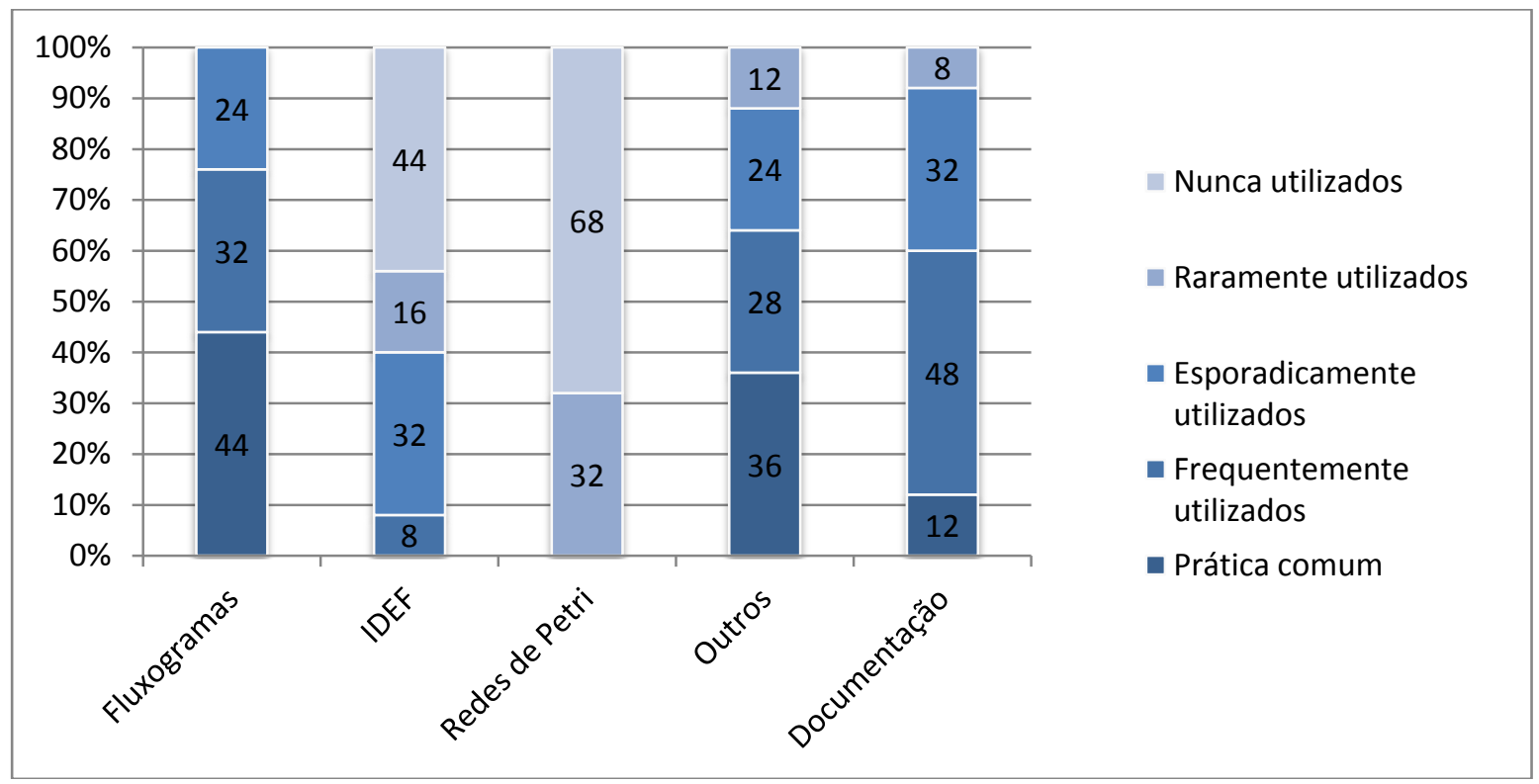

Figura 7 - Técnicas de modelagem de processos de negócio utilizadas pelas organizações (Adaptado de Vergidis, Turner e Tiwari, 2008)

Não é possível encontrar na literatura uma survey semelhante à realizada por Vergidis, Turner e Tiwari (2008) voltada para a análise de empresas de desenvolvimento de produtos. Porém, Heisig et al. (2009), em seu documento de desafios da modelagem de processos identificados a partir de workshops com a indústria, indicam de maneira geral os fluxogramas como o método de modelagem mais utilizado. Outros autores, como O'Donovan et al. (2005) e Browning et al. (2006), que realizaram revisões específicas sobre modelagem de processos de desenvolvimento de produtos, também indicam os fluxogramas como o método mais popular de modelagem para o PDP.

O fluxograma representa principalmente o fluxo de informações, e é um dos métodos de modelagem mais simples e flexíveis, o que talvez explique sua ampla aplicação pela comunidade prática (HEISIG et al., 2009). A documentação também é simples e flexível, mas não oferece a vista de fluxo de informações, o que, dependendo do propósito do usuário, pode ou não ser uma desvantagem (por exemplo, se o propósito for definir entregas padrão de um processo, talvez uma lista ordenada em um documento de texto seja mais eficiente do que um fluxograma). Apesar de suas vantagens, ambos os métodos possuem limitações sérias para atender a vários dos propósitos dos usuários de modelos de referência de PDP. A notação tradicional de fluxograma, por exemplo, possui objetos para representar 
apenas atividades e pontos de decisão. Não há objetos para entregas, papéis, ferramentas, o que não permite que o modelo seja usado para propósitos como:

- Definir entregas padrão e padrões de qualidade

- Definir ferramentas e templates padrão

- Definir pessoal, papéis, responsabilidades e habilidades padrão

A documentação, por sua vez, pode até possuir informações suficientes para o atendimento de um número maior de propósitos, porém muitas vezes não oferece uma forma rápida e fácil para o usuário encontrar e visualizar estas informações. Ou seja, a informação está presente, mas não está evidente.

\subsubsection{Ferramentas computacionais empregadas na representação de modelos de referência}

Serão descritas aqui apenas as ferramentas computacionais mais representativas, diretamente ligadas à modelagem do PDP ou não, que tenham relevância para a modelagem de modelos de referência. O levantamento destas ferramentas foi feito por meio de consultas a especialistas, membros da comunidade prática, websites de desenvolvedores e fornecedores de software e revisão da literatura.

\subsubsection{Plataformas de modelagem de empresas}

O ARIS (Architecture of Integrated Information Systems) é uma das mais tradicionais arquiteturas para modelagem de empresas, desenvolvida pelo Prof. Scheer, na Alemanha, entre 1992 e 1994. É comercializada hoje na forma de plataforma de modelagem pela Software AG@, líder global na área de modelagem de processos $^{8}$. Permite a modelagem da empresa como um todo, ou seja, não só dos seus processos, mas também da estrutura organizacional, documentos,

${ }^{8}$ Informação extraída do site da empresa. Mais detalhes sobre a AG (antiga IDS Scheer) podem ser encontrados em http://www.softwareag.com. 
informações, materiais, entre outras. A base de dados é única, integrando as diferentes vistas oferecidas, que são originalmente quatro (AMARAL, 2002):

- Vista funcional: representa de maneira hierárquica as funções da empresa, a partir da definição dos objetivos e metas do negócio.

- Vista dos dados: representa modelos de dados e seus relacionamentos (relatórios, normas, documentos e conjunto de informações).

- Vista organizacional: representa a estrutura organizacional da empresa, as suas áreas, papéis e responsabilidades.

- Vista de processo: representa os processos da empresa, permitindo relacionar elementos das três visões anteriores, por ex: atividades com papéis, atividades com documentos, etc. (Figura 8).

A base de dados integrada significa, na prática, que uma alteração em um elemento compartilhado entre duas vistas é automaticamente realizada em ambas, e também que é possível navegar entre as vistas clicando nos elementos em comum.

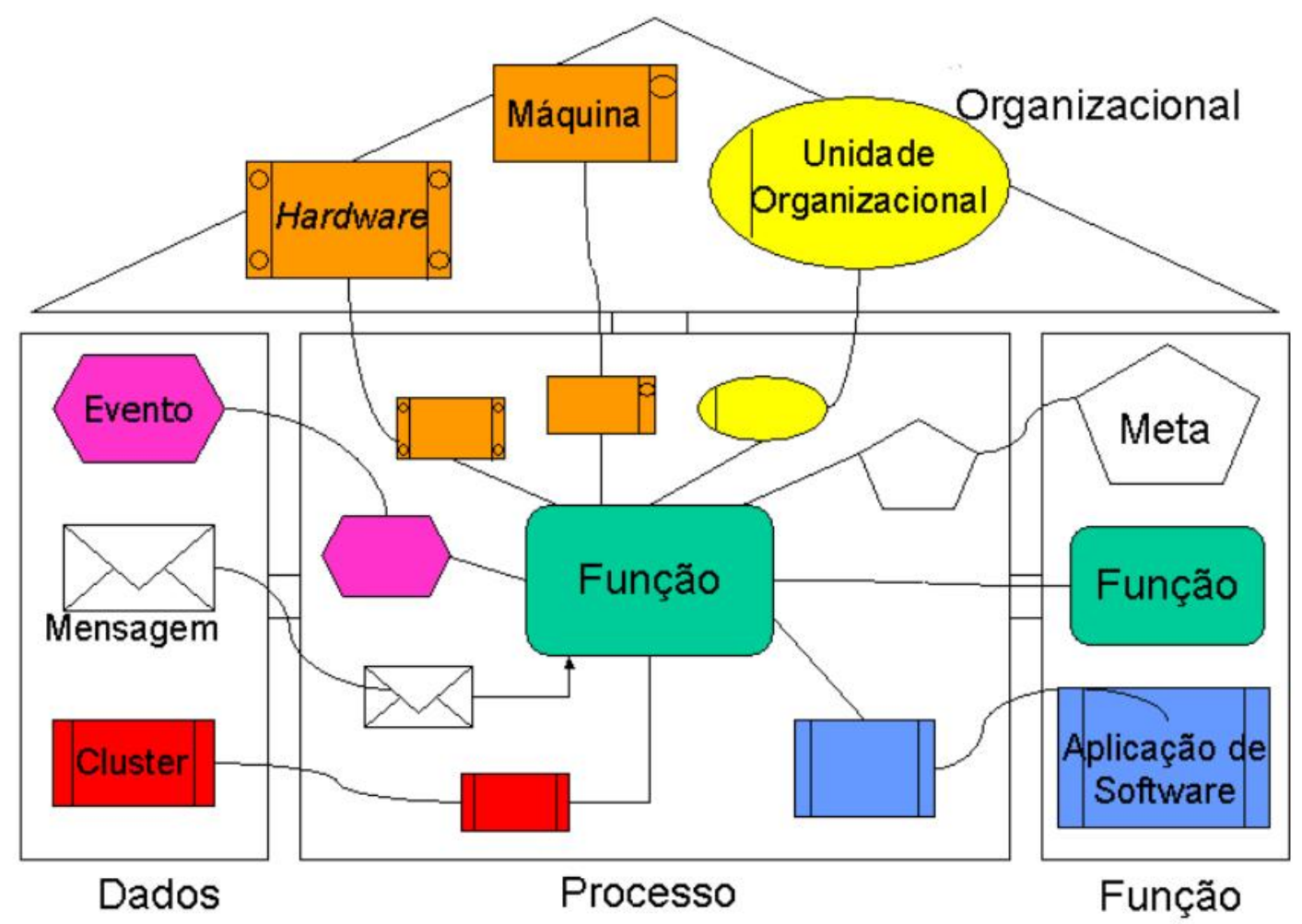

Figura 8 - Exemplo de integração entre as vistas ARIS (AMARAL, 2002)

A plataforma ARIS suporta a modelagem de processos utilizando os métodos BPMN (Business Process Modeling) e eEPC (Extended event process chain), entre 
outros. Permite a modelagem de processos em vários níveis (do modelo de referência genérico ao projeto), inclusive a automação de processos (workflow).

A plataforma nacional ARPO, desenvolvida pela Klug Solutions ${ }^{9}$ é inspirada na plataforma ARIS e oferece funcionalidades semelhantes. $\mathrm{Na}$

Figura 9 é possível ver os construtos de modelagem disponíveis no ARPO e na Figura 10 estão exemplos das diferentes vistas oferecidas por essa plataforma.

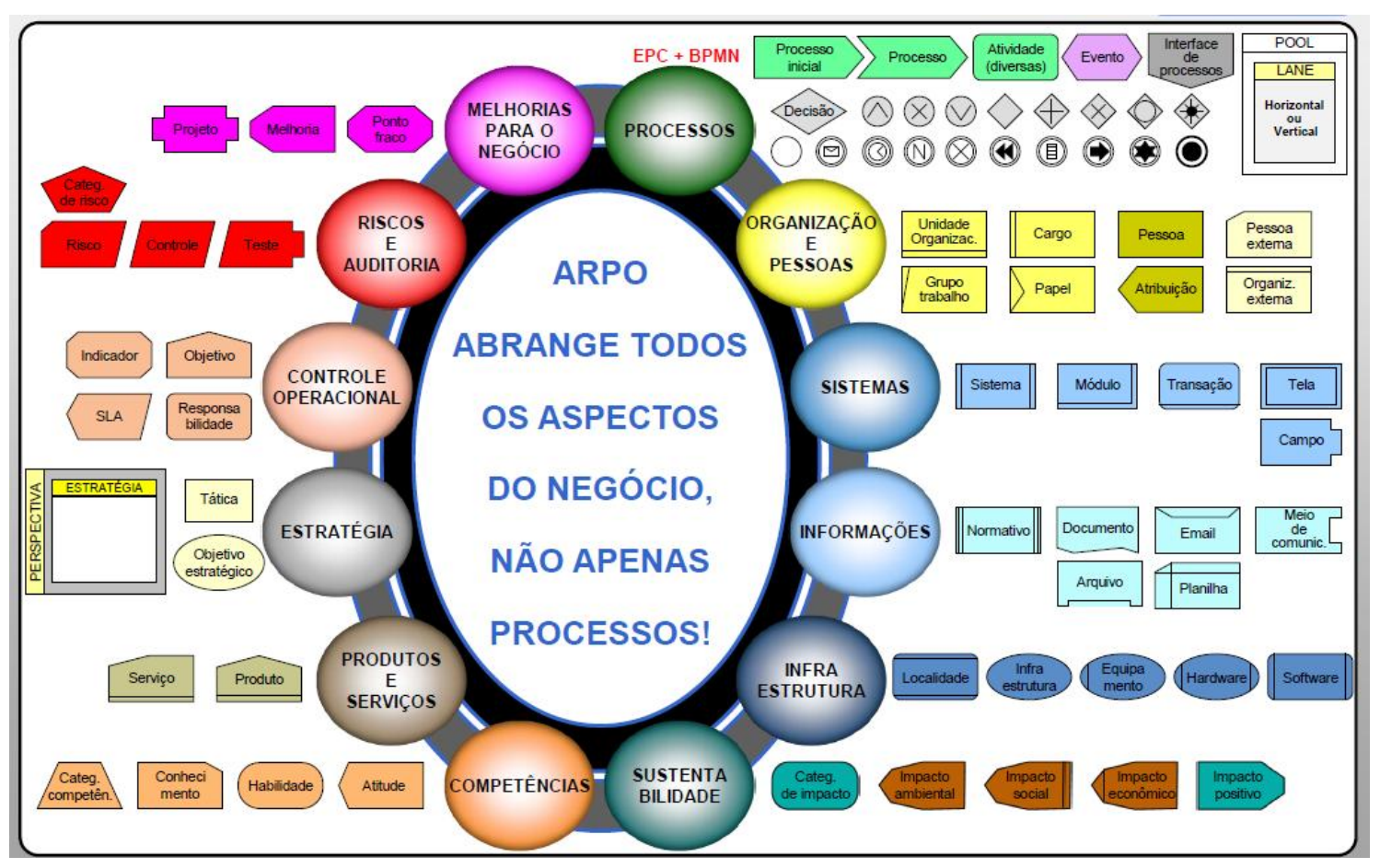

Figura 9 - Construtos para modelagem de empresas disponíveis na plataforma ARPO usando os métodos EPC e BPMN (Fonte: material de apresentação da Klug Solutions, disponível em http://www.klugsolutions.com)

\footnotetext{
${ }^{9}$ Mais detalhes em http://www.klugsolutions.com/.
} 


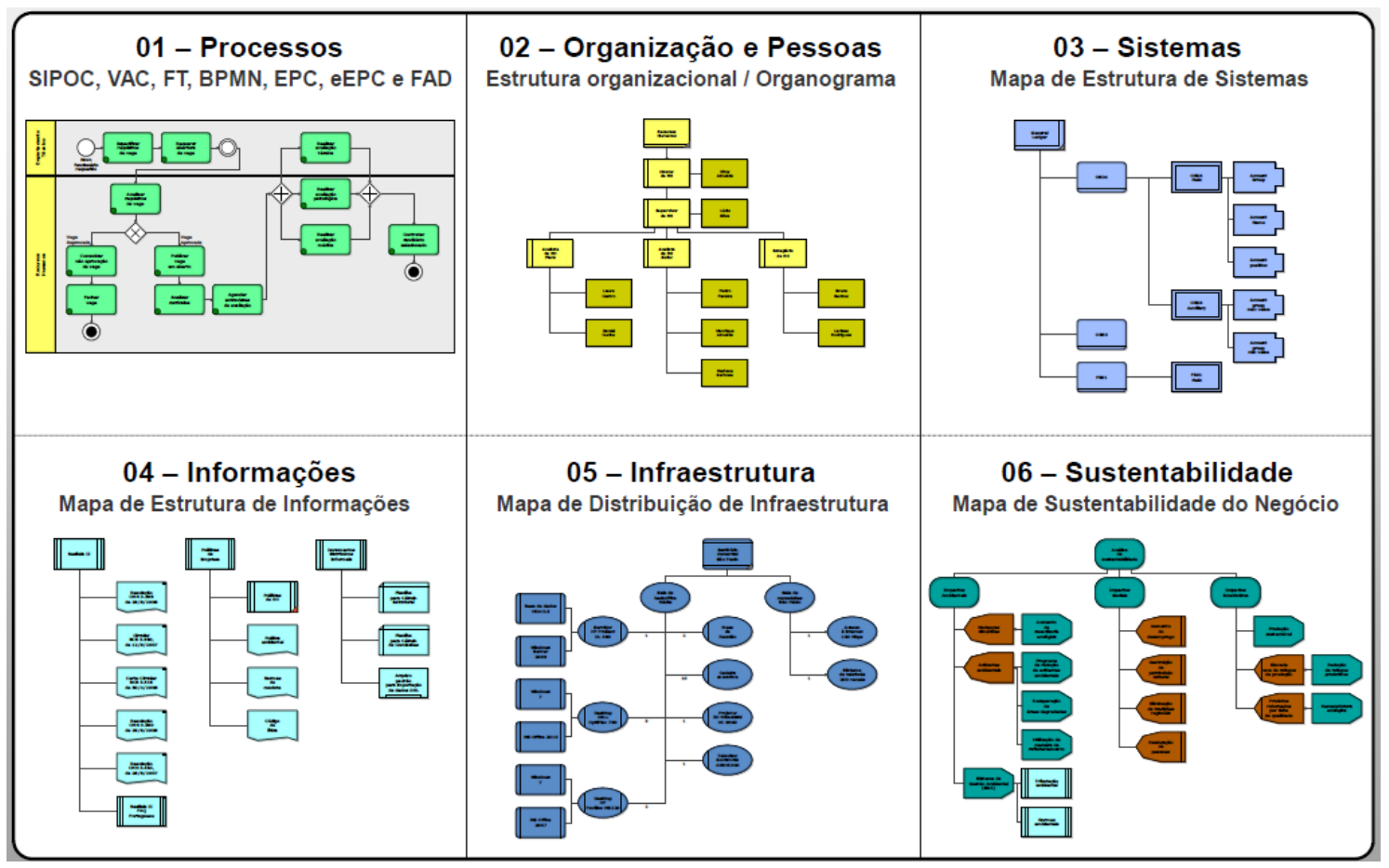

Figura 10 - Exemplos de vistas oferecidas pela plataforma ARPO, usando os métodos EPC e BPMN (Fonte: material de apresentação da Klug Solutions, disponível em http://www.klugsolutions.com)

A possibilidade de representar diversas dimensões das empresas, em vistas dinâmicas interligadas entre si (processos, organização e pessoas, informações, etc.) em um ambiente computacional é uma grande vantagem para o usuário em relação às representações estáticas. Permite a integração das informações dentro da empresa, com o acesso rápido aos diferentes pontos de vista e atualizações rápidas e sem complicações. Para um usuário de um modelo de PDP, essas vistas são úteis. Por exemplo, no momento de buscar informações relacionadas a uma determinada atividade, o usuário pode não só entender qual papel deve executá-la por ela como também acessar informações sobre as responsabilidades organizacionais desse papel.

Porém, estas vistas não permitem a combinação livre dos construtos de modelagem, apesar do relacionamento na base de dados muitas vezes possuir essa combinação. Elas são baseadas em um fluxo lógico de atividades e possuem, relacionado a elementos desse fluxo lógico, um conjunto determinado de construtos. Por exemplo, é possível relacionar apenas um determinado conjunto de construtos na vista de processos (atividade, entrega, papel, ferramenta e área), baseada nos construtos de atividades, e na vista de organização e pessoas apenas outro conjunto (papel, área, responsabilidade), organizado na forma de organograma. 
Dessa forma, elas não cobrem algumas necessidades importantes dos usuários de modelos de PDP, como, por exemplo: visualizar rapidamente todas as atividades de um determinado papel deve realizar dentro de uma fase; ou visualizar as entregas que um papel deve produzir em uma fase. A Figura 11 ilustra este exemplo com um trecho de processo modelado com o método eEPC na plataforma ARPO: para saber quais as atividades que o gerente de projetos deve realizar no gate do projeto informacional, o usuário deve procurar uma a uma as atividades que possuem o gerente de projetos ligados a elas. Se o usuário clicar sobre "gerente de projeto", se abrirá a vista da dimensão organização e pessoas (Figura 12), que possui outra estrutura e outros construtos (no caso, mostra as responsabilidades organizacionais desse papel, de uma maneira global em relação ao processo). Porém, é possível acessar as propriedades do construto na base de dados e ver a lista de atividades relacionadas com o gerente de projetos (Figura 13). Ou seja, a informação está presente, apenas não disponível de forma rápida e fácil para o usuário. 


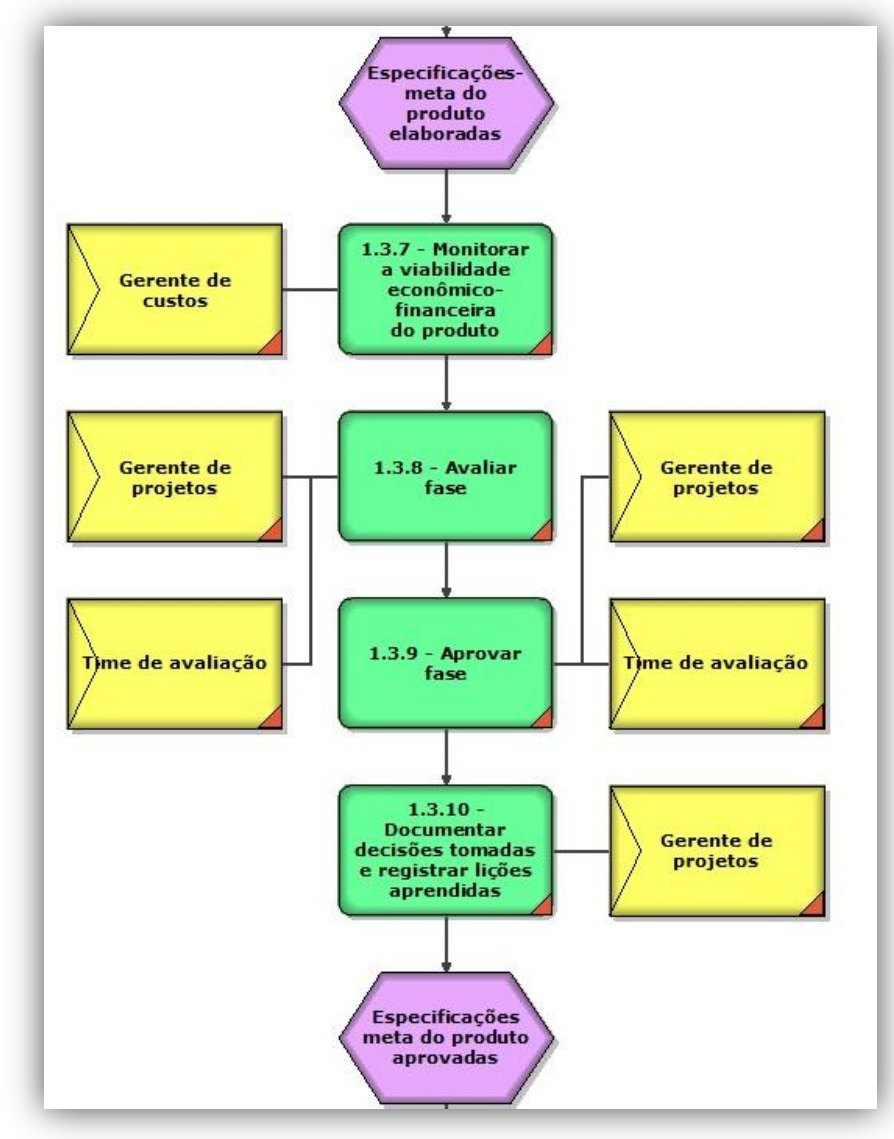

Figura 11 - Trecho de um processo modelado em EPC, na dimensão processos da plataforma ARPO

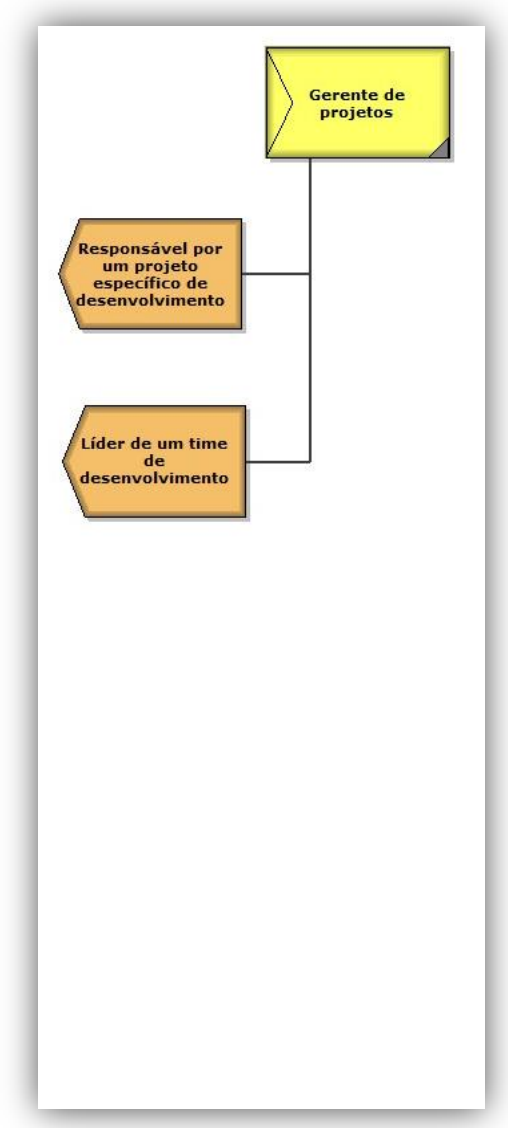

Figura 12 - Trecho de um processo modelado em EPC, na dimensão organização e pessoas da plataforma ARPO

\begin{tabular}{|l|l||}
\hline \multicolumn{1}{|c|}{ Propriedade } & \multicolumn{1}{|c||}{ Valor } \\
\hline Nome do objeto & Gerente de projetos \\
\hline \hline Tipo de objeto & Papel \\
\hline \hline Descrição & $\begin{array}{l}\text { Responsabilidades: Responsável por um projeto específico de } \\
\text { desenvolvimento e líder de um time de desenvolvimento. }\end{array}$ \\
\hline \hline Responsabilidades principais & $\begin{array}{l}\text { Responsável por um projeto específico de desenvolvimento e } \\
\text { líder de um time de desenvolvimento. }\end{array}$ \\
\hline \hline \multicolumn{1}{|c|}{ Diagrama com ocorrência do objeto } \\
\hline 1.3 .1 - Atualizar plano do projeto informacional \\
\hline 1.3 .10 - Documentar decisões tomadas e registrar lições aprendidas \\
\hline 1.3 .2 - Revisar e atualizar o escopo do produto \\
\hline 1.3 .8 - Avaliar fase \\
\hline 1.3 .9 - Aprovar fase \\
\hline 1.4 .1 - Atualizar o plano do projeto conceitual \\
\hline 1.4 .13 - Avaliar fase \\
\hline 1.4 .14 - Aprovar fase \\
\hline 1.4 .15 - Documentar decisões tomadas e registrar lições aprendidas \\
\hline 1.5 .1 - Atualizar plano do projeto detalhado \\
\hline \hline-1 - - \\
\hline
\end{tabular}

Figura 13 - Propriedades "Gerente de projeto" na base de dados do ARPO, onde é possível identificar as vistas com ocorrência desse construto. 


\subsubsection{Modelos de referência customizáveis para uma área de conhecimento}

Existem modelos de referência genéricos que se encontram disponíveis para uso eletrônico, alguns com opção de customização para a realidade específica de uma empresa. O RUP (Rational Unified Process) é um exemplo desses modelos (LARMAN et al.; KRUCHTEN, 1995; HEIJSTEK; CHAUDRON, 2008). O RUP é um framework popular para a área de desenvolvimento de software desenvolvido pela Rational Unified Process@e hoje comercializado pela IBMC na forma de um sistema customizável ${ }^{10}$. Possui três elementos centrais que o definem:

- Um conjunto de filosofias e práticas para o sucesso do desenvolvimento de software

- Um modelo de processo associado com um repositório de conteúdo

- Uma linguagem de modelagem

O RUP oferece uma visão geral do processo, com suas principais fases, iterações e disciplinas envolvidas (Figura 14). Essa visualização geral é navegável (os usuários podem clicar nos elementos para ver mais detalhes), e fornece aos gestores um template inicial do projeto, mostrando os principais milestones, quais produtos devem ser entregues em cada milestone e que recursos serão necessários para cada fase.

\footnotetext{
${ }^{10}$ Mais informações em http://www-01.ibm.com/software/rational/rup/.
} 


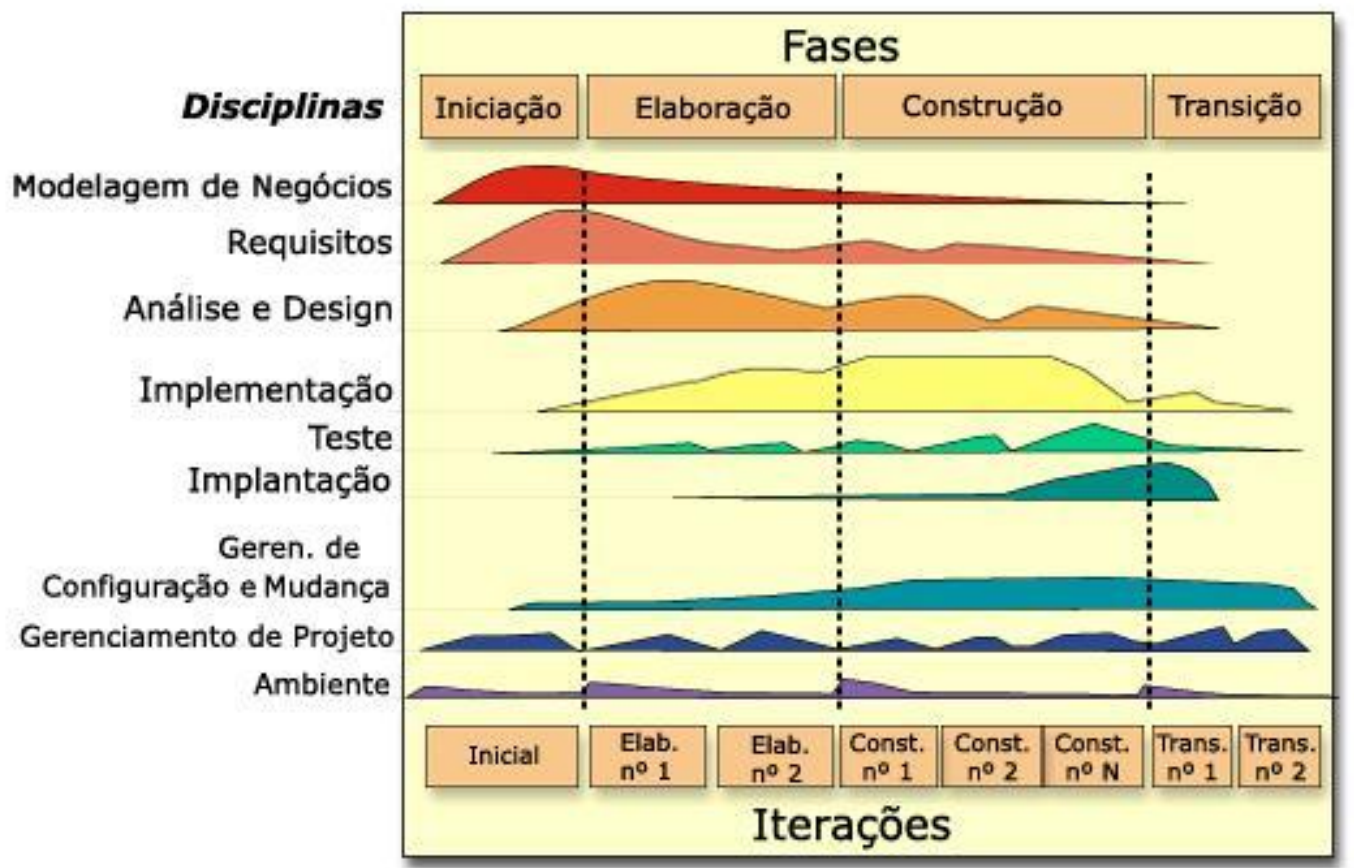

Figura 14 - Visão geral do processo de desenvolvimento pelo RUP (Fonte: Software RUP®) IBM).

O principal diferencial do RUP é que ele oferece vistas de caráter analógico, alternativas às baseadas no fluxo lógico entre atividades. Dessa forma, é possível visualizar de uma só vez todas as atividades ou artefatos ${ }^{11}$ de uma fase (Figura 15), ou entender de forma mais rápida quais os papéis e artefatos estão relacionados às atividades de um conjunto do workflow (Figura 16). Neste último caso, a compreensão é facilitada principalmente na visualização em monitores comuns, pois, ao eliminar a necessidade de representação lógica do fluxo, a visualização fica mais compacta e exige menos rolagem de tela para ser compreendida.

${ }^{11}$ No RUP a palavra artefatos se refere aos elementos do modelo que não sejam de fluxo de informações (atividades e conjuntos de atividades) nem papéis, por ex: melhores práticas, ferramentas, templates, documentos, etc. 


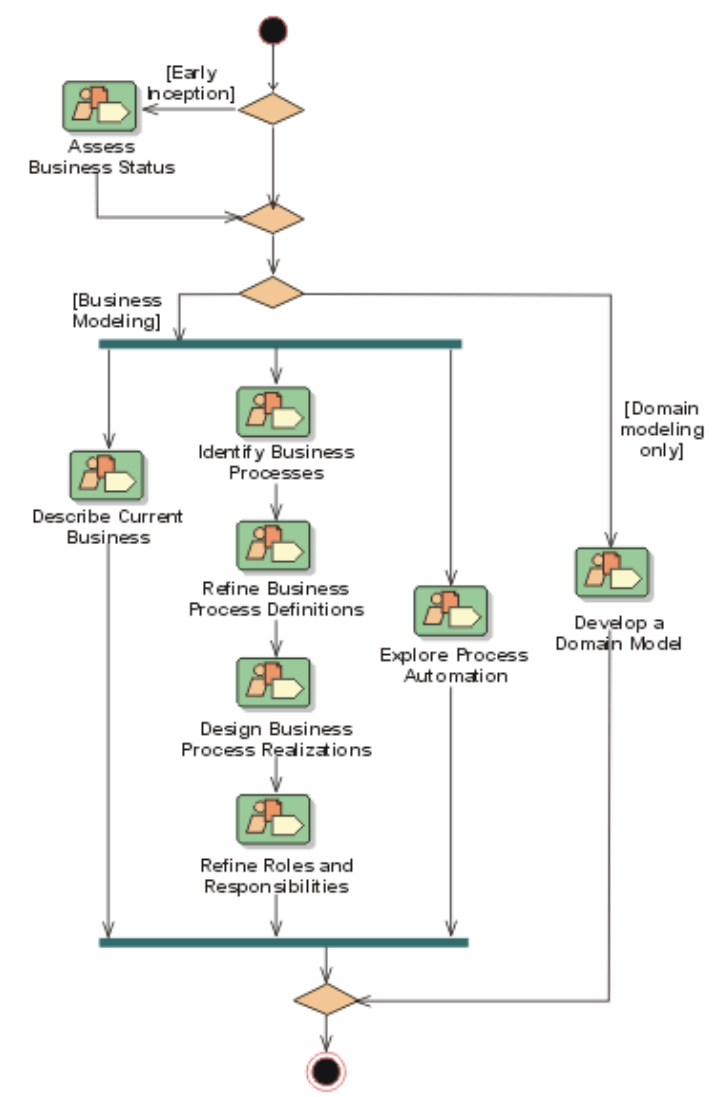

(A)

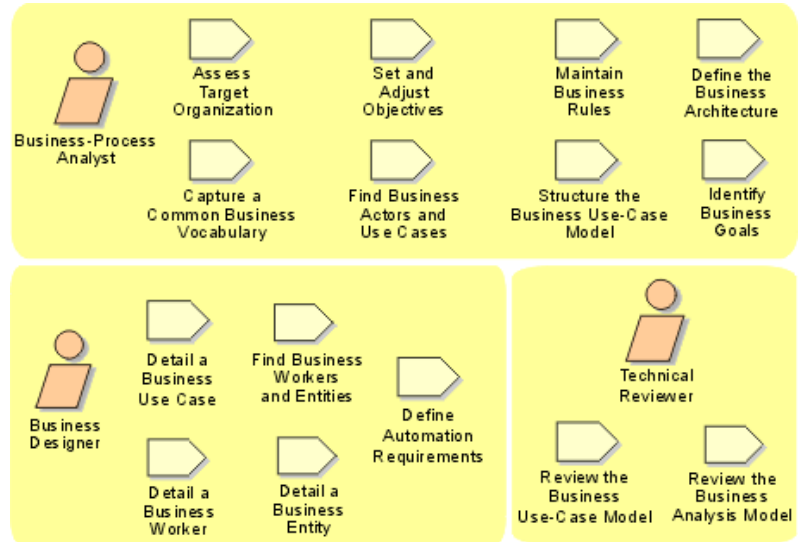

(B)

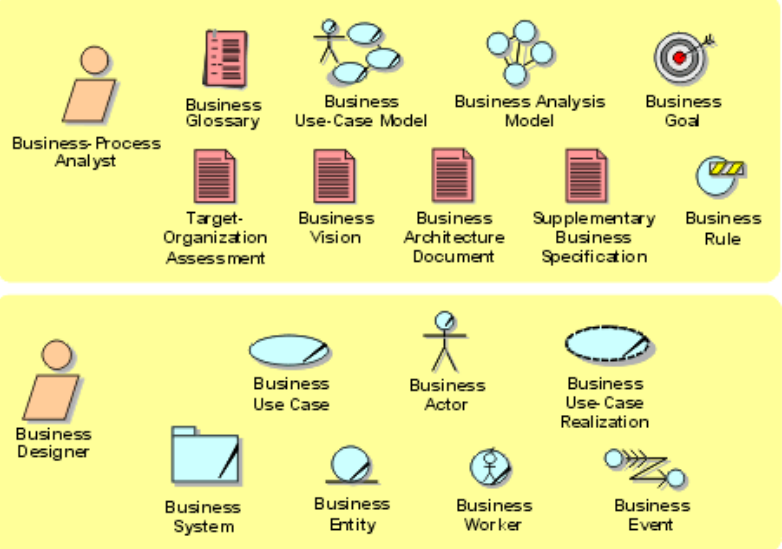

(C)

Figura 15 - Diferentes vistas oferecidas pelo RUP para a disciplina "Modelagem de Negócios": vista do workflow com conjuntos de atividades (A), vista geral das atividades (B) e vista geral dos artefatos (C) (Fonte: Software RUP® IBM). 


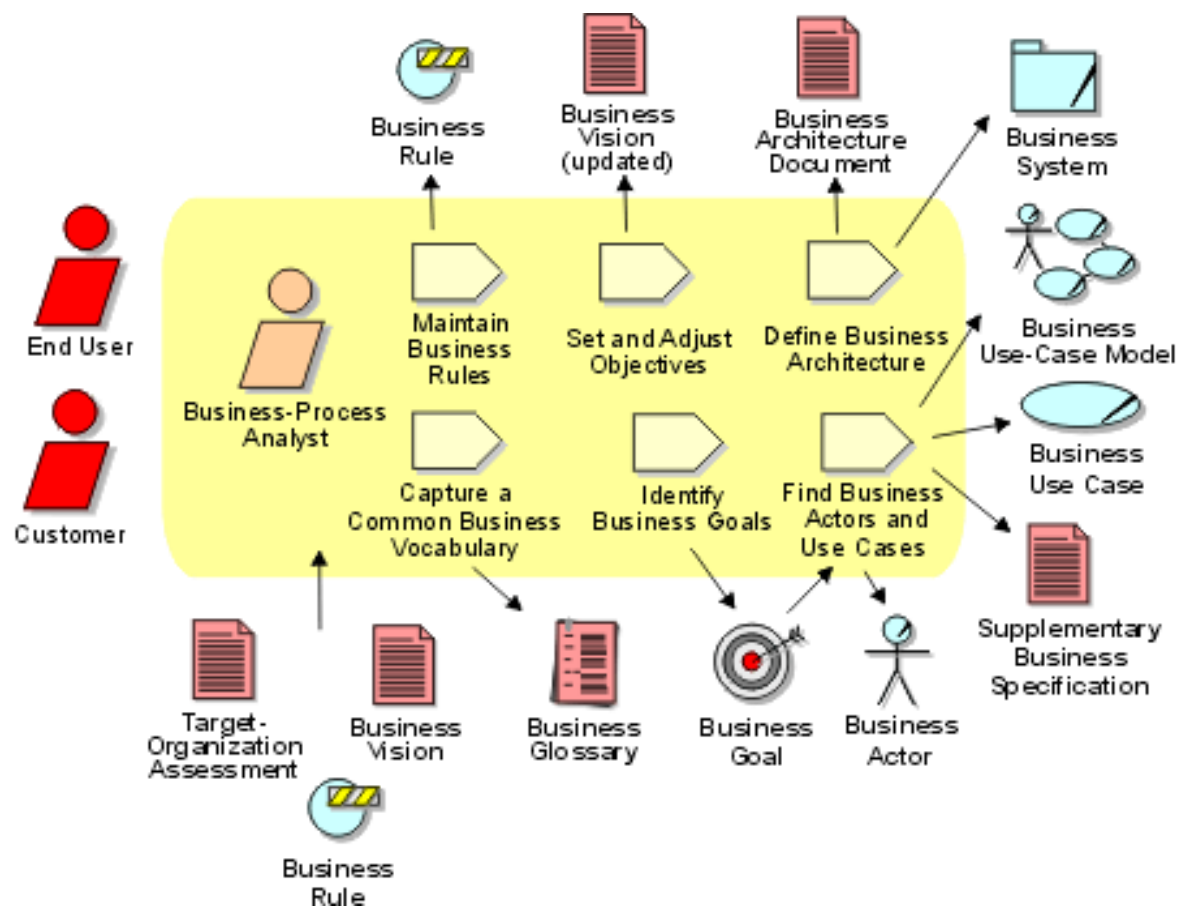

Figura 16 - Vista detalhada do conjunto de atividades "Identificar processos de negócios" (Fonte: Software RUP® IBM).

O RUP oferece também vistas analógicas centradas em papéis além das centradas em atividades. Nestas vistas é possível, por exemplo, visualizar rapidamente todos os construtos do modelo relacionados a um determinado papel em cada fase do processo, o que é uma grande vantagem para o usuário no momento de compreender o trabalho que ele deve realizar. A Figura 17 mostra a visualização oferecida pelo RUP para o papel "gerente de projeto". 


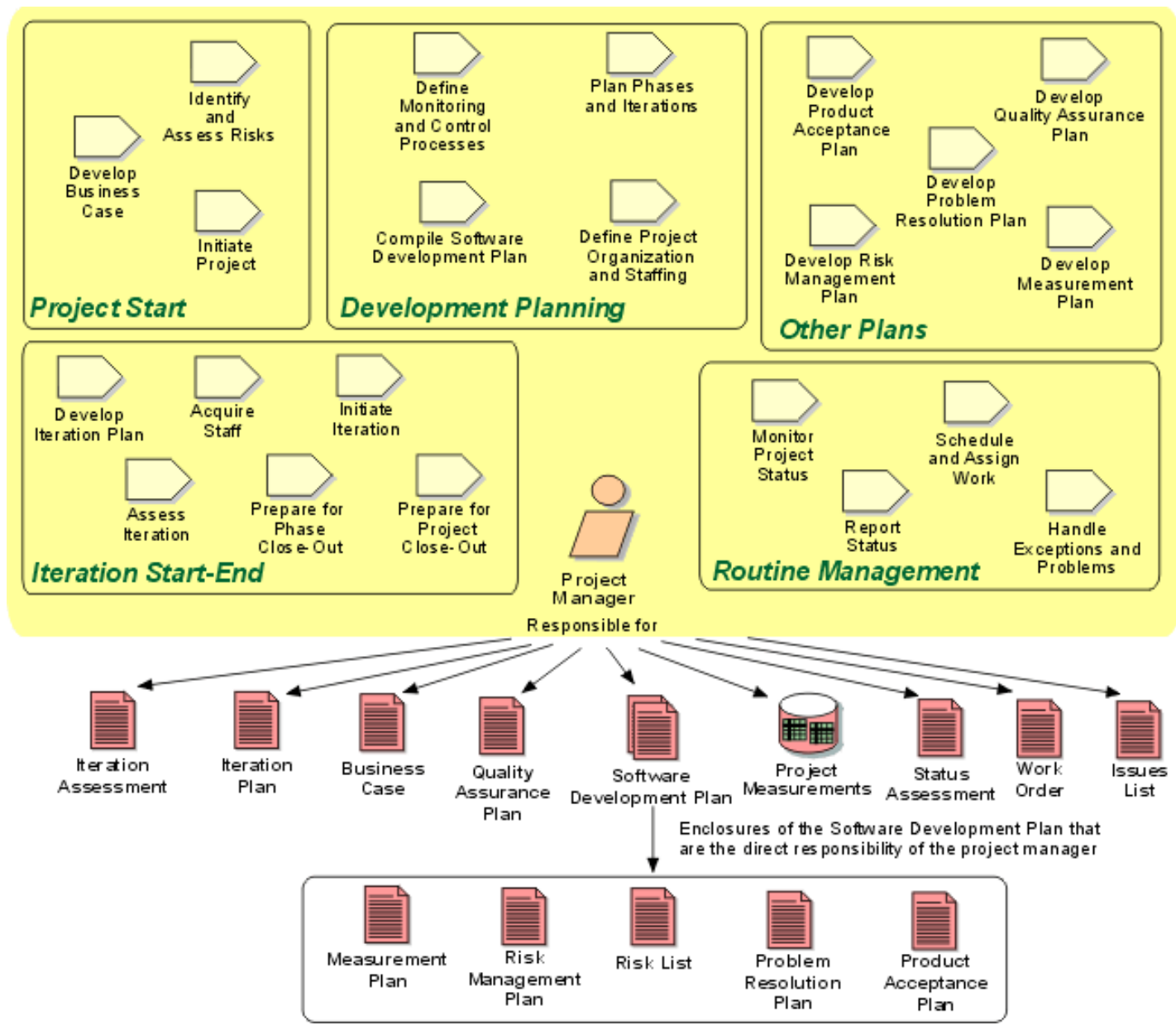

Figura 17 - Exemplo da visualização centrada em papéis do RUP (Fonte: Software RUP®) IBM)

Não há nenhum sistema customizável nos moldes do RUP para modelos de referência de desenvolvimento de produtos. Porém, ele oferece vantagens que poderiam ser exploradas nessa área de conhecimento.

\subsubsection{Softwares para modelagem de workflow}

São softwares originalmente pensados para modelagem de workflow $^{12}$ que também podem ser empregados para representação de modelos de referência de

${ }^{12}$ Vide definição de workflow no Apêndice A - Definições de termos relevantes para a modelagem de PDP. 
PDP. Existe um grande número de softwares deste tipo disponíveis no mercado. Alguns exemplos que são de uso livre são o Intalio, da Intalio Inc.(๑) ${ }^{13}$ e o Bizagi@ ${ }^{14}$.

Esses softwares servem principalmente para a modelagem do fluxo lógico de atividades dos processos, não oferecendo funcionalidades para a modelagem de outros aspectos das empresas ligados aos processos. O método de modelagem comumente disponível nestes softwares é o BPMN (Business Process Model and Notation). Permitem a modelagem em vários níveis de detalhamento, mas não permitem vistas alternativas à de fluxo lógico. Por esta razão, não atendem a vários dos propósitos dos usuários de modelos de referência de PDP, como, por exemplo, visualizar rapidamente todas as atividades de um determinado papel deve realizar dentro de uma fase; ou visualizar as entregas que um papel deve produzir em uma fase.

\subsubsection{Softwares de desenho ou planilhas}

Softwares de desenho ou planilhas viabilizam a representação de modelos em ambiente virtual, de forma muito semelhante aos modelos em papel. São ferramentas acessíveis e fáceis de usar, e permitem que se adicionem links aos elementos para a obtenção de mais informações ou principais relacionamentos. Exemplos de softwares de desenho são o Power Point ${ }^{\circledR}$ e o Visio ${ }^{\circledR}$, da Suíte Microsoft Office $\bigodot^{15}$, e o Excel®, da mesma suíte, é um exemplo de planilha eletrônica.

A principal desvantagem desse tipo de software é que é difícil manter a consistência das informações no modelo em caso de necessidade de alterações, já que cada elemento é apenas um desenho e não uma ocorrência ligada a uma base de dados. Outra desvantagem (que também existe em menor escala nas ferramentas computacionais listadas anteriormente) é que, se houver a necessidade de se representar o fluxo lógico de atividades em um nível de detalhamento maior,

\footnotetext{
${ }^{13}$ Mais informações em http://www.intalio.com/

${ }^{14}$ Mais informações em http://www.bizagi.com/

${ }^{15}$ Mais informações em http://office.microsoft.com/pt-br/products/?CTT=97
} 
provavelmente a representação excederá em muito o tamanho da tela de um monitor comum. Sendo assim, algumas empresas fazem uso de painéis interativos touchscreen para minimizar a necessidade de rolagem da tela e facilitar a busca de informações pelos usuários (Figura 18).

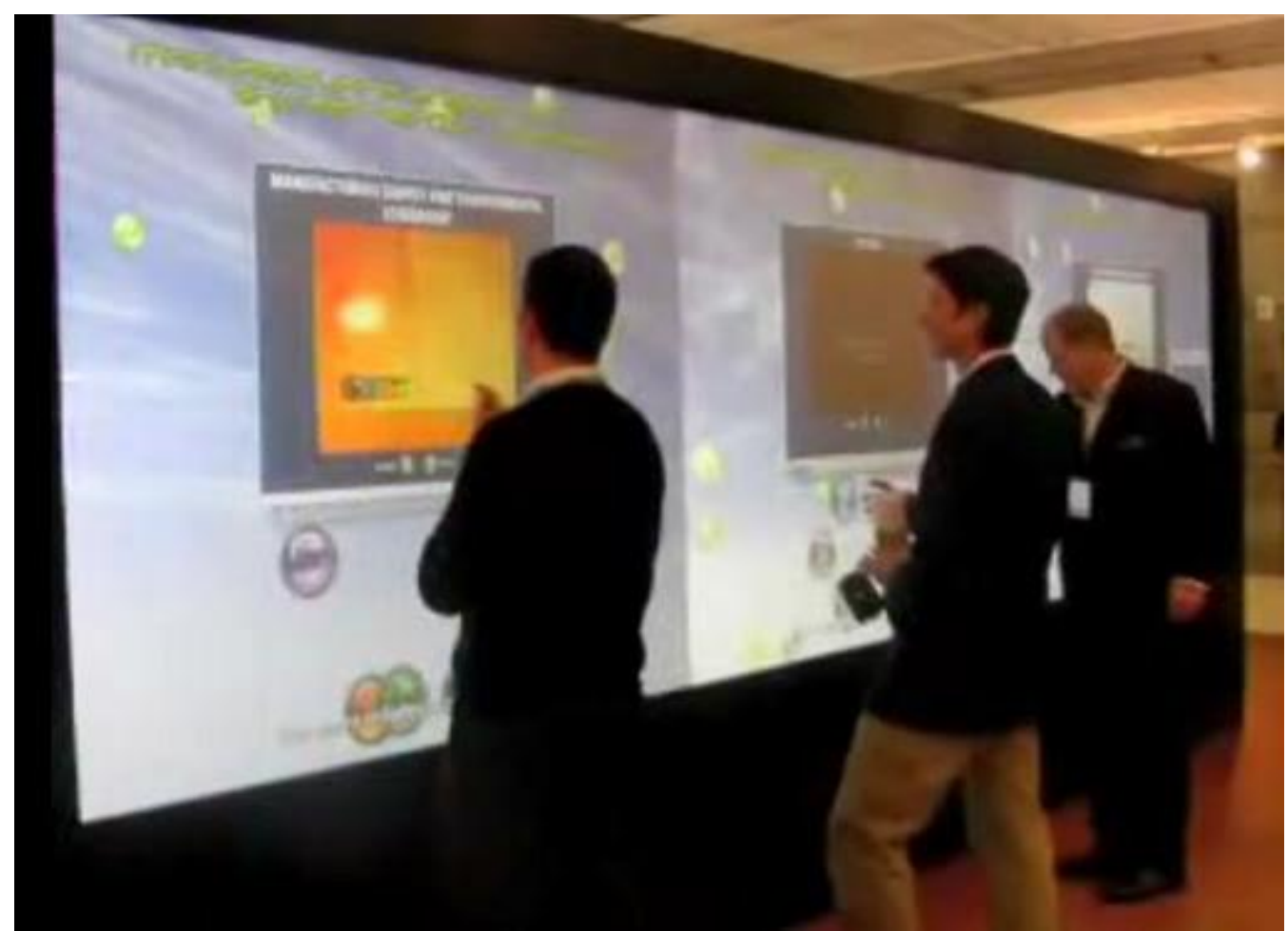

Figura 18 - Exemplo de painel interativo touchscreen (Fonte: Blog G\&G Comunicação interativa ${ }^{16}$ )

Em geral, as empresas montam os próprios modelos de referência, combinando métodos de modelagem simples como representações de alto nível e fluxogramas com descrição textual. Devido ao caráter confidencial que as informações presentes nestes modelos possuem, não foi possível fornecer imagens com exemplos nesta dissertação.

16 Disponível em http://propaganda-e-marketing.blogspot.com.br/2008/07/g-comunicao- 


\subsection{Propósitos de modelos de PDP}

Segundo Rozenfeld et al. (2006), o processo de desenvolvimento de produtos pode ser definido como

[...] o conjunto de atividades por meio das quais busca-se, a partir das necessidades do mercado e das possibilidades e restrições tecnológicas, e considerando as estratégias competitivas e de produto da empresa, se chegar às especificações de projeto de um produto e de seu processo de produção.

O processo de desenvolvimento de produtos é considerado um processo de negócio com características específicas. Ao contrário de outros processos de negócio, que procuram obter o mesmo resultado repetidamente, o PDP tem por objetivo criar algo novo e único. As saídas das atividades do PDP não são tão tangíveis e verificáveis como as de outros processos, pois muitas vezes elas consistem apenas em informações (BROWNING et al., 2006; ROZENFELD et al., 2006).

Sendo assim, os usuários de modelos de referência de PDP têm necessidades específicas em relação aos usuários de modelos de outros processos de negócios. Segundo Browning e Ramasesh (2007), os propósitos de um modelo estão relacionados com questões-chave que usuários enfrentam ao empregar modelos no desenvolvimento e gestão do PDP.

Browning (2010) sugere uma lista de propósitos de modelos organizados por tipo de usuário do processo. Apesar de não exaustiva, essa lista é uma das únicas referências específicas sobre propósitos de PDP disponíveis na literatura ${ }^{17}$. Ele considera cinco categorias de usuários do processo, detalhadas na Tabela 5. Ele afirma que cada tipo de usuário vê o processo a partir de um ponto de vista específico, e que é necessário adequar o modelo a seus usuários a fim de facilitar a visualização, evitando informações desnecessárias e garantindo que todas as informações relevantes estarão representadas. O usuário que possui propósitos mais parecidos com os de um usuário de modelo de referência de PDP está destacado em cinza na tabela: dono do processo. A Tabela 6 é uma adaptação da tabela de Browning (2010), apenas com os propósitos correspondentes aos donos

${ }^{17}$ Para mais referências, consulte o Apêndice D - Artigo: Views of process models suitable for PD reference models purposes. 
do processo. Todos os propósitos citados nesta categoria via de regra fazem parte das atribuições de donos de processos.

Tabela 5 - Categorias de usuários de modelos de processos (adaptada de Browning, 2010)

\begin{tabular}{ll}
\hline Usuário & Descrição \\
\hline Dono do processo & $\begin{array}{l}\text { Responsável por documentar e manter processos padrão; inclui } \\
\text { autores do processo; executivos que financiam o processo; e } \\
\text { mantenedores das ferramentas de modelagem. }\end{array}$ \\
\hline $\begin{array}{l}\text { Planejador e programador } \\
\text { do projeto }\end{array}$ & $\begin{array}{l}\text { Especialistas nas ferramentas de software para gestão de projetos } \\
\text { que trabalham mantendo os planos e cronogramas para grandes } \\
\text { projetos. }\end{array}$ \\
\hline $\begin{array}{l}\text { Gestor do projeto ou líder } \\
\text { de time }\end{array}$ & $\begin{array}{l}\text { Usam os modelos de processos primordialmente para apoiar } \\
\text { decisões gerenciais }\end{array}$ \\
\hline $\begin{array}{l}\text { Engenheiro, designer, } \\
\text { membro de time }\end{array}$ & $\begin{array}{l}\text { Usam modelos de processos intermitentemente no seu trabalho } \\
\text { diário em times interfuncionais. }\end{array}$ \\
\hline Auditor/assessor/perito & $\begin{array}{l}\text { Procuram verificar se os processos desenvolvidos e utilizados nos } \\
\text { projetos estão de acordo com o processo padrão da empresa. }\end{array}$ \\
\hline
\end{tabular}

Tabela 6 - Propósitos de modelos de processos, identificados para o usuário "Dono do processo" (adaptado de Browning, 2010)

\begin{tabular}{|c|c|c|}
\hline Usuário & Propósito & Explicação \\
\hline \multirow{7}{*}{$\begin{array}{l}\text { Dono do } \\
\text { processo } \\
\text { (responsável } \\
\text { por documentar } \\
\text { e manter } \\
\text { processos } \\
\text { padrão; inclui } \\
\text { autores do } \\
\text { processo; } \\
\text { executivos que } \\
\text { financiam o } \\
\text { processo; e } \\
\text { mantenedores } \\
\text { das ferramentas } \\
\text { de modelagem.) }\end{array}$} & $\begin{array}{l}\text { Definir atividades padrão e } \\
\text { preferidas }\end{array}$ & $\begin{array}{l}\text { O modelo do processo pode documentar as } \\
\text { práticas consideradas apropriadas às } \\
\text { organizações funcionais }\end{array}$ \\
\hline & $\begin{array}{l}\text { Definir entregas padrão e } \\
\text { padrões de qualidade }\end{array}$ & $\begin{array}{l}\text { O modelo do processo pode documentar os } \\
\text { resultados desejados de cada atividade, } \\
\text { incluindo as medidas de eficácia e seus } \\
\text { níveis de aceitação. }\end{array}$ \\
\hline & $\begin{array}{l}\text { Definir controle padrão e } \\
\text { estruturar workflow padrão }\end{array}$ & $\begin{array}{l}\text { O modelo do processo pode relacionar } \\
\text { entregas a atividades por meio de listas de } \\
\text { entradas e saídas, resultando em um fluxo } \\
\text { de trabalho sequenciado. }\end{array}$ \\
\hline & $\begin{array}{l}\text { Definir ferramentas e } \\
\text { templates padrão }\end{array}$ & $\begin{array}{l}\text { Um conjunto de ferramentas padrão e } \\
\text { templates pode ser associado a cada } \\
\text { atividade. }\end{array}$ \\
\hline & $\begin{array}{l}\text { Definir pessoal, papéis, } \\
\text { responsabilidades e } \\
\text { habilidades padrão }\end{array}$ & $\begin{array}{l}\text { Um conjunto de papéis a serem preenchidos } \\
\text { e/ou responsabilidades pode ser } \\
\text { especificado a cada atividade, juntamente } \\
\text { com o número típico de pessoas, nível de } \\
\text { esforço, e habilidades requeridas para } \\
\text { assegurar que a atividade será executada } \\
\text { efetivamente. }\end{array}$ \\
\hline & $\begin{array}{l}\text { Visualizar, entender, } \\
\text { analisar e melhorar } \\
\text { processos }\end{array}$ & $\begin{array}{l}\text { Donos do processo desejam maneiras de } \\
\text { representar, examinar e melhorar processos. }\end{array}$ \\
\hline & $\begin{array}{l}\text { Identificar efeitos em } \\
\text { cadeia de mudanças de } \\
\text { processo }\end{array}$ & $\begin{array}{l}\text { Quando múltiplos projetos usam um modelo } \\
\text { de processo, o dono do processo recebe } \\
\text { uma série de solicitações de mudança no } \\
\text { processo. Ele deve tentar avaliar os efeitos } \\
\text { potenciais de cada mudança em todos os } \\
\text { processos e decidir quais deve implantar. }\end{array}$ \\
\hline
\end{tabular}




\begin{tabular}{lll}
\hline Usuário & Propósito & Explicação \\
\hline & Organizar conhecimento & Modelos de processo podem ajudar a \\
& sobre o trabalho & estruturar a vasta quantidade de informação \\
& que existe em uma grande empresa sobre o \\
& trabalho e como realizá-lo. \\
\hline
\end{tabular}

Browning (2010) ainda relaciona as vistas de modelos de processos com os propósitos dos modelos para gestão de projetos, por meio dos atributos que cada um representa (Figura 19). Ele identifica em seu artigo um conjunto de 28 propósitos de modelos de PDP; um conjunto de 15 vistas de modelos de processos; e um conjunto de 56 atributos envolvidos no suporte aos propósitos e que são fornecidos pelas vistas. Ele considera os propósitos de modelos de PDP de uma forma geral, considerando o ponto de vista de vários atores envolvidos com a gestão desse processo, e as vistas de modelos mais comuns.

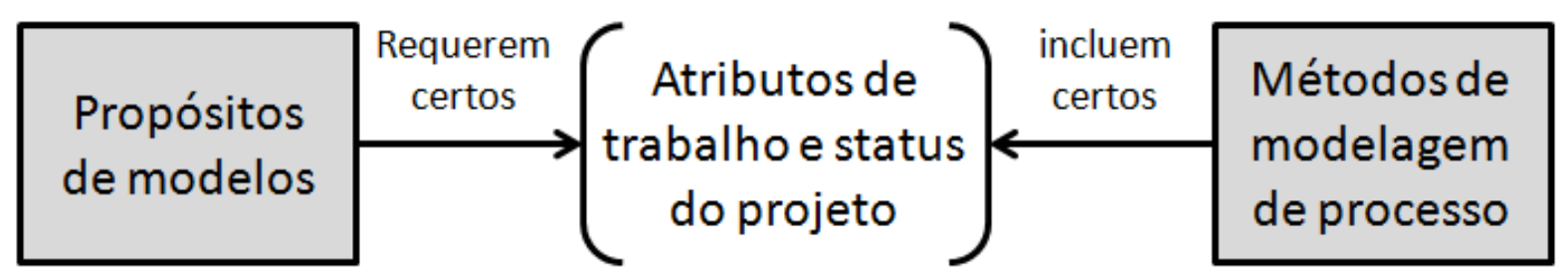

Figura 19 - Propósitos e vistas relacionados por meio de tributos (adaptado de Browning, 2010)

O método empregado por Browning (2010) está detalhado na Tabela 7. Por meio de entrevistas semi-estruturadas com diversos atores do PDP, cada um com uma diferente perspectiva do processo, Browning (2010) elabora uma matriz relacionando os atributos que oferecem suporte a um determinado propósito do modelo. Por exemplo, para que um modelo atenda ao propósito de definir ferramentas e templates padrão, um dos atributos das atividades do processo deve ser ferramenta. Também por meio de entrevistas, ele elabora uma segunda matriz, dessa vez relacionando os métodos de modelagem com os atributos que cada um fornece. Por exemplo, o IDEF0 ${ }^{18}$ sempre mostra entradas e saídas de uma atividade e às vezes também as ferramentas aplicadas, mesmo que parcialmente. Ele relaciona as duas matrizes de forma a obter um índice de alinhamento entre

\footnotetext{
${ }^{18}$ Integration Definition for Function Modeling.
} 
propósitos e métodos de modelagem (vide etapa 5 do método da Tabela 7), elaborando uma terceira matriz com os resultados.

Ele conclui que há um desalinhamento significativo entre os propósitos dos modelos e o que os métodos de modelagem podem proporcionar. Segundo ele, isso indica a necessidade de novos métodos de modelagem, que possam atender melhor aos propósitos dos modelos. Como principal limitação do seu trabalho, Browning (2010) indica o fato de sua análise ter se baseado apenas no conteúdo de informação objetiva dos modelos. Ele não considera aspectos mais subjetivos que também interferem no desempenho de um modelo, por exemplo, facilidade de uso e interação com o usuário, que são o foco desta pesquisa.

Tabela 7 - Etapas do método para obtenção do alinhamento entre propósitos de modelos e métodos de modelagem (Adaptado de Browning, 2010) \begin{tabular}{l}
\hline Etapa 1 - Identificação dos propósitos dos modelos e métodos de modelagem \\
Consiste em determinar o conjunto de propósitos e o conjunto de métodos de modelagem \\
que serão utilizados.
\end{tabular}

Etapa 2 - Identificação de atributos de modelos de processo relacionados com propósitos e métodos de modelagem

Consiste em criar um conjunto de atributos, a partir de atributos representados pelos métodos de modelagem e os atributos necessários para apoiar os propósitos.

\section{Etapa 3 - Mapeamento dos propósitos para os atributos}

Consiste em criar uma matriz correlacionando e qualificando a relação entre propósitos e atributos. Atributos essenciais para um propósito ficam com nota 2; atributos que podem auxiliar um propósito ficam com nota 1; e atributos que não são usados para um propósito ficam com nota 0.

\section{Etapa 4 - Mapeamento dos métodos de modelagem para os atributos}

Consiste em criar uma matriz correlacionando e qualificando a relação entre métodos de modelagem e atributos. Atributos que usualmente são representados por um método ficam com nota 2; atributos que são representados às vezes ou parcialmente por um método ficam com nota 1,5; atributos que podem potencialmente ser representados por um método ficam com nota 1; e atributos que nunca são representados por um método ficam com nota 0.

Etapa 5 - Alinhamento dos propósitos com os métodos de modelagem

Consiste na obtenção de três índices para cada relacionamento entre propósito e método de modelagem, a partir dos dados das duas matrizes criadas nos estágios 3 e 4 e das equações abaixo:

Diferença positiva (D)

(indica o tamanho da entre os atributos necessários para um propósito i e os fornecidos por um método j)

$$
D_{i j}=\sum_{k=1}^{x} \operatorname{Max}\left(P_{i k}-V_{j k}, 0\right)
$$

\section{Suficiência (S)}

(Compara a porcentagem de atributos essenciais e que podem auxiliar um propósito i com sua representação usual, parcial ou potencial fornecida por um método j)
Estraneidade (E)
(Indica a porcentagem de atributos representados

$$
E_{i j}=\frac{\sum_{k=1}^{x} \operatorname{Max}\left(V_{j k}-P_{i k}, 0\right)}{\sum_{k=1}^{x} V_{j k}}
$$
por um método j que não são usados por um propósito i)

\section{Alinhamento (PVA)}

(Indica a porcentagem de alinhamento entre um propósito i e um método j)

$$
\begin{aligned}
& \boldsymbol{P}=\text { Série de atributos dos } \\
& \text { propósitos } \\
& \boldsymbol{V}=\begin{array}{l}
\text { Série de atributos dos } \\
\text { métodos }
\end{array}
\end{aligned}
$$

$$
\begin{aligned}
& i=\text { índice do } \\
& \text { propósito } \\
& j=\text { índice do } \\
& \text { método }
\end{aligned}
$$

$$
S_{i j}=1-\frac{D_{i j}}{\sum_{k=1}^{x} P_{i k}}
$$




\subsection{Interação dos usuários com um modelo de processo}

Modelos de processo de desenvolvimento de produtos podem ser considerados um tipo de sistema de visualização de informações. De acordo com Yi et al. (2007), sistemas de visualização de informações parecem ter dois componentes principais: representação e interação. O componente "representação" refere-se ao mapeamento de dados e a forma como esses dados são representados na tela. O componente "interação" refere-se à interface entre usuário e sistema e a maneira que o usuário dialoga com ela. Um estudo que considere a perspectiva do usuário em relação ao uso de modelos precisa considerar esses dois componentes, já que eles não são independentes e se influenciam mutuamente.

O componente "representação", nesta pesquisa, é considerado como o conjunto dos métodos de modelagem (formalismos) e suas vistas. Segundo a definição de Vernadat (1996) anteriormente apresentada, modelos são representações da realidade, expressos por meio de um formalismo, que nesta pesquisa é considerado equivalente a um método de modelagem. O método de modelagem vai determinar a forma de coleta dos dados e como eles serão representados (linguagem de modelagem). As vistas determinarão a perspectiva de visualização do conjunto de informações do modelo, que pode considerar, por exemplo, o ponto de vista de um usuário específico.

O componente "interação" é ainda pouco explorado na literatura sobre modelagem de PDP, e é o principal foco desta pesquisa. Ele é detalhado no item 2.3.1 a seguir.

\subsubsection{Interação e interface}

A interação, no âmbito desta pesquisa, pode ser compreendida como o processo de ação e reação que se dá quando um usuário se utiliza de um sistema computacional (ARAUJO, 2012). Essa interação se dá por meio da interface, que pode ser definida como "parte de um sistema computacional com a qual a pessoa entra em contato - física, perceptiva ou conceitualmente." (MORAN, 1981). O usuário realiza um conjunto de ações por meio de uma interface e obtém uma 
resposta (reação) do sistema computacional. Modelos de processos de PDP podem ser visualizados por meio de um sistema computacional (item 2.1.5). A parte do modelo com que o usuário toma contato por meio da interface do sistema computacional são as vistas concebidas (item 2.1.2).

A interação de um usuário com um sistema pode ser influenciada tanto pela forma como os elementos estão representados na interface, como também no paradigma de interação utilizado. O paradigma de interação mais comum é o GUI (Graphical User Interface), ou WIMP (acrônimo para Windows, Icons, Mouse and Pointers), que é o que um computador desktop normalmente oferece. Há uma tendência atual para se promover paradigmas além do desktop, como a computação ubíqua (tecnologia inserida no ambiente), realidade aumentada, computação vestível (wearables), entre outras (PREECE et al., 2006). O paradigma de interação adotado nesta pesquisa é o tradicional do computador desktop (WIMP), extensível para os computadores portáteis (notebooks) já que se optou nesta pesquisa em priorizar a avaliação da forma como os elementos estão representados na interface e não o paradigma em si.

Há dois modelos conceituais de interação relacionados com o paradigma de interação WIMP: os baseados em objetos e os baseados em atividades. Segundo Preece et al. (2006), um modelo conceitual é:

Uma descrição do sistema proposto - em termos de conjunto de ideias e conceitos integrados a respeito do que ele deve fazer, de como deve se comportar e com o que deve se parecer para que seja compreendida pelos usuários da maneira pretendida.

Modelos conceituais baseados em um objeto referem-se aos sistemas e/ou ferramentas computacionais desenvolvidas de maneira análoga a um objeto real utilizado dentro de um contexto específico. Preece et al. (2006) dão como exemplo de ferramenta desenvolvida por meio desse tipo de modelo conceitual a planilha eletrônica. Ela é análoga às planilhas físicas de livros caixa.

Já os modelos conceituais baseados em atividades partem do tipo de atividades que eles esperam que os usuários realizem para conceber um sistema ou ferramenta computacional (PREECE et al., 2006). Os tipos mais comuns de 
atividades estão descritos abaixo; eles podem ser empregados de forma combinada em alguns sistemas:

- Instrução: o usuário dá instruções ao sistema para realizar uma tarefa, por ex: digitar comandos, selecionar opções de menus em um ambiente de janelas, dar comandos de voz, pressionar botões, utilizar uma combinação de teclas de funções, etc.

- Conversação: o usuário conversa com o sistema, de maneira análoga à conversação entre duas pessoas. Ele pode fazer a pergunta verbalmente ou digitando no sistema, e obter dessa forma uma resposta, que pode ser verbal ou via texto.

- Manipulação e navegação: o usuário navega em um ambiente virtual e pode manipulá-lo. Em geral o ambiente virtual se comporta como o físico, permitindo que o usuário interaja com os objetos da mesma forma como interage no mundo real. Um exemplo é o ambiente desktop do Windows $\odot$.

- Exploração e pesquisa: o usuário tem acesso à informação estruturada de modo a permitir que ele encontre informações, sem ter que formular perguntas específicas ao sistema (PREECE et al., 2006).

O tipo de atividade que é mais relacionado com os objetivos desta pesquisa é o de manipulação e navegação (em menor medida também o de exploração e pesquisa). Nesse tipo de atividade de manipulação e navegação, o usuário não precisa se lembrar de comandos para executar as atividades; basta o pressionar de ícones e botões. Ele tem uma resposta imediata às suas ações no sistema, não necessitando de informações adicionais, como mensagens de erro. Ele pode reverter as ações realizadas facilmente e também perceber imediatamente se as ações o estão auxiliando a atingir o objetivo pretendido (PREECE et al., 2006).

É comum o uso de metáforas de interface quando se opta pelo tipo de atividade "manipulação e navegação". Metáforas de interface combinam o conhecimento familiar ao usuário com novos conceitos, visando facilitar o aprendizado do sistema (PREECE et al., 2006). As metáforas são amplamente empregadas nos ícones dos sistemas computacionais. Um ícone, diferente de um símbolo, possui semelhança ou analogia com aquilo ao que se refere (PIGNATARI, 1965). Um exemplo de um ícone é um desenho de uma ferramenta sendo utilizado 
para representar as ferramentas empregadas na realização de uma atividade de um processo. Um símbolo possui uma relação de convenção, arbitrária, com aquilo ao que se refere. Por exemplo, um quadrado amarelo representando um papel de uma empresa (Figura 20).

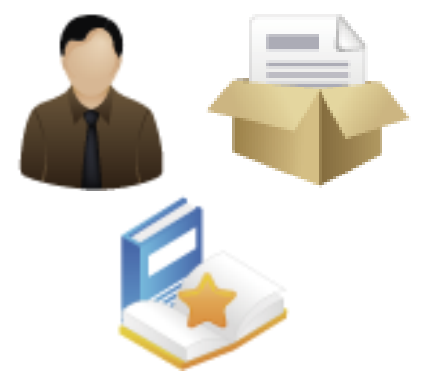

(A)

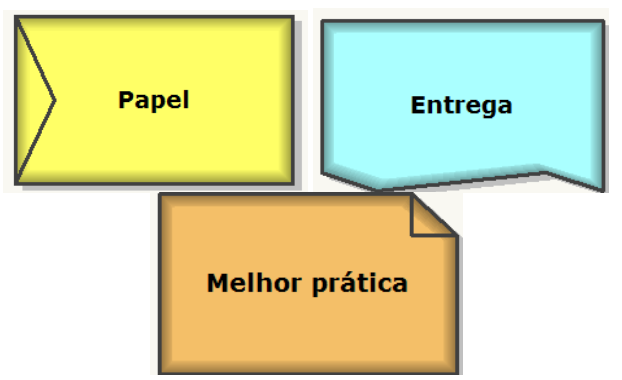

(B)

Figura 20 - Exemplos de ícones (A), e símbolos (B), para construtos com mesmo significado.

\subsubsection{Usabilidade}

A usabilidade de um software é um dos aspectos mais relevantes da sua interface. Ela está relacionada aos aspectos de uso dessa interface, e tem sido utilizada na avaliação da qualidade da interface de sistemas computacionais nas últimas três décadas (SEFFAH et al., 2006).

Encontram-se na literatura diversas definições para a usabilidade de sistemas, elaboradas por autores de modelos para a usabilidade ou por normas específicas (SEFFAH et al., 2006). Para este estudo, foram selecionadas as definições de usabilidade listadas abaixo, pelo destaque dado aos atributos de qualidade de uso e aprendizado do usuário.

Usabilidade é:

[...] a capacidade de um produto ser usado por usuários específicos para atingir objetivos específicos com eficácia, eficiência e satisfação em um contexto específico de uso. (ISO-9241, 1998)

Onde:

- Eficácia: Acurácia e completude com as quais usuários alcançam objetivos específicos. 
- Eficiência: Recursos gastos em relação à acurácia e abrangência com as quais usuários atingem objetivos.

- Satisfação: Ausência do desconforto e presença de atitudes positivas durante o uso do produto.

- Usuário: Pessoa que interage com o sistema.

- Objetivo: Resultado pretendido (ISO-9241, 1998).

E também:

A usabilidade é um atributo de qualidade relacionado à facilidade de uso de algo. Mais especificamente, refere-se à rapidez com que os usuários podem aprender a usar alguma coisa, a eficiência do usuário no uso do sistema, o quanto se lembram dele, seu grau de propensão a erros e o quanto gostam de utilizar o sistema. Se as pessoas não puderem e/ou não utilizarem um recurso, ele pode muito bem não existir. (NIELSEN; LORANGER, 2007)

Dentro os modelos de usabilidade encontrados na literatura, o de Preece et al. (2006) é um dos mais completos em relação aos objetivos da usabilidade. Segundo o autor, a usabilidade deve garantir que o software seja:

- Eficaz na utilização (eficácia)

- Eficiente na utilização (eficiência)

- Seguro na utilização (segurança)

- Possuir boa utilidade (utilidade)

- Fácil de aprender (capacidade de aprendizado)

- Fácil de lembrar como utilizar (capacidade de memorização) 


\section{Metodologia de pesquisa}

O objetivo da pesquisa científica, segundo Karlsson (2008), é a criação e o desenvolvimento de conhecimento, e o seu resultado é uma contribuição ao conhecimento pré-existente. O conceito de conhecimento é complexo, e é possível encontrar diversas definições na literatura. Para a presente pesquisa a seguinte definição de Turban e Frenzel (1992) é adotada:

Conhecimento é informação que foi organizada e analisada, a fim de torná-la compreensível e aplicável à resolução de problemas e tomada de decisões.

O grande desafio do pesquisador na área de gestão de operações é criar contribuições e valor tanto para a academia quanto para a prática. As pesquisas em geral têm caráter multidisciplinar e são conduzidas de forma próxima às indústrias. $A$ prática, porém, deve extrapolar a dimensão da organização e ser vista de forma mais abrangente, pois tem potencial para contribuir em vários níveis: sociedade, indústria, organização, grupo e indivíduo (KARLSSON, 2008).

Este estudo visa realizar uma contribuição à área de conhecimento de modelagem de processos, especificamente em relação à modelagem de processos de desenvolvimento de produtos. Tem como grupo alvo usuários de modelos de referência de PDP. A contribuição pretendida que norteia o planejamento desta pesquisa está nos itens 1.2 e 1.3 deste documento: objetivos e justificativas.

\subsection{Planejamento da pesquisa}

É fundamental que haja alinhamento entre o problema de pesquisa, o método de pesquisa e a contribuição que se deseja construir (KARLSSON, 2008). Nem todos os problemas de pesquisa podem ser respondidos por todos os métodos de pesquisa, e há métodos mais ou menos adequados para cada tipo de contribuição pretendida. A fim de orientar a escolha dos métodos, dados e análises que serão necessárias para a construção dessa contribuição, é útil compreender esta pesquisa 
de acordo com sua natureza e a natureza de seus objetivos, posição filosófica adotada (paradigmas) e forma de abordagem do problema.

A Figura 21 sintetiza o raciocínio empregado no planejamento da pesquisa e na escolha dos métodos que serão utilizados, bem como sua ligação com os pacotes de trabalho expostos no item 3.2. Ela serve como guia para a compreensão dessa seção.

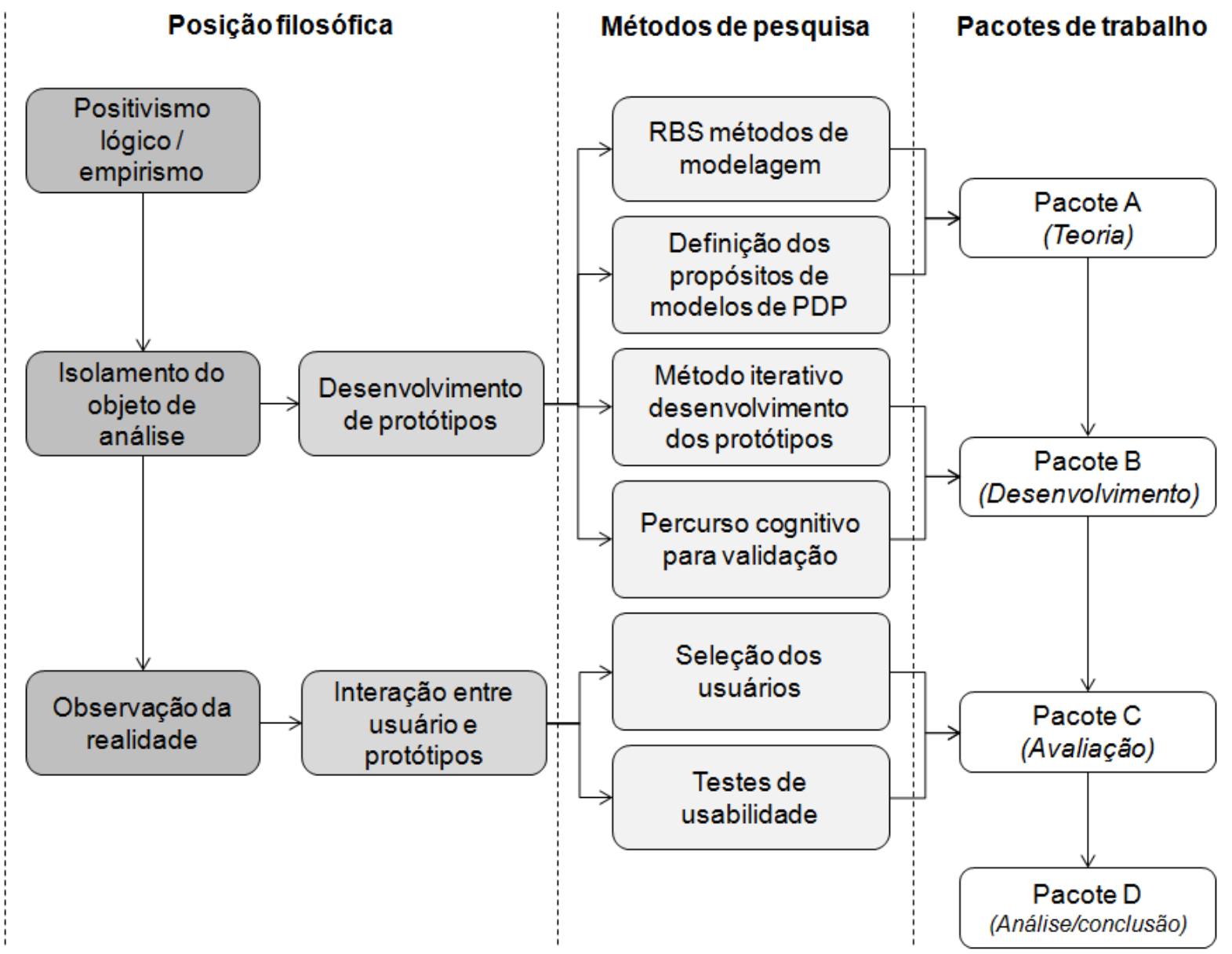

Figura 21 - Síntese do raciocínio empregado no planejamento da pesquisa

Uma pesquisa pode ser de natureza básica ou aplicada. A presente pesquisa é de natureza aplicada, já que se propõe a gerar conhecimentos para aplicação prática, dirigidos à solução de um problema específico conforme exposto no item 1.2. A natureza do objetivo de uma pesquisa depende do grau de maturidade da área em estudo. Estudos iniciais em uma área de conhecimento possuem objetivos de natureza exploratória, enquanto estudos em áreas maduras de conhecimento possuem objetivos de natureza prescritiva, capazes de evidenciar relações de causa e efeito e prever resultados. Ainda há os objetivos de natureza descritiva, que visam estruturar o conhecimento obtido na fase exploratória e sugerir padrões (KARLSSON, 2008). 
Apesar da área de modelagem de processos já possuir um grau de maturidade avançado, o aspecto da interação de usuários com modelos de PDP é praticamente inexplorado. A grande maioria dos estudos concentra-se nas informações objetivas que os modelos representam, e nos formalismos utilizados para isso. Eles não consideram, por exemplo, se a informação dos modelos estará evidente para os usuários (BROWNING, 2010). Pretende-se, portanto, explorar este aspecto (conforme exposto no item 1.2), o que torna a natureza do objetivo desta pesquisa exploratória.

Em relação à posição filosófica, a maioria da literatura sobre metodologia de pesquisa da área de gestão adota os paradigmas de Burrell e Morgan (1979) apud Karlsson (2008). Estes paradigmas têm como extremos o positivismo e o construtivismo. Para o positivismo, a verdade é objetiva e vista como um produto da razão pura, livre do seu contexto. A ênfase é em fatos observáveis e mensuráveis, e em resultados que podem ser replicáveis e generalizáveis. No outro extremo, para o construtivismo a verdade é subjetiva e dependente do seu contexto. Ela deve ser interpretada a partir das circunstâncias específicas de uma situação (KARLSSON, 2008).

Meredith et al. (1989) propõem um framework para classificar métodos de pesquisa que se baseia na posição filosófica adotada e nas fontes e tipo de informações utilizadas na pesquisa (Figura 22). Os paradigmas filosóficos que adota são equivalentes aos de Burrell e Morgan (1979) apud Karlsson (2008): racional ou dedutivo (positivista) e existencial ou indutivo (construtivista). Esses paradigmas incluem quatro perspectivas: axiomática, positivismo lógico/empirismo, interpretativa e teoria crítica. A axiomática está no extremo do paradigma racional, enquanto a teoria crítica no extremo do paradigma existencial.

Em relação às fontes e tipo de informações, Meredith et al. (1989) as classificam entre dois extremos: natural e artificial. O natural está relacionado com o empirismo, utilizando dados objetivos e concretos normalmente resultantes de observação direta; e o artificial está relacionado com o subjetivismo, utilizando dados provenientes de interpretação e construção artificial da realidade. Meredith et al. (1989) consideram três categorias a partir desses extremos: observação direta da realidade objeto (relacionada com o extremo natural), percepção das pessoas sobre a realidade objeto e reconstrução artificial da realidade objeto (relacionada com o extremo artificial). 
Adota-se para esta pesquisa a perspectiva de positivismo lógico/empirismo, que é coerente com a natureza exploratória do objetivo desta pesquisa. Essa perspectiva assume que o fenômeno sob estudo pode ser isolado do contexto em que ocorre e que fatos e observações são independentes das teorias usadas para explicá-los (MEREDITH et al., 1989). Apesar de próxima do extremo racional e dedutivo, que focam em fatos observáveis e mensuráveis, essa perspectiva também permite que se utilizem dados obtidos a partir da percepção das pessoas (por vezes subjetiva), para a análise de uma realidade ou objeto. Como esta pesquisa tem como foco a interação de usuários com vistas de modelos de PDP, as fontes e tipo de informações utilizadas são baseados em dados objetivos de eficácia e desempenho, mas também na percepção desses usuários (satisfação) sobre as vistas de PDP submetidas à análise.

Para viabilizar a análise, as vistas de modelos são isoladas do seu contexto de uso real por meio da elaboração de protótipos de um modelo de referência genérico. Esses protótipos utilizam diferentes métodos para a modelagem de um único conteúdo, fornecido por um modelo de referência genérico do PDP (vide item 4.1.3): um dos protótipos, denominado $A$, propõe novas vistas para esse conteúdo (vide item 4.2.1), enquanto outro protótipo, denominado $B$, emprega um método de modelagem existente para a elaboração dessas vistas (vide item 4.2.2).

Para elaboração do protótipo $A$, é feito um levantamento sobre as ferramentas computacionais atualmente empregadas para visualização de modelos de referência, para compreender que recursos poderiam ser utilizados nas vistas propostas. Para a elaboração do protótipo $B$, é realizada uma revisão bibliográfica sistemática sobre métodos de modelagem do PDP, bem como um levantamento dos propósitos a que esses métodos atendem, a fim de identificar qual método de modelagem (vide item 4.1.2) atende ao maior número de propósitos de usuários de modelos de referência de PDP (já que essa informação não está disponível na literatura).

O framework proposto por Meredith et al. (1989) indica, a partir da posição filosófica e fontes e tipo de informações que serão utilizadas, os métodos para coleta dos dados que são mais adequados para esta pesquisa (destacado em cinza na 
Figura 22). Os métodos são entrevistas estruturadas e surveys ${ }^{19}$. Como o foco desta pesquisa está na interação do usuário com as vistas, o método escolhido é o de entrevistas estruturadas, a serem realizadas na forma de testes de usabilidade (vide item 3.5.2) com um grupo selecionado de usuários (vide item 3.5.1). A elaboração do roteiro de tarefas dos testes de usabilidade é baseada nos propósitos de usuários de modelos de referência de PDP identificados para a elaboração do protótipo B (vide item 3.3.2).

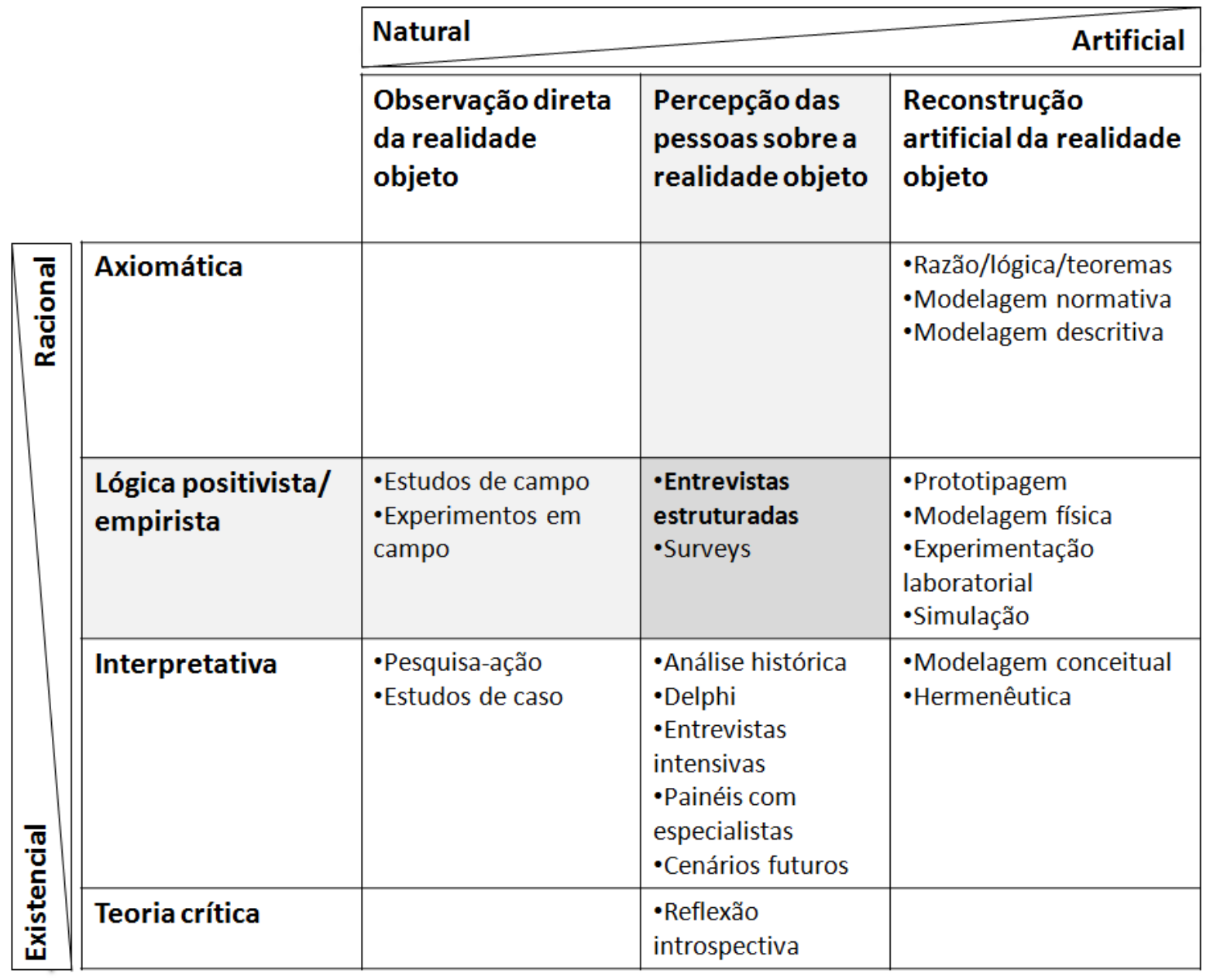

Figura 22 - Framework para classificação de métodos de pesquisa (adaptado de Meredith et al., 1989)

A escolha pelo desenvolvimento de protótipos e pelas entrevistas estruturadas baliza a definição da forma de abordagem desta pesquisa, pois determina o tipo de dados a serem analisados. A forma de abordagem pode ser quantitativa ou qualitativa. Esta pesquisa emprega ambas, analisando dados objetivos de eficácia e

${ }^{19}$ As surveys não oferecem recursos para a coleta de dados objetivos sobre a interação de usuários com as vistas, apenas os dados subjetivos (por exemplo respostas referentes à percepção dos usuários). 
eficiência (quantitativa), e dados subjetivos de satisfação do usuário (qualitativa). Apesar da forma de abordagem qualitativa ser mais frequentemente associada à posição filosófica construtivista ou existencial, é comum encontrá-la associada à posição positivista ou realista na literatura (KARLSSON, 2008), pois é possível atribuir números a variáveis qualitativas ${ }^{20}$.

\subsection{Pacotes de trabalho, principais entregas e respectivas atividades}

Como resultado do planejamento da pesquisa, este estudo é composto por quatro pacotes de trabalho. As principais entregas de cada pacote são mostradas na Figura 23 e suas principais atividades na Tabela 8.

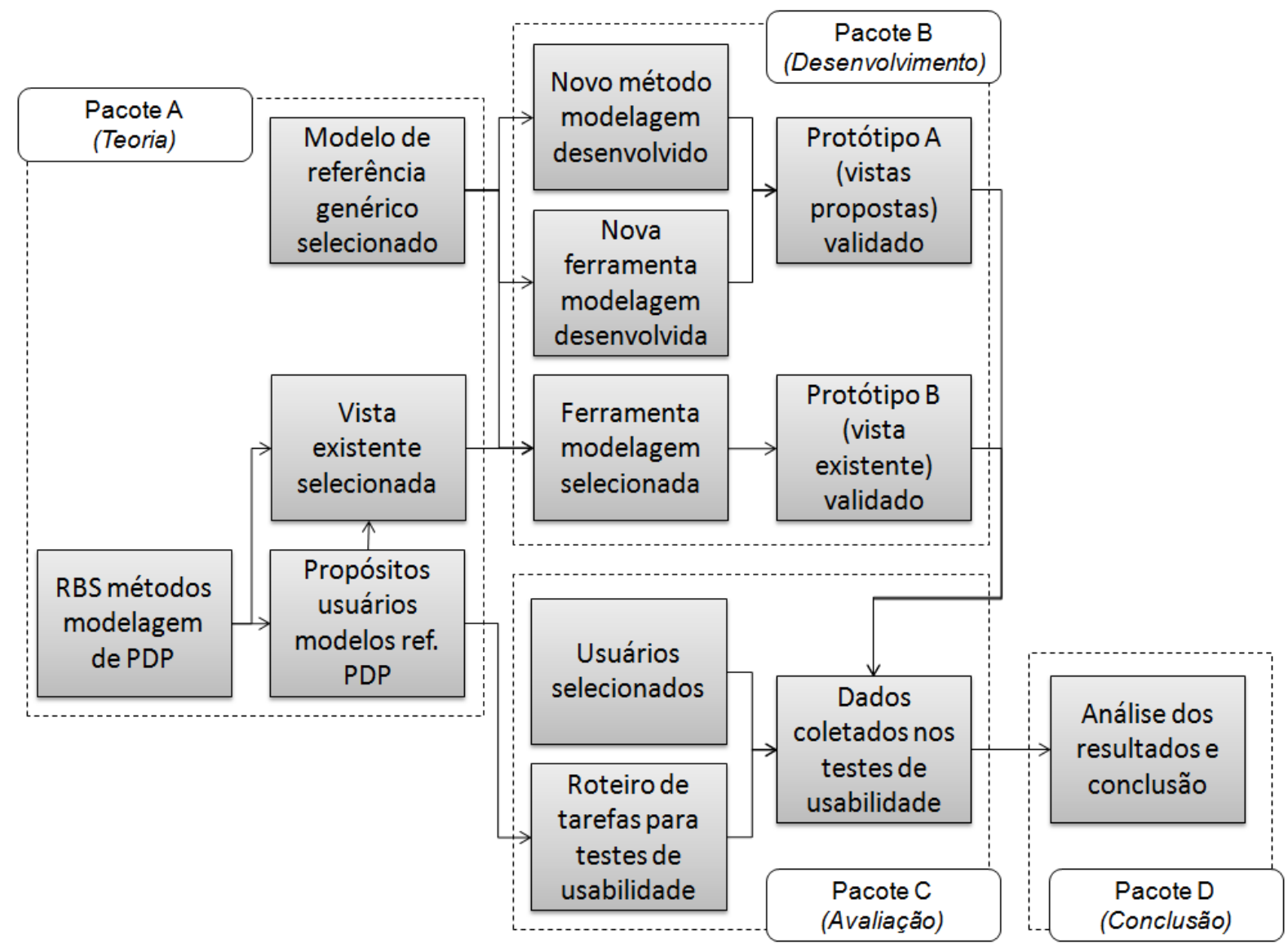

Figura 23 - Pacotes de trabalho com suas principais entregas e relacionamento entre elas

${ }^{20}$ Por exemplo, é possível contabilizar o número de respondentes de uma survey em relação à resposta afirmativa a uma questão (KARLSSON, 2008). 
Tabela 8 - Principais atividades dos pacotes de trabalho

\section{A. Teoria}

1 Realização de revisão bibliográfica sistemática (RBS) com o objetivo de identificar os métodos de modelagem utilizados para processos de desenvolvimento de produtos.

2 Levantamento dos propósitos de modelos de PDP pertinentes ao escopo desta pesquisa, com base na RBS.

3 Seleção do método de modelagem para o protótipo $\mathrm{B}$, de acordo com o número de propósitos atendidos por ele (com base em levantamento da literatura).

4 Seleção e análise do modelo de referência genérico para o processo de desenvolvimento de produtos que servirá como referencial teórico.

\section{B. Desenvolvimento}

1 Seleção da ferramenta de modelagem adequada à modelagem do protótipo $\mathrm{B}$.

2 Desenvolvimento das novas vistas para modelagem do protótipo $A$.

3 Desenvolvimento da ferramenta de modelagem para o protótipo $\mathrm{A}$.

4 Realização da primeira iteração de desenvolvimento dos protótipos.

5 Avaliação preliminar dos protótipos por meio de percurso cognitivo.

6 Realização da segunda iteração de desenvolvimento dos protótipos.

7 Realização do teste piloto para validação final dos protótipos.

\section{Avaliação}

1 Elaboração de roteiro de tarefas para o teste de usabilidade, baseado nos propósitos de modelos de processo de desenvolvimento de produtos selecionados no item 2 do pacote $A$.

2 Seleção dos usuários para realização dos testes de usabilidade.

3 Realização dos testes de usabilidade e extração dos dados para uma planilha.

\section{Análise dos resultados e conclusão}

1 Tratamento estatístico dos resultados.

2 Análise dos resultados.

3 Elaboração das conclusões.

4 Elaboração da dissertação, relatórios e artigos científicos.

O pacote de trabalho A consiste no levantamento e estruturação das informações encontradas na literatura que ainda não estejam no formato ideal para a aplicação nesta pesquisa. É realizada uma revisão bibliográfica sistemática com o objetivo de identificar os métodos utilizados especificamente na modelagem de processos de desenvolvimento de produtos. São então levantados os propósitos de modelos de referência de PDP, pertinentes ao escopo desta pesquisa (item 4.1.2). A seleção do método de modelagem a ser utilizado nos protótipo $B$ é realizada a partir do mapeamento dos propósitos a que ele atende, de acordo com o levantamento da literatura realizado pela RBS. O conteúdo a ser modelado (um modelo de referência genérico de PDP) também é selecionado nesse pacote, considerando a disponibilidade e confiabilidade das informações.

O pacote de trabalho B trata do desenvolvimento dos protótipos. desenvolvimento do protótipo A envolve a geração das vistas (método de modelagem) e também o desenvolvimento de uma ferramenta de modelagem específica. O desenvolvimento do protótipo $B$ envolve a seleção da ferramenta de modelagem a ser empregada (de acordo com o método de modelagem selecionado no pacote A). O desenvolvimento passa por duas iterações, sendo que entre elas é 
realizado um percurso cognitivo por especialistas, a fim de identificar potenciais problemas a serem sanados. Ao final do desenvolvimento, ambos os protótipos são submetidos a um teste piloto para a validação final. As principais entregas são os protótipos validados, prontos para serem testados.

O pacote de trabalho $\mathrm{C}$ consiste na avaliação dos protótipos por meio dos testes de usabilidade. São selecionados os usuários e o roteiro de tarefas para realização dos testes, baseado no levantamento dos propósitos de usuários do PDP realizado no pacote A. Os dados coletados nos testes de usabilidade são submetidos a um tratamento estatístico para a análise dos resultados, que é realizada no pacote $D$. $O$ pacote de trabalho $D$ também envolve a elaboração da conclusão e da dissertação, relatórios e artigos científicos.

\subsection{Métodos empregados no pacote de trabalho A: Teoria}

No pacote de trabalho A são empregados os seguintes métodos: uma revisão bibliográfica sistemática com o objetivo de identificar os métodos que são utilizados especificamente na modelagem de processos de desenvolvimento de produtos; e levantamento dos propósitos de modelos de referência de PDP, pertinentes ao escopo desta pesquisa (item 4.1.2).

\subsubsection{Revisão bibliográfica sistemática}

Considerando que nenhuma das revisões sobre métodos de modelagem existentes na literatura tem intenção de esgotar o tema e que as revisões mais recentes encontradas podem estar desatualizadas, é necessário realizar uma revisão bibliográfica sistemática sobre métodos de modelagem de PDP.

Para a realização da revisão bibliográfica sistemática, adota-se o modelo proposto por Conforto et al. (2011), denominado RBS Roadmap, com algumas adaptações. O RBS Roadmap foi elaborado para a área de gestão de desenvolvimento de produtos, baseado em boas práticas de revisão sistemática adotadas por pesquisadores de outras áreas do conhecimento (LEVY; ELLIS, 2006; 
ALMEIDA BIOLCHINI, DE et al., 2007; DYBÅ; DINGS $\varnothing Y R, 2008$ apud CONFORTO et al., 2011).

Para Conforto et al. (2011), revisão bibliográfica sistemática (RBS) pode ser definida como "o processo de coletar, conhecer, compreender, analisar, sintetizar e avaliar um conjunto de artigos científicos com o propósito de criar um embasamento teórico-científico (estado da arte) sobre um determinado tópico ou assunto pesquisado". O RBS Roadmap tem como principais características: os testes e refinamentos das strings de busca; o processamento dos resultados de forma iterativa, com filtros de seleção dos artigos realizados de forma mais detalhada a cada iteração; e a realização de busca cruzada, que visa encontrar mais artigos relevantes por meio da análise das referências da amostra final de artigos selecionados.

O modelo é composto por 15 etapas divididas em 3 fases. A Figura 24 traz uma representação do modelo e a Tabela 9 a síntese de cada uma das etapas. $O$ protocolo de realização da RBS encontra-se no Apêndice B - Protocolo da revisão bibliográfica sistemática.

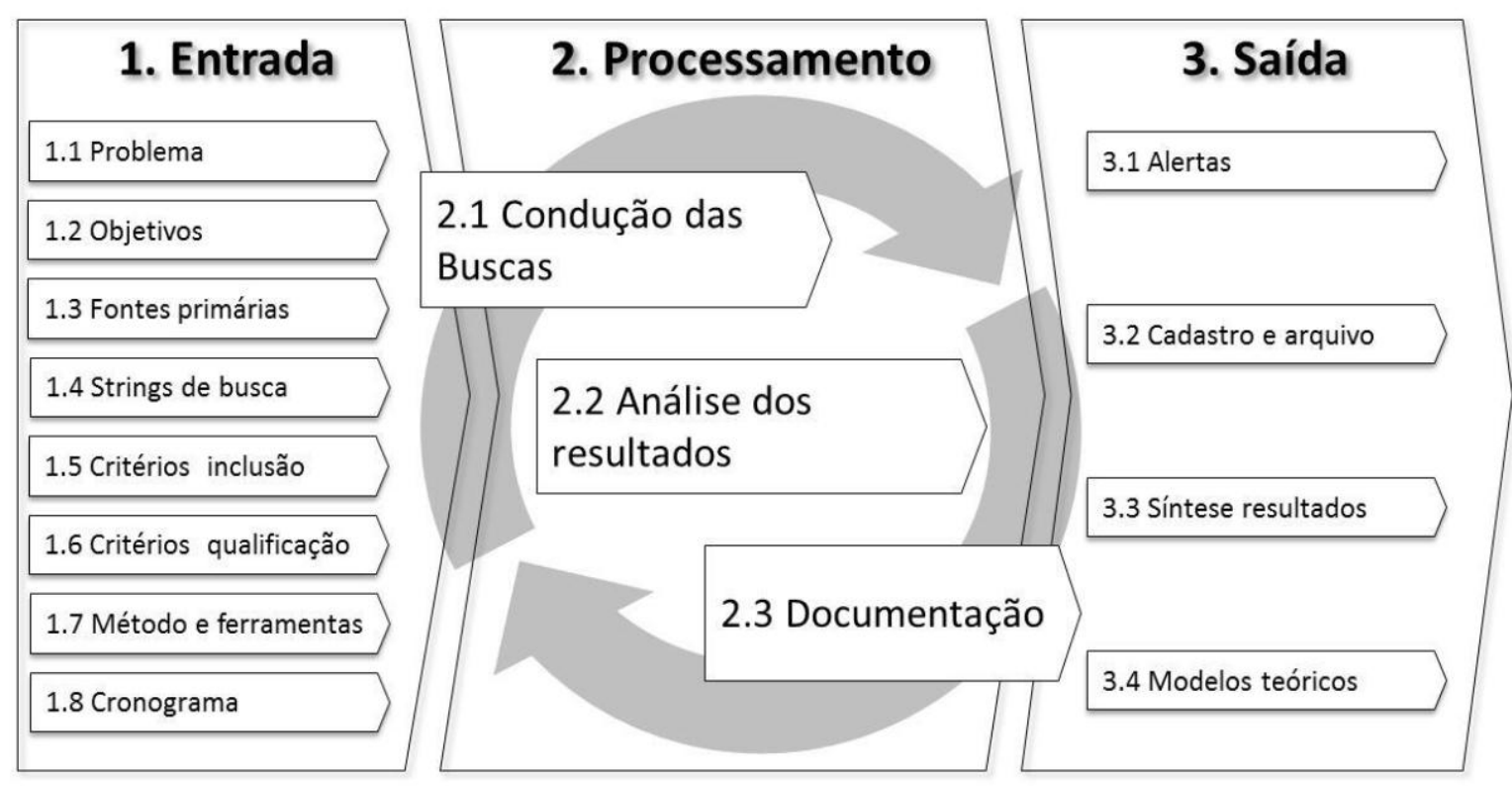

Figura 24 - Modelo para condução da revisão bibliográfica sistemática - RBS Roadmap (CONFORTO et al., 2011) 
Tabela 9 - Síntese das etapas do modelo para condução de RBS

\begin{tabular}{|c|c|}
\hline \multicolumn{2}{|c|}{ Etapa } \\
\hline 1.1 & Problema: problema que a RBS visa solucionar. \\
\hline 1.2 & $\begin{array}{l}\text { Objetivos: objetivo da RBS, que não deve ser confundido com o objetivo da pesquisa. É o } \\
\text { ponto de partida para a definição de critérios de inclusão. }\end{array}$ \\
\hline 1.3 & $\begin{array}{l}\text { Fontes primárias: Artigos, periódicos e bases de dados relevantes para o assunto } \\
\text { pesquisado, que podem ser úteis para a definição das palavras-chave e identificação dos } \\
\text { principais autores e artigos da área. Exemplos de fontes primárias: revisões bibliográficas } \\
\text { preliminares e opinião de especialistas. }\end{array}$ \\
\hline 1.4 & $\begin{array}{l}\text { Strings de busca: uma string de busca compreende uma série de palavras-chave ligadas por } \\
\text { operadores lógicos (AND, OR, NOT, entre outros). Ela deve ser elaborada buscando-se } \\
\text { esgotar os sinônimos possíveis para as palavras-chave e devem ser testadas e refinadas } \\
\text { algumas vezes antes de serem utilizadas. }\end{array}$ \\
\hline 1.5 & $\begin{array}{l}\text { Critérios de inclusão: garantem que a amostra de artigos analisada está de acordo com o } \\
\text { objetivo da RBS. Os artigos que não atendem aos critérios de inclusão devem ser excluídos } \\
\text { da revisão. }\end{array}$ \\
\hline 1.6 & $\begin{array}{l}\text { Critérios de qualificação: garantem a qualidade da amostra de artigos analisada, e podem } \\
\text { incluir fator de impacto do periódico, método de pesquisa, quantidade de citações, entre } \\
\text { outros. }\end{array}$ \\
\hline 1.7 & $\begin{array}{l}\text { Método e ferramentas: Envolve a definição das etapas de busca, a definição dos filtros, as } \\
\text { ferramentas para armazenamento dos dados, entre outros. }\end{array}$ \\
\hline 1.8 & $\begin{array}{l}\text { Cronograma: Dada a extensão que uma RBS pode tomar, a elaboração de um cronograma é } \\
\text { imprescindível e deve ser feita com cautela. As estimativas podem ser feitas com base na } \\
\text { medição do tempo empregado para a busca em uma base de dados ou na realização dos } \\
\text { filtros em um artigo. }\end{array}$ \\
\hline 2.1 & $\begin{array}{l}\text { Condução das buscas: consiste na realização das buscas em cada base de dados } \\
\text { selecionada. A adaptação da string para cada base de dados normalmente é necessária. }\end{array}$ \\
\hline 2.2 & $\begin{array}{l}\text { Análise dos resultados: consiste na leitura dos artigos e realização dos filtros de busca. } \\
\text { Durante o último filtro, onde acontece a leitura completa dos artigos, é comum encontrar } \\
\text { citações a outros artigos relevantes para o tema que não surgiram na busca pela string nas } \\
\text { bases de dados. Essa busca indireta por artigos é denominada busca cruzada. A busca } \\
\text { cruzada fornece novas informações que podem implicar no refinamento da string e na } \\
\text { realização de uma nova iteração de busca e análise dos resultados. }\end{array}$ \\
\hline 2.3 & $\begin{array}{l}\text { Documentação: consiste no armazenamento dos artigos em um software de gestão de } \\
\text { referências bibliográficas e extração de dados sobre a RBS, como quantidade de artigos } \\
\text { encontrados por periódico, quantidade de artigos excluídos, quantidade encontrada na busca } \\
\text { cruzada, entre outros. }\end{array}$ \\
\hline 3.1 & $\begin{array}{l}\text { Alertas: o cadastro de alertas nos principais periódicos de interesse, usando a string de } \\
\text { busca, ajuda o pesquisador a monitorar a publicação de novos artigos no tema de interesse. }\end{array}$ \\
\hline 3.2 & $\begin{array}{l}\text { Cadastro e arquivo: os artigos selecionados na RBS devem ser organizados e arquivados } \\
\text { com auxílio de um software de gerenciamento de referências. }\end{array}$ \\
\hline 3.3 & $\begin{array}{l}\text { Síntese dos resultados: os resultados devem ser sintetizados na forma de um relatório. } \\
\text { Normalmente eles identificam o estado atual do corpo de conhecimentos no assunto } \\
\text { pesquisado, principais autores, evolução do conhecimento, termos, quantidade de artigos na } \\
\text { área, entre outros. }\end{array}$ \\
\hline 3.4 & $\begin{array}{l}\text { Modelos teóricos: no caso da RBS ter se baseado em hipóteses, o modelo teórico resultante } \\
\text { da comprovação ou refutação dessa hipótese é o principal resultado da RBS. Esta etapa não } \\
\text { se aplica a esta pesquisa. }\end{array}$ \\
\hline
\end{tabular}

\subsubsection{Definição dos propósitos de modelos de referência de PDP e escolha do método de modelagem}

Considerando que a literatura sobre propósitos de modelos de referência de PDP é escassa (vide item 2.2), é necessário realizar um levantamento bibliográfico 
adicional, bem como uma análise crítica para agregar, complementar e atualizar as informações já disponíveis. O ponto de partida para esse levantamento é a tabela síntese com os dados coletados a partir do conjunto de artigos selecionados por meio da revisão bibliográfica sistemática descrita no item 4.1.1. Esse conjunto de artigos (disponível no Apêndice C - Tabela síntese dos métodos de modelagem de PDP) descreve os métodos de modelagem e, dentre outras dados, informam quais propósitos dos usuários dos modelos de PDP cada método atende.

O método empregado para análise crítica e refinamento desta tabela síntese é descrito brevemente aqui, pois está detalhado em um artigo elaborado a partir desta pesquisa para um periódico internacional (disponível no Apêndice D - Artigo: Views of process models suitable for PD reference models purposes). Ele possui duas fases: na primeira, os propósitos são analisados e selecionados, resultando em uma lista de propósitos de modelos de referência; na segunda, a tabela síntese é ajustada de acordo com a lista selecionada de propósitos, a fim de servir de base para montagem de uma matriz relacionando métodos de modelagem com propósitos de modelos de referência.

A primeira fase possui as seguintes atividades, algumas das quais são repetidas em várias iterações:

1. Identificação e exclusão dos propósitos duplicados (quando dois autores se referem ao mesmo propósito com nomes distintos) e de eventuais discrepâncias;

2. Uniformização e padronização dos propósitos restantes, unificando propósitos semelhantes e reformulando a maneira como estavam escritos (por exemplo, usando um verbo seguido por um substantivo).

3. Exclusão dos propósitos que não pertencem ao escopo da pesquisa, que são propósitos relacionados ao planejamento e gestão de projetos de DP (por ex: calcular tempo de folga, estimar o tempo de realização; identificar e organizar/alocar recursos requeridos; agendar atividades/tarefas de design, etc.).

4. Desdobramento dos propósitos para um nível de abstração mais baixo, ou decomposição de propósitos para possibilitar posteriormente a elaboração do roteiro de tarefas (item 4.3.2) para os testes de usabilidade (por ex.: "definir entregas padrão e padrões de qualidade" foi decomposta em "definir entregas ou milestones padrão" e "definir padrões de qualidade para as entregas padrão"). 
5. Comparação da lista obtida com a lista de propósitos de modelos para donos de processos de Browning (2010), que são os propósitos mais relacionados com modelos de referência de PDP que são encontrados na literatura, a fim de verificar se todos estavam incluídos.

Essa lista resultante de propósitos está no item 4.1.2, Tabela 20. Ela serve de entrada para a segunda fase, que possui as seguintes atividades:

1. Eliminação dos propósitos da tabela síntese que não fazem parte do escopo da pesquisa.

2. Ajuste dos propósitos restantes, a fim de adaptar a tabela síntese à lista de propósitos selecionados na fase anterior. Isso é realizado encontrando equivalências com a ajuda de consultas adicionais aos artigos da revisão bibliográfica sistemática.

3. Construção da matriz a partir da tabela, dispondo os métodos de modelagem nas linhas e os propósitos a que eles atendem nas colunas.

A matriz resultante permite identificar o método de modelagem que atende ao maior número de propósitos de modelos de referência de PDP, segundo a literatura. Esse método é o que deve ser empregado para a modelagem do protótipo $B$ (definido no item 4.1.2), já que representa a melhor possibilidade existente para representação de modelos de referência.

\subsection{Métodos empregados no pacote de trabalho B: Desenvolvimento dos protótipos}

O desenvolvimento do protótipo $A$ envolve tanto a geração do método de modelagem (desenho dos ícones, organização dos elementos na tela, etc.) quanto da ferramenta computacional a ser empregada para modelagem destas vistas. A geração do método de modelagem do protótipo $\mathrm{A}$ tem como inspiração a análise da bibliografia e pesquisa na comunidade prática para melhor compreensão das ferramentas computacionais empregadas na representação de modelos de referência de PDP (item 2.1.5).

O desenvolvimento do protótipo $B$ parte da análise dos resultados da revisão bibliográfica sistemática para determinar qual método de modelagem existente atende ao maior número de propósitos de usuários de modelos de referência de 
PDP (item 4.1.2). A partir da seleção do método de modelagem a ser empregado, a ferramenta computacional para a modelagem das vistas é definida.

O desenvolvimento dos protótipos ocorre em duas iterações principais, e consiste nas atividades da Tabela 10.

Tabela 10 - Etapas e atividades do desenvolvimento dos protótipos

\begin{tabular}{|c|c|c|}
\hline & Protótipo A & Protótipo B \\
\hline $\begin{array}{l}\text { Primeira } \\
\text { iteração }\end{array}$ & $\begin{array}{l}\text { 1. Geração do método de modelagem } \\
\text { das vistas do novo protótipo, baseada } \\
\text { nos resultados etapa anterior. } \\
\text { 2. Desenvolvimento da ferramenta } \\
\text { computacional a ser utilizada para } \\
\text { modelagem das vistas desenvolvidas. } \\
\text { 3. Modelagem das vistas novas. }\end{array}$ & $\begin{array}{l}\text { 1. Seleção da ferramenta de } \\
\text { modelagem a ser utilizada para gerar } \\
\text { as vistas a partir do método de } \\
\text { modelagem selecionado. } \\
\text { 2. Modelagem das vistas. }\end{array}$ \\
\hline $\begin{array}{l}\text { Avaliação } \\
\text { preliminar }\end{array}$ & $\begin{array}{l}\text { 4. Realização de percurso cognitivo para } \\
\text { identificação de possíveis problemas } \\
\text { no protótipo. }\end{array}$ & $\begin{array}{l}\text { 3. Realização de percurso cognitivo } \\
\text { para identificação de possíveis } \\
\text { problemas no protótipo. }\end{array}$ \\
\hline $\begin{array}{l}\text { Segunda } \\
\text { iteração }\end{array}$ & $\begin{array}{l}\text { 5. Correção e modificação de eventuais } \\
\text { problemas encontrados no protótipo } \\
\text { durante o percurso cognitivo. }\end{array}$ & $\begin{array}{l}\text { 4. Correção e modificação de eventuais } \\
\text { problemas encontrados no protótipo } \\
\text { durante o percurso cognitivo. }\end{array}$ \\
\hline $\begin{array}{l}\text { Validação } \\
\text { final }\end{array}$ & $\begin{array}{l}\text { 6. Realização de dois testes piloto para } \\
\text { validação final do protótipo para os } \\
\text { testes. }\end{array}$ & $\begin{array}{l}\text { 5. Realização de dois testes piloto para } \\
\text { validação final do protótipo para os } \\
\text { testes. }\end{array}$ \\
\hline
\end{tabular}

O percurso cognitivo, empregado na avaliação preliminar, é um método de avaliação analítica utilizada comumente para avaliar a usabilidade de sistemas. Optou-se pela avaliação analítica já que ela é mais adequada à análise de protótipos e permite uma análise aprofundada de todos os atributos de usabilidade. O percurso cognitivo é realizado por especialistas e foca na identificação de potenciais problemas específicos dos usuários, com um grande nível de detalhes (Preece, 2006). O método foi adaptado para a aplicação neste estudo, e consiste nas seguintes atividades:

2. Elaboração do roteiro de tarefas para teste de usabilidade (item 4.3.2)

3. Elaboração de um gabarito com as respostas corretas das tarefas do roteiro e da sequencia preferencial de ações necessárias (estratégia ideal) para cumprir cada tarefa (disponível no Apêndice G - Gabarito do roteiro de tarefas dos testes de usabilidade).

4. Realização da análise por dois especialistas. À medida que o protótipo for percorrido com base no roteiro, os especialistas procuram responder às seguintes questões:

a. A ação correta será suficientemente evidente para o usuário? (o usuário sabe o que fazer?) 
b. O usuário notará se a ação correta está disponível? (o usuário sabe como fazer?)

5. Documentação das críticas à medida que o percurso foi realizado, contendo as suposições do que poderá causar dificuldades aos usuários e porque, notas sobre problemas paralelos e sugestões de mudanças no protótipo e um resumo dos resultados.

\subsection{Métodos empregados no pacote de trabalho C: Avaliação dos protótipos}

O método para avaliação da usabilidade adotado baseia-se no framework sugerido por Preece et al. (2005), que é constituído pelos seguintes passos:

1. Determinar os objetivos da avaliação: o objetivo da avaliação é comparar a usabilidade de dois protótipos de modelo de PDP, modelados com diferentes métodos de modelagem.

2. Explorar as questões mais específicas relacionadas com a avaliação (detalhadas no item 3.5.2)

3. Escolher a abordagem e métodos de avaliação: Segundo Preece et al. (2005), há quatro paradigmas centrais de avaliação: avaliação rápida e suja, testes de usabilidade, estudos de campo e avaliação preditiva. Para esta pesquisa, serão empregados os paradigmas de avaliação preditiva (percurso cognitivo) (já detalhado no item 3.4) e testes de usabilidade (detalhado no item 3.5.2).

4. Identificar as questões práticas: qual a infraestrutura necessária para realização dos testes (vide item 3.5.2) e onde serão encontrados os usuários-alvo vide item 3.5.1).

5. Decidir como lidar com as questões éticas: um termo de consentimento livre e esclarecido será submetido à assinatura do usuário antes da realização deste (detalhado no item 3.5.2).

6. Avaliar, analisar, interpretar e apresentar os dados (detalhado no próximo pacote de trabalho, item 3.6). 


\subsubsection{Seleção dos usuários}

Para seleção dos usuários, a análise do perfil desejado é realizada observando as três dimensões sugeridas por (NIELSEN, 1994): experiência computacional do usuário, conhecimento da tarefa e experiência do usuário nos protótipos em questão. Nesta pesquisa, a estas dimensões é acrescentada ainda a caracterização do participante. Os critérios adotados para seleção dos usuários em cada uma dessas dimensões estão Tabela 11.

De maneira geral, os usuários devem ter obtido conhecimento estruturado sobre o modelo de referência genérico a ser utilizado como conteúdo dos protótipos, por meio da realização de uma disciplina ou estudo guiado. Esse requisito favorece que todos os usuários selecionados tenham um conhecimento uniforme do conteúdo, e que, dessa maneira, haja menos variação nos resultados devido aos diferentes níveis de familiarização com o modelo genérico utilizado.

Os usuários não devem possuir conhecimento sobre o método de modelagem utilizado no protótipo $B$, nem devem ter usado anteriormente o software empregado nessa modelagem (ou similares). Conhecimentos pré-adquiridos sobre o protótipo $B$ poderiam influenciar os resultados, pois diminuiriam a curva de aprendizado que obrigatoriamente existe para o protótipo A (que é novo, então nenhum usuário teria como conhecer de antemão).

É importante chamar a atenção para o fato de que, no caso desta pesquisa, é mais importante selecionar os usuários que tenham características semelhantes, e que possam dessa maneira compor uma amostra uniforme, do que potenciais usuários reais dos protótipos testados. O direcionamento do trabalho está dado pela seleção dos propósitos de modelos de referência para a elaboração do roteiro de tarefas dos testes de usabilidade. Selecionar usuários com treinamento específico, que sejam capazes de entender o jargão utilizado nas tarefas do roteiro, e que não possuam nenhum vício adquirido em relação ao uso de modelos é a maneira mais segura de garantir que os resultados sejam influenciados o mínimo possível por elementos estranhos à pesquisa.

Além disso, o fato da avaliação final dos dados ser comparativa, e não absoluta (ou seja, um protótipo é avaliado em relação ao outro, e não isoladamente), também minimiza eventuais diferenças nos resultados dos testes decorrentes da seleção de tipos diversos de usuários. Por exemplo, ao analisar o tempo de 
realização de uma tarefa, uma pessoa que tenha como característica ser mais rápida pode ter um tempo significativamente menor do que outra mais lenta. Simplesmente calcular as médias dos tempos absolutos de todas as pessoas para o protótipo A e depois o mesmo para B e compará-las pode levar a uma interpretação errônea da eficiência. Porém, ao comparar a proporção entre os tempos de uma mesma pessoa para os dois protótipos, e comparar esta proporção com a dos demais usuários elimina a influência dessas características individuais.

Os dados sobre o perfil dos usuários foram coletados por meio do "Questionário Perfil do Usuário”, disponível no Apêndice E - Questionário . O perfil dos usuários selecionados está na seção de resultados, item 4.3.1.

Tabela 11 - Critérios para seleção de usuários para os testes de usabilidade

\begin{tabular}{|c|c|c|}
\hline \multicolumn{2}{|l|}{ Critério } & Faixa de valores aceitos \\
\hline \multirow{6}{*}{$\begin{array}{l}\text { Caracterização } \\
\text { do participante }\end{array}$} & Disponibilidade para realizar o teste & "Sim" \\
\hline & Idade & Até 40 anos \\
\hline & Conflito de interesses & Nenhum \\
\hline & Grau de instrução & $\begin{array}{l}\text { "Pós graduação em andamento" } \\
\text { "Pós graduação completo" }\end{array}$ \\
\hline & Curso de ensino superior & Qualquer \\
\hline & Curso de pós graduação & Engenharia de produção \\
\hline \multirow{6}{*}{$\begin{array}{l}\text { Conhecimento } \\
\text { da tarefa }\end{array}$} & $\begin{array}{l}\text { Disciplina cursada em } \\
\text { desenvolvimento de produtos }\end{array}$ & Obrigatório ao menos 1 disciplina \\
\hline & $\begin{array}{l}\text { Experiência profissional com } \\
\text { desenvolvimento de produtos }\end{array}$ & $\begin{array}{l}\text { Preferível ter alguma experiência, mas } \\
\text { não obrigatório }\end{array}$ \\
\hline & $\begin{array}{l}\text { Uso profissional de modelos de } \\
\text { referência }\end{array}$ & $\begin{array}{l}\text { Preferível ter alguma experiência, mas } \\
\text { não obrigatório }\end{array}$ \\
\hline & $\begin{array}{l}\text { Familiaridade com modelo de } \\
\text { referência de Rozenfeld et al. (2006) }\end{array}$ & $\begin{array}{l}\text { "Sim", de preferência por meio da } \\
\text { realização de uma disciplina relacionada. }\end{array}$ \\
\hline & Familiaridade com EPC & "1" ou "2" (Nenhuma ou pouca) \\
\hline & $\begin{array}{l}\text { Contato com métodos de } \\
\text { modelagem }\end{array}$ & $\begin{array}{l}\text { Qualquer exceto o método empregado no } \\
\text { protótipo B }\end{array}$ \\
\hline \multirow{4}{*}{$\begin{array}{l}\text { Experiência } \\
\text { computacional }\end{array}$} & $\begin{array}{l}\text { Anos de experiência com } \\
\text { computador }\end{array}$ & "Mais de 6 anos" \\
\hline & $\begin{array}{l}\text { Tempo de utilização semanal do } \\
\text { computador }\end{array}$ & "Entre 10 e 20 horas" ou mais \\
\hline & Anos de experiência com internet & Entre 4 e 6 anos ou mais \\
\hline & $\begin{array}{l}\text { Ferramentas computacionais que } \\
\text { utiliza }\end{array}$ & Ao menos "Navegador de Internet" \\
\hline \multirow[t]{2}{*}{$\begin{array}{l}\text { Experiência no } \\
\text { sistema }\end{array}$} & $\begin{array}{l}\text { Utilização de softwares de } \\
\text { modelagem }\end{array}$ & $\begin{array}{l}\text { Todos exceto "Utilizo em todos os } \\
\text { projetos que conduzo na minha vida } \\
\text { profissional, de simples aos mais } \\
\text { complexos" }\end{array}$ \\
\hline & $\begin{array}{l}\text { Familiaridade com determinados } \\
\text { softwares de modelagem }\end{array}$ & $\begin{array}{l}\text { Todos exceto o empregado para } \\
\text { modelagem do protótipo } \mathrm{B} \text { e similares }\end{array}$ \\
\hline
\end{tabular}

O número ideal de usuários a serem entrevistados seguiu as recomendações de Tullis e Albert, (2008), que dá como regra geral um mínimo de 6 a 8 participantes. 


\subsubsection{Testes de usabilidade}

Testes de usabilidade "são entrevistas estruturadas focadas em características específicas de um protótipo de interface. O coração dessa entrevista é uma série de tarefas que são realizadas pelo avaliador da interface."(KUNIAVSKY, 2003). Segundo recomendação de Tullis e Albert (2008), os testes de usabilidade são ideais para comparar a usabilidade de dois protótipos. Para isso é importante empregar as seguintes métricas (TULLIS; ALBERT, 2008):

- eficácia (sucesso das tarefas),

- eficiência (tempo e número de ações para realizar uma tarefa),

- métricas auto reportadas (satisfação, que nesta pesquisa considera apenas a percepção do usuário em relação à facilidade de uso) e

- métricas comparativas e combinadas (todas as anteriores normalizadas e comparadas para um resultado global).

Tullis e Albert (2008) recomendam que os testes sejam realizados individualmente por cada usuário, com o acompanhamento do pesquisador e mais um assistente. Este assistente seria responsável por anotar o tempo de execução das tarefas, número de ações, erros e eventuais comentários. Nesta pesquisa, porém, foi determinado que os testes de usabilidade seriam gravados por um software de captura de tela e áudio, o ZD Soft Screen Recorder $\AA^{21}$, possibilitando a análise posterior dos testes e dispensando dessa forma a necessidade do assistente.

Com base no framework de avaliação de Preece et al. (2006) descrito no item 3.5, em relação às questões específicas para o caso desta pesquisa é necessário:

- Realizar uma apresentação e proporcionar um tempo de familiarização do usuário com os protótipos, para minimizar o efeito da curva de aprendizado nos resultados dos testes;

- Cada usuário deve avaliar ambos os protótipos, para que se estabeleça uma relação válida de comparação. Isto é necessário, por exemplo, porque dois usuários diferentes podem ter ritmos de execução das tarefas diferentes, o que podem influenciar os resultados de eficiência;

\footnotetext{
${ }^{21}$ Disponível em http://www.zdsoft.com/.
} 
- Duas tarefas equivalentes, porém diferentes, devem ser elaboradas para cada propósito a ser avaliado (vide item 4.3.2). Isto é necessário já que, como cada usuário deve avaliar ambos os protótipos, ele pode memorizar a resposta na primeira avaliação e utilizá-la para a segunda, o que influenciaria os resultados;

- Inverter a ordem dos protótipos em metade dos testes, a fim de minimizar eventuais influências decorrentes do aprendizado do usuário em relação à tarefa;

- Realizar testes piloto para localizar e corrigir eventuais problemas.

Em relação às questões éticas, nesta pesquisa opta-se pela a assinatura de um "termo de consentimento livre e esclarecido", explicitando as condições do teste, o tratamento que será dado às informações e garantindo a confidencialidade do usuário (Apêndice I - Termo de consentimento livre e esclarecido).

Em relação às questões práticas, a baia para realização dos testes é montada de acordo com a Figura 25. Um posto de teste é reservado ao usuário e outro ao pesquisador. O posto do usuário dispõe de duas telas, uma com o roteiro de tarefas a serem realizadas, e outra tela com as vistas a serem testadas. Além das telas, o usuário tem a sua disposição um mouse para navegação nas telas e um teclado para a digitação das respostas. Folhas para anotação também foram disponibilizadas. O posto do pesquisador dispõe de um mouse sem fio que controla as telas em que o usuário está realizando as tarefas, um cronômetro e folhas para anotações. A realização dos testes segue a sequência mostrada na Tabela 12. 


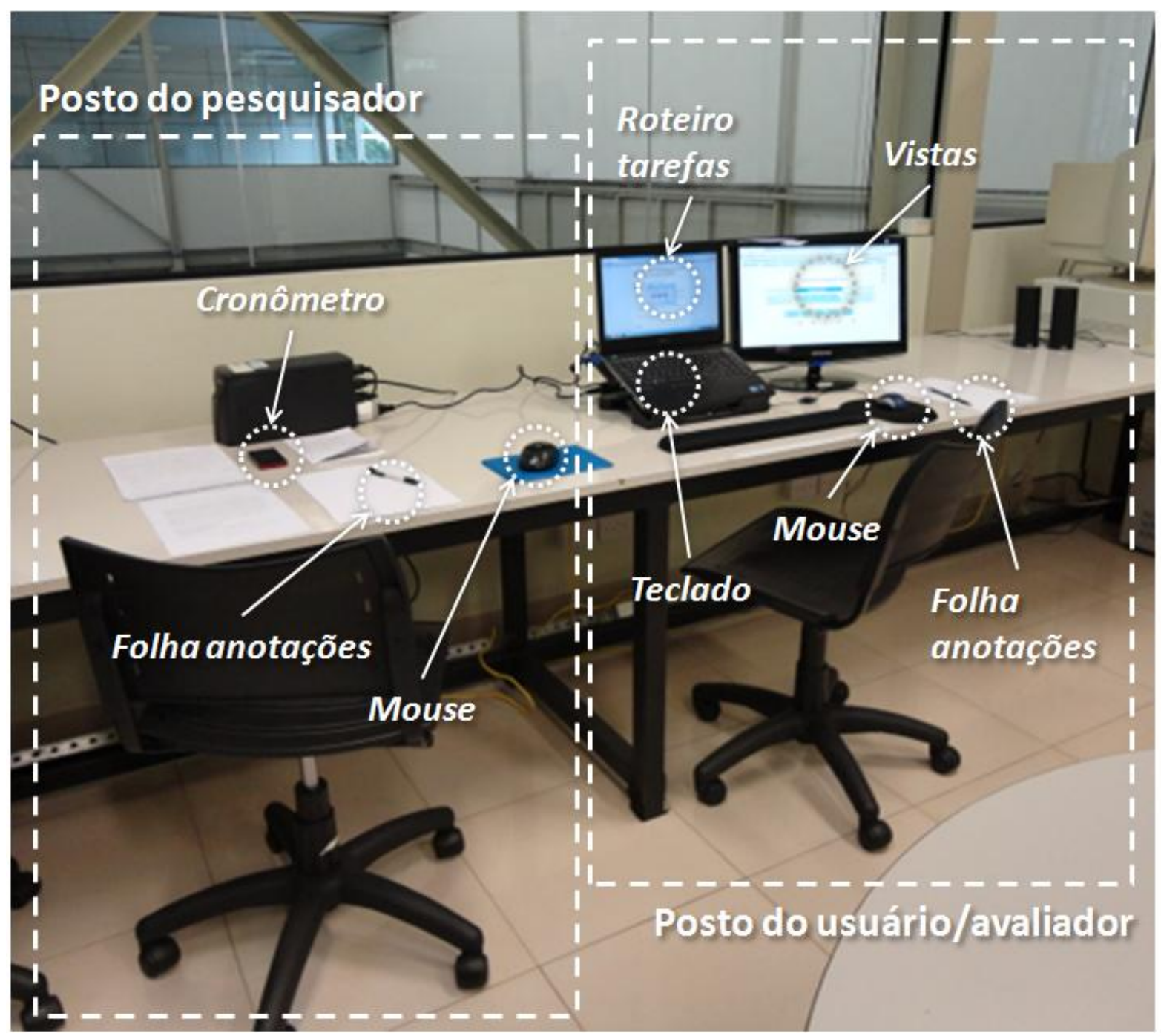

Figura 25 - Baia de testes

Tabela 12 - Sequência de atividades para realização dos testes de usabilidade

1 Apresentação de aproximadamente 10 minutos sobre a pesquisa, seus objetivos e visão geral dos protótipos para o usuário.

2 Período livre de exploração dos protótipos pelo usuário, 5 minutos em cada um.

3 Apresentação e assinatura do "Termo de consentimento livre e esclarecido" pelo usuário.

4 Instruções para a execução do teste.

5 Configuração do computador para o início do teste, com a abertura do roteiro de tarefas e início da gravação da tela.

6 Acompanhamento silencioso da realização do teste pela pesquisadora, que permaneceu próxima ao usuário para realizar a troca de protótipos entre as tarefas e atender a eventuais pedidos de ajuda ou problemas.

7 Solicitação de comentários gerais ao término do teste, enquanto o software de gravação ainda estava ativo capturando o áudio.

8 Término da gravação da tela e verificação do vídeo.

9 Agradecimentos e entrega de um brinde para o usuário. 


\subsubsection{Procedimentos para extração dos dados dos testes de usabilidade}

Para a coleta dos dados de eficácia, são utilizadas as respostas da planilha gerada automaticamente e também a análise dos vídeos para compreensão da sequência de ações realizadas pelo usuário. A sequência de ações é comparada com a sequência considerada ideal no gabarito elaborado (Apêndice $G$ - Gabarito do roteiro de tarefas dos testes de usabilidade), considerando as estratégias de realização que melhor atendem aos requisitos de usabilidade de Preece et al. (2006) (item 2.3.2). Ambos os dados coletados são avaliados no pacote de trabalho $D$ de acordo com a escala de eficácia, no item 3.6.1.

Para a coleta dos dados de eficiência, de acordo com a recomendação de Tullis e Albert (2008) opta-se por número de ações realizadas por tarefa e tempo planejando e realizando a tarefa. A coleta dos dados é feita de forma manual a partir dos vídeos. O número de ações realizadas por tarefa é contada não só a partir do número de cliques, mas também de ações como rolagem de tela e acionamento de botões por meio de passagem do cursor. Já o tempo é calculado subtraindo o tempo empregado em atividades que não de planejamento e execução da tarefa do tempo total de execução da tarefa, conforme exposto na Tabela 13. Isso foi necessário porque, em um ambiente real de uso, os usuários já sabem que informação eles estão procurando no modelo e apenas precisam encontrá-la (não digitarão respostas nem terão que entender tarefas, entre outros). A contabilização desse tempo como tempo planejando e realizando a tarefa poderia interferir nos resultados.

Tabela 13 - Método para o cálculo do tempo planejando e realizando a tarefa

\begin{tabular}{ccc}
\hline Tempo & Tempo entendendo a tarefa \\
planejando e \\
realizando a \\
tarefa
\end{tabular}$=\begin{aligned} & \text { Tempo aguardando sistema } \\
& \text { Tempo total de } \\
& \text { execução da tarefa }\end{aligned} \quad \begin{aligned} & \text { Tempo comentando e pedindo ajuda } \\
& \text { Tempo digitando a resposta } \\
& \text { Tempo conferindo resposta }\end{aligned}$

Já a coleta dos dados de satisfação do usuário se dá de forma automática, já que as respostas ao questionário são transportadas para a planilha de respostas gerada automaticamente. Todas as informações coletadas são consolidadas em uma planilha para posterior análise, realizada no pacote $D$. 


\subsection{Métodos empregados no pacote de trabalho D: Análise dos resultados}

Os métodos utilizados para a análise dos testes de usabilidade estão listados a seguir. Ao lado do título de cada método empregado, está a métrica a que ele se destina a analisar: eficácia, eficiência, métricas auto-reportadas (satisfação) e métricas comparativas e combinadas, segundo recomendação de Tullis e Albert (2008).

\subsubsection{Escala para medir eficácia}

A eficácia das tarefas realizadas pelos usuários é medida de acordo com a escala da Tabela 14, elaborada pela autora com base nas recomendações para mensuração de níveis de sucesso de tarefas de Tullis e Albert (2008). A porcentagem relativa em relação ao total de usuários (14 para cada tarefa) é utilizada para avaliar o resultado global de cada tarefa. As porcentagens são representadas em dois gráficos de colunas (item 4.3.3.1), um mostrando a porcentagem em relação ao tipo de sucesso (total, parcial e falha), e outro detalhando o tipo de estratégia empregada pelo usuário (ideal ou não ideal).

Tabela 14 - Escala utilizada para avaliar a eficácia das tarefas. Fonte: adaptada de Tullis e Albert (2008).

\begin{tabular}{|c|c|}
\hline Escala & Descrição \\
\hline $\begin{array}{l}\text { Sucesso total / estratégia } \\
\text { ideal }\end{array}$ & $\begin{array}{l}\text { Resposta totalmente correta completa, seguindo o caminho de } \\
\text { menor esforço e risco / Resposta totalmente correta completa, } \\
\text { seguindo o caminho de menor esforço e risco com erros }\end{array}$ \\
\hline $\begin{array}{l}\text { Sucesso total / estratégia } \\
\text { ideal / ajuda }\end{array}$ & Idem acima / Com pedido de ajuda \\
\hline $\begin{array}{l}\text { Sucesso total / estratégia } \\
\text { não ideal }\end{array}$ & $\begin{array}{l}\text { Resposta totalmente correta completa, sem seguir o caminho de } \\
\text { menor esforço e risco / Resposta totalmente correta completa, sem } \\
\text { seguir o caminho de menor esforço e risco com erros }\end{array}$ \\
\hline $\begin{array}{l}\text { Sucesso total / estratégia } \\
\text { não ideal / ajuda }\end{array}$ & Idem acima / Com pedido de ajuda \\
\hline $\begin{array}{l}\text { Sucesso parcial / estratégia } \\
\text { ideal }\end{array}$ & $\begin{array}{l}\text { Resposta parcialmente incorreta seguindo o caminho de menor } \\
\text { esforço e risco / Resposta incompleta seguindo o caminho de menor } \\
\text { esforço e risco / Não observou todas as informações necessárias, } \\
\text { mesmo dando a resposta correta e seguindo o caminho de menor } \\
\text { esforço e risco }\end{array}$ \\
\hline $\begin{array}{l}\text { Sucesso parcial / estratégia } \\
\text { ideal / ajuda }\end{array}$ & Idem acima / Com pedido de ajuda \\
\hline $\begin{array}{l}\text { Sucesso parcial / estratégia } \\
\text { não ideal }\end{array}$ & $\begin{array}{l}\text { Resposta parcialmente incorreta não seguindo o caminho de menor } \\
\text { esforço e risco / Resposta incompleta não seguindo o caminho de } \\
\text { menor esforço e risco / Não observou todas as informações }\end{array}$ \\
\hline
\end{tabular}




\begin{tabular}{ll}
\hline Escala & Descrição \\
\hline $\begin{array}{l}\text { Sucesso parcial / estratégia } \\
\text { não ideal / ajuda }\end{array}$ & $\begin{array}{l}\text { necessárias, mesmo dando a resposta correta e não seguindo o } \\
\text { caminho de menor esforço e risco }\end{array}$ \\
Falha & $\begin{array}{l}\text { Idem acima / Com pedido de ajuda } \\
\text { Falha / ajuda }\end{array}$ \\
Desistência & observada no modelo (talvez com base em conhecimento prévio) \\
Desistência / ajuda & Idem acima / Com pedido de ajuda \\
\hline
\end{tabular}

\subsubsection{Estatística descritiva para métricas de eficiência}

Para análise da eficiência, são apenas consideradas as tarefas que tem sucesso total ou parcial, com qualquer estratégia e sem ajuda. Duas métricas de eficiência são consideradas: número de segundos despendidos em cada tarefa, e número de ações empregadas para a realização de cada tarefa. Para cada uma destas métricas, são calculados: média, mediana, desvio padrão, valor mínimo, valor máximo e intervalo de confiança (95\%). O intervalo de confiança fornece o intervalo (valor acima e abaixo da média da amostra) onde há $95 \%$ de confiança de que a população se localiza. É útil para estimar o real valor de população em relação à média, neste caso. (TULLIS; ALBERT, 2008)

\subsubsection{Teste $t$ de student (eficiência)}

Tullis e Albert (2008) recomendam o teste $t$ de student para analisar duas amostras em par para médias, quando o mesmo conjunto de usuários testou os dois produtos e quando o número de usuários (tamanho da amostra) é menor que 30.

O teste t de student é um teste de hipótese que usa conceitos estatísticos para rejeitar ou não uma hipótese nula quando a estatística de teste segue uma distribuição t de Student (se a população possui distribuição normal com variância desconhecida, é usada a variância amostral e ela passa a seguir então uma distribuição t de student).

O teste é realizado com o auxílio do pacote de análise de dados do Microsoft Excel, adotando os valores:

- Hipótese de diferença de média (nula) $=0$

- Alpha (nível de significância) =0,05 
O resultado do teste fornece um valor de p que, se menor que 0,05 (valor de alpha), significa que a hipótese nula (de que os modelos não são diferentes) foi rejeitada com 95\% de confiança. Outra maneira de pensar nesse nível de significância adotado é que se está aceitando concluir, em $5 \%$ das vezes, que há uma diferença entre os protótipos onde na realidade não há. As hipóteses adotadas para o teste t de student estão na Tabela 15.

Tabela 15 - Hipóteses para teste t de student

\begin{tabular}{lll} 
Ho & Hipótese da diferença das médias (nula) & 0, ou seja, as médias não são diferentes \\
H1 & Hipótese da pesquisa & As médias são diferentes \\
\hline
\end{tabular}

A importância de se estabelecer se as médias encontradas nas métricas de eficiência possuem ou não diferenças estatisticamente relevantes está em prevenir o pesquisador de fazer interpretações errôneas. Por exemplo, a média de segundos para realização da tarefa $A$ pode ter sido o dobro da média de segundos para realização da tarefa $B$, mas o teste $t$ de student pode indicar que essa diferença não é estatisticamente relevante, o que não permite que se conclua que a tarefa $A$ foi menos eficiente que a tarefa $B$.

\subsubsection{Escala comparativa (métricas auto-reportadas/satisfação)}

A escala likert, criada por Rensis Likert em 1932, é uma escala clássica para a coleta de métricas auto-reportadas (TULLIS; ALBERT, 2008). Nesta pesquisa, opta-se por utilizar uma escala inspirada na escala likert, de 5 pontos entre dois extremos, onde o usuário deve posicionar, de forma relativa, os dois protótipos analisados em relação à sua percepção sobre facilidade de uso. Posicionar de forma relativa significa comparar os dois no momento de posicioná-los na escala. Por exemplo, o usuário pode, de maneira geral, ter achado ambos os protótipos fáceis. Porém, pensando comparativamente, a realização da tarefa pode ter sido um pouco mais fácil no protótipo $A$ do que no $B$. Sendo assim, ao invés de classificar ambos no extremo "Muito fácil" da escala, o usuário deveria optar por classificar o protótipo A no extremo "Muito fácil" e o protótipo B no "Fácil". Como o objetivo desta pesquisa é a comparação entre os protótipos, a escala relativa nos dá informações mais acuradas. A Figura 26 mostra a escala como mostrada para o usuário. 
Posicione os protótipos avaliados na escala abaixo de acordo com a sua percepção em relação à facilidade para execução da tarefa:

A escala é comparativa; posicione os protótipos na escala de acordo com a dificuldade relativa para realização das tarefas.

Muito difícil Difícil $\quad \begin{aligned} & \text { Conforme } \\ & \text { esperado }\end{aligned}$ Fácil Muito fácil

$\begin{array}{lllll}\text { Modelo A } & 0 & 0 & 0 & 0 \\ \text { Modelo B } & 0 & 0 & 0 & 0\end{array}$

« Voltar Continuar»

Figura 26 - Escala utilizada para a coleta de métricas auto-reportadas pelo usuário

É importante chamar a atenção para uma adaptação que é feita nesta pesquisa para a interpretação dos resultados obtidos por meio desta escala. Apesar da escala ser discreta, os resultados são tratados como dados contínuos, um recurso comum em pesquisas na área. São atribuídos valores a cada um dos pontos, conforme Tabela 16, e a interpretação geral da avaliação de todos os usuários é feita pela média destes valores, em conjunto com o índice de concordâcia exposto no item 3.6.5. Apesar de não ser rigorosamente correto, este procedimento é amplamente aceito na área como um artifício a fim de proporcionar uma visão geral da avaliação feita por um grupo de pessoas.

Tabela 16 - Valores numéricos atribuídos à escala likert

\begin{tabular}{lc}
\hline Valor & Número \\
\hline Muito fácil & 5 \\
Fácil & 4 \\
Conforme esperado & 3 \\
Difícil & 2 \\
Muito difícil & 1 \\
\hline
\end{tabular}




\subsection{5 Índice de Concordância (métricas auto-reportadas)}

O índice de concordância (JAMES et al., 1984) avalia quantitativamente o grau de alinhamento entre as respostas dos usuários para determinar se eles concordam ou não entre si, ou seja, se há ou não consenso entre eles em relação a uma dada resposta. Para o caso desta pesquisa, o índice de concordância adotado é o within-group, pois os $K$ juízes (nesse caso os usuários que realizaram os testes de usabilidade) de quem as observações foram coletadas são vistas como um grupo no sentido estatístico (JAMES et al., 1984). Para um único item a ser avaliado, denominado $X_{j}$ (neste caso, cada um dos protótipos em cada uma das tarefas), o índice de concordância within-group $\left(r_{W G(1)}\right)$ é calculado pela equação:

$$
r_{W G(1)}=1-\left(S_{X_{j}}^{2} / \sigma_{E U}^{2}\right)
$$

(Equação 1)

Onde $s_{X_{j}}^{2}$ é a variância observada entre as pontuações fornecidas pelos $K$ juízes na avaliação de $X_{j}$, e $\sigma_{E U}^{2}$ é a variância do erro esperado, assumindo distribuição uniforme ${ }^{22}$.

A variância $s_{X_{j}}^{2}$ é calculada pela equação:

$$
s_{X_{j}}^{2}=\frac{\sum_{i}^{K}\left(x_{i}-\bar{X}\right)^{2}}{K-1}
$$

Onde $x_{i}$ é o valor da avaliação de um dado juiz para um único item $X_{j}, \bar{X}$ é a média das avaliações dos $K$ juízes para um único item $X_{j}$.

A variância $\sigma_{E U}^{2}$ é calculada pela equação:

$$
\sigma_{E U}^{2}=\left(A^{2}-1\right) / 12
$$

Onde $A$ é o número de alternativas na escala de resposta que, neste caso, é constante e igual a 5 (escala likert do item 3.6.4).

Nos casos mais comuns, o índice de concordância $\left(r_{W G(1)}\right)$ calculado conforme a Equação 1 assume valores que variam entre 0,00 e 1,00. Valores próximos de 1,00 indicam maior homogeneidade entre as respostas (elevada concordância, forte consenso). Da mesma forma, valores que se aproximam de 0,00

${ }^{22} \mathrm{O}$ índice "EU" se refere a uma variância do erro esperado (E), baseada em uma distribuição uniforme $(U)$. 
indicam baixa concordância e consenso fraco (JAMES et al., 1984). Para esta pesquisa, o valor 0,5 é considerado como mínimo para concluir que houve concordância entre os usuários.

Finalmente, vale observar que, para ser aplicado, o método deve satisfazer três premissas (FARRIS et al., 2007):

1. As questões devem ser as mesmas para todos os respondentes;

2. Deve haver uma escala discreta que seja comum para todos os respondentes;

3. Os respondentes devem interpretar a escala da mesma maneira.

Para atender às premissas acima, nesta pesquisa os questionários utilizados são os mesmos para todos os usuários e os usuários selecionados possuem o mesmo perfil. Também é feita uma breve apresentação do questionário no momento do teste para cada usuário, buscando garantir que todos possam interpretar as variáveis e a escala da mesma forma. 


\section{Resultados}

Esta seção apresenta as principais entregas da pesquisa conforme já exposto na Figura 23.

\subsection{Pacote de trabalho A: Teoria}

O pacote A é composto pelas entregas da Figura 27.

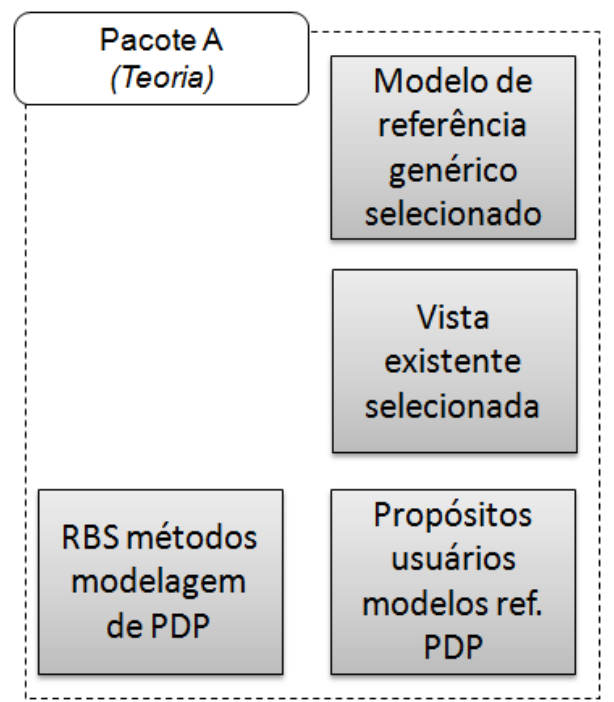

Figura 27 - Entregas do pacote de trabalho A

\subsubsection{Revisão bibliográfica sistemática sobre métodos de modelagem para o PDP}

É possível encontrar algumas revisões sobre métodos de modelagem de PDP já realizadas anteriormente na literatura, conforme descrito no item 2.1.4. Como as revisões sobre métodos de modelagem existentes na literatura não tem intenção de esgotar o tema e podem estar desatualizadas, essa RBS visou atualizar e complementar esses trabalhos anteriores. A RBS realizada teve como objetivo identificar os métodos de modelagem que são utilizados na modelagem dos processos de desenvolvimento de produtos. A questão que orientou a RBS foi, 
portanto: Quais os métodos que são utilizados na modelagem de processos de desenvolvimento de produtos?

A busca pela string (vide protocolo da RBS no Apêndice B - Protocolo da revisão bibliográfica sistemática) resultou em um total de 5646 artigos, combinando os resultados das duas bases de dados utilizadas (Scopus e WoS). Desse total, 1394 artigos eram duplicados. Dessa forma, 4252 artigos foram submetidos aos filtros.

A Figura 28 mostra $\circ$ aproveitamento dos artigos a partir desse total analisado, que foi de $1 \%$, e a Tabela 17 traz os resultados da RBS. Os artigos considerados indisponíveis são aqueles que não são de livre acesso pela Universidade de São Paulo ou portal de periódicos CAPES. A Figura 28 também mostra a sobreposição entre as bases de dados. A sobreposição entre as bases de dados foi de $33 \%$, havendo contribuição expressiva de ambas para o conjunto de artigos obtidos com a string.

As fontes (periódicos e conferências) e os autores que possuem mais artigos selecionados pela RBS estão respectivamente na Tabela 18 e Tabela 19. Percebese prevalência de fontes das áreas de engenharia e computação. Dos autores que mais possuem artigos relevantes para a RBS, dois deles realizaram revisões da literatura sobre modelagem de PDP que foram especialmente úteis a essa pesquisa (JUN; SUH, 2008; BROWNING, 2010). Por fim, o número de artigos encontrados por ano está na Figura 29. Observa-se um aumento crescente do número de artigos sobre o tema, especialmente nos últimos cinco anos. Isso pode ser uma evidência de que $o$ assunto ainda apresenta lacunas que despertam 0 interesse dos pesquisadores. 


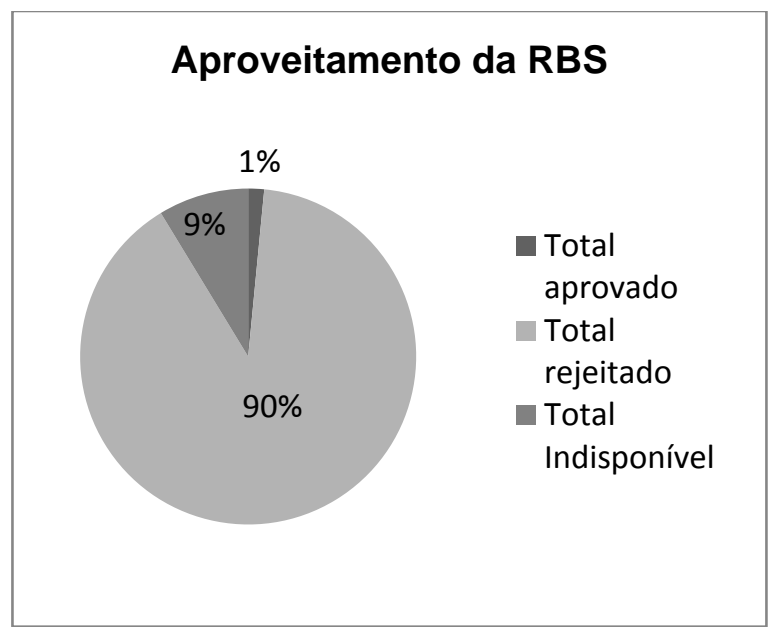

\section{Sobreposição entre as bases de dados Scopus e WoS}

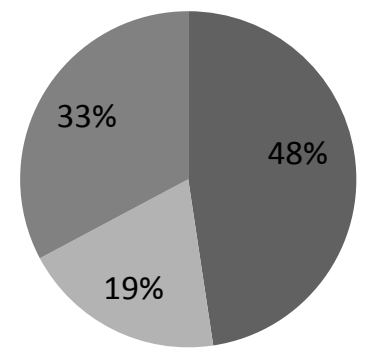

Artigos Scopus

Artigos Wos

Artigos em Ambos

Figura 28 - Aproveitamento da RBS e sobreposição entre as bases de dados

Tabela 17 - Resultados da RBS

\begin{tabular}{|c|c|c|c|c|}
\hline & & \\
\hline & & Scopus & Wos & Scopus+WoS \\
\hline \multirow{3}{*}{$\begin{array}{l}\text { Busca String } 1 \\
\text { Busca String } 2\end{array}$} & Total resultados & 3111 & 2041 & 5152 \\
\hline & Total resultados & 3419 & 2227 & 5646 \\
\hline & Duplicados & 1387 & 0 & 1387 \\
\hline \multirow[b]{2}{*}{ Filtro 1} & Total analisado & 2032 & 2227 & 4252 \\
\hline & Aprovados & 244 & 358 & 602 \\
\hline \multirow{5}{*}{ Filtro 2} & Rejeitados & 1788 & 1869 & 3657 \\
\hline & Aprovados & 46 & 71 & 117 \\
\hline & Rejeitados & 34 & 74 & 108 \\
\hline & Indisponíveis & 157 & 213 & 370 \\
\hline & Duplicados & 7 & 0 & 7 \\
\hline \multirow[t]{4}{*}{ Filtro 3} & Aprovados & 22 & 43 & 65 \\
\hline & Rejeitados & 24 & 28 & 52 \\
\hline & Total Aprovado & 22 & 43 & 65 \\
\hline & Total Rejeitado & 1846 & 1971 & 3817 \\
\hline
\end{tabular}

Tabela 18 - Periódico com mais artigos selecionados pela RBS

Fonte/Periódico

Artigos

selecionados por periódico

\begin{tabular}{ll}
\hline CONCURRENT ENGINEERING-RESEARCH AND APPLICATIONS & 4 \\
\hline IEEE TRANSACTIONS ON ENGINEERING MANAGEMENT & 4 \\
\hline COMPUTERS \& INDUSTRIAL ENGINEERING & 3 \\
\hline
\end{tabular}

PROCEEDINGS OF THE 2008 12TH INTERNATIONAL CONFERENCE ON COMPUTER SUPPORTED COOPERATIVE WORK IN DESIGN, VOLS I AND II

3

\begin{tabular}{ll}
\hline 2009 INTERNATIONAL CONFERENCE ON MEASURING TECHNOLOGY AND & 2 \\
MECHATRONICS AUTOMATION, VOL III & 2 \\
\hline COMPUTERS IN INDUSTRY & 2 \\
\hline EUROPEAN JOURNAL OF OPERATIONAL RESEARCH & 2 \\
\hline
\end{tabular}


Fonte/Periódico

Artigos

selecionados por

periódico

IEEM: 2008 INTERNATIONAL CONFERENCE ON INDUSTRIAL ENGINEERING

AND ENGINEERING MANAGEMENT, VOLS 1-3

JOURNAL OF ENGINEERING DESIGN 2

JOURNAL OF INTELLIGENT MANUFACTURING 2

JOURNAL OF PRODUCT INNOVATION MANAGEMENT 2

MATERIALS AND PRODUCT TECHNOLOGIES 2

R \& D MANAGEMENT 2

SYSTEMS ENGINEERING 2

Tabela 19 - Número de artigos selecionados por autor

\begin{tabular}{ll}
\hline Autores & $\begin{array}{l}\text { Número de artigos } \\
\text { selecionados por } \\
\text { autor }\end{array}$ \\
\hline Tang, DB & 5 \\
\hline Suh H.-W. & 4 \\
\hline Browning T.R. & 3 \\
\hline Jun H.-B. & 3 \\
\hline Karniel A. & 3 \\
\hline Reich Y. & 3 \\
\hline Brombacher A.C. & 2 \\
\hline Ding H. & 2 \\
\hline Huang, HZ & 2 \\
\hline Ko Y.-T. & 2 \\
\hline Liu, M & 2 \\
\hline Luh, YP & 2 \\
\hline Qian, XM & 2 \\
\hline Zhong, PS & 2 \\
\hline
\end{tabular}

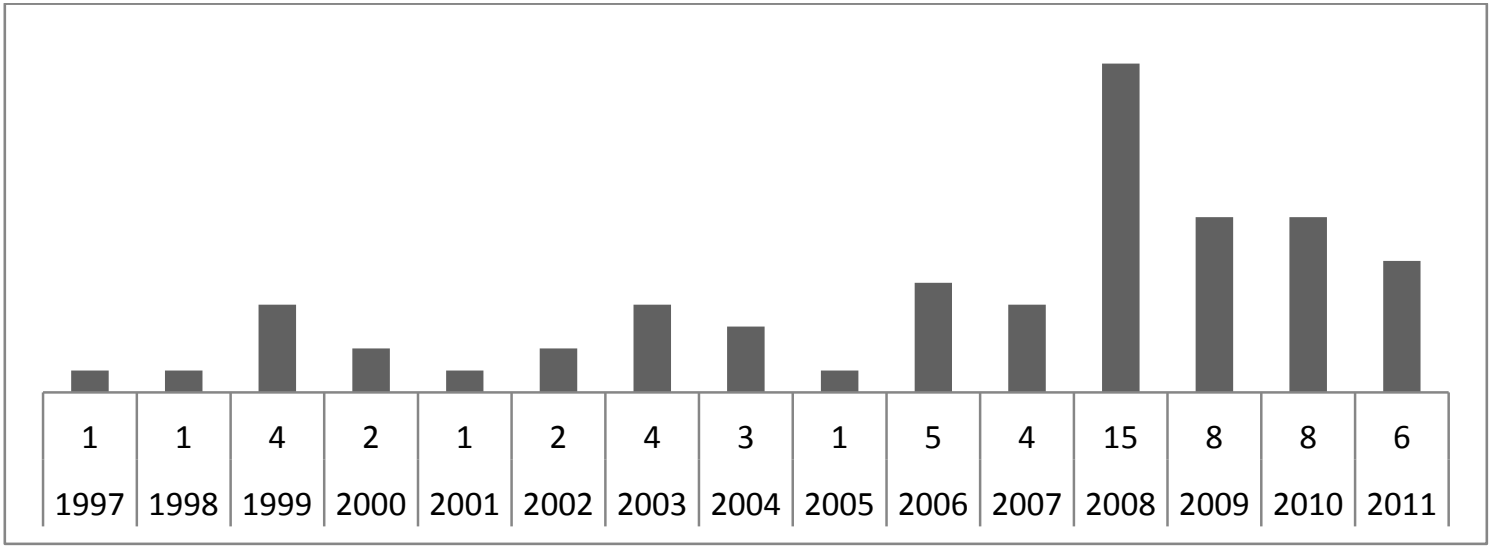

Figura 29 - Número de artigos por ano

O principal resultado da RBS é a tabela com a síntese completa dos métodos encontrados na literatura para a modelagem de PDP, que está no Apêndice C Tabela síntese dos métodos de modelagem de PDP. Os métodos de modelagem 
estão listados com sua descrição, variáveis-chave e atributos, propósitos, facilidade de atualização e forças e fraquezas em relação ao usuário.

\subsubsection{Propósitos de usuários de modelos de referência de PDP e método existente de modelagem selecionado}

O levantamento e análise crítica dos propósitos de modelos de referência de PDP (vide item 3.3.2) resultou em uma lista de propósitos (Tabela 20), que foi a que serviu como base para elaboração do roteiro de tarefas (item 4.3.2), e também em uma matriz que relaciona os métodos de modelagem aos respectivos propósitos de modelos de referência a que atendem (mais detalhes sobre esse resultado estão no Apêndice D - ).

Os propósitos que estão dentro do escopo deste trabalho são os correspondentes aos de usuários de modelos de referência do processo, o que implica na eliminação dos propósitos mais adequados ao planejamento e gestão do projeto (por ex.: calcular tempo de folga, estimar o tempo de realização; identificar e organizar/alocar recursos requeridos; agendar atividades/tarefas de design, etc.). A matriz mostra que o método de modelagem que atende a um maior número de propósitos que estão dentro do escopo deste trabalho é o eEPC (Extended Event Process Chain). Isso significa que esse é o melhor método já disponível para a modelagem de modelos de referência de PDP. Por esta razão, este foi o método de modelagem escolhido para a elaboração do protótipo B.

Tabela 20 - Propósitos de usuários de modelos de referência de PDP

\begin{tabular}{|c|c|}
\hline Propósitos de modelos de PDP & Explicação \\
\hline $\begin{array}{l}\text { 1. Definir atividades padrão e } \\
\text { preferidas }\end{array}$ & $\begin{array}{l}\text { O modelo do processo pode listar as atividades padrão e } \\
\text { preferidas bem como descrevê-las. }\end{array}$ \\
\hline $\begin{array}{l}\text { 2. Definir/sugerir sequencia } \\
\text { para as atividades }\end{array}$ & O modelo pode ordenar as atividades padrão e preferidas. \\
\hline $\begin{array}{l}\text { 3. Mostrar relação hierárquica } \\
\text { entre atividades }\end{array}$ & $\begin{array}{l}\text { O modelo do processo pode apresentar a hierarquia entre as } \\
\text { atividades: relações pais/filhos, decomposição estrutural. } \\
\text { Pode também indicar os níveis hierárquicos do PDP. }\end{array}$ \\
\hline $\begin{array}{l}\text { 4. Definir entregas ou } \\
\text { milestones padrão }\end{array}$ & $\begin{array}{l}\text { O modelo pode documentar entregas e/ou milestones do } \\
\text { processo ressaltando resultados desejados e eventos } \\
\text { importantes. Pode também estabelecer momentos adequados } \\
\text { para entrega/análise de determinados pacotes de trabalho. }\end{array}$ \\
\hline $\begin{array}{l}\text { 5. Definir padrões de qualidade } \\
\text { para as entregas padrão }\end{array}$ & $\begin{array}{l}\text { O modelo do processo pode incluir as medidas de eficácia e } \\
\text { seus níveis de aceitação para os resultados desejados de } \\
\text { cada atividade }\end{array}$ \\
\hline $\begin{array}{l}\text { 6. Identificar } \\
\text { dependência/precedência de }\end{array}$ & $\begin{array}{l}\text { O modelo do processo pode relacionar entregas a atividades } \\
\text { por meio de suas entradas e saídas, resultando em um fluxo }\end{array}$ \\
\hline
\end{tabular}




\section{Propósitos de modelos de PDP \\ atividades/funções via inputs \\ e outputs}

\section{Automatizar o processo}

8. Definir ferramentas e templates padrão

9. Relacionar papéis a atividades, entregas e demais elementos do processo

10. Definir responsabilidades e habilidades padrão para papéis e pessoal

11. Visualizar/entender o processo de design

12. Melhorar continuamente 0 processo de design

13. Identificar efeitos em cadeia provocados por mudanças de processo

14. Intercambiar dados do processo

15. Organizar conhecimento sobre o trabalho

16. Avaliar a complexidade do processo de design

17. Decompor o processo para reduzir a complexidade

\section{Explicação}

de trabalho sequenciado a partir das dependências entre as atividades. Dessa forma é possível mostrar paralelismo entre atividades, minimizar sobreposição e analisar a rede de atividades.

O modelo pode permitir o gerenciamento/modelagem do fluxo de trabalho (workflow). Ou seja, pode descrever um processo de maneira a ser realizado por computadores.

O modelo pode associar a cada atividade, um conjunto de ferramentas e templates padrão baseados nas melhores práticas indicadas na literatura, ou benchmarking, ou projetos anteriores bem sucedidos, etc.

O modelo pode atribuir para cada atividade e/ou demais elementos do processo um conjunto de responsabilidades e/ou papéis a serem desempenhados.

O modelo pode definir responsabilidades e habilidades padrão desejadas para cada papel, juntamente com o número típico de pessoas, nível de esforço, e habilidades requeridas para assegurar que a atividade será executada efetivamente. O modelo pode prover uma representação concisa do processo, apresentando-o de maneira intuitiva e acessível.

O modelo pode indicar oportunidades de melhoria no processo a fim de aumentar a sua eficiência, obter melhores resultados e/ou promover sua reengenharia.

O modelo pode permitir a fácil visualização de efeitos em cadeia gerados por solicitações de mudança no processo. Quando múltiplos projetos utilizam um mesmo modelo de processo, o dono do processo recebe uma série de solicitações de mudança provenientes dos diferentes projetos. Ele deve ser capaz de identificar facilmente os efeitos potenciais de cada mudança nas demais atividades do processo.

O modelo pode prover intercâmbio entre diferentes sistemas computacionais por meio de uma base de dados integrada ou linguagem comum.

O modelo do processo pode ajudar a estruturar/documentar a vasta quantidade de informação que existe em uma grande empresa sobre o trabalho e como realizá-lo.

O modelo pode auxiliar na análise do nível de complexidade do processo de desenvolvimento (por exemplo, por número de atividades, dependências ou recursos necessários).

O modelo pode facilitar a compartimentação do processo em pacotes de trabalho de gerenciamento mais simples.

\subsubsection{Modelo de referência genérico selecionado}

É possível encontrar diversos modelos de referência para o processo de desenvolvimento de produtos considerados clássicos na literatura (PAHL; BEITZ, 1988; CLARK; WHEELWRIGHT, 1993; URBAN; HAUSER, 1993; PUGH; CLAUSING, 1996; COOPER, 2001; CRAWFORD; BENEDETTO, 2006; ULRICH; EPPINGER, 2007). Nesta pesquisa, o modelo utilizado será o de Rozenfeld et al. 
(2006), que se propõe a unificar diversos destes modelos clássicos. Esta escolha foi baseada nos seguintes fatos:

- Informações detalhadas sobre este modelo estão totalmente disponíveis e acessíveis à pesquisadora, pelo fato dele ter sido desenvolvido no mesmo grupo de pesquisa onde esta pesquisa foi realizada.

- Este modelo é estudado detalhadamente em disciplinas obrigatórias do programa de engenharia de produção da EESC/USP, o que viabiliza a seleção de usuários com conhecimento estruturado sobre ele.

O modelo de referência genérico de Rozenfeld et al. (2006) é composto por nove fases, divididas em três macrofases: pré-desenvolvimento, desenvolvimento e pós-desenvolvimento (Figura 30). O pré-desenvolvimento é composto por duas fases: planejamento estratégico de produtos, onde se transformam as informações contidas nas estratégias corporativas no plano estratégico de produtos, que contém a descrição do portfólio de produtos; e planejamento do projeto, onde se determina o escopo e planejamento macro do projeto do produto selecionado no portfólio.

A macrofase de desenvolvimento é composta por cinco fases: projeto informacional, onde se elaboram as especificações-meta do produto; projeto conceitual, onde é elaborado o conceito do produto e a definição da sua arquitetura; projeto detalhado, onde se realizam todos os cálculos e desenhos detalhados para a produção, protótipos do produto, e planos de lançamento, vendas e apoio ao produto no mercado; preparação da produção, onde são realizadas as especificações de máquinas e ferramentas e dos métodos de produção, e é gerada toda a documentação necessária para produzir o produto com qualidade; e lançamento do Produto, onde o produto é lançado e o time de desenvolvimento desfeito.

A macrofase de pós-desenvolvimento é composta pelas fases de acompanhamento do produto e processo e descontinuação do produto no mercado. Realiza o acompanhamento sistemático e produz a documentação correspondente às melhorias de um produto ao longo de sua fase de uso. Inclui a retirada sistemática do produto do mercado e a avaliação de todo o seu ciclo de vida, para que sirva de referência para desenvolvimentos futuros.

Ao final de cada fase realiza-se uma atualização do plano da fase, um monitoramento de viabilidade econômico-financeira, o gate de aprovação e a documentação de decisões tomadas e lições aprendidas. Há ainda dois processos 
de apoio que correm paralelos às fases, o processo de gerenciamento de mudanças de engenharia e o processo de melhoria do PDP.

Optou-se pela modelagem apenas da macrofase de desenvolvimento na elaboração dos protótipos, pois é a maior macrofase e oferece conteúdo suficiente para a avaliação comparativa.

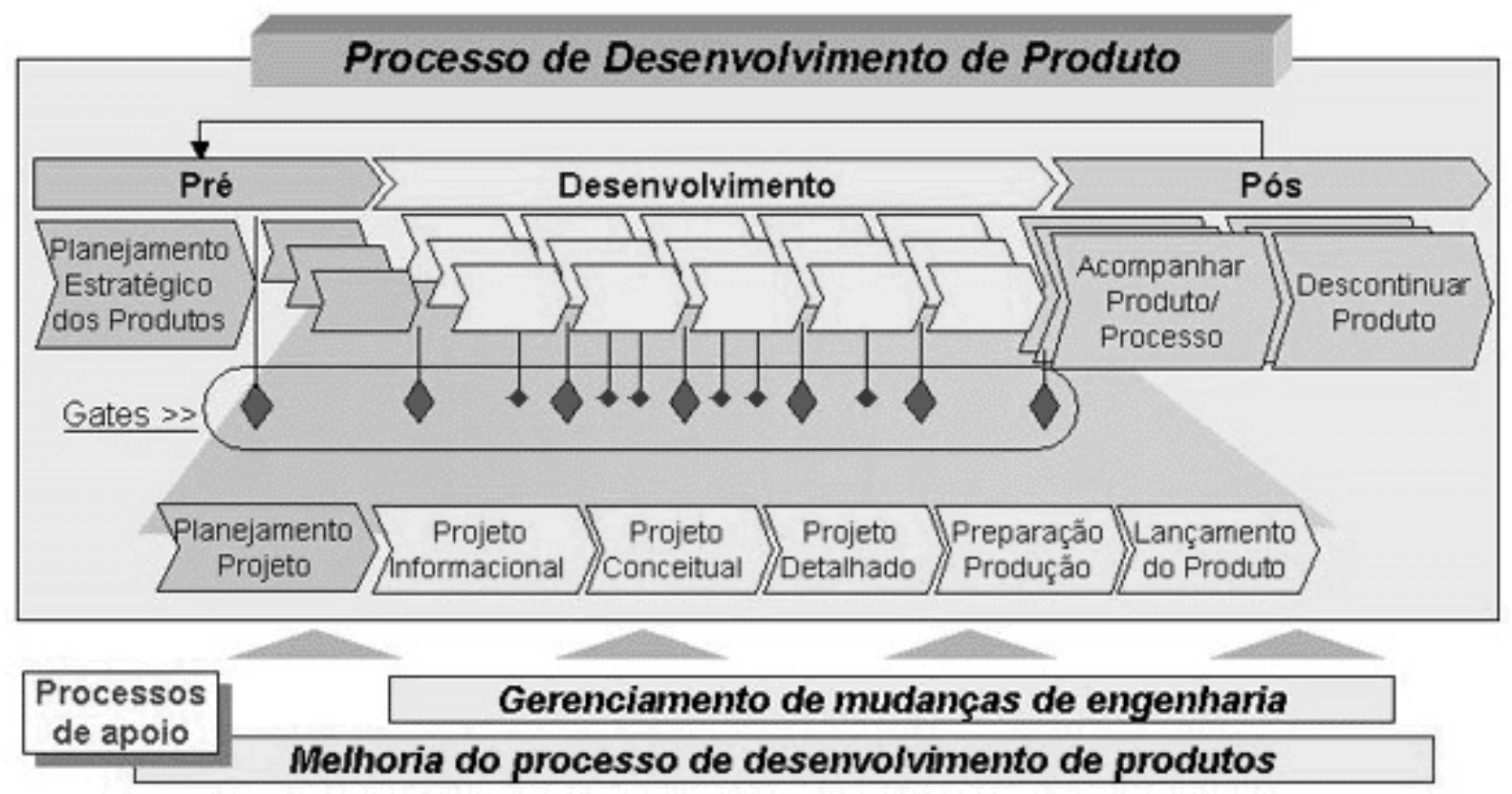

Figura 30 - Modelo de referência para o processo de desenvolvimento de produtos (ROZENFELD et al., 2006). 


\subsection{Pacote de trabalho B: Desenvolvimento dos protótipos}

Foram desenvolvidos dois protótipos: o protótipo A, proposto pela autora; e o protótipo B, com vistas modeladas com o método eEPC (Figura 31).

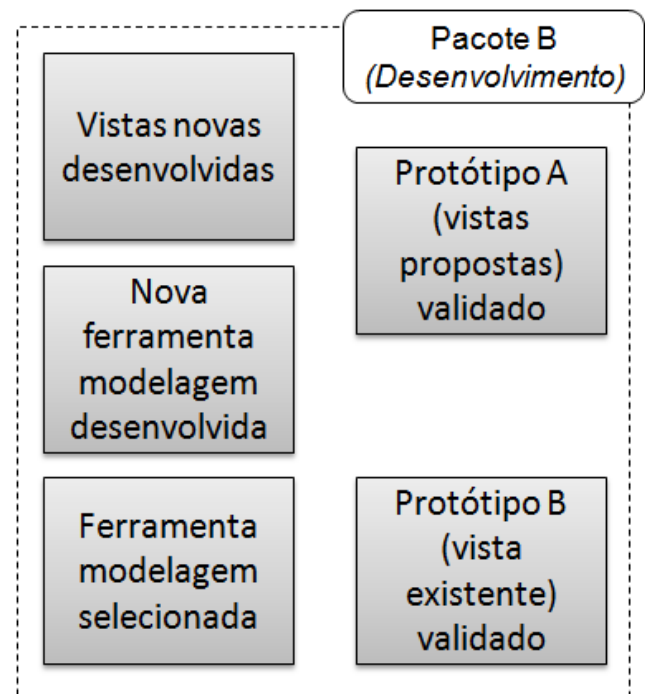

Figura 31 - Entregas do pacote de trabalho B

\subsubsection{Protótipo A: vistas propostas}

Os resultados apresentados nesta seção foram obtidos por meio do emprego dos métodos já expostos no 3.4. É importante ressaltar que, para esse protótipo, foi necessário desenvolver tanto as vistas quanto a ferramenta de modelagem. Ambos foram desenvolvidos de maneira iterativa e concomitantemente. Por esta razão, esta seção está dividida em iterações de desenvolvimento, e não por entregas.

\subsubsection{Primeira iteração}

As vistas foram propostas utilizando como ponto de partida o levantamento das ferramentas computacionais empregadas na representação de modelos de referência já expostas no item 2.1.5. O principal objetivo durante o desenvolvimento foi elaborar vistas com o nível de detalhamento adequado aos propósitos de usuários de modelos de referência do PDP, que oferecessem múltiplas perspectivas 
do processo, com o maior número de combinações possíveis entre os construtos do modelo. As vistas deveriam permitir a visualização do um conjunto desejado de informações de uma só vez, sem exigir muita rolagem de tela, e deveriam possuir interface agradável e com elementos fáceis de memorizar. A partir destes objetivos, optou-se por:

- Utilizar órbitas de navegação, inspiradas no conceito do modelo RUP (item 2.1.5.2), que permitem várias combinações diferentes entre os construtos de um modelo, cada vista centrada em um diferente tipo de construto. Estas órbitas representam o fluxo de maneira analógica, proporcionando uma representação mais sintética e evitando engessar a organização dos construtos em um fluxo lógico de atividades ou funções (Figura 37).

- Utilizar ícones ao invés de símbolos, que, por serem metáforas da realidade, podem facilitar a compreensão e memorização do seu significado pelo usuário (item 2.3.1).

Além disso, optou-se por oferecer ao usuário:

- Modelo gráfico de alto nível navegável, inspirado nos documentos elaborados internamente nas empresas elaborados com softwares de desenho.

- Visão geral das fases e gates do modelo, com suas principais entregas (Figura 35).

- Telas com tabelas organizadas com todos os elementos de uma fase (Figura 36), inspiradas nas representações com o método de modelagem SIPOC (acrônimo de suppliers, inputs, process, outputs, and customers).

- Menu alfabético dos elementos do modelo, em forma de listas.

Apesar de implícitas nas vistas, a semântica e sintaxe desenvolvidas não estão dentro do escopo desta pesquisa e por esta razão não serão detalhadas nesta dissertação (vide item 1.2). A Figura 32 traz uma visão geral do relacionamento dos principais construtos e blocos de construções empregados na elaboração das vistas, que é suficiente para a compreensão do seu funcionamento. Os ícones de papéis e áreas ainda fazem o uso de cores para diferenciar seus tipos, por exemplo, gerente 
de projeto é amarelo e gerente de design é roxo. O Apêndice $\mathrm{J}$ - Legenda dos ícones do protótipo A traz mais detalhes, apresentando as legendas de todos os ícones empregados nas vistas propostas.

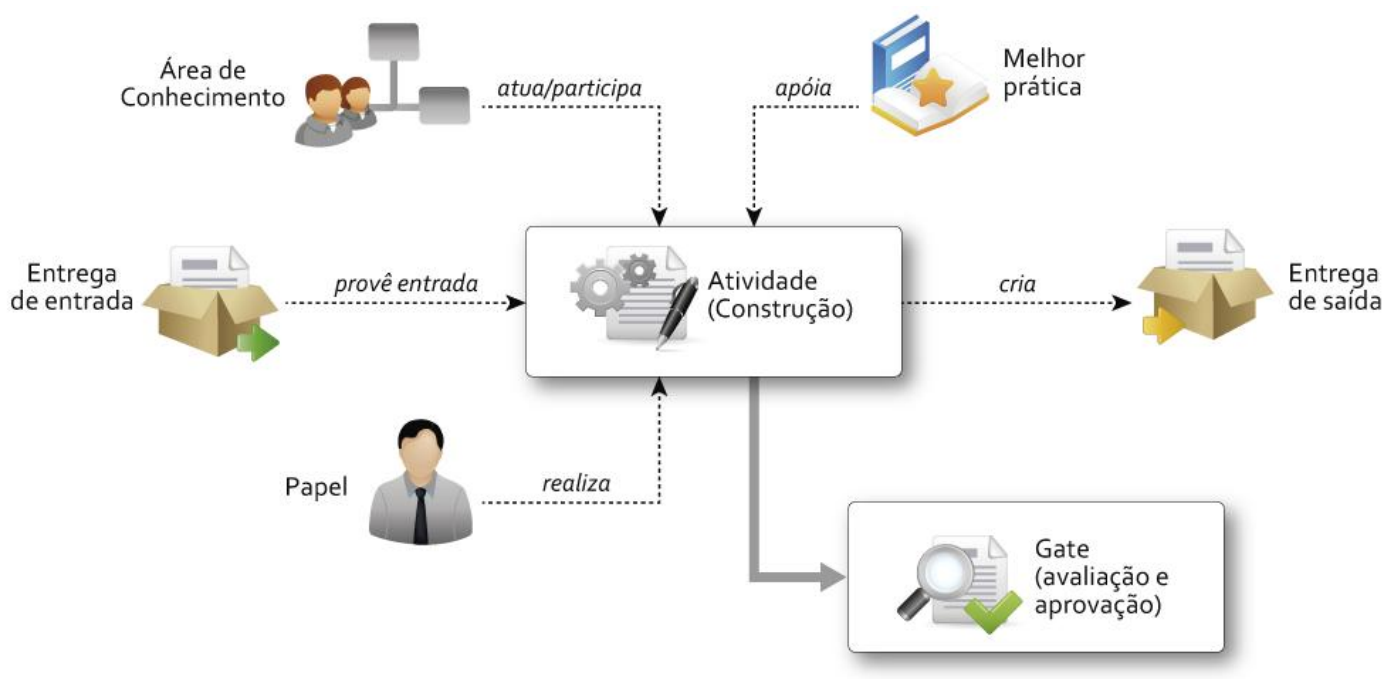

Figura 32 - Relacionamento entre os principais construtos e blocos de construção das vistas propostas

Os construtos empregados na modelagem desse protótipo são, além dos comuns em modelos de PDP (citados no item 2.1.2, Tabela 3):

- Melhor prática: compreende as ferramentas, técnicas e conhecimentos, entre outros recursos que apoiem a execução de uma atividade (Ex: QFD, Brainstorming, FMEA, etc.).

- Área de conhecimento: área referente a uma especialidade dentro de uma organização, como marketing, compras, suprimentos, entre outras.

Conforme citado anteriormente, foi também necessário desenvolver a ferramenta de modelagem para a elaboração das vistas concebidas, já que nenhuma ferramenta disponível oferecia os recursos desejados. A ferramenta foi elaborada na forma de um website ligado a uma base de dados. A utilização de uma base de dados automatiza a montagem das vistas, facilita atualização, e pode permitir intercâmbio com outras plataformas/softwares. A base de dados foi elaborada em uma plataforma SQL, utilizando o diagrama de classes da Figura 33 como referência. O framework de programação empregado foi o Ruby on Rail $\AA^{23}$, que permite uma elaboração rápida e elegante de interfaces gráficas orientadas a

$\overline{{ }^{23} \text { Mais detalhes em http://rubyonrails.org/ }}$ 
base de dados. Folhas de estilo em CSS (Cascading Style Sheets) também foram empregadas para a elaboração das telas.

A ferramenta desenvolvida permite a modelagem de qualquer conteúdo com o método de modelagem detalhado acima, bastando para isso trocar as informações da base de dados. A alteração da base de dados é facilitada por meio de uma interface de edição amigável desenvolvida para a ferramenta.

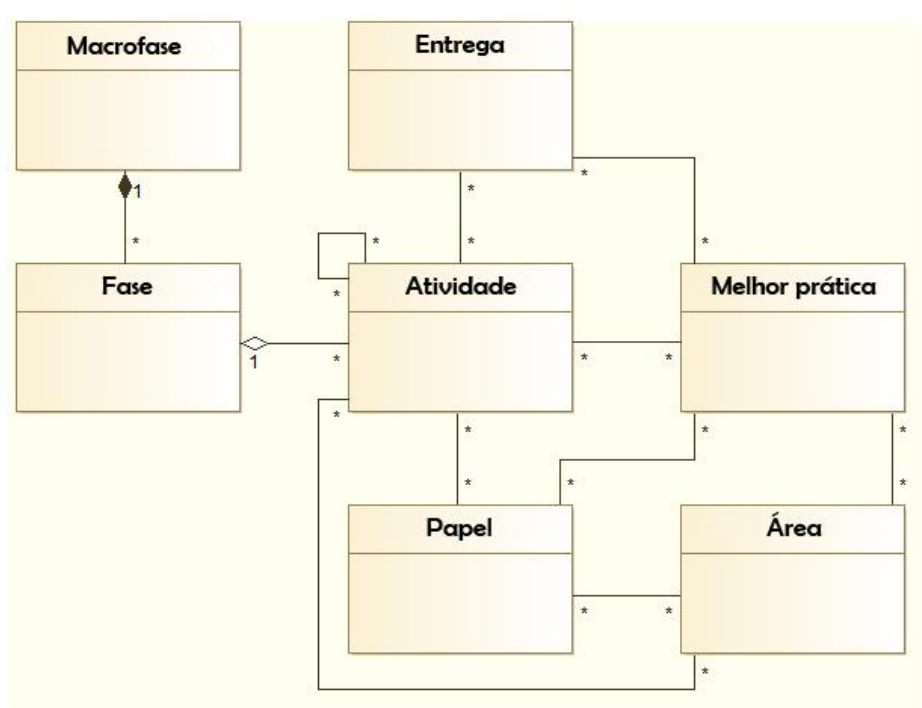

Figura 33 - Diagrama de classes elaborado para a base de dados do protótipo A

\subsubsection{Avaliação preliminar}

O percurso cognitivo foi realizado pelo pesquisador, com base no gabarito com as respostas corretas das tarefas do roteiro (Apêndice $G$ - Gabarito do roteiro de tarefas dos testes de usabilidade) e da sequência preferencial de ações necessárias (estratégia ideal) para cumprir cada tarefa (Apêndice $\mathrm{H}$ - ). O protótipo também foi submetido à avaliação de dois especialistas, acadêmicos com experiência em modelos de PDP.

Os resultados da avaliação preliminar indicaram a necessidade de:

- Inserção de uma ferramenta de filtros nas telas das órbitas, pois em algumas situações o número de elementos apresentados é tão grande que alguns ícones se sobrepõem e dificultam a leitura.

- Ajustes nos ícones de atividade de origem e de destino, que poderiam causar confusão nos usuários. 
- Ajustes nos links das listas alfabéticas de elementos do modelo, que não deixavam claro para qual fase do modelo estavam direcionando o usuário (optou-se por sempre levar ao começo do processo).

- Inserção de botões em algumas das vistas que permitissem a navegação entre fases ou entre elementos.

O relatório completo do percurso cognitivo realizado no protótipo $A$ está no Apêndice K - Relatório do percurso cognitivo para os protótipos A e B.

\subsubsection{Segunda iteração - Vistas finais}

A vista inicial com que o usuário toma contato é a tela com a representação gráfica do modelo navegável (Figura 34). Ele pode optar depois por acessar mais informações clicando sobre:

- as macrofases, tanto no modelo gráfico quanto do navegador no topo da tela, para acessar a vista da Figura 35.

- as fases, tanto no modelo gráfico quanto do navegador no topo da tela, para acessar a vista da Figura 36.

- listas alfabéticas, no menu, para acessar as vistas da Figura 38 e da Figura 37.

Qualquer elemento (bloco de construção) do modelo pode estar no centro de uma órbita, o que permite múltiplas perspectivas do processo para o usuário. Por exemplo, se ao usuário for atribuído o papel de gestor de projeto, ele pode rapidamente observar todos os outros elementos do processo que se relacionam com ele, como as atividades que ele realizará, entregas pelas quais terá que se responsabilizar, e melhores práticas que terá que lançar mão. Por outro lado, se um usuário do processo estiver interessado em uma entrega específica, poderá facilmente visualizar as suas atividades de origem e destino, as melhores práticas utilizadas para sua obtenção e papéis do modelo relacionados com ela. É possível também entender em quais atividades do processo será necessário utilizar uma melhor prática específica, assim como quais os papéis que devem ser capacitados nessa melhor prática, entre outros. As figuras abaixo mostram exemplos de diferentes órbitas (Figura 39 até Figura 43). 


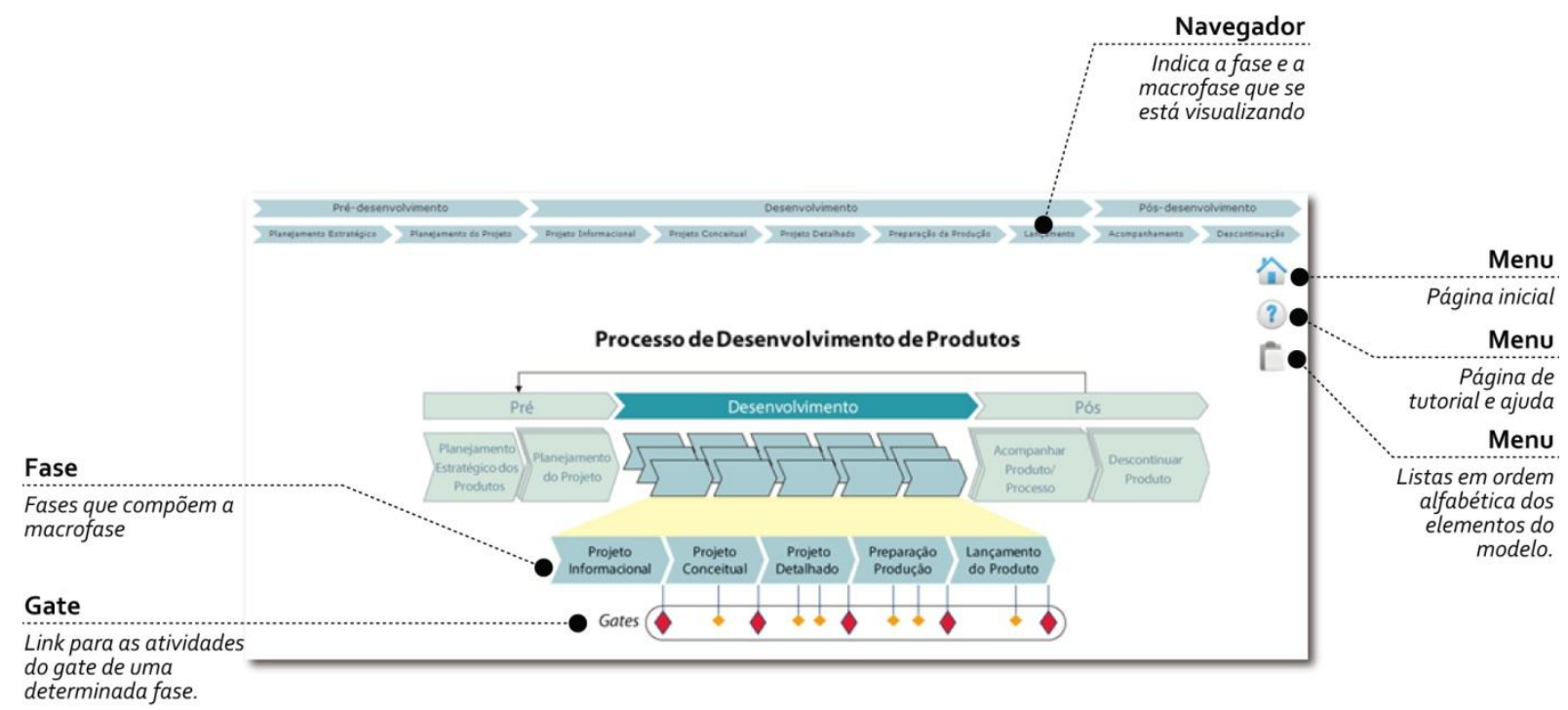

Figura 34 - Vista com representação gráfica do modelo navegável (tela inicial)

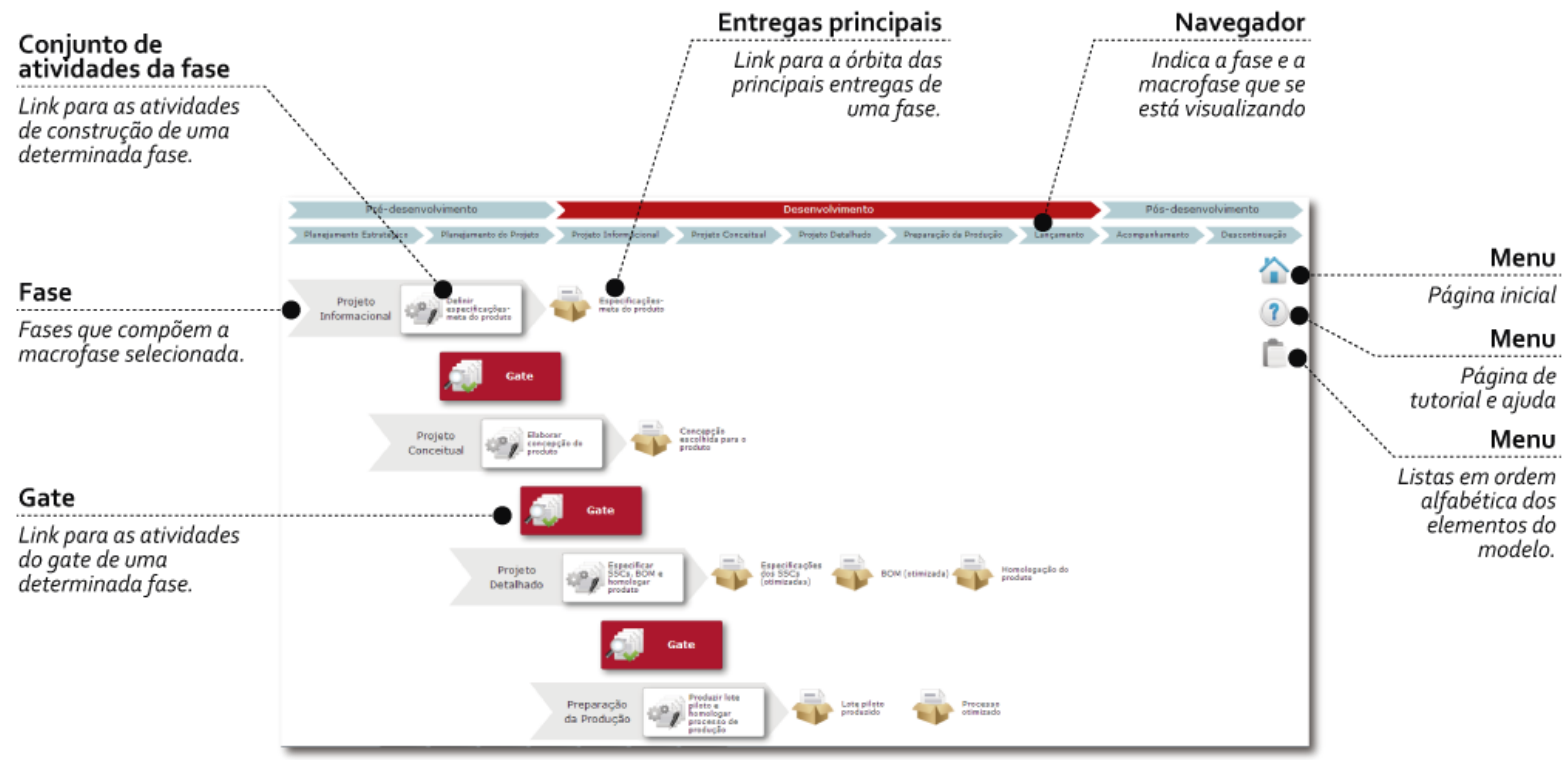

Figura 35 - Vista das fases e gates do processo, com entregas principais 


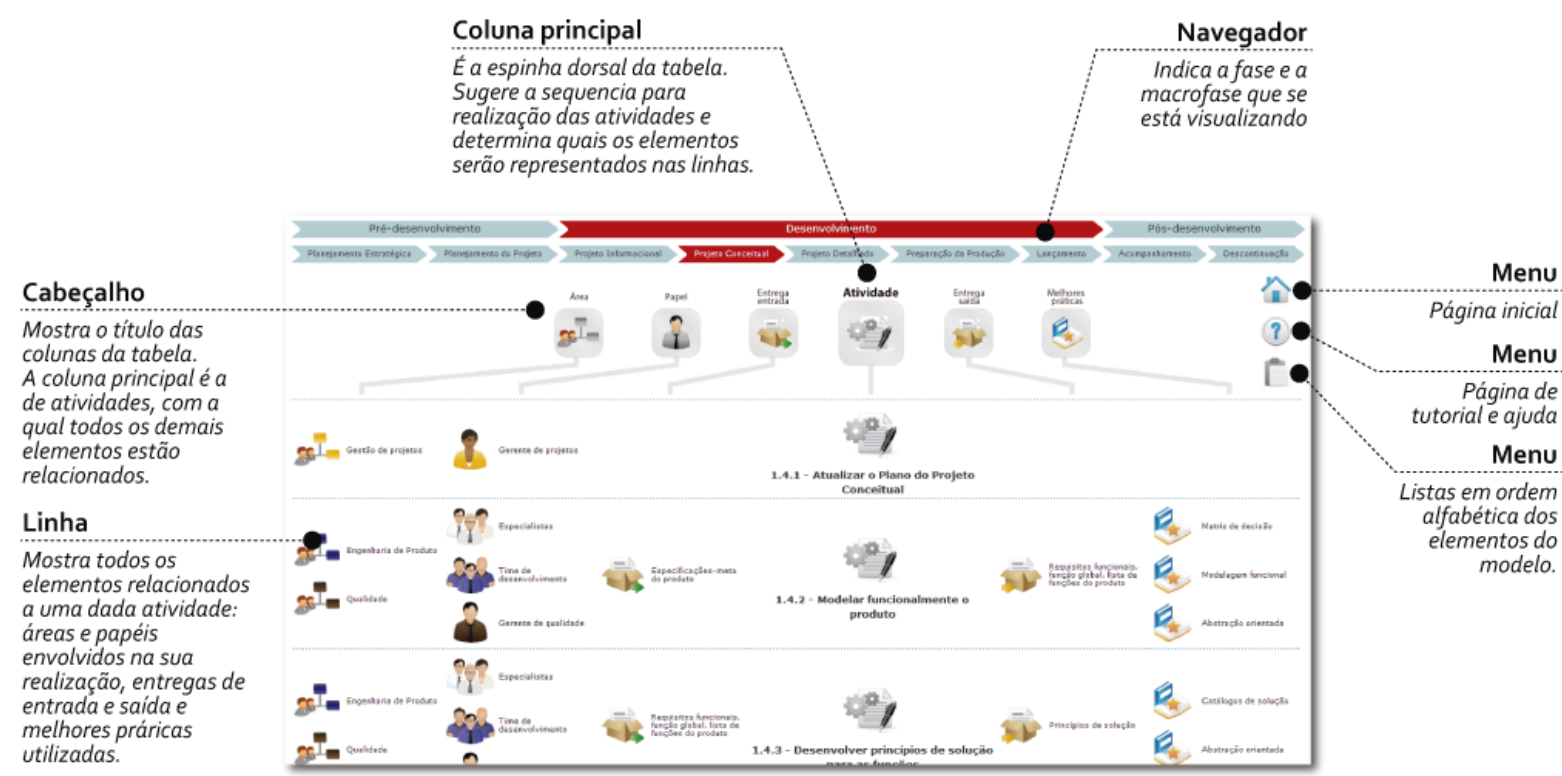

Figura 36 - Vista de tabela, organizada com todos os construtos de uma fase

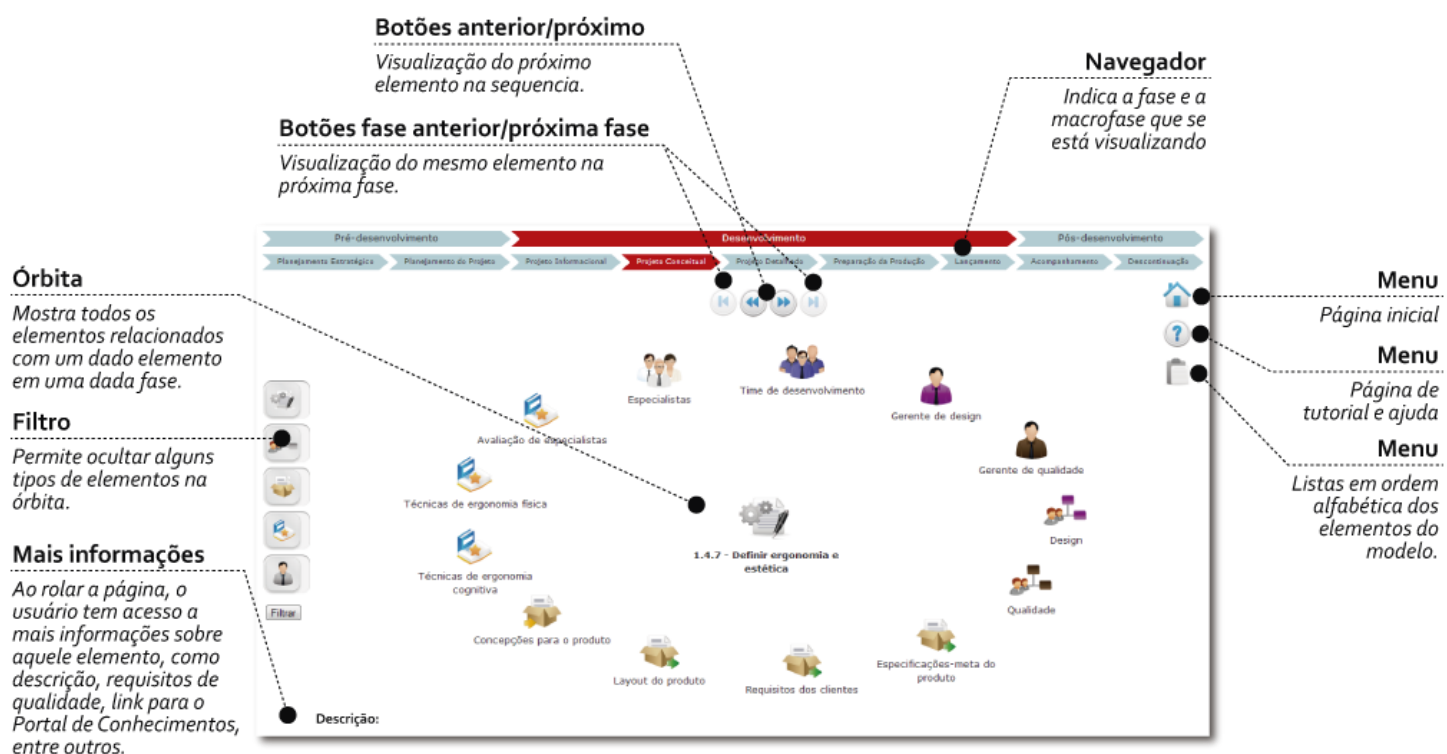

Figura 37 - Vista de órbita de um elemento 


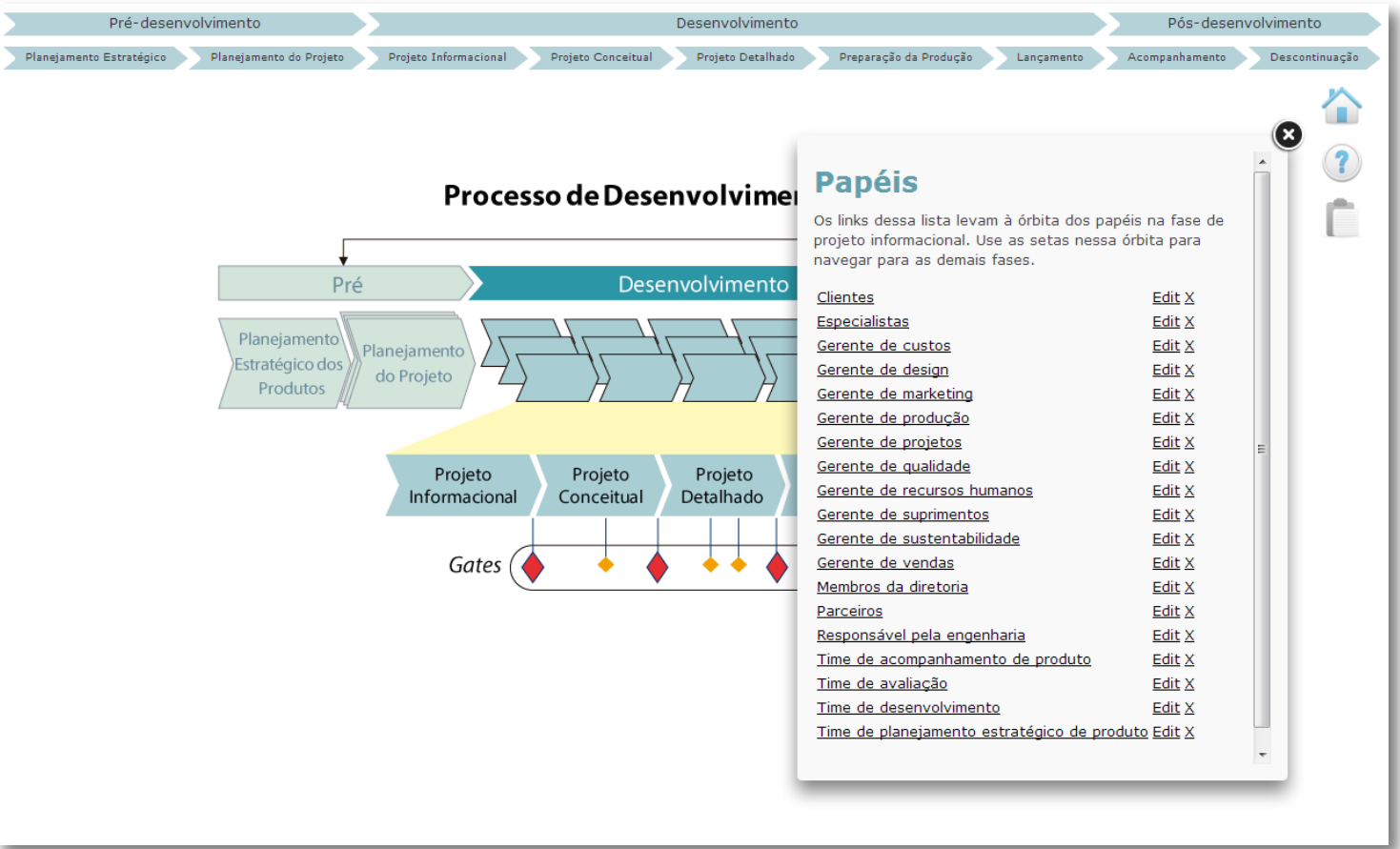

Figura 38 - Menu de listas para o construto "Papéis".

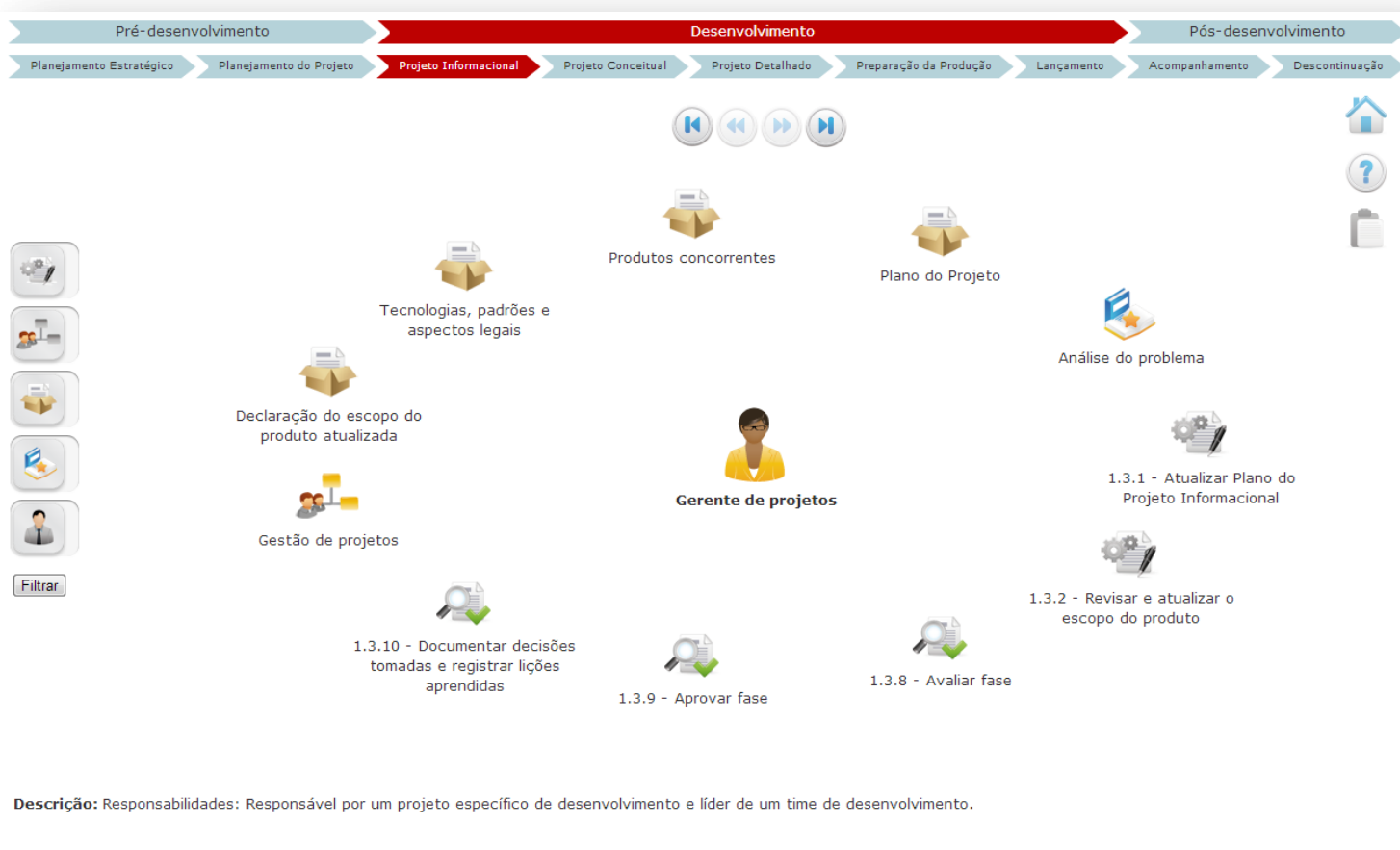

Figura 39 - Exemplo de vista de órbita centrada em um papel: é possível observar as atividades, entregas, melhores práticas e áreas relacionadas com este papel na fase selecionada. 


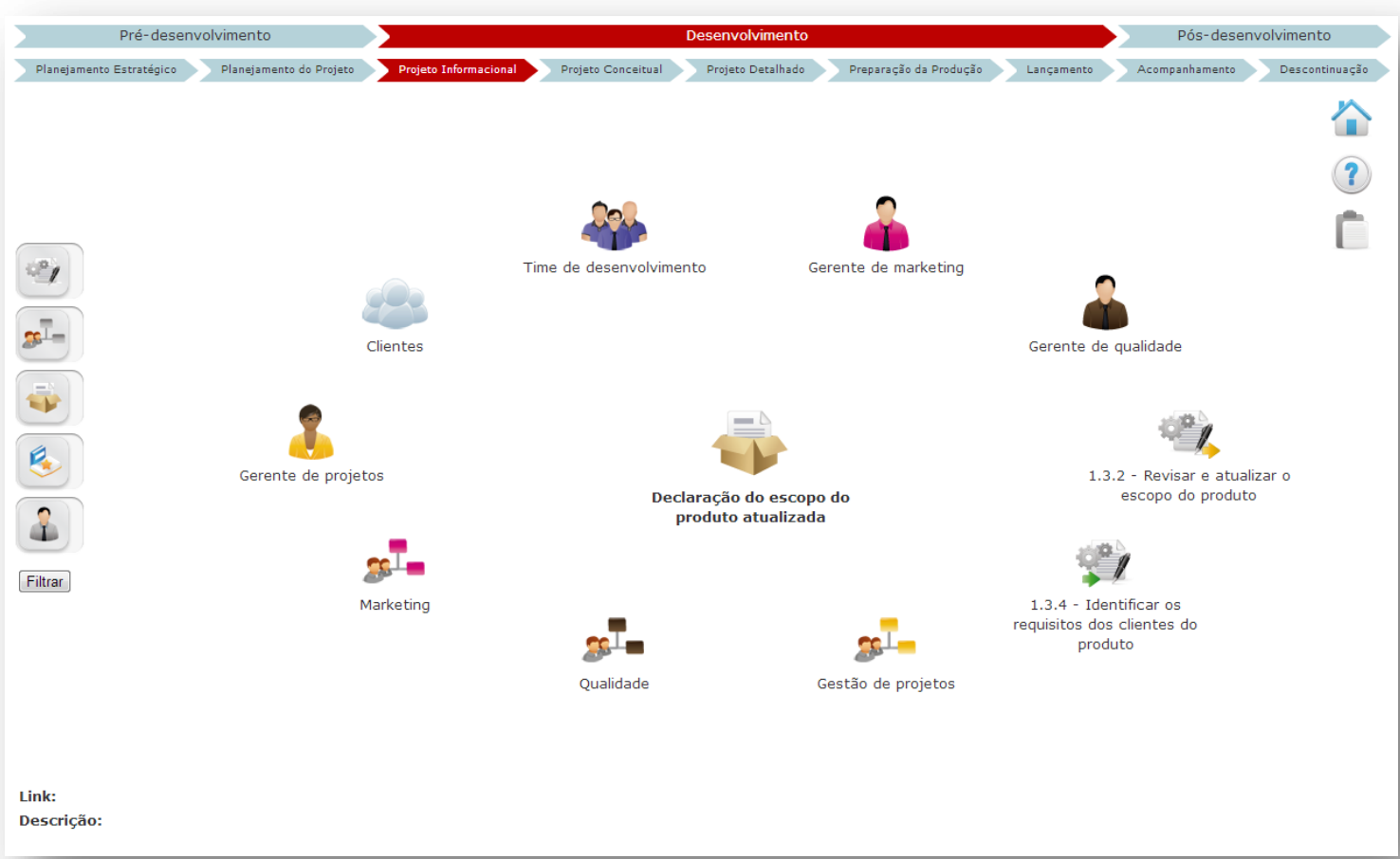

Figura 40 - Exemplo de vista de órbita centrada em uma entrega: é possível observar as atividades, papéis e áreas relacionadas com essa entrega na fase selecionada.

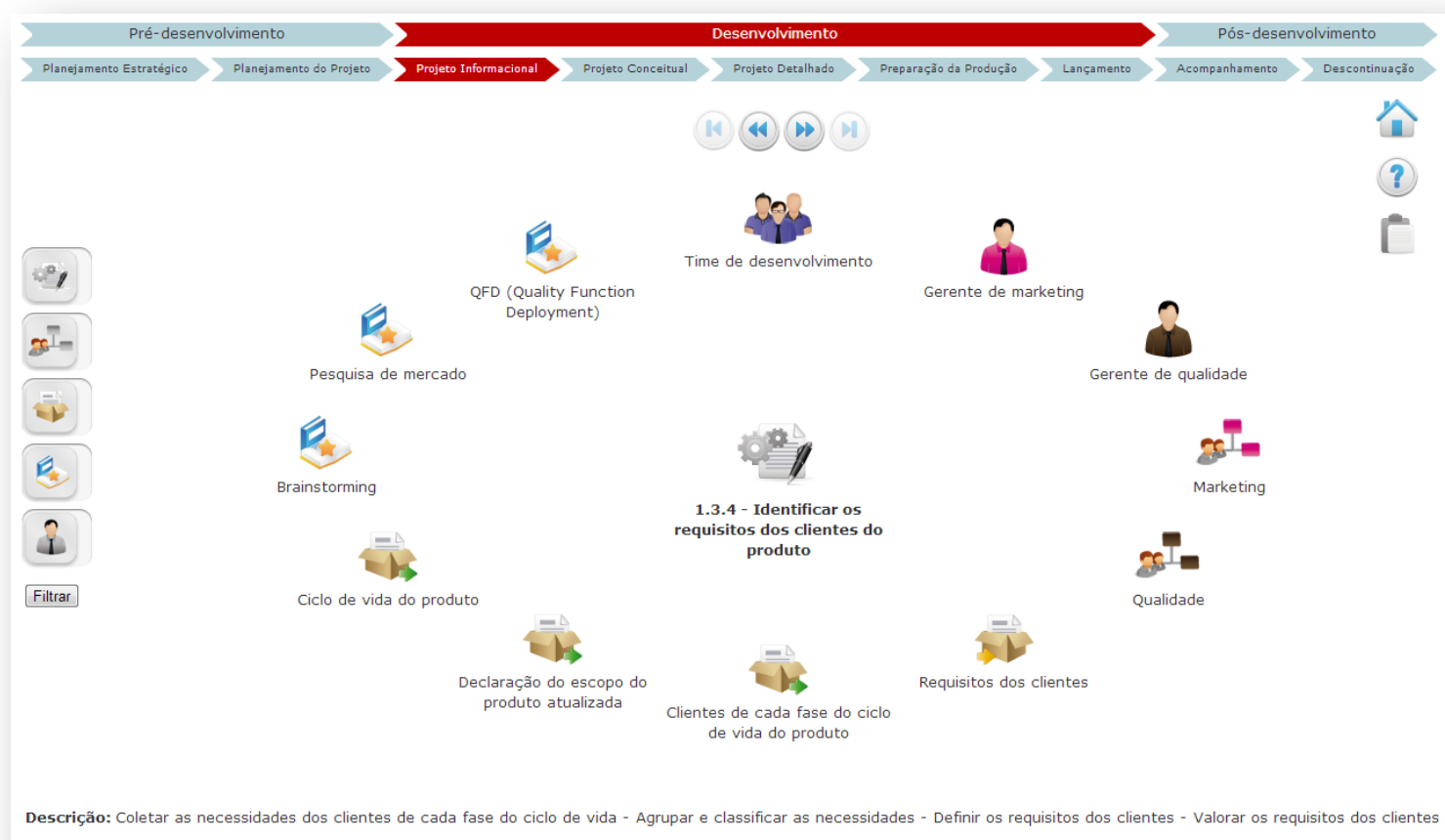

Figura 41 - Exemplo de vista de órbita centrada em uma atividade: é possível observar os papéis, entregas, melhores práticas e áreas relacionadas com essa atividade na fase selecionada. 


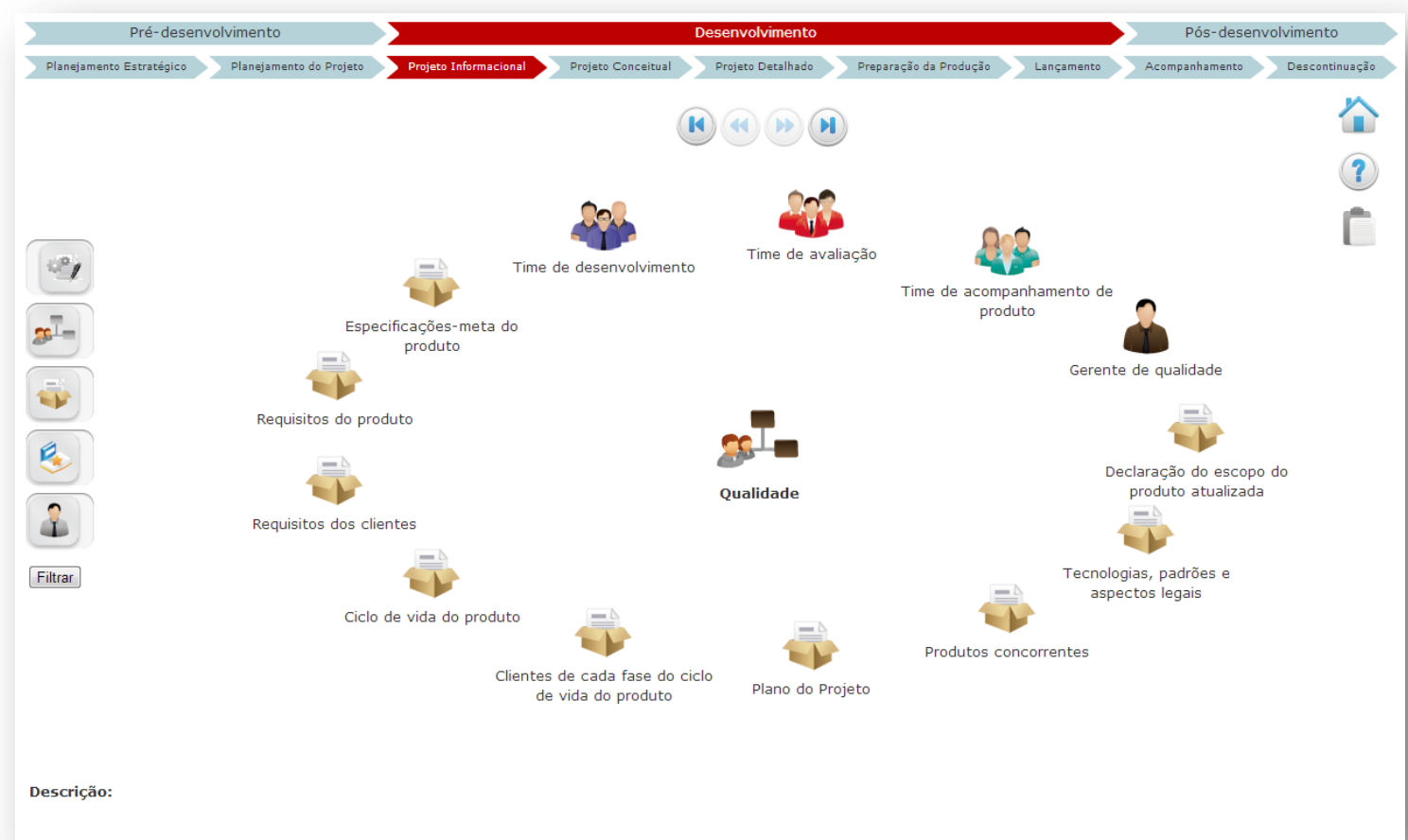

Figura 42 - Exemplo de vista de órbita centrada em uma área (neste caso, com o filtro de atividades acionado): é possível observar as entregas e os papéis relacionados com essa área na fase selecionada.

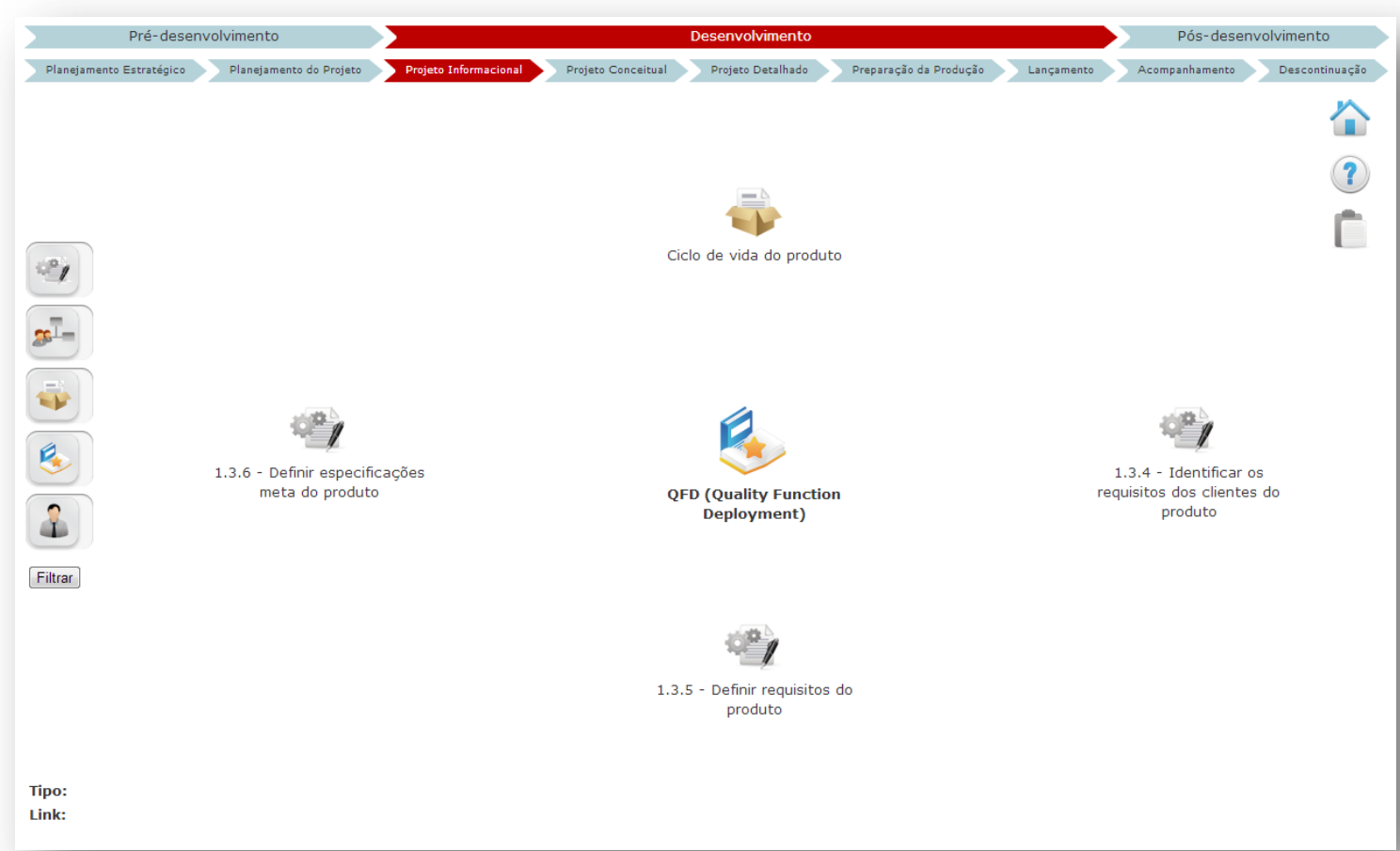

Figura 43 - Exemplo de vista de órbita centrada em uma melhor prática: é possível observar as atividades e entregas relacionadas com essa melhor prática na fase selecionada. 


\subsubsection{Protótipo B: vistas do método de modelagem eEPC}

Os resultados apresentados nesta seção foram obtidos por meio do emprego dos métodos já expostos no 3.4. O método de modelagem selecionado para a modelagem do protótipo $B$, a partir da análise da literatura (item 4.1.2), foi o eEPC.

\subsubsection{Primeira iteração}

O protótipo foi desenvolvido de acordo com as instruções disponíveis na literatura para modelagem de processos com o método escolhido (eEPC). O eEPC é um método modelagem de processos baseado no controle dos fluxos de atividades, eventos e seus relacionamentos lógicos. O eEPC é a versão estendida do EPC, e possui construtos para a representação de diversos elementos da modelagem de negócios (entregas, ferramentas, papéis, etc.) enquanto que a versão simples descreve o fluxo como uma cadeia de funções, eventos e conectores lógicos (SCHEER et al., 2005).

Segundo Scheer et al. (2005), os três elementos básicos da modelagem EPC são:

- Funções: são atividades como processos e tarefas e juntamente com os eventos constituem a espinha dorsal do modelo.

- Eventos: descrevem condições de mudanças e caracterizam o resultado de uma atividade, desencadeando a próxima função.

- Conectores: são responsáveis por conectar os eventos e funções e são usados como controle de fluxo, definindo a lógica do mesmo. Existem três tipos de lógica: "e" $(\Lambda)$, "ou" $(V)$ ou "ou exclusivo" $(X)$.

As seguintes regras devem ser seguidas para a modelagem em EPC (SCHEER et al., 2005):

- A sequência lógica que deve ser seguida é função - evento - função.

- Um modelo em EPC contém pelo menos uma atividade/função;

- Um EPC pode conter diversos EPCs (vários níveis de detalhamento);

- Um evento não pode preceder ou suceder outro evento; 
- Uma atividade/função não pode preceder ou suceder outra atividade/função;

- Cada evento e cada atividade/função possuem somente uma extremidade de entrada e/ou uma extremidade de saída.

Ainda, Scheer et al. (2005) sugerem os seguintes passos para a modelagem EPC:

1. Determinar o nome do processo de negócio a ser modelado;

2. Definir o evento inicial e o evento final, ou seja, quando e através de quais circunstâncias o processo tem início ou fim;

3. Preencher o espaço entre o evento inicial e final com os controles de fluxo e atividades. Quando apropriado, utilizar conectores adequados;

4. Determinar um ou mais eventos para cada transição entre atividades;

5. Testar as regras propostas para evitar erros;

6. Adicionar todas as entidades relevantes para outras perspectivas, adicionando departamentos, responsáveis ou funções às atividades.

A modelagem foi realizada utilizando-se o software $A R P O \AA$, que tem funcionalidades semelhantes ao pacote ARIS $\AA$. O software ARPO® é um software desenvolvido no Brasil e foi gentilmente cedido para a realização desta pesquisa pela empresa responsável por seu desenvolvimento ${ }^{24}$. As vistas geradas pela funcionalidade "website" do software ARPO® têm opção de zoom e ainda oferecem um menu em árvore e acesso às informações sobre propriedades dos elementos. $O$ $A R P O{ }^{\circledR}$ ainda oferece o método de modelagem VAC para modelar macroprocessos, associado ao eEPC.

Os construtos empregados na modelagem estão na Figura 44, e os principais elementos das vistas elaboradas pelo ARPO estão na

Figura 45. Os construtos empregados na modelagem desse protótipo são, além dos comuns em modelos de PDP (citados no item 2.1.2, Tabela 3):

- Evento: eventos descrevem mudanças de condições que desencadeiam a execução da próxima função (SCHEER et al., 2005). Podem descrever o resultado de uma atividade, por exemplo "plano de projeto desenvolvido".

${ }^{24}$ Para mais detalhes, visite http://www.klugsolutions.com/ 
- Melhor prática: compreende ferramentas, técnicas, conhecimentos entre outros recursos que apoiem a execução de uma atividade (Ex: QFD, Brainstorming, FMEA, etc.).

- Área: área referente a uma especialidade dentro de uma organização, como marketing, compras, suprimentos, entre outras.

- Responsabilidade: conjunto de atribuições padrão de um papel.

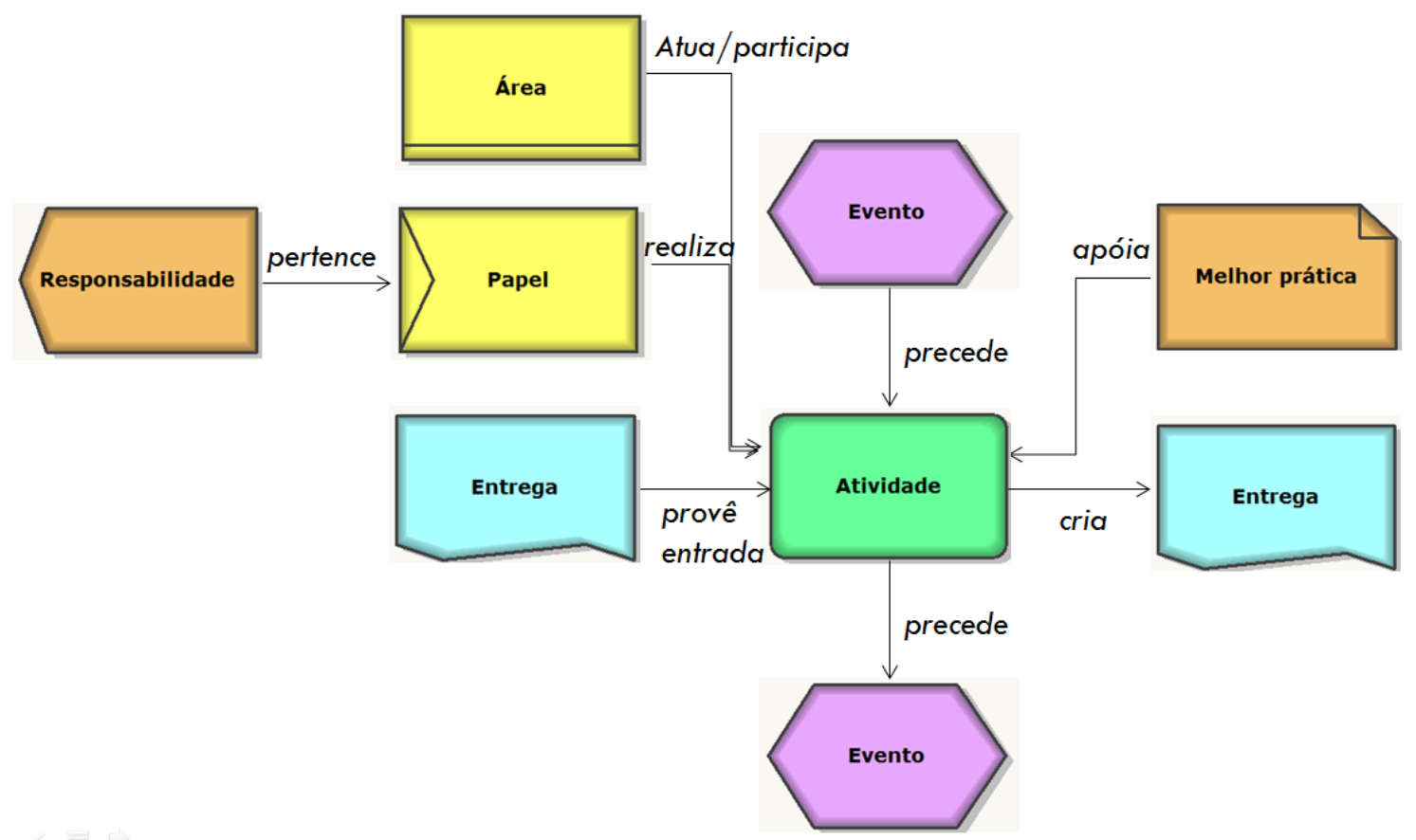

Figura 44 - Principais construtos empregados na modelagem das vistas em EPC

\subsubsection{Avaliação preliminar}

O percurso cognitivo foi realizado pelo pesquisador, com base no gabarito com as respostas corretas das tarefas do roteiro e da sequência preferencial de ações necessárias (estratégia ideal) para cumprir cada tarefa (Apêndice G Gabarito do roteiro de tarefas dos testes de usabilidade). O protótipo também foi submetido à avaliação de dois especialistas, um acadêmico com experiência em modelos de PDP, um especialista da comunidade prática no método de modelagem EPC.

Os resultados da avaliação preliminar indicaram a necessidade de acrescentar a dimensão organização ao modelo, que havia sido modelado apenas com a dimensão de processos. $O$ acréscimo da dimensão organização facilitou o 
acesso às informações relacionadas aos departamentos e aos papéis, como responsabilidades e melhores práticas utilizadas.

O relatório completo do percurso cognitivo realizado no protótipo $B$ está no Apêndice K - Relatório do percurso cognitivo para os protótipos A e B.

\subsubsection{Segunda iteração - Vistas finais}

A tela inicial com que o usuário toma contato é a tela de macrofases, modelada em VAC (

Figura 45). A partir dessa tela, o usuário pode clicar:

- No símbolo de macrofase para visualizar a vista modelada em VAC com fases, gates e objetivos das fases (Figura 46).

- No menu em árvore para acessar qualquer macrofase, fase, atividade (na dimensão processos) ou área e papel (na dimensão organizacional).

As vistas finais do modelo estão exemplificadas nas figuras abaixo ( Figura 45 até Figura 51).

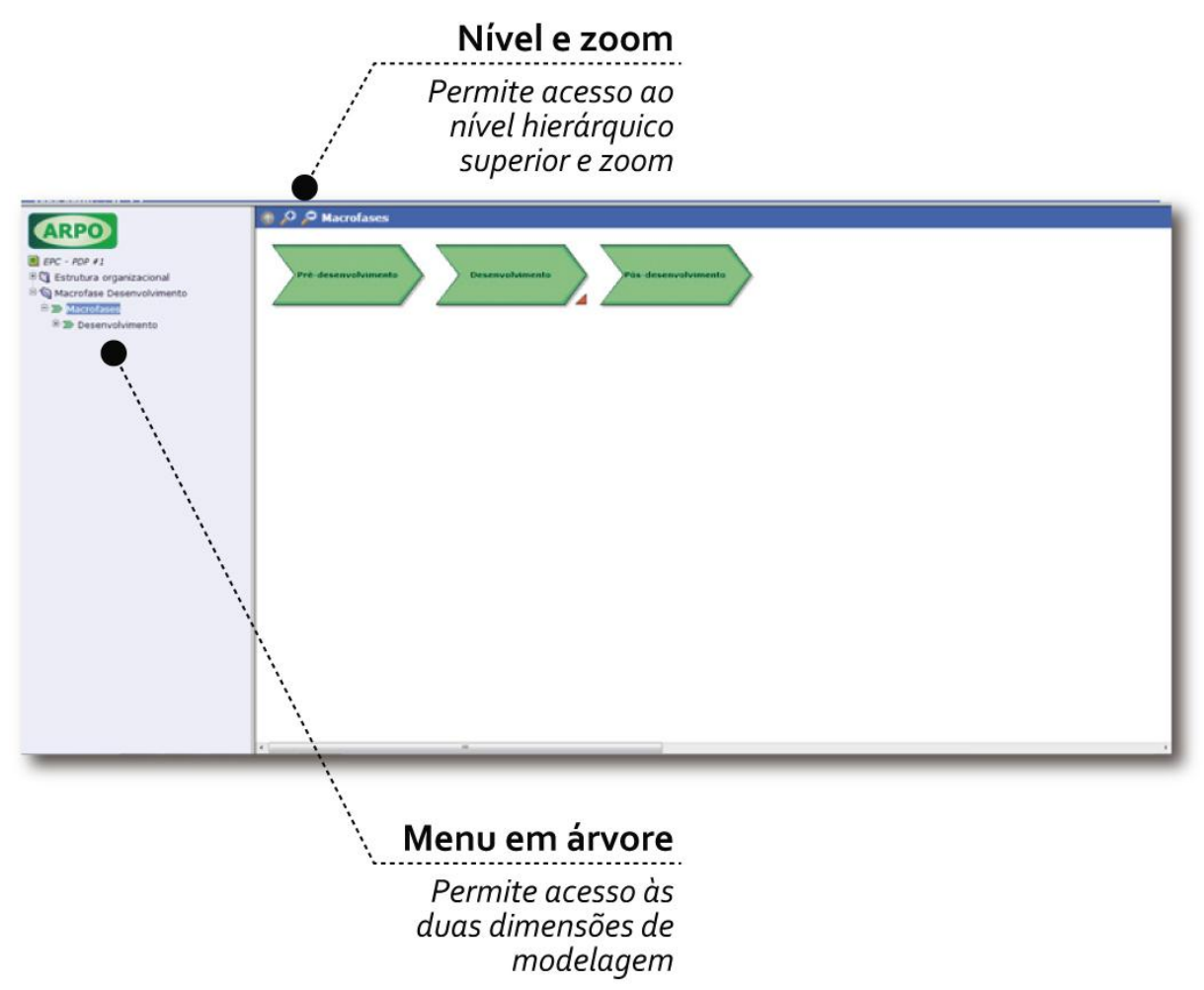

Figura 45 - Vista modelada em VAC das macrofases do processo (tela inicial) 


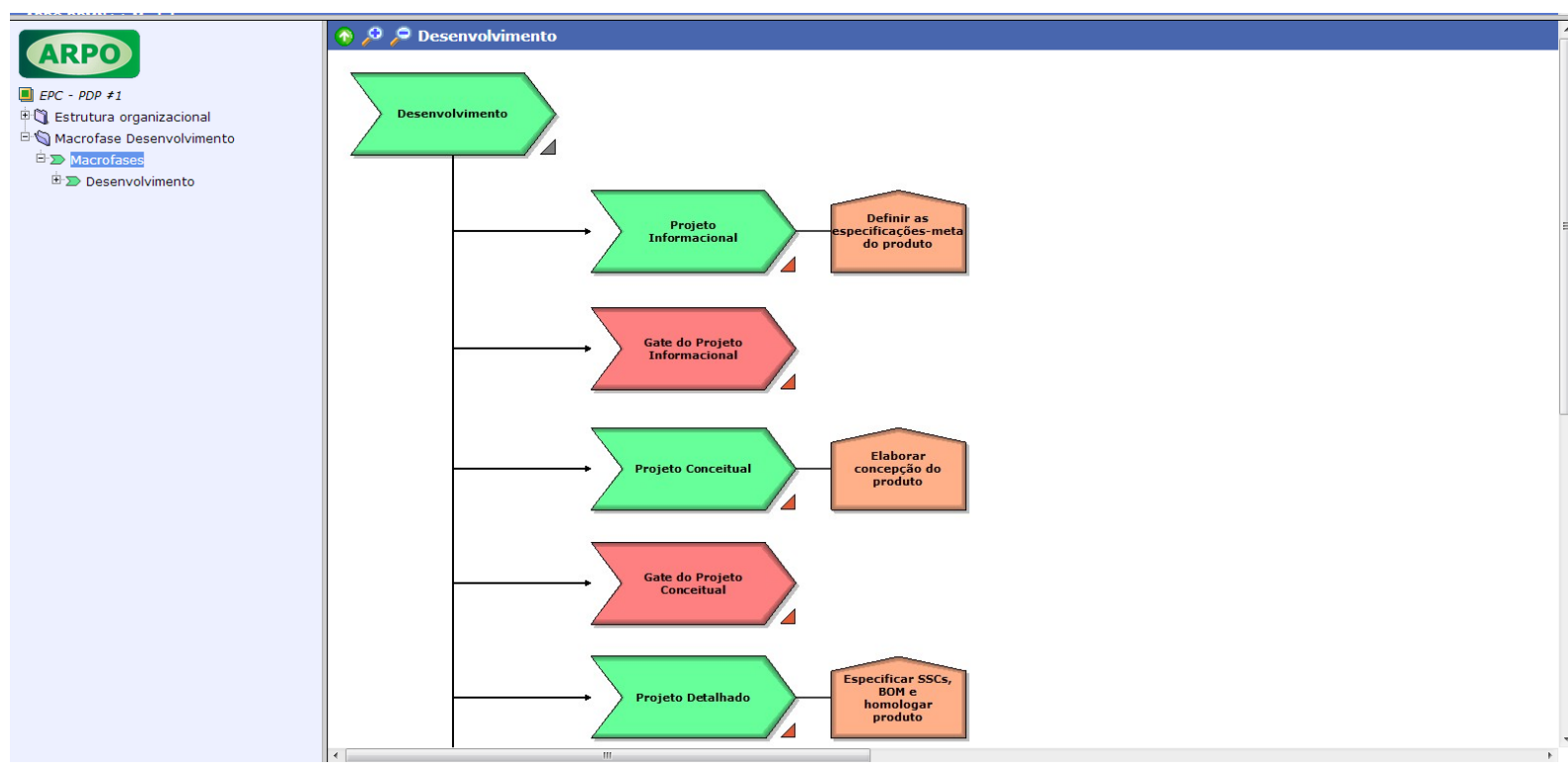

Figura 46 - Vista modelada em VAC das fases e gates do processo

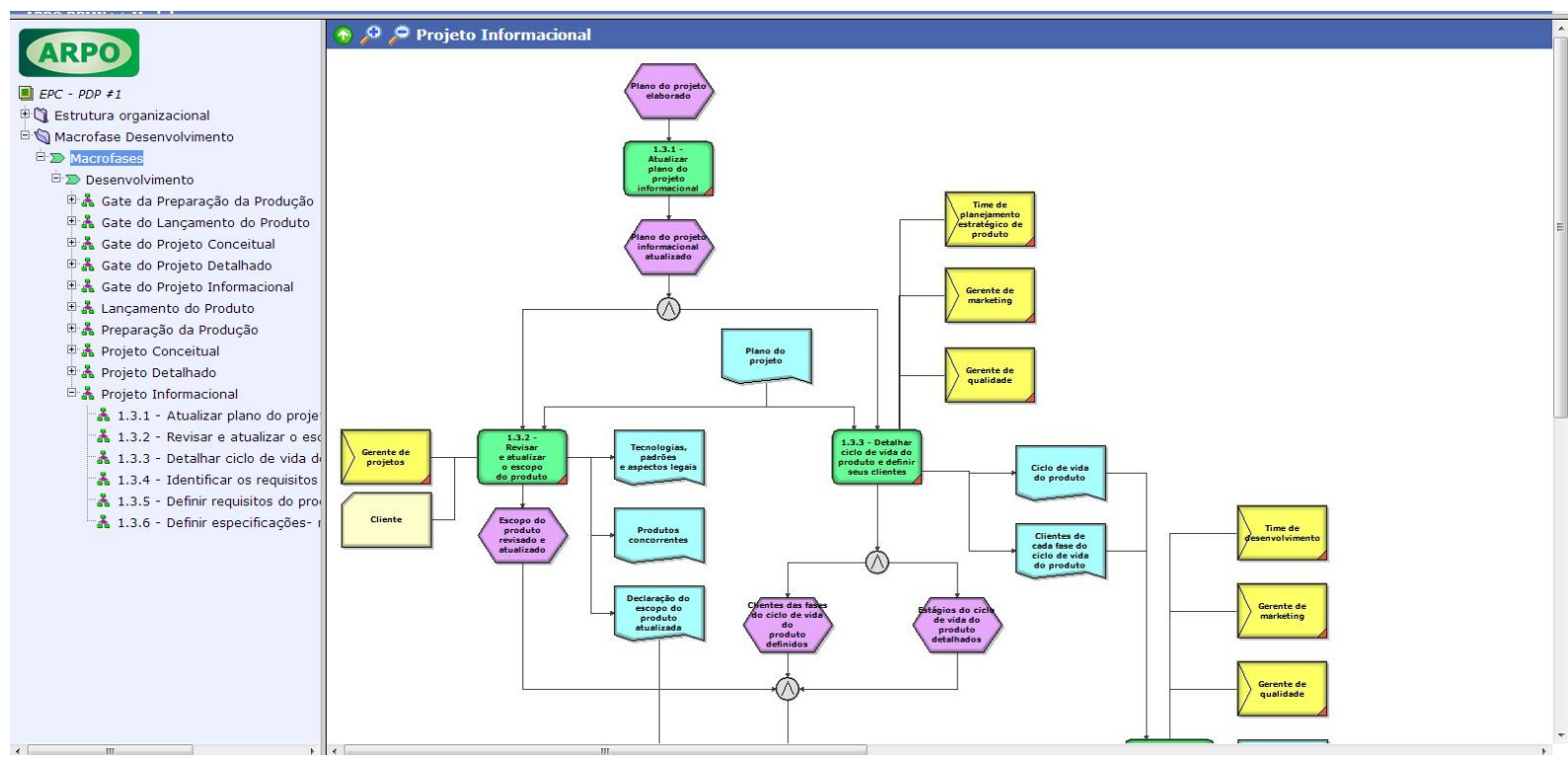

Figura 47 - Exemplo de vista de uma fase modelada em eEPC, na dimensão de processos. O fluxo de informações é dado pelos eventos e atividades. 


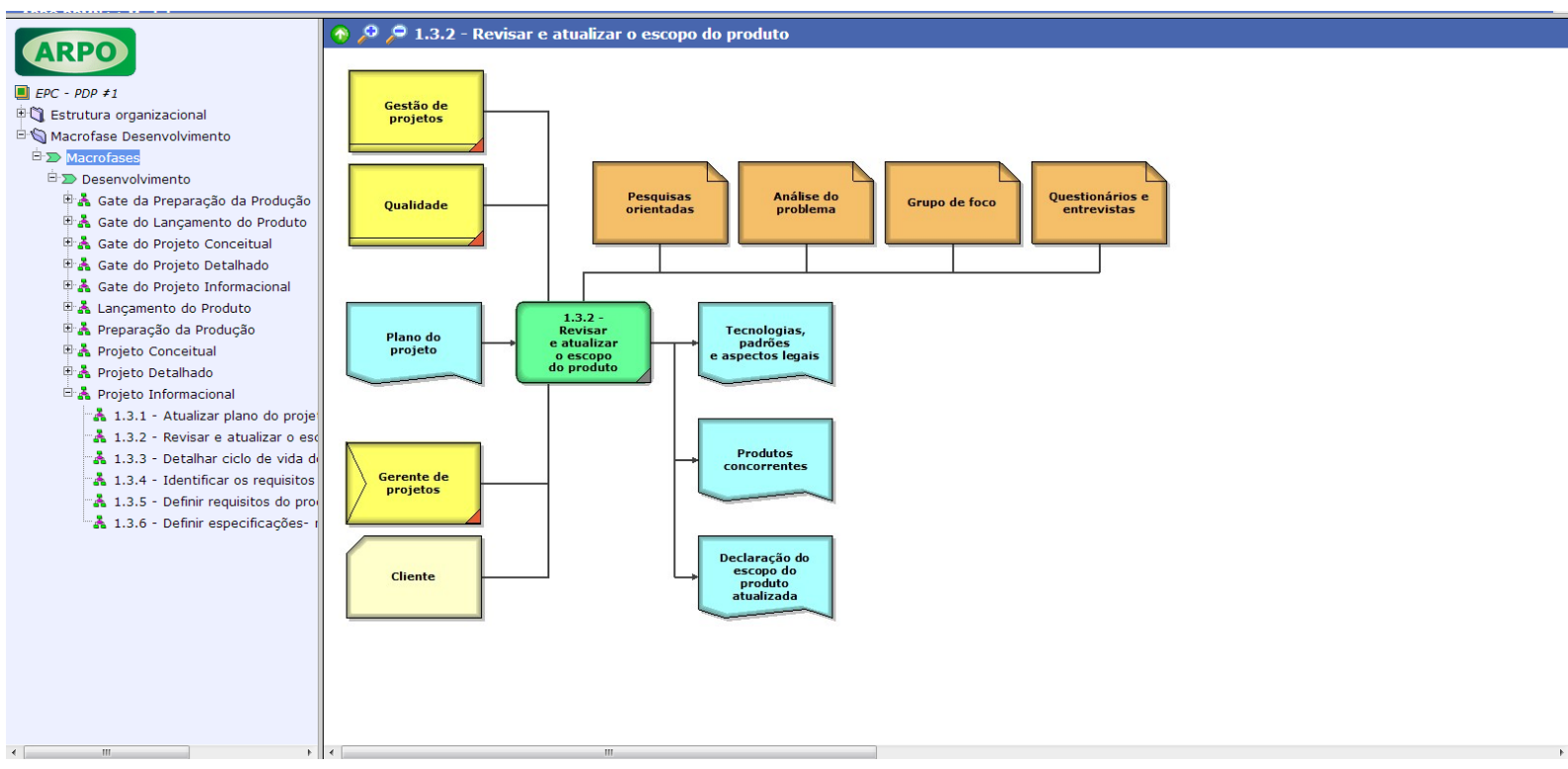

Figura 48 - Exemplo de vista de uma atividade modelada em eEPC, na dimensão de processos. Construtos que não os de fluxo lógico de atividades são representados nessas vistas.

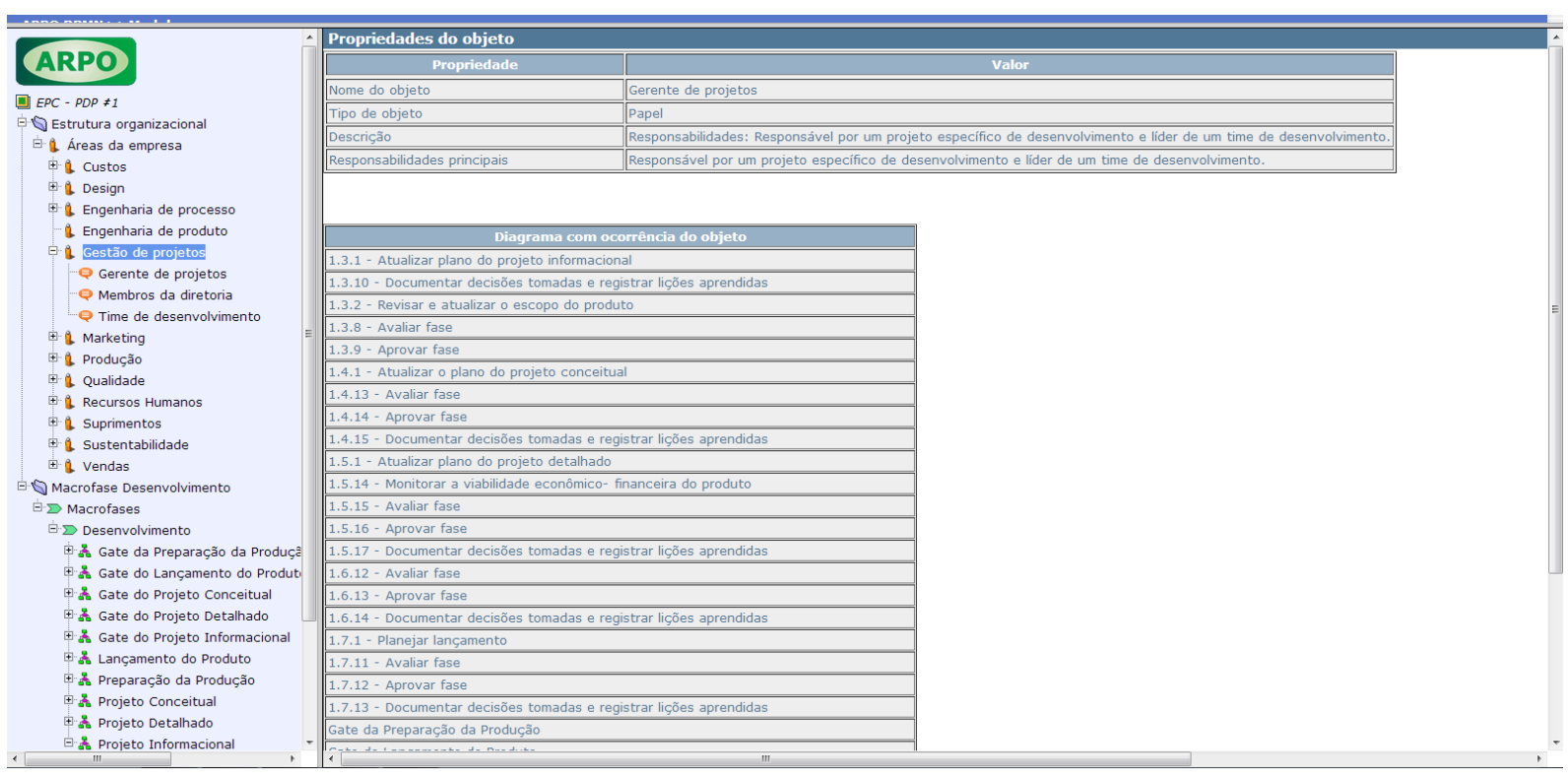

Figura 49 - Exemplo de vista de propriedades de um elemento do processo. É possível identificar em quais vistas o elemento selecionado ocorre no modelo. 


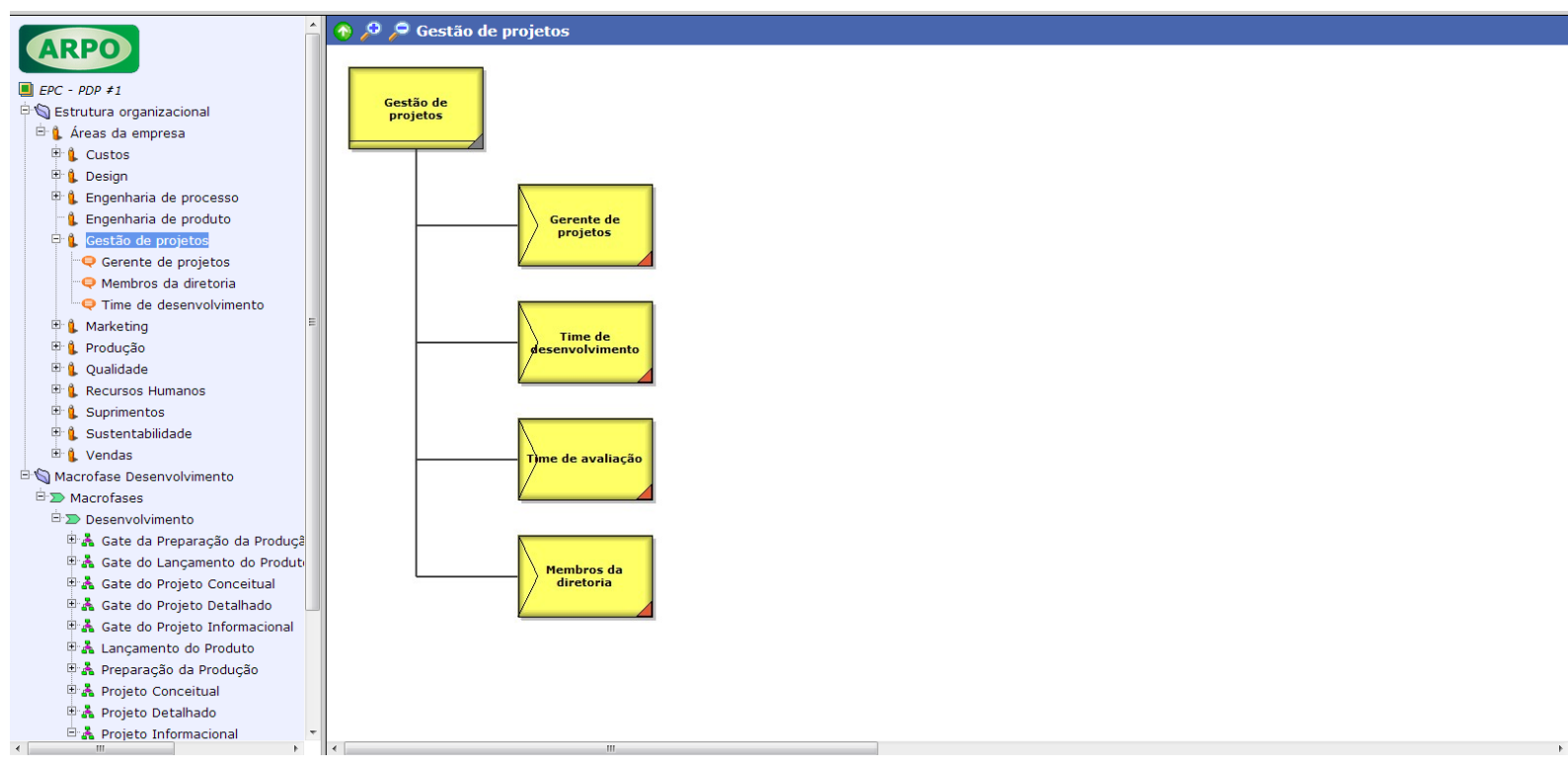

Figura 50 - Exemplo de vista de uma área do processo (com seus papéis subordinados), modelada em eEPC, na dimensão organizacional.

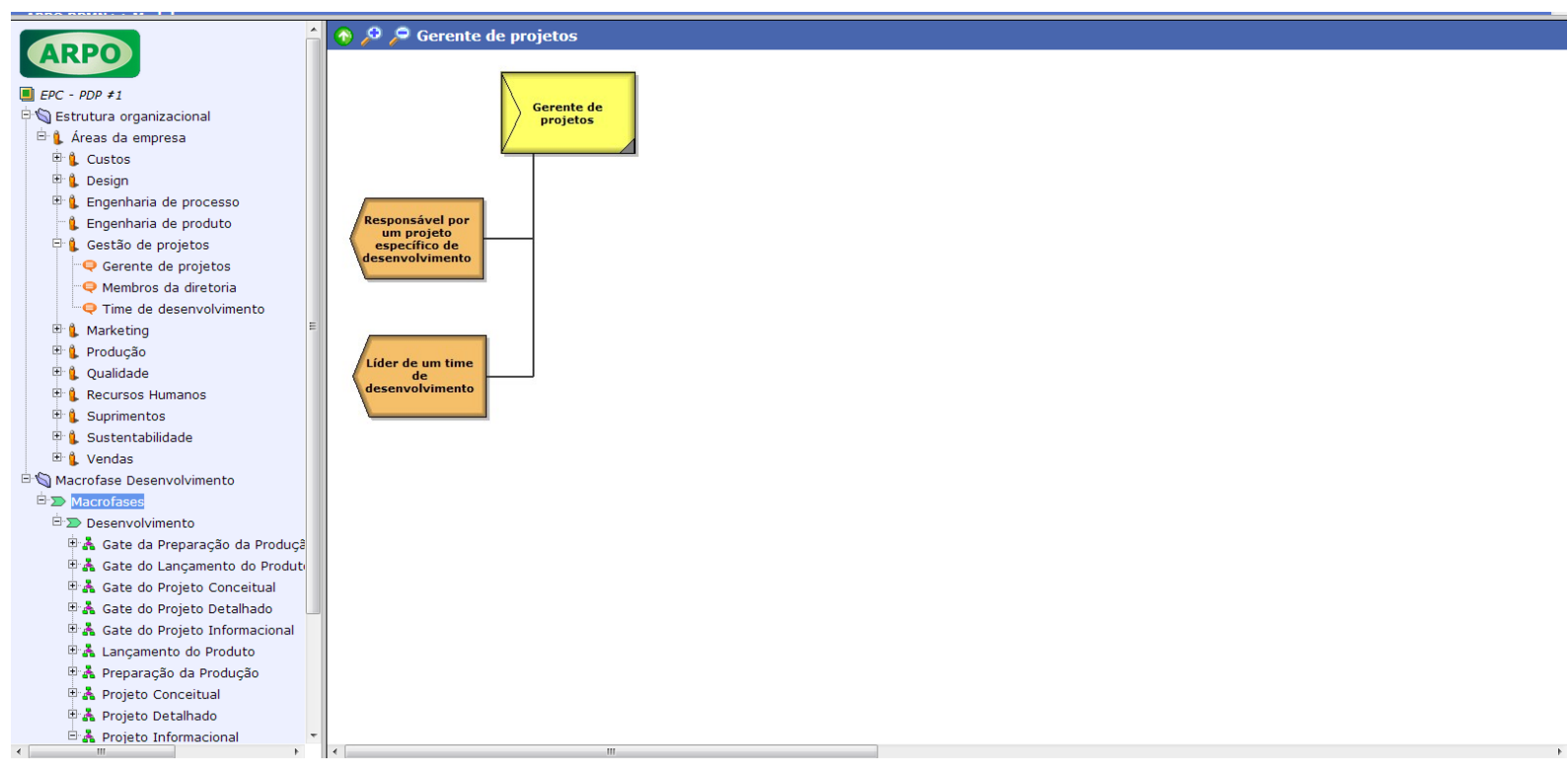

Figura 51 - Exemplo de vista de um papel (com suas responsabilidades) modelada em eEPC na dimensão organizacional. 


\subsubsection{Teste piloto}

Foram realizados dois testes piloto com os protótipos, um seguindo a ordem protótipo $A$, protótipo $B$ para a realização de cada tarefa, e outro com esta ordem invertida. Os testes piloto seguiram o mesmo método empregado para a realização dos testes de usabilidade (item 3.5.2). Nos testes pilotos foi possível:

- Estimar a duração dos testes e consolidar o procedimento para sua realização;

- Perceber a necessidade de uma apresentação prévia da pesquisa e dos protótipos para os usuários antes do início das tarefas;

- Garantir que a inversão da ordem na realização das tarefas não traria nenhum problema para o usuário;

- Testar o funcionamento do software de captura da tela do computador, bem como do áudio;

- Observar se seria necessário algum equipamento adicional aos que já estavam dispostos na baia de testes. Foi adicionada uma folha para anotações do usuário;

- Testar o posicionamento dos equipamentos na baia de testes, garantindo conforto para o usuário;

- Determinar que informações o pesquisador deveria anotar durante a realização do teste, que seriam importantes para a análise posterior dos resultados. 


\subsection{Pacote de trabalho C: Avaliação dos protótipos}

O pacote $\mathrm{C}$ é composto pelas entregas da Figura 52.

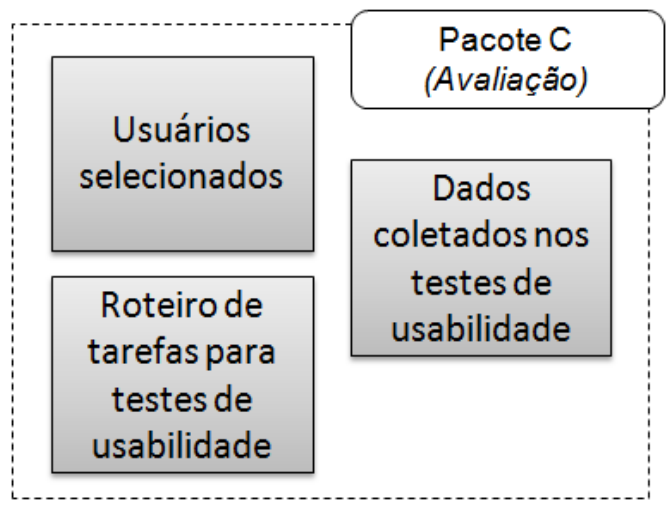

Figura 52 - Entregas do pacote de trabalho C

\subsubsection{Usuários selecionados}

Foram selecionados 14 usuários com perfil desejado para realização dos testes. O perfil dos usuários está explicitado na Tabela 21. Estão destacados em negrito os valores que tiveram o maior número de usuários.

Tabela 21 - Perfil dos usuários selecionados para o teste de usabilidade

\begin{tabular}{|c|c|c|}
\hline \multicolumn{2}{|l|}{ Critério } & Valor e Número de usuários/valor \\
\hline \multirow{6}{*}{$\begin{array}{l}\text { Caracterização } \\
\text { do participante }\end{array}$} & $\begin{array}{l}\text { Disponibilidade para } \\
\text { realizar o teste }\end{array}$ & “Sim" (14) \\
\hline & Idade & $\begin{array}{l}\text { Menos de } 30(12) \\
30 \text { a } 34 \text { anos (1) } \\
35 \text { a } 39 \text { anos (2) }\end{array}$ \\
\hline & Conflito de interesses & Nenhum (14) \\
\hline & Grau de instrução & $\begin{array}{l}\text { "Pós graduação em andamento" (12) } \\
\text { "Pós graduação completo" (2) }\end{array}$ \\
\hline & Curso de ensino superior & $\begin{array}{l}\text { Engenharia (10) } \\
\text { Processamento de dados (1) } \\
\text { Administração (1) } \\
\text { Farmácia (1) } \\
\text { Química (1) }\end{array}$ \\
\hline & Curso de pós graduação & Engenharia de produção (14) \\
\hline $\begin{array}{l}\text { Conhecimento } \\
\text { da tarefa }\end{array}$ & $\begin{array}{l}\text { Disciplina cursada em } \\
\text { desenvolvimento de } \\
\text { produtos }\end{array}$ & $\begin{array}{l}\text { "Processo de desenvolvimento de produtos (pós } \\
\text { graduação)" (7) } \\
\text { "Processo de desenvolvimento do produto" } \\
\text { (graduação) (4) } \\
\text { Ambas (3) }\end{array}$ \\
\hline
\end{tabular}




\begin{tabular}{|c|c|c|}
\hline \multicolumn{2}{|l|}{ Critério } & \multirow[b]{2}{*}{$\begin{array}{l}\text { Valor e Número de usuários/valor } \\
\text { "Sim, como membro de equipe (ou cargo } \\
\text { subordinado ao gerente de produto)" (4) } \\
\text { "Sim, como membro externo à organização } \\
\text { (consultor ou especialista, entre outros)" (2) } \\
\text { "Nunca participei profissionalmente de um } \\
\text { projeto de desenvolvimento de produto" (8) }\end{array}$} \\
\hline & $\begin{array}{l}\text { Experiência profissional } \\
\text { com desenvolvimento de } \\
\text { produtos }\end{array}$ & \\
\hline & $\begin{array}{l}\text { Uso profissional de } \\
\text { modelos de referência }\end{array}$ & $\begin{array}{l}\text { "Não" (5) } \\
\text { "Sim" (5) } \\
\text { "Em branco" ou "Não se aplica" (4) }\end{array}$ \\
\hline & $\begin{array}{l}\text { Familiaridade com modelo } \\
\text { de referência de Rozenfeld } \\
\text { et al. (2006) }\end{array}$ & $\begin{array}{l}\text { "Sim - cursando uma disciplina que ensinava } \\
\text { o Modelo de Referência para PDP (Rozenfeld et. } \\
\text { al., 2006)" (13) } \\
\text { "Sim - preparo para processo seletivo de Doutorado" } \\
\text { (1) }\end{array}$ \\
\hline & Familiaridade com EPC & $\begin{array}{l}\text { "1 - Nunca tomei contato, nem como usuário } \\
\text { nem modelando um processo" (9) } \\
\text { "2 - Já li/ouvi um pouco sobre o método; tenho uma } \\
\text { ideia geral de como funciona mas nunca usei" (5) }\end{array}$ \\
\hline & $\begin{array}{l}\text { Contato com métodos de } \\
\text { modelagem }\end{array}$ & $\begin{array}{l}\text { BPMN (Business Process Modeling Notation) e } \\
\text { similares (11) } \\
\text { VSM (Value Stream Mapping) e similares (9) } \\
\text { Fluxograma (13) } \\
\text { IDEF (Integration definition for function modeling) e } \\
\text { similares (1) } \\
\text { SADT (Structured analysis and design technique) e } \\
\text { similares (1) } \\
\text { Não se aplica (1) }\end{array}$ \\
\hline \multirow[b]{4}{*}{$\begin{array}{l}\text { Experiência } \\
\text { computacional }\end{array}$} & $\begin{array}{l}\text { Anos de experiência com } \\
\text { computador }\end{array}$ & "Mais de 6 anos" (14) \\
\hline & $\begin{array}{l}\text { Tempo de utilização } \\
\text { semanal do computador }\end{array}$ & $\begin{array}{l}\text { "Entre } 10 \text { e } 20 \text { horas" (4) } \\
\text { "Mais de } 20 \text { horas" (10) }\end{array}$ \\
\hline & $\begin{array}{l}\text { Anos de experiência com } \\
\text { internet }\end{array}$ & $\begin{array}{l}\text { "Entre } 4 \text { e } 6 \text { anos" (1) } \\
\text { "Mais de } 6 \text { anos" (13) }\end{array}$ \\
\hline & $\begin{array}{l}\text { Ferramentas } \\
\text { computacionais que utiliza }\end{array}$ & $\begin{array}{l}\text { "Navegador de Internet" (14) } \\
\text { "Gerenciador de emails" (5) } \\
\text { "Pacotes de escritório instalados no computador" } \\
\text { (14) } \\
\text { "Pacotes de escritório "nas nuvens" (12) } \\
\text { Software do tipo ERP (2) } \\
\text { Software de gerenciamento de projetos (5) } \\
\text { Outros (2) }\end{array}$ \\
\hline \multirow{2}{*}{$\begin{array}{l}\text { Experiência no } \\
\text { sistema }\end{array}$} & $\begin{array}{l}\text { Utilização de softwares de } \\
\text { modelagem }\end{array}$ & $\begin{array}{l}\text { "Utilizo raramente, apenas quando exigido na minha } \\
\text { organização" (6) } \\
\text { "Utilizo frequentemente, mas apenas para os } \\
\text { principais projetos que conduzo na minha } \\
\text { organização" (2) } \\
\text { Em branco ou "Não se aplica" (6) }\end{array}$ \\
\hline & $\begin{array}{l}\text { Familiaridade com } \\
\text { determinados softwares de } \\
\text { modelagem }\end{array}$ & $\begin{array}{l}\text { Visio (8) } \\
\text { PowerPoint (14) } \\
\text { Yed (7) } \\
\text { Bizagi (3) } \\
\text { Intalio (1) }\end{array}$ \\
\hline
\end{tabular}




\subsubsection{Roteiro de tarefas para testes de usabilidade}

O roteiro para realização das entrevistas foi elaborado segundo a lista final de propósitos de modelos de referência de PDP levantados a partir da revisão da literatura (Tabela 20). Tarefas que pudessem ser realizadas utilizando as vistas dos modelos foram elaboradas a partir desses propósitos, conforme explicitado na Tabela 22. Duas tarefas equivalentes, porém diferentes, foram elaboradas para cada propósito, uma para cada protótipo a ser avaliado. Por exemplo, para o propósito 1, foram elaboradas as tarefas "Informe as três primeiras atividades da fase de Projeto informacional" e "Informe as três primeiras atividades da fase de Lançamento". Apesar de possuir a mesma estrutura e ter o mesmo nível de dificuldade, as tarefas pedem por respostas diferentes, mudando apenas o foco no conteúdo do modelo solicitado como resposta.

É importante ressaltar que nem todos os propósitos da Tabela 20 foram considerados para a elaboração das tarefas. Foram selecionados 10 propósitos que se encaixavam no escopo desta pesquisa: visualização e compreensão do processo (vide item 1.2). Ou seja, os propósitos relacionados com a melhoria do processo (por ex.: "Melhorar continuamente o processo de design") foram excluídos. Também foram excluídos os propósitos que fossem tão genéricos a ponto de impossibilitarem a elaboração de uma tarefa para o teste de usabilidade (por ex. "visualizar/entender processo de design").

Em alguns casos, foi necessário elaborar mais de uma tarefa para explorar todas as possibilidades relacionadas com um dado propósito. Por exemplo, para o propósito "Definir ferramentas e templates padrão", foram elaboradas duas tarefas. Uma é "Informe as melhores práticas sugeridas para a realização da atividade Detalhar ciclo de vida do produto e definir seus clientes da fase de Projeto informacional', que possibilita analisar se o usuário é capaz de encontrar com facilidade as ferramentas e templates relacionados a uma dada atividade. A outra é "Você é um especialista em Abstração orientada. Informe as atividades nas quais essa melhor prática é empregada na fase de Projeto conceitual", que possibilita analisar se o usuário é capaz de entender com facilidade em que pontos do processo ele deve utilizar uma dada ferramenta ou template. Por essa razão, a partir dos 10 propósitos foram elaboradas 15 tarefas (em pares, uma para cada protótipo). 
Tabela 22 - Tarefas do roteiro para os testes de usabilidade

\begin{tabular}{|c|c|c|c|}
\hline & $\begin{array}{l}\text { Propósitos dos } \\
\text { usuários }\end{array}$ & Tarefa de leitura $A$ & Tarefa de leitura B \\
\hline 1 & $\begin{array}{l}\text { Definir atividades } \\
\text { padrão e } \\
\text { preferidas }\end{array}$ & $\begin{array}{l}\text { Informe as três primeiras atividades da } \\
\text { fase de "Projeto informacional". }\end{array}$ & $\begin{array}{l}\text { Informe as três primeiras } \\
\text { atividades da fase de } \\
\text { "Lançamento". }\end{array}$ \\
\hline 2 & $\begin{array}{l}\text { Definir/sugerir } \\
\text { sequencia para } \\
\text { as atividades }\end{array}$ & $\begin{array}{l}\text { Você acaba de concluir a atividade } \\
\text { "Definir requisitos do produto" da fase de } \\
\text { "Projeto informacional". Qual a próxima } \\
\text { atividade a ser realizada segundo o } \\
\text { modelo? }\end{array}$ & $\begin{array}{l}\text { Você acaba de concluir a } \\
\text { atividade "Selecionar a } \\
\text { concepção do produto" da fase } \\
\text { de "Projeto conceitual". Qual a } \\
\text { próxima atividade a ser } \\
\text { realizada segundo o modelo? }\end{array}$ \\
\hline 3 & $\begin{array}{l}\text { Mostrar relação } \\
\text { hierárquica entre } \\
\text { atividades }\end{array}$ & $\begin{array}{l}\text { Informe as duas primeiras fases que } \\
\text { compõem a macrofase de } \\
\text { "Desenvolvimento". }\end{array}$ & $\begin{array}{l}\text { Informe as duas últimas fases } \\
\text { que compõem a macrofase de } \\
\text { "Desenvolvimento". }\end{array}$ \\
\hline 4 & $\begin{array}{l}\text { Definir entregas } \\
\text { ou milestones } \\
\text { padrão }\end{array}$ & $\begin{array}{l}\text { Informe as entregas de saída da } \\
\text { atividade "Detalhar ciclo de vida do } \\
\text { produto e definir seus clientes" da fase } \\
\text { de "Projeto informacional". }\end{array}$ & $\begin{array}{l}\text { Informe as entregas de saída da } \\
\text { atividade "Promover marketing } \\
\text { de lançamento" da fase de } \\
\text { "Lançamento". }\end{array}$ \\
\hline 5 & $\begin{array}{l}\text { Definir entregas } \\
\text { ou milestones } \\
\text { padrão }\end{array}$ & $\begin{array}{l}\text { Informe a principal entrega da fase } \\
\text { "Projeto informacional". }\end{array}$ & $\begin{array}{l}\text { Informe a principal entrega da } \\
\text { fase "Lançamento". }\end{array}$ \\
\hline 6 & $\begin{array}{l}\text { Definir padrões } \\
\text { de qualidade } \\
\text { para as entregas } \\
\text { padrão }\end{array}$ & $\begin{array}{l}\text { Informe os padrões de qualidade que o } \\
\text { modelo fornece para a entrega "Estrutura } \\
\text { do produto (BOM)" na fase de "Projeto } \\
\text { detalhado". }\end{array}$ & $\begin{array}{l}\text { Informe os padrões de } \\
\text { qualidade que o modelo fornece } \\
\text { para a entrega "Concepção } \\
\text { escolhida para o produto" na } \\
\text { fase de "Projeto conceitual". }\end{array}$ \\
\hline 7 & $\begin{array}{l}\text { Identificar } \\
\text { dependência/pre } \\
\text { cedência de } \\
\text { atividades/funçõe } \\
\text { s via inputs e } \\
\text { outputs }\end{array}$ & $\begin{array}{l}\text { Informe as entregas da atividade } \\
\text { "Promover marketing de lançamento" que } \\
\text { são entradas para a atividade "Lançar } \\
\text { produto" na fase de "Lançamento". }\end{array}$ & $\begin{array}{l}\text { Informe as entregas da } \\
\text { atividade "Detalhar ciclo de vida } \\
\text { do produto e definir seus } \\
\text { clientes" que são entradas para } \\
\text { a atividade "Identificar os } \\
\text { requisitos dos clientes do } \\
\text { produto" na fase de "Projeto } \\
\text { informacional". }\end{array}$ \\
\hline 8 & $\begin{array}{l}\text { Identificar } \\
\text { dependência/pre } \\
\text { cedência de } \\
\text { atividades/funçõe } \\
\text { s via inputs e } \\
\text { outputs }\end{array}$ & $\begin{array}{l}\text { Informe as atividades que dependem das } \\
\text { entregas da seguinte atividade para } \\
\text { serem iniciadas: "1.4.2 - Modelar } \\
\text { funcionalmente o produto" da fase de } \\
\text { "Projeto conceitual". }\end{array}$ & $\begin{array}{l}\text { Informe as atividades que } \\
\text { dependem das entregas da } \\
\text { seguinte atividade para serem } \\
\text { iniciadas: "1.4.7 - Definir } \\
\text { ergonomia e estética" da fase } \\
\text { de "Projeto conceitual". }\end{array}$ \\
\hline 9 & $\begin{array}{l}\text { Definir } \\
\text { ferramentas e } \\
\text { templates padrão }\end{array}$ & $\begin{array}{l}\text { Informe as melhores práticas sugeridas } \\
\text { para a realização da atividade "Detalhar } \\
\text { ciclo de vida do produto e definir seus } \\
\text { clientes" da fase de "Projeto } \\
\text { informacional". }\end{array}$ & $\begin{array}{l}\text { Informe as melhores práticas } \\
\text { sugeridas para a realização da } \\
\text { atividade "Otimizar produção" } \\
\text { da fase de "Preparação da } \\
\text { produção". }\end{array}$ \\
\hline 10 & $\begin{array}{l}\text { Definir } \\
\text { ferramentas e } \\
\text { templates padrão }\end{array}$ & $\begin{array}{l}\text { Você é um especialista em "Abstração } \\
\text { orientada". Informe as atividades nas } \\
\text { quais essa melhor prática é empregada } \\
\text { na fase de "Projeto conceitual". }\end{array}$ & $\begin{array}{l}\text { Você é um especialista em } \\
\text { "QFD (Quality Function } \\
\text { Deployment)". Informe as } \\
\text { atividades nas quais essa } \\
\text { melhor pratica é empregada na } \\
\text { fase de "Projeto informacional". }\end{array}$ \\
\hline 11 & $\begin{array}{l}\text { Relacionar } \\
\text { papéis a } \\
\text { atividades, } \\
\text { entregas e } \\
\text { demais } \\
\text { elementos do } \\
\text { processo }\end{array}$ & $\begin{array}{l}\text { Informe as atividades da fase de } \\
\text { "Preparação da produção" com as quais } \\
\text { o "Gerente de qualidade" está } \\
\text { relacionado. }\end{array}$ & $\begin{array}{l}\text { Informe as atividades da fase de } \\
\text { "Projeto informacional" com as } \\
\text { quais o "Gerente de marketing" } \\
\text { está relacionado. }\end{array}$ \\
\hline 12 & $\begin{array}{l}\text { Relacionar } \\
\text { papéis a }\end{array}$ & $\begin{array}{l}\text { Informe as entregas com as quais o } \\
\text { "Gerente de design" está relacionado na }\end{array}$ & $\begin{array}{l}\text { Informe as entregas com as } \\
\text { quais o "Gerente de }\end{array}$ \\
\hline
\end{tabular}




\begin{tabular}{|c|c|c|c|}
\hline & $\begin{array}{l}\text { Propósitos dos } \\
\text { usuários }\end{array}$ & Tarefa de leitura $\mathrm{A}$ & Tarefa de leitura B \\
\hline & $\begin{array}{l}\text { atividades, às } \\
\text { entregas e aos } \\
\text { demais } \\
\text { elementos do } \\
\text { processo }\end{array}$ & $\begin{array}{l}\text { fase de "Projeto conceitual" (tanto } \\
\text { entregas de entrada quanto de saída). }\end{array}$ & $\begin{array}{l}\text { suprimentos" está relacionado } \\
\text { na fase de "Preparação da } \\
\text { produção" (tanto entregas de } \\
\text { entrada quanto de saída). }\end{array}$ \\
\hline 13 & $\begin{array}{l}\text { Definir } \\
\text { responsabilidade } \\
\text { s e habilidades } \\
\text { padrão para } \\
\text { papéis e pessoal }\end{array}$ & $\begin{array}{l}\text { Informe as melhores práticas de que o } \\
\text { "Gerente de suprimentos" necessitará } \\
\text { lançar mão na fase de "Projeto } \\
\text { conceitual". }\end{array}$ & $\begin{array}{l}\text { Informe as melhores práticas } \\
\text { sugeridas de que o "Gerente de } \\
\text { vendas" necessitará lançar mão } \\
\text { na fase de "Projeto detalhado". }\end{array}$ \\
\hline 14 & $\begin{array}{l}\text { Definir } \\
\text { responsabilidade } \\
\text { s e habilidades } \\
\text { padrão para } \\
\text { papéis e pessoal }\end{array}$ & $\begin{array}{l}\text { Informe as responsabilidades atribuídas } \\
\text { ao papel de "Gerente de projetos" } \\
\text { segundo o modelo. }\end{array}$ & $\begin{array}{l}\text { Informe as responsabilidades } \\
\text { atribuídas ao papel de "Time de } \\
\text { planejamento estratégico de } \\
\text { produto" segundo o modelo. }\end{array}$ \\
\hline 15 & $\begin{array}{l}\text { Avaliar a } \\
\text { complexidade do } \\
\text { processo de } \\
\text { design }\end{array}$ & $\begin{array}{l}\text { Informe o número de papéis envolvidos } \\
\text { na fase de "Projeto informacional". }\end{array}$ & $\begin{array}{l}\text { Informe o número de papéis } \\
\text { envolvidos na fase de } \\
\text { "Lançamento". }\end{array}$ \\
\hline
\end{tabular}

Este roteiro foi colocado na forma de um questionário online, onde, para um dado propósito, o usuário realizava a tarefa $A$ (no modelo $A$ ), em seguida a tarefa $B$ (no modelo B) e ao final respondia a questão com a escala comparativa (explicada no item 3.6.4) em relação à facilidade de execução das tarefas. No Apêndice $F$ Exemplo da apresentação do roteiro de tarefas para, a sequência de telas para o primeiro propósito é mostrada, a fim de exemplificar o procedimento. Optou-se por utilizar um formulário eletrônico online para facilitar o processamento das respostas.

\subsubsection{Dados coletados nos testes de usabilidade}

Os teste de usabilidade duraram em média de 01h30min cada um, e foram realizados com 14 usuários de acordo com os métodos expostos no item 3.5.2. A seguir seguem os principais resultados obtidos.

\subsubsection{Eficácia}

Foram elaborados dois gráficos, um considerando o número de usuários que atingiu cada tipo de sucesso (total, sucesso parcial e falha) (Figura 53), e outro mais 
detalhado, com informações sobre o tipo de estratégia empregada pelo usuário para a realização das tarefas (ideal ou não ideal) e pedidos de ajuda (Figura 54).

O gráfico da Figura 53 mostrou que apenas duas tarefas não atingiram 0 mínimo de 50\% de eficácia (7 usuários) em ambos os protótipos: a tarefa 5 e a tarefa 15. Ambas as tarefas eram relacionadas ao propósito "Definir entregas ou milestones padrão". Por não atingir o índice mínimo de eficácia, estas tarefas não foram consideradas para as demais análises (métricas de eficiência, auto-reportadas e comparativas e combinadas).

A tarefa 5 consistia em:

- Informe a principal entrega da fase "Projeto informacional", ou

- Informe a principal entrega da fase "Lançamento".

$\mathrm{Na}$ tarefa 5, os usuários tiveram, na sua maioria, as seguintes dificuldades:

- Protótipo A: Apesar da apresentação realizada antes do teste, os usuários não se lembravam da vista de fases, gates e entregas principais, única que possuía a informação solicitada.

- Protótipo B: O protótipo $B$ não possuía construto para a representação de entregas principais, apenas para objetivo geral da fase. Apenas dois usuários notaram isso e deram a resposta correta, ou seja, "não é possível identificar".

A tarefa 15 consistia em:

- Informe o número de papéis envolvidos na fase de "Projeto informacional", ou

- Informe o número de papéis envolvidos na fase de "Lançamento".

Ambas as tarefas eram relacionadas ao propósito "Avaliar a complexidade do processo de design". A tarefa 15 exigia memorização de mais de três elementos pelos usuários para fornecer a resposta correta. Sendo assim, um grande índice de erros era esperado.

Já o gráfico da Figura 54 mostra que as tarefas 8, 10 e 14 (três tarefas) no protótipo A tiveram índices de eficácia total com estratégia ideal menores que 50\% ( 7 usuários), enquanto que o mesmo se passou com as tarefas de 7 a 13 (sete tarefas) no protótipo B. 


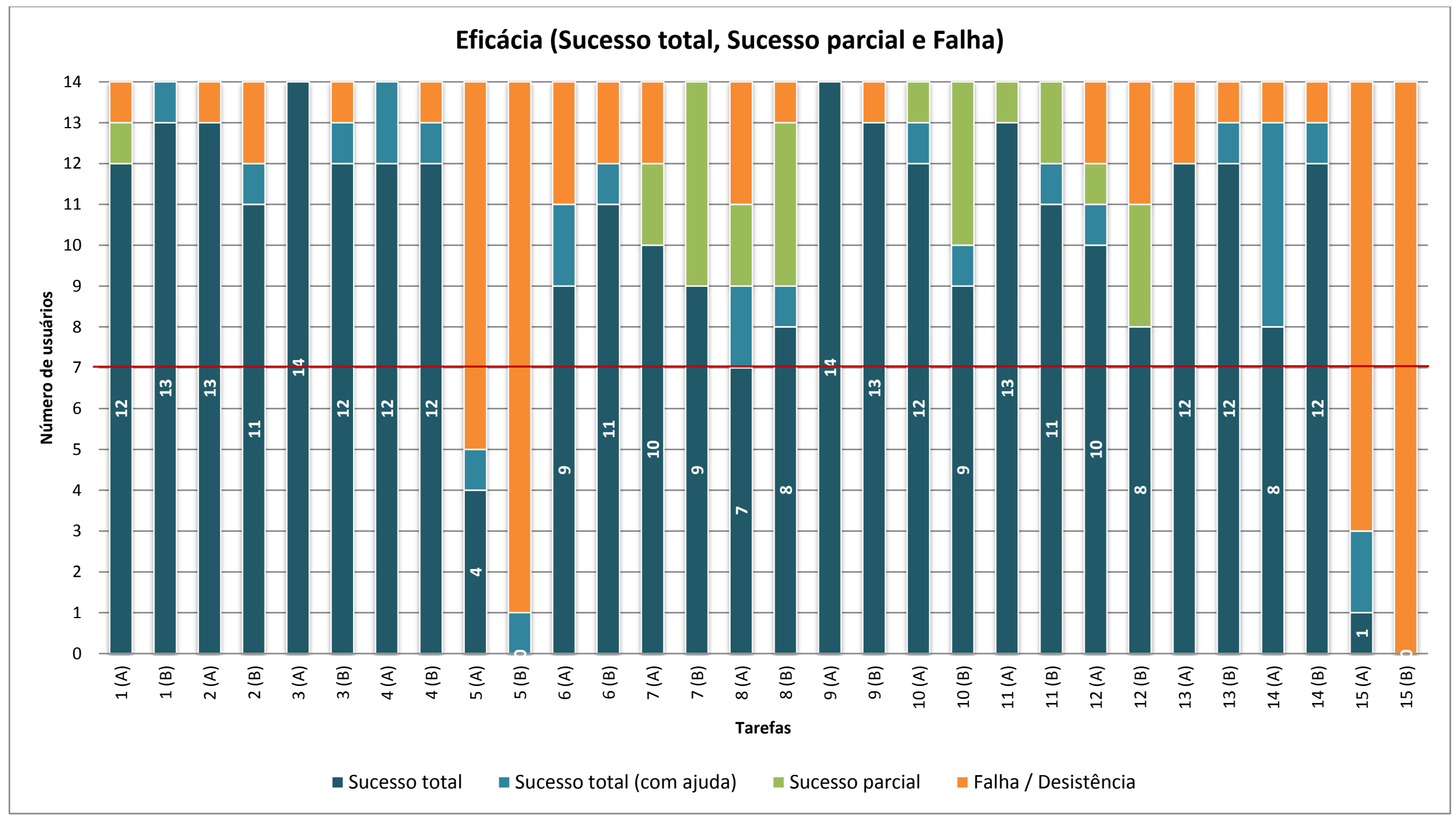

Figura 53 - Eficácia (Sucesso total, Sucesso parcial e Falha) 


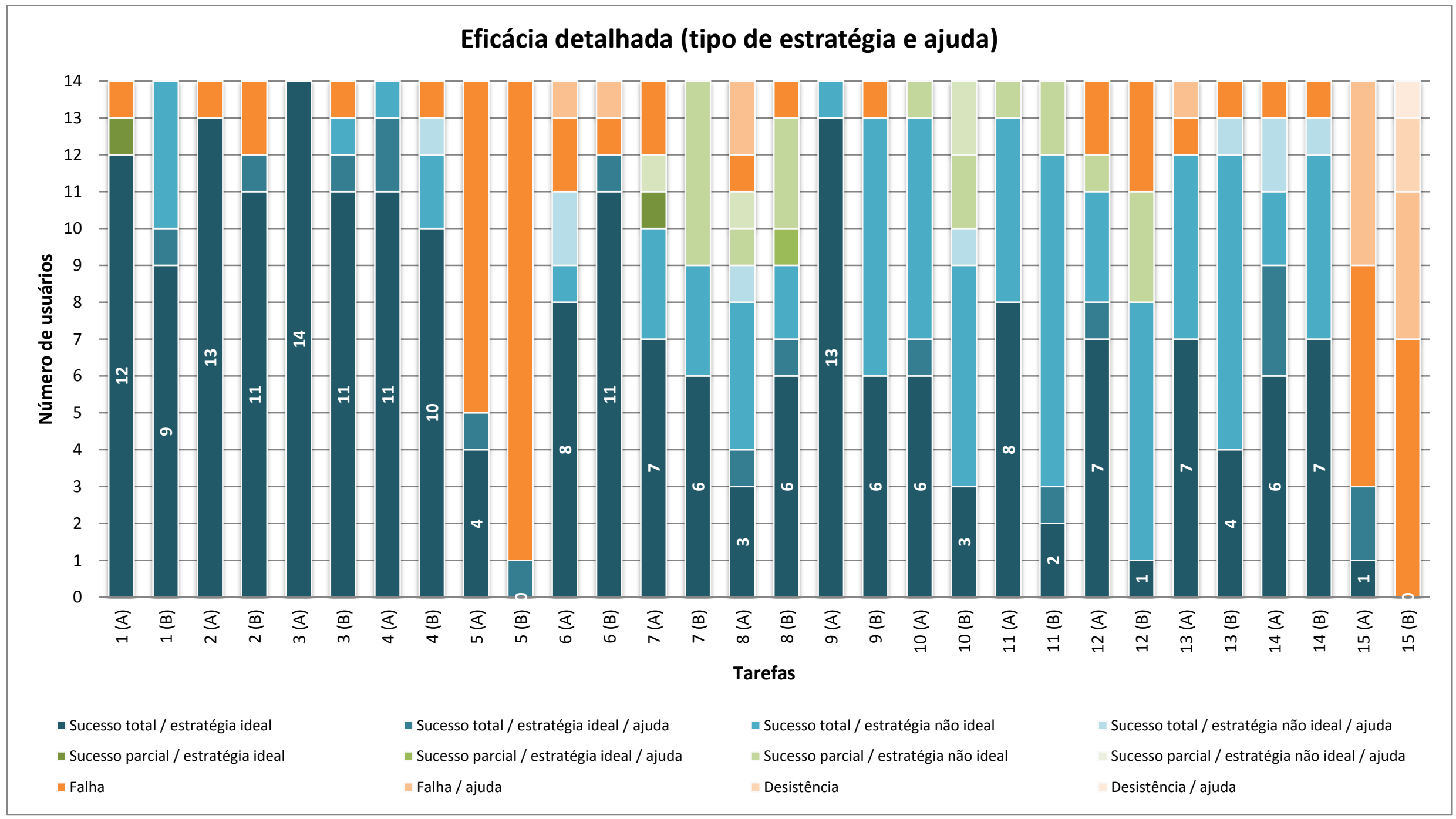

Figura 54 - Eficácia detalhada (tipo de estratégia e ajuda) 


\subsubsection{Eficiência}

As métricas de eficiência coletadas foram o número de ações por tarefa e os segundos por tarefa, conforme já exposto no item 3.5.2. Foram considerados para a análise dos dados de eficiência apenas os usuários que tiveram sucesso total em ambos os protótipos para uma dada tarefa, conforme recomendação de Tullis e Albert (2008). A utilização das respostas dos usuários que tiveram sucesso total em ambas as tarefas garante que eles as compreenderam perfeitamente e aumenta as chances de que eles tenham avaliado os protótipos a partir de uma mesma base de comparação. Dessa forma, a amostra analisada para cada tarefa variou em tamanho (para algumas tarefas foram consideradas 11 dos 14 usuários, para outras 9 dos 14 usuários, etc.).

O gráfico da Figura 55 mostra a média do número de ações empregadas pelos usuários para a realização das tarefas. As médias de ações por tarefa do protótipo A aparece em azul, e as médias de ações por tarefa do protótipo B aparecem em vermelho. As barras em tom mais claro dão o número mínimo de ações necessárias para realizar a tarefa, de acordo com o gabarito. A média de ações por tarefa para a tarefa 3 no protótipo A não aparece representada porque é igual a 0 (a informação necessária estava na página inicial do modelo, dispensando ações pelo usuário). As linhas verticais em preto dão o intervalo de confiança de $95 \%$ dos dados.

O gráfico da Figura 56 mostra a porcentagem de esforço a mais que foi empregada pelos usuários em relação ao mínimo suficiente de ações para realizar a tarefa, considerando a estratégia ideal do Apêndice $\mathrm{H}$ - Sequência preferencial de ações necessárias (estratégia ideal) para cumprir cada tarefa. Em 10 tarefas das 13 realizadas, o esforço a mais empregado em relação ao mínimo no protótipo A foi menor do que o esforço a mais empregado em relação ao mínimo no protótipo $\mathrm{B}$.

É possível observar que o protótipo A exigiu um número menor de ações por tarefa que o protótipo B em 11 das 13 tarefas. De acordo com o teste t de student, a diferença entre os dois protótipos pode ser considerada estatisticamente significativa em 8 destas tarefas: 1, 2, 3, 4, 9, 10, 12 e 13. 
A diferença entre as médias de todas as outras tarefas (inclusive as em que o protótipo $B$ teve vantagem) foram consideradas sem relevância estatística pelo teste t de student. Isto significa que, com a amostra disponível, para estas ultimas tarefas, não é possível garantir que os modelos sejam diferentes com 95\% de confiança.

O gráfico da Figura 57 mostra a média de segundos utilizados pelos usuários para realização das tarefas. As médias de segundos por tarefa do protótipo A aparecem em azul, e as médias de segundos por tarefa do protótipo B aparecem em vermelho. As linhas verticais em preto dão o intervalo de confiança de $95 \%$ dos dados. Em 12 das 13 tarefas o protótipo A teve uma média menor de segundos por tarefa que o protótipo B. Em 8 destas tarefas $(1,2,3,4,9,10,11,13)$ esta diferença pode ser considerada estatisticamente significativa a partir da análise pelo teste $t$ de student.

A diferença entre as médias de todas as outras tarefas (inclusive a em que 0 protótipo $B$ teve vantagem) foram consideradas sem relevância estatística pelo teste t de student. Isto significa que, para essas tarefas, com a amostra disponível não é possível garantir que os modelos sejam diferentes com 95\% de confiança.

Os dados utilizados para a elaboração dos gráficos, bem como os resultados dos testes t de student estão disponíveis no Apêndice $L$ - Estatistica descritiva e teste $t$ de student para métricas de eficiência. 


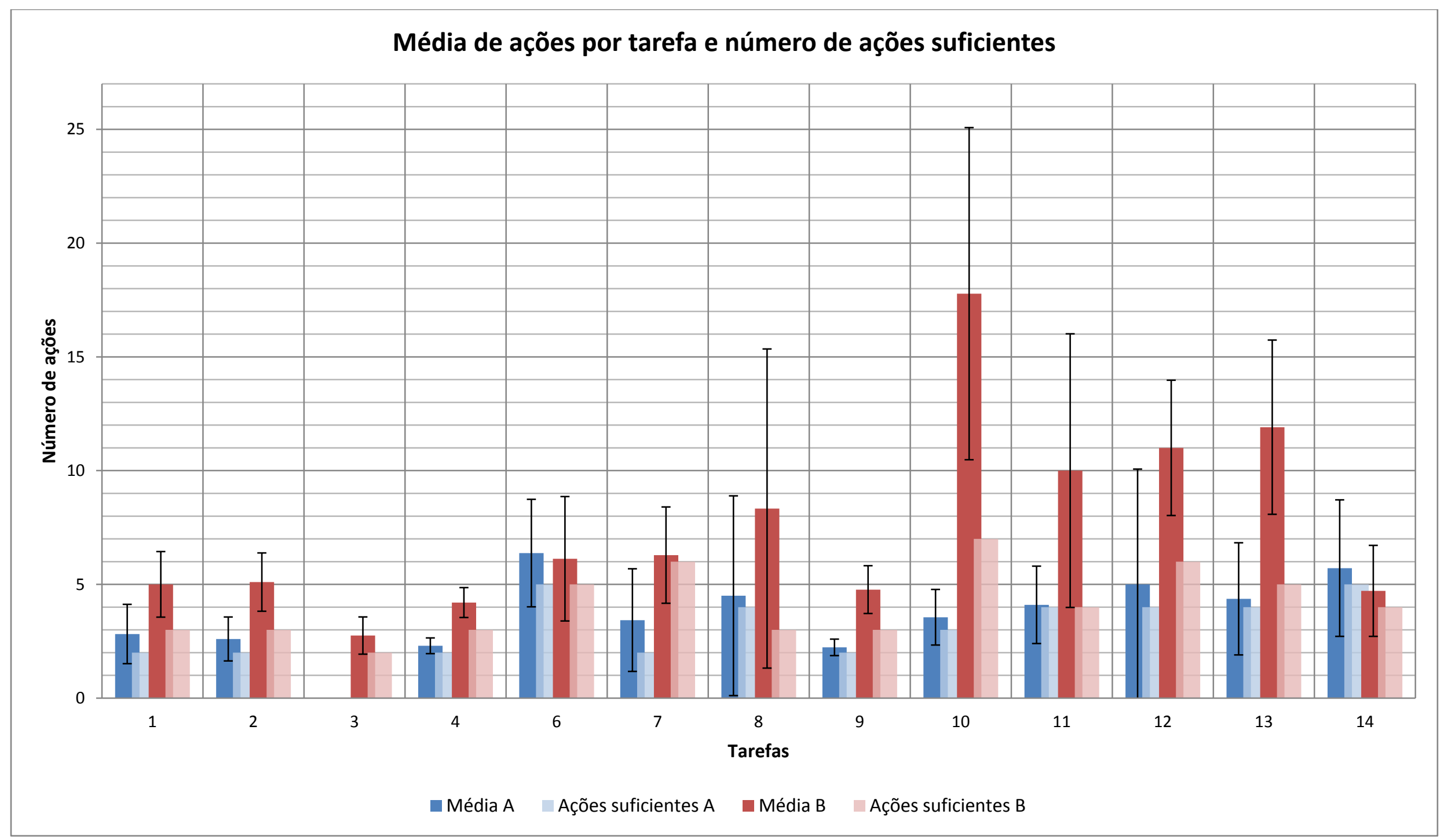

Figura 55 - Média de ações por tarefa e número de ações suficientes para realização das tarefas de acordo com a estratégia ideal. 


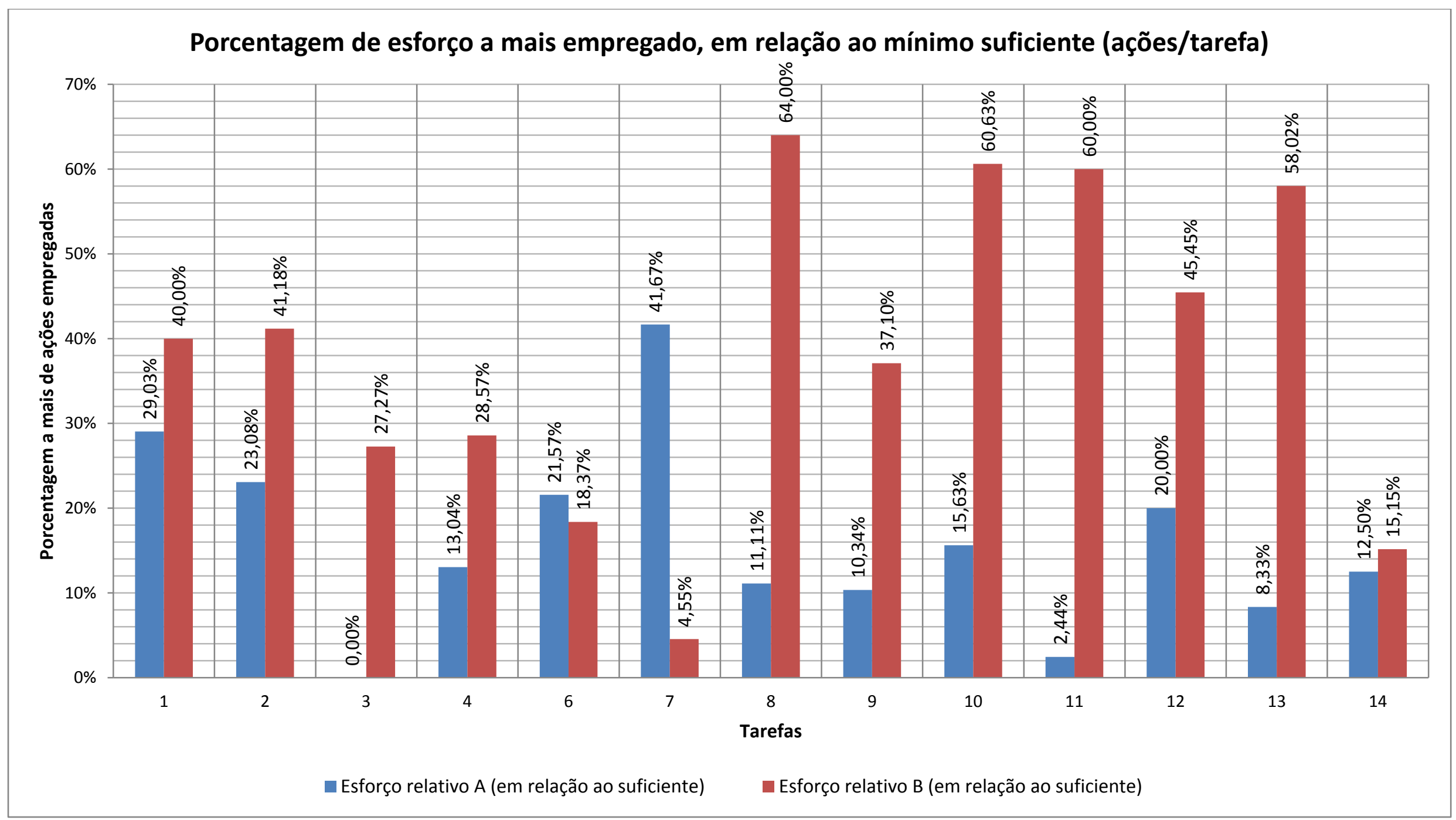

Figura 56 - Porcentagem de esforço a mais empregado (ações) pelos usuários para realizar uma tarefa, em relação ao mínimo de ações necessárias de acordo com a estratégia ideal para cada protótipo. 


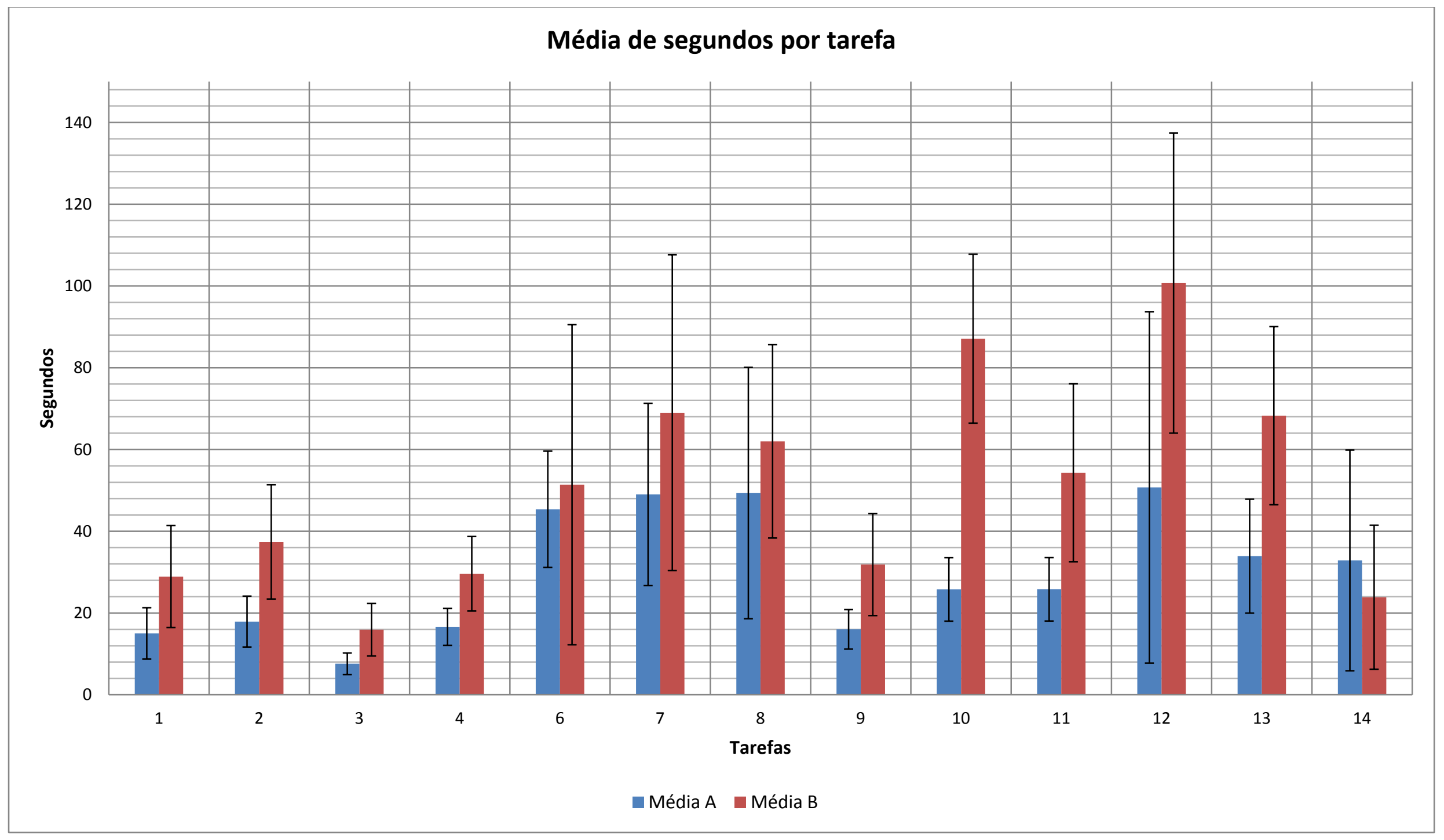

Figura 57 - Média de segundos por tarefa 


\subsubsection{Métricas auto-reportadas (Satisfação)}

Assim como para as métricas de eficiência, apenas foram considerados para a análise dos dados de satisfação os usuários que tiveram sucesso total em ambos os protótipos para uma dada tarefa, conforme recomendação de Tullis e Albert (2008). A utilização das respostas dos usuários que tiveram sucesso total em ambas as tarefas garante que eles as compreenderam perfeitamente e aumenta as chances de que eles tenham avaliado os protótipos a partir de uma mesma base de comparação. Dessa forma, a amostra analisada para cada tarefa variou em tamanho (para algumas tarefas foram consideradas 11 dos 14 usuários, para outras 9 dos 14 usuários, etc.).

No gráfico da Figura 58 é possível observar que o protótipo A foi considerado mais fácil pelos usuários em 12 das 13 tarefas (colunas com valores referentes ao eixo esquerdo do gráfico). Porém, para apenas 7 destas tarefas o índice de concordância ficou acima de 0,5 (representado pelos pontos plotados, com valores referentes ao eixo do lado direito do gráfico). $\mathrm{Na}$ tarefa em que o protótipo $\mathrm{B}$ foi considerado mais fácil, o nível de concordância também ficou acima de 0,5 para ambos os protótipos. 


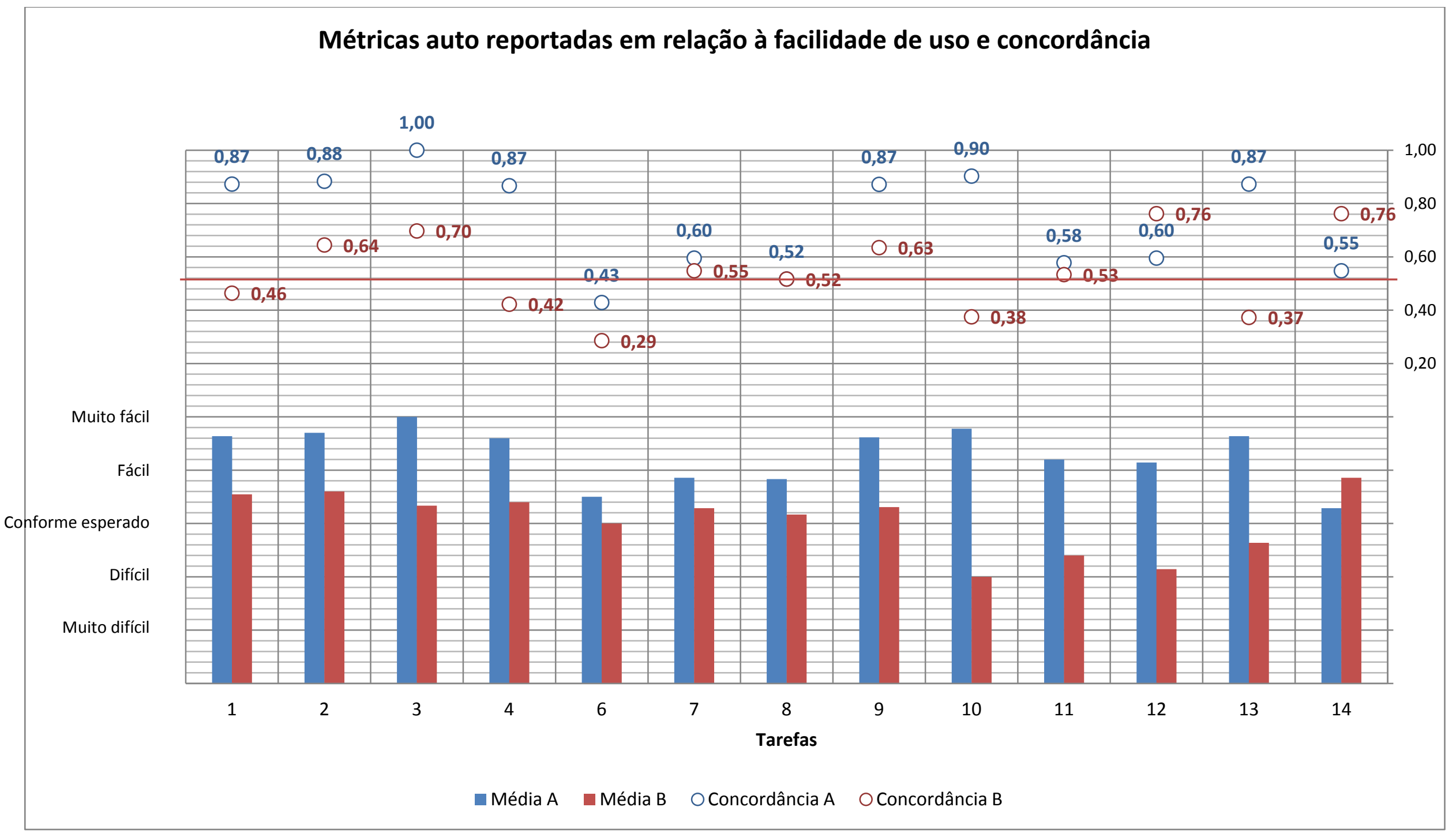

Figura 58 - Métricas auto reportadas em relação à facilidade de uso e concordância 


\subsubsection{Métricas comparativas e combinadas}

As métricas comparativas e combinadas foram realizadas com os valores de eficácia, eficiência e satisfação relativos entre os protótipos. Por exemplo, a eficácia relativa de $B$ em relação a $A$ mostra o esforço a mais que foi demandado do usuário no protótipo $B$ em relação ao protótipo $A$, em porcentagem, para a realização de uma tarefa. $O$ gráfico da Figura 59 resume as porcentagens relativas do protótipo $B$ em relação ao A para eficácia, satisfação, esforço (ações) e tempo (segundos). Porcentagens positivas para esforço e tempo são favoráveis para o protótipo $A$, assim como porcentagens negativas para eficácia e satisfação. 


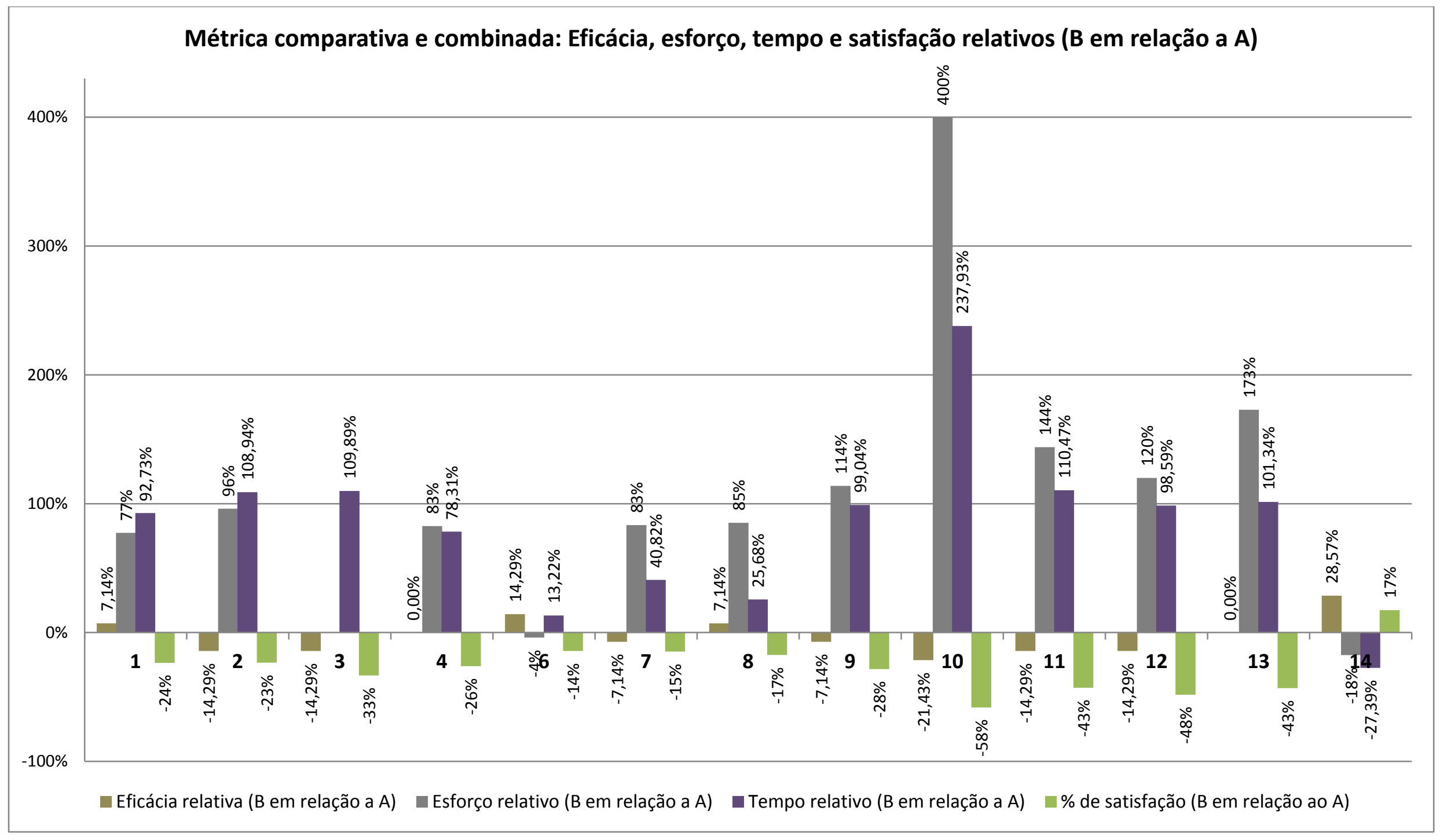

Figura 59 - Métricas comparativas e combinadas: Eficácia, esforço, tempo e satisfação relativos (B em relação a A) 



\section{Análise dos resultados e conclusões}

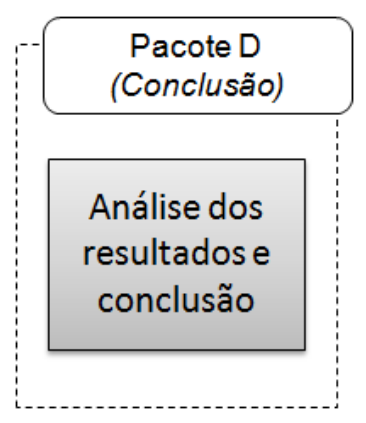

Figura 60 - Entregas do pacote de trabalho D

A análise é realizada por grupos de propósitos, a fim de deixar mais evidentes os resultados desta pesquisa. Ao final faz-se uma análise geral dos resultados. É importante relembrar neste ponto que mais de uma tarefa correspondia a um mesmo propósito (item 4.3.2), por isso o número de propósitos analisados é menor que o número de tarefas (10 propósitos e 15 tarefas).

Para dois dos propósitos analisados (5 e 15), nenhum dos dois protótipos é eficaz (Tabela 23). Provavelmente isso é devido a limitações dos protótipos, que podem ser sanadas em trabalhos futuros (mais detalhadas no item 5.1).

Tabela 23 - Propósitos para os quais nenhum protótipo testado é eficaz

\begin{tabular}{llll}
\hline & $\begin{array}{l}\text { Propósitos dos } \\
\text { usuários }\end{array}$ & Tarefa de leitura A & Tarefa de leitura B \\
\hline $\mathbf{5}$ & $\begin{array}{l}\text { Definir entregas } \\
\text { ou milestones } \\
\text { padrão }\end{array}$ & $\begin{array}{l}\text { Informe a principal entrega da fase } \\
\text { "Projeto informacional". }\end{array}$ & $\begin{array}{l}\text { Informe a principal entrega da } \\
\text { fase "Lançamento". }\end{array}$ \\
$\mathbf{1 5}$ & $\begin{array}{l}\text { Avaliar a } \\
\text { complexidade do } \\
\text { processo de } \\
\text { design }\end{array}$ & $\begin{array}{l}\text { Informe o número de papéis envolvidos } \\
\text { na fase de "Projeto informacional". }\end{array}$ & $\begin{array}{l}\text { Informe o número de papéis } \\
\text { envolvidos na fase de } \\
\text { "Lançamento". }\end{array}$ \\
\hline
\end{tabular}

Para os propósitos relacionados com as tarefas 6, 7/8 e 11/12 (Tabela 24), com a amostra analisada não é possível concluir com 95\% de confiança que os protótipos apresentaram diferenças em relação à eficiência. $O$ protótipo $B$ mostrou maior eficiência que o protótipo A para o propósito 6 , e menor eficiência para os propósitos 7,8 e 11/12, porém mais testes são necessários para garantir que essa 
diferença tenha significância estatística (possa ser estendida à toda a população) para o nível de confiança estabelecido.

Em relação a esse grupo de propósitos, apenas é possível elaborar uma conclusão em relação à eficácia e satisfação:

- Para os propósitos relacionados com as tarefas 7 e 11/12, o protótipo A foi mais eficaz que o protótipo $B$; o inverso é verdadeiro para os propósitos 6 e 8 .

- Para os propósitos relacionados com as tarefas 7, 8 e 11/12, o protótipo $\mathrm{A}$ foi considerado mais fácil pelos usuários que $\circ \mathrm{B}$ (com concordância acima de 0,5).

Concluindo, apenas os propósitos 7 e 11/12 são atendidos pelo protótipo A com maior eficácia e satisfação dos usuários que o protótipo B.

Tabela 24 - Propósitos para os quais não é possível garantir com 95\% de confiança que há diferença em relação à eficiência dos protótipos.

\begin{tabular}{|c|c|c|c|}
\hline & $\begin{array}{l}\text { Propósitos dos } \\
\text { usuários }\end{array}$ & Tarefa de leitura $\mathrm{A}$ & Tarefa de leitura B \\
\hline 6 & $\begin{array}{l}\text { Definir padrões } \\
\text { de qualidade } \\
\text { para as entregas } \\
\text { padrão }\end{array}$ & $\begin{array}{l}\text { Informe os padrões de qualidade que o } \\
\text { modelo fornece para a entrega "Estrutura } \\
\text { do produto (BOM)" na fase de "Projeto } \\
\text { detalhado". }\end{array}$ & $\begin{array}{l}\text { Informe os padrões de } \\
\text { qualidade que o modelo fornece } \\
\text { para a entrega "Concepção } \\
\text { escolhida para o produto" na } \\
\text { fase de "Projeto conceitual". }\end{array}$ \\
\hline 7 & $\begin{array}{l}\text { Identificar } \\
\text { dependência/pre } \\
\text { cedência de } \\
\text { atividades/funçõe } \\
\text { s via inputs e } \\
\text { outputs }\end{array}$ & $\begin{array}{l}\text { Informe as entregas da atividade } \\
\text { "Promover marketing de lançamento" que } \\
\text { são entradas para a atividade "Lançar } \\
\text { produto" na fase de "Lançamento". }\end{array}$ & $\begin{array}{l}\text { Informe as entregas da } \\
\text { atividade "Detalhar ciclo de vida } \\
\text { do produto e definir seus } \\
\text { clientes" que são entradas para } \\
\text { a atividade "Identificar os } \\
\text { requisitos dos clientes do } \\
\text { produto" na fase de "Projeto } \\
\text { informacional". }\end{array}$ \\
\hline 8 & $\begin{array}{l}\text { Identificar } \\
\text { dependência/pre } \\
\text { cedência de } \\
\text { atividades/funçõe } \\
\text { s via inputs e } \\
\text { outputs }\end{array}$ & $\begin{array}{l}\text { Informe as atividades que dependem das } \\
\text { entregas da seguinte atividade para } \\
\text { serem iniciadas: "1.4.2 - Modelar } \\
\text { funcionalmente o produto" da fase de } \\
\text { "Projeto conceitual". }\end{array}$ & $\begin{array}{l}\text { Informe as atividades que } \\
\text { dependem das entregas da } \\
\text { seguinte atividade para serem } \\
\text { iniciadas: "1.4.7 - Definir } \\
\text { ergonomia e estética" da fase } \\
\text { de "Projeto conceitual". }\end{array}$ \\
\hline 11 & $\begin{array}{l}\text { Relacionar } \\
\text { papéis a } \\
\text { atividades, } \\
\text { entregas e } \\
\text { demais } \\
\text { elementos do } \\
\text { processo }\end{array}$ & $\begin{array}{l}\text { Informe as atividades da fase de } \\
\text { "Preparação da produção" com as quais } \\
\text { o "Gerente de qualidade" está } \\
\text { relacionado. }\end{array}$ & $\begin{array}{l}\text { Informe as atividades da fase de } \\
\text { "Projeto informacional" com as } \\
\text { quais o "Gerente de marketing" } \\
\text { está relacionado. }\end{array}$ \\
\hline 12 & $\begin{array}{l}\text { Relacionar } \\
\text { papéis a } \\
\text { atividades, às } \\
\text { entregas e aos } \\
\text { demais } \\
\text { elementos do } \\
\text { processo }\end{array}$ & $\begin{array}{l}\text { Informe as entregas com as quais o } \\
\text { "Gerente de design" está relacionado na } \\
\text { fase de "Projeto conceitual" (tanto } \\
\text { entregas de entrada quanto de saída). }\end{array}$ & $\begin{array}{l}\text { Informe as entregas com as } \\
\text { quais o "Gerente de } \\
\text { suprimentos" está relacionado } \\
\text { na fase de "Preparação da } \\
\text { produção" (tanto entregas de } \\
\text { entrada quanto de saída). }\end{array}$ \\
\hline
\end{tabular}


Para o propósito relacionado com as tarefas 13/14 (Tabela 25) foram obtidos resultados discrepantes. Para a tarefa 13, o protótipo A é claramente mais eficaz, eficiente e satisfatório que o B. Para o propósito 14, o inverso é verdadeiro, com a ressalva de que não é possível afirmar com 95\% de confiança que há diferença entre os protótipos em relação à eficiência nessa atividade. Essa diferença provavelmente é devida ao fato das responsabilidades dos papéis, no protótipo $A$, não estarem tão evidentes para o usuário como estavam no protótipo B.

Tabela 25 - Propósito que teve resultados discrepantes para suas tarefas

\begin{tabular}{|c|c|c|c|}
\hline & $\begin{array}{l}\text { Propósito dos } \\
\text { usuários }\end{array}$ & Tarefa de leitura A & Tarefa de leitura B \\
\hline 13 & $\begin{array}{l}\text { Definir } \\
\text { responsabilidades } \\
\text { e habilidades } \\
\text { padrão para } \\
\text { papéis e pessoal }\end{array}$ & $\begin{array}{l}\text { Informe as melhores práticas de que o } \\
\text { "Gerente de suprimentos" necessitará } \\
\text { lançar mão na fase de "Projeto } \\
\text { conceitual". }\end{array}$ & $\begin{array}{l}\text { Informe as melhores práticas } \\
\text { sugeridas de que o "Gerente de } \\
\text { vendas" necessitará lançar mão } \\
\text { na fase de "Projeto detalhado". }\end{array}$ \\
\hline 14 & $\begin{array}{l}\text { Definir } \\
\text { responsabilidades } \\
\text { e habilidades } \\
\text { padrão para } \\
\text { papéis e pessoal }\end{array}$ & $\begin{array}{l}\text { Informe as responsabilidades atribuídas } \\
\text { ao papel de "Gerente de projetos" } \\
\text { segundo o modelo. }\end{array}$ & $\begin{array}{l}\text { Informe as responsabilidades } \\
\text { atribuídas ao papel de "Time de } \\
\text { planejamento estratégico de } \\
\text { produto" segundo o modelo. }\end{array}$ \\
\hline
\end{tabular}

E por fim, com base nos dados obtidos, pode-se considerar que para 6 dos 10 propósitos $(1,2,3,4,9 / 10$, e 13), o protótipo A é claramente mais eficiente e mais satisfatório que o protótipo B (Tabela 26). O protótipo B exigiu significativamente mais esforço e tempo para a realização das tarefas relacionadas com estes propósitos, e também foi considerado significativamente mais difícil. Em relação à eficácia, de modo geral o protótipo $A$ foi tanto ou mais eficaz em todos estes propósitos, com exceção do propósito 1, onde o protótipo B foi discretamente mais eficaz (7,14\%). A conclusão, portanto, é que em relação a este grupo de propósitos o objetivo desta pesquisa foi atingido.

Tabela 26 - Propósitos para os quais é possível concluir que o protótipo A é mais eficaz, eficiente e satisfatório que o protótipo B.

\begin{tabular}{llll}
\hline & $\begin{array}{l}\text { Propósitos dos } \\
\text { usuários }\end{array}$ & Tarefa de leitura A & Tarefa de leitura B \\
\hline $\mathbf{1}$ & $\begin{array}{l}\text { Definir atividades } \\
\text { padrão e } \\
\text { preferidas }\end{array}$ & $\begin{array}{l}\text { Informe as três primeiras atividades da } \\
\text { fase de "Projeto informacional". }\end{array}$ & $\begin{array}{l}\text { Informe as três primeiras } \\
\text { atividades da fase de } \\
\text { "Lançamento". }\end{array}$ \\
$\begin{array}{l}\text { Definir/sugerir } \\
\text { sequencia para } \\
\text { as atividades }\end{array}$ & $\begin{array}{l}\text { Você acaba de concluir a atividade } \\
\text { "Definir requisitos do produto" da fase de } \\
\text { "Projeto informacional". Qual a próxima } \\
\text { atividade a ser realizada segundo o }\end{array}$ & $\begin{array}{l}\text { Você acaba de concluir a } \\
\text { atide "Selecionar a } \\
\text { concepção do produto" da fase } \\
\text { de "Projeto conceitual". Qual a }\end{array}$ \\
\hline
\end{tabular}




\begin{tabular}{|c|c|c|c|}
\hline & $\begin{array}{l}\text { Propósitos dos } \\
\text { usuários }\end{array}$ & Tarefa de leitura $A$ & Tarefa de leitura B \\
\hline & & modelo? & $\begin{array}{l}\text { próxima atividade a ser } \\
\text { realizada segundo o modelo? }\end{array}$ \\
\hline 3 & $\begin{array}{l}\text { Mostrar relação } \\
\text { hierárquica entre } \\
\text { atividades }\end{array}$ & $\begin{array}{l}\text { Informe as duas primeiras fases que } \\
\text { compõem a macrofase de } \\
\text { "Desenvolvimento". }\end{array}$ & $\begin{array}{l}\text { Informe as duas últimas fases } \\
\text { que compõem a macrofase de } \\
\text { "Desenvolvimento". }\end{array}$ \\
\hline 4 & $\begin{array}{l}\text { Definir entregas } \\
\text { ou milestones } \\
\text { padrão }\end{array}$ & $\begin{array}{l}\text { Informe as entregas de saída da } \\
\text { atividade "Detalhar ciclo de vida do } \\
\text { produto e definir seus clientes" da fase } \\
\text { de "Projeto informacional". }\end{array}$ & $\begin{array}{l}\text { Informe as entregas de saída da } \\
\text { atividade "Promover marketing } \\
\text { de lançamento" da fase de } \\
\text { "Lançamento". }\end{array}$ \\
\hline 9 & $\begin{array}{l}\text { Definir } \\
\text { ferramentas e } \\
\text { templates padrão }\end{array}$ & $\begin{array}{l}\text { Informe as melhores práticas sugeridas } \\
\text { para a realização da atividade "Detalhar } \\
\text { ciclo de vida do produto e definir seus } \\
\text { clientes" da fase de "Projeto } \\
\text { informacional". }\end{array}$ & $\begin{array}{l}\text { Informe as melhores práticas } \\
\text { sugeridas para a realização da } \\
\text { atividade "Otimizar produção" } \\
\text { da fase de "Preparação da } \\
\text { produção". }\end{array}$ \\
\hline 10 & $\begin{array}{l}\text { Definir } \\
\text { ferramentas e } \\
\text { templates padrão }\end{array}$ & $\begin{array}{l}\text { Você é um especialista em "Abstração } \\
\text { orientada". Informe as atividades nas } \\
\text { quais essa melhor prática é empregada } \\
\text { na fase de "Projeto conceitual". }\end{array}$ & $\begin{array}{l}\text { Você é um especialista em } \\
\text { "QFD (Quality Function } \\
\text { Deployment)". Informe as } \\
\text { atividades nas quais essa } \\
\text { melhor pratica é empregada na } \\
\text { fase de "Projeto informacional". }\end{array}$ \\
\hline 13 & $\begin{array}{l}\text { Definir } \\
\text { responsabilidade } \\
\text { s e habilidades } \\
\text { padrão para } \\
\text { papéis e pessoal }\end{array}$ & $\begin{array}{l}\text { Informe as melhores práticas de que o } \\
\text { "Gerente de suprimentos" necessitará } \\
\text { lançar mão na fase de "Projeto } \\
\text { conceitual". }\end{array}$ & $\begin{array}{l}\text { Informe as melhores práticas } \\
\text { sugeridas de que o "Gerente de } \\
\text { vendas" necessitará lançar mão } \\
\text { na fase de "Projeto detalhado". }\end{array}$ \\
\hline
\end{tabular}

Considerando que, para eficácia, eficiência e satisfação foram analisados ao todo 8 propósitos dos 10 selecionados para o roteiro de tarefas (os propósitos 5 e 15 foram excluídos por não apresentar o nível mínimo de eficácia), pode-se concluir que o protótipo A foi mais eficaz, eficiente e satisfatório que o protótipo B para a maioria dos propósitos analisados. Além disso, o número maior de tarefas classificadas em sucesso total com estratégia ideal no protótipo A pode indicar que as estratégias ideais estavam mais evidentes para o usuário nesse protótipo que no protótipo B (gráfico da Figura 54). Outro dado que reforça esta hipótese é que, em 10 tarefas das 14 realizadas, o esforço a mais empregado em relação ao mínimo no protótipo $A$ foi menor do que o esforço a mais empregado em relação ao mínimo no protótipo $\mathrm{B}$, considerando o número de ações necessárias para realizar uma tarefa (gráfico da Figura 56).

Essa conclusão pode indicar que a representação do fluxo lógico de atividades de um processo, como a existente no eEPC, não é a mais adequada para a maior parte dos propósitos analisados nesta pesquisa. Já a representação analógica proposta no protótipo A parece mais adequada, pois permite uma visualização de alto nível sintética das informações relevantes para os propósitos de um usuário de modelos de referência do PDP. 
Como a órbita e os ícones do protótipo A não foram testados isoladamente, mas sim combinados no protótipo, não é possível afirmar o quanto cada um desses conceitos contribui para o melhor desempenho do protótipo A. A pesquisadora pode apenas registrar suas impressões a partir da observação dos usuários durante os testes:

- Os usuários se sentem confortáveis na vista de tabela (Figura 36). Apesar de conter muita informação, ela está ordenada. O usuário tem a sensação de que está vendo todo o conteúdo relevante de uma só vez, e tende a preferir esta vista. Em alguns casos, apesar de não ser a estratégia ideal, os usuários preferiram esta vista às vistas de órbitas para a realização de algumas atividades.

- Muitos dos erros ocorridos nas tarefas foram devidos ao fato do usuário não perceber que havia mais informações nas vistas que não estavam evidentes. Por exemplo, ao usar a vista de tabela ao invés da vista de órbita nas atividades, onde a órbita seria mais adequada, o usuário poderia achar uma ocorrência da informação desejada e não notar as outras, achando que já havia encontrado todas as informações necessárias.

- Mais de um usuário comentou que foi mais fácil memorizar o significado dos ícones em relação aos símbolos. Mais de um usuário também se mostrou confuso com os símbolos empregados na modelagem eEPC, vários deles pedindo ajuda sobre seu significado no decorrer do teste.

\subsection{Limitações e sugestões de trabalhos futuros}

Como a análise do atendimento dos protótipos aos propósitos dos usuários foi feita por meio de tarefas, uma limitação deste trabalho é o quanto as tarefas formuladas realmente representam seus respectivos propósitos. A pesquisadora procurou abranger o máximo possível as variantes de interpretação que um propósito pode oferecer, mas se isso foi suficiente para dar um resultado confiável é algo passível de maiores investigações. Podem ser úteis trabalhos futuros que procurem entender melhor os propósitos dos usuários de um modelo de PDP em 
ambientes reais de uso destes modelos, que possam dessa maneira levantar as tarefas realizadas por esses usuários no seu dia a dia, relacionando-as com os propósitos.

Problemas na compreensão das tarefas pelos usuários podem ter afetado os resultados. Durante os testes, alguns usuários dentre dos que não obtiveram sucesso total chegaram a comentar que não haviam entendido "o que era para fazer". Problemas de usabilidade dos próprios protótipos (ícones confusos, vistas pouco aparentes ou outros problemas nas interfaces) também foram observados durante os testes com os usuários, e constituem outra limitação. As sugestões de melhorias para os principais problemas encontrados, a serem realizadas em trabalhos futuros, estão listadas a seguir:

- Para melhor atender ao propósito $5^{25}$, é possível incrementar as vistas propostas (protótipo A) com um ícone especial para as entregas que são as principais de uma fase, garantindo que essa informação esteja disponível em mais vistas do processo. Para o protótipo $\mathrm{B}$, talvez seja interessante elaborar um símbolo para as principais entregas do processo.

- Uma mudança na vista de órbita centrada em um papel, no protótipo A, poderia contribuir para um melhor desempenho desse protótipo em relação à tarefa 14, que solicita informações sobre responsabilidades de um papel.

- Em relação ao propósito $15^{26}$, é possível oferecer o número total de elementos em cada coluna nas telas de tabela (protótipo A), para facilitar a identificação do número de papéis envolvidos em uma fase.

- Manter a barra de zoom no topo da tela quando a página é rolada para baixo no protótipo B foi uma solicitação feita por vários usuários.

O tamanho da amostra pode ter sido uma limitação neste trabalho, pois alguns dos resultados não tiveram significância estatística. Em estudos futuros, testes com um número maior de usuários podem confirmar que o protótipo $A$ teve melhor eficácia, eficiência e foi mais satisfatório que o protótipo $B$ em um número maior de propósitos que o observado nesta pesquisa.

\footnotetext{
25 "Definir entregas ou milestones padrão".

26 "Avaliar a complexidade do processo de design"
} 
Por fim, é necessário realizar mais estudos que possam confirmar que a representação analógica empregada no protótipo $A$ realmente tem papel relevante no seu melhor desempenho em relação à representação do fluxo lógico de atividades do protótipo B. Outros fatores podem ter interferido nos resultados, como por exemplo o uso de ícones que conferem maior qualidade à interface. Podem ser úteis estudos futuros que busquem isolar os elementos para testes mais focados. Por exemplo, testar a órbita com ícones comparada a uma órbita com símbolos, a fim de determinar o quanto o uso de ícones melhora a eficácia, eficiência e satisfação do usuário em relação às vistas. A autora deixa aqui registradas as suas percepções quando da interpretação dos resultados, que podem servir de ponto de partida para a formulação de hipóteses para pesquisas futuras:

- A órbita tem potencial para facilitar a visualização das informações relevantes para propósitos de modelos de referência em relação ao fluxo lógico de atividades. Porém, nem todos os usuários lançaram mão desse recurso. Por que razão isso ocorreu? É possível, com mais tempo de treinamento do usuário, garantir que a órbita é mais adequada para a representação de modelos de referência de PDP em relação aos modelos centrados em fluxo de informações?

- O uso de ícones parece ajudar o usuário a memorizar seu significado e realizar a tarefa de forma mais eficaz e eficiente. Como isso pode ser comprovado?

- As representações de fluxo lógico são importantes para outros propósitos de usuários de modelos de PDP, de maneira geral relacionados com a gestão e planejamento de projetos. As representações analógicas podem ser usadas em conjunto com as de fluxo lógico, visando à elaboração de modelos que atendam de maneira eficaz, eficiente e satisfatória a um conjunto mais amplo de propósitos. Estudos futuros podem desenvolver estes modelos e testálos para verificar seu desempenho. 


\subsection{Principais contribuições para a área de conhecimento}

As principais contribuições desta pesquisa para a área de conhecimento de modelagem de processos de PDP estão listadas a seguir:

- O melhor desempenho de representações analógicas (órbita, SIPOC) em relação às representações de fluxo lógico (eEPC) para modelos de referência de PDP, por proporcionarem um visão de alto nível sintética mais apropriada para os propósitos de usuários desse tipo de modelos.

- A revisão bibliográfica sistemática trouxe métodos de modelagem que não estavam listados nas revisões existentes sobre o tema na literatura. A revisão também levantou de forma mais completa as informações sobre cada um dos métodos listados, pois reúne informações dadas por diversos autores para sua descrição, variáveischave e atributos, propósitos, facilidade de atualização e forças e fraquezas em relação ao usuário.

- A lista de propósitos de modelos de referência de PDP, pois as pesquisas existentes na literatura enfatizam apenas os propósitos de gestão e planejamento de projetos de DP.

- A nova abordagem metodológica trazida por esta pesquisa para o estudo de modelos de PDP, que aplica conhecimentos advindos da área de design de interação e experiência do usuário em um tema até então pesquisado majoritariamente pela engenharia, computação e matemática.

- A possível relevância do uso de ícones ao invés de símbolos em modelos de processos.

- A ferramenta de modelagem desenvolvida, que pode ser utilizada para a modelagem de outros conteúdos. Ela pode ser utilizada inclusive para a instanciação de modelos de referência genéricos de PDP para modelos de referência específicos de uma organização. 


\section{Referências bibliográficas}

AGUILARSAVEN, R. Business process modelling: Review and framework. International Journal of Production Economics, v. 90, n. 2, p. 129-149, 2004.

ALEXANDER, C. Notes on the synthesis of form. Harvard University Press, 1964.

ALMEIDA BIOLCHINI, J. C. DE; MIAN, P. G.; NATALI, A. C. C.; CONTE, T. U.; TRAVASSOS, G. H. Scientific research ontology to support systematic review in software engineering. Advanced Engineering Informatics, v. 21, n. 2, p. 133-151, 2007.

AMARAL, D.C. Arquitetura para gerenciamento de conhecimentos explícitos sobre o processo de desenvolvimento de produto, 2002. Universidade de São Paulo.

ARAUJO, C. DE. Proposta de interface de painel digital interativo para planejamento de projetos, 2012. Universidade de São Paulo.

BARCZAK, G.; GRIFFIN, A.; KAHN, K. B. PERSPECTIVE: Trends and Drivers of Success in NPD Practices: Results of the 2003 PDMA Best Practices Study *. Journal of Product Innovation Management, v. 26, n. 1, p. 3-23, 2009.

BASU, A.; BLANNING, R. W.; SHTUB, A. Metagraphs in Hierarchical Modeling. Management Science, v. 43, n. 5, p. 623-639, 1997.

BESSANT, J.; FRANCIS, D. Implementing the new product development process. Technovation, v. 17, n. 4, p. 189-222, 1997.

BROWNING, T.R.; RAMASESH, R. V. A survey of activity network-based process models for managing product development projects. Production and Operations Management, v. 16, n. 2, p. 217-240, 2007.

BROWNING, TYSON R. The Many Views of a Process : Toward a Process Architecture Framework for Product Development Processes. Systems Engineering, v. 12, n. 1, p. 69-90, 2008.

BROWNING, TYSON R. On the alignment of the purposes and views of process models in project management. Journal of Operations Management, v. 28, n. 4, p. 316332, 2010. Elsevier B.V.

BROWNING, TYSON R.; FRICKE, E.; NEGELE, H. Key concepts in modeling product development processes. Systems Engineering, v. 9, n. 2, p. 104-128, 2006.

BURRELL, G.; MORGAN, G. Sociological Paradigms and Organizational Analysis: Elements of the Sociology of Corporate Life. Reprinted ed. Ashgate Publishing, 1979.

CHECKLAND, P. Systems thinking, systems practice. John Wiley, 1999.

CLARK, K. B.; FUJIMOTO, T. Product development performance: strategy, organization, and management in the world auto industry. Harvard Business School Press, 1991. 
CLARK, K. B.; WHEELWRIGHT, S. C. Managing new product and process development: text and cases. Free Press, 1993.

CONFORTO, E. C.; AMARAL, DANIEL CAPALDO; SILVA, SERGIO LUIS DA. Roteiro para revisão bibliográfica sistemática : aplicação no desenvolvimento de produtos e gerenciamento de projetos. $8^{\circ}$ Congresso Brasileiro de Gestão de Desenvolvimento de Produto - CBGDP. Anais... p.1-12, 2011. Porto Alegre.

COOPER, R. G. Winning at new products. 3rd ed. Cambridge, Mass., M.I.T: Perseus Publishing, 2001.

COOPER, R. G.; KLEINSCHMIDT, E. J. Benchmarking the firm's critical sucess factors in new product development. Journal of Product Innovation Management, 1995.

CRAWFORD, C. M.; BENEDETTO, C. A. DI. New products management. 8th ed. McGraw-Hill/Irwin, 2006.

DAVENPORT, T H. Process innovation: reengineering work through information technology. Harvard Business School Press, 1993.

DAVENPORT, T. H. Reengenharia de Processos. Rio de Janeiro, 1994.

DESCHAMPS, J. P.; NAYAK, P. R. Produtos irresistíveis. Makron Books, 1997.

DOUMEINGTS, G.; VALLESPIR, B.; CHEN, D. Methodologies for designing CIM systems: A survey. Computers in Industry, 1995.

DYBÅ, T.; DINGS $\varnothing Y R, T$. Empirical studies of agile software development: A systematic review. Information and Software Technology, v. 50, n. 9-10, p. 833-859, 2008.

ENGWALL, M.; KLING, R.; WERR, A. Models in action: how management models are interpreted in new product development. R and D Management, v. 35, n. 4, p. 427-439, 2005.

FARRIS, J. A.; AKEN, E. M. VAN; LETENS, G.; ELLIS, K. P.; BO, J. A Structured Approach for Assessing the Effectiveness of Engineering Design T ... Management, 2007.

FETTKE, P.; LOOS, P. Using Reference Models for Business Engineering - State-ofthe-Art and Future Developments. Information Systems, 2006.

FETTKE, P.; LOOS, P.; ZWICKER, J. Business Process Reference Models: Survey and Classification. 3rd International Conference on Business Process Management. Anais... p.469 - 483, 2006. Nancy, FRANCE.: Springer-Verlag Berlin.

GRIFFIN, A. Modeling and measuring product development cycle time across industries. Journal of product innovation management, v. 14, n. 6, p. 429-458, 1997.

HACKATHORN, R. D.; KARIMI, J. A framework for comparing information engineering methods. MIS Q., v. 12, n. 2, p. 203-220, 1988. Minneapolis, MN, USA: Society for Information Management and The Management Information Systems Research Center.

HARRINGTON, H. J.; ESSELING, E. K. C.; NIMWEGEN, H. VAN. Business Process Improvement Workbook: Documentation, Analysis, Design, and Management of Business Process Improvement. McGraw-Hill, 1997. 
HEIJSTEK, W.; CHAUDRON, M. R. V. Evaluating RUP Software Development Processes Through Visualization of Effort Distribution. 2008 34th Euromicro Conference Software Engineering and Advanced Applications, p. 266-273, 2008. leee.

HEISIG, P.; CLARKSON, J.; HEMPHÄLÄ, J. et al. Challenges and Future Fields of Research for Modelling and Management of Engineering Processes. Outlook, , $n$. September, 2009.

ISO-9241. Ergonomic requirements for office work with visual display terminals ( VDTs ) - Part 11: Guidance on usability. International Organization, 1998.

JAMES, L. R.; DEMAREE, R. G.; WOLF, G. Estimating within-group interrater reliability with and without response bias. Journal of Applied Psychology, v. 69, n. 1, p. 85-98, 1984.

JESTON, J.; NELIS, J. Business Process Management - Practical Guidelines to Successful Implementations. Elsevier, 2006.

JUN, H. H.; SUH, H. H. A Modeling Framework for Product Development Process Considering its Characteristics. IEEE Transactions on Engineering Management, v. 55, n. 3, p. 103-119, 2008.

KALPIC, B.; BERNUS, P. Business process modelling in industry: the powerful tool in enterprise management. Computers in Industry, v. 47, n. 3, p. 299-318, 2002.

KARLSSON, C. Researching Operations Management. Taylor and Francis, 2008.

KETTINGER, W. J.; TENG, J. T. C.; GUHA, S. Business Process Change: A Study of Methodologies, Techniques, and Tools. MIS Quarterly, v. 21, n. 1, p. 55, 1997.

KLINE, S. J. Innovation is not a linear process. Research Management, v. 26, n. 2, p. $36-45,1985$.

KRISHNAN, V.; ULRICH, KARL T. Product Development Decisions: A Review of the Literature. Management Science, v. 47, n. 1, p. 1-21, 2001.

KRUCHTEN, P. P. B. P.; KRUCHTEN, B. Architectural Blueprints - The " $4+1$ " View Model of Software Architecture. IEEE Software, v. 12, n. November, p. 42-50, 1995. New York, New York, USA: ACM Press.

KUNIAVSKY, M. Observing the user experience: a practitioner's guide to user research. San Francisco, CA: Morgan Kaufmann, 2003.

LARMAN, C.; KRUCHTEN, P.; BITTNER, K. How to Fail with the Rational Unified Process : Seven Steps to Pain and Suffering. Thinking, p. 1-14.

LEVY, Y.; ELLIS, T. J. A Systems Approach to Conduct an Effective Literature Review in Support of Information Systems Research. Science Journal, v. 9, 2006.

LU, R.; SADIQ, S. A survey of comparative business process modeling approaches. Business Information Systems. Anais... p.82-94, 2007. Springer.

MELÃO, N.; PIDD, M. A conceptual framework for understanding business processes and business process modelling. Information Systems Journal, p. 105-129, 2000. 
MEREDITH, J.; RATURI, A.; AMOAKO-GYAMPAH, K.; KAPLAN, B. Alternative research paradigms in operations. Journal of Operations Management, v. 8, n. 4, p. 297326, 1989.

MORAN, T. P. The Command Language Grammar: a representation for the user interface of interactive computer systems? Int. J. Man-Machine Studies, , n. 15, p. 3-50, 1981.

MUNDIM, A. P. F.; ROZENFELD, HENRIQUE; AMARAL, DANIEL CAPALDO; et al. Aplicando o cenário de desenvolvimento de produtos em um caso prático de capacitação profissional. Gestão \& Produção, v. 9, n. 1, 2002.

NEELY, A.; GREGORY, M.; PLATTS, K. Performance measurement system design. A literature review and research agenda. International Journal of Operations \& Production Management, v. 25, n. 12, p. 1228-1263, 2005.

NIELSEN, J. Usability engineering. AP Professional, 1994.

NIELSEN, J.; LORANGER, H. Usabilidade na Web: projetando websites com qualidade. Rio de Janeiro: Campus, 2007.

O'DONOVAN; BROWNING, T.R.; ECKERT, C. M.; CLARKSON, P. J. Design planning and modeling. Design process improvement: a review of current practice. p.60-87, 2005. Springer.

PAHL, G.; BEITZ, W. Engineering Design. London: The Design Council, 1988.

PALL, G. A. The process-centered enterprise: The power of commitments. New York: St. Lucie Press, 1999.

PALVIA, P.; NOSEK, J. T. A field examination of system life cycle techniques and methodologies. Information \& Management, v. 25, n. 2, p. 73-84, 1993.

PARK, H.; CUTKOSKY, M. R. Framework for Modeling Dependencies in Collaborative Engineering Processes. Research in Engineering Design, p. 84-102, 1999. Cultrix, 1965.

PIGNATARI, D. Informação, linguagem e comunicação. 19th ed. Rio de Janeiro:

PMI. Um Guia Do Conhecimento Em Gerenciamento de Projetos: Project Management Institute, 2008.

PREECE, J.; ROGERS, Y.; SHARP, H. Design de Interação: além da interação homem-computador. Bookman, 2006.

PUGH, S.; CLAUSING, D. Creating Innovative Products Using Total Design: The Living Legacy of Stuart Pugh. 1st ed. Boston, MA, USA: Addison-Wesley Longman Publishing Co., Inc., 1996.

ROZENFELD, H; FORCELLINI, F. A.; AMARAL, D C; et al. Gestão de Desenvolvimento de Produtos. 1st ed. São Paulo: Saraiva Editora, 2006.

SCHEER, A.; THOMAS, O.; ADAM, O. Process Modeling Using Event-Driven Process Chains. , p. 119-145, 2005. 
SEFFAH, A.; DONYAEE, M.; KLINE, R. B.; PADDA, H. K. Usability measurement and metrics: A consolidated model. Software Quality Journal, v. 14, n. 2, p. 159-178, 2006.

SIMON, H. A. The sciences of the artificial. MIT Press, 1996.

SLATER, S. F. The Challenge of Sustaining Competitive Advantage. Management Science, v. 86, p. 79-86, 1996.

SMITH, R. P.; MORROW, J. A. Product development process modeling. Design Studies, v. 20, n. 3, p. 237-261, 1999.

STEIGER, D. M. Enhancing user understanding in a Decision Support System : A theoretical basis and framework. Journal of Management, 1998.

TULLIS, T.; ALBERT, B. Meauring the user experience: Collecting, analysing, and presenting usability metrics. Morgan Kaufmann, 2008.

TURBAN, E.; FRENZEL, L. E. Expert systems and applied artificial intelligence. Macmillan Pub. Co., 1992.

ULRICH, K T; EPPINGER, S. D. Product Design and Development. 4th ed. McGraw-Hill Higher Education, 2007. Hall, 1993.

URBAN, G. L.; HAUSER, J. R. Design and marketing of new products. Prentice

VERGIDIS, K.; TIWARI, A.; MAJEED, B. Business Process Analysis and Optimization: Beyond Reengineering. IEEE Transactions on Systems, Man, and Cybernetics, Part C (Applications and Reviews), v. 38, n. 1, p. 69-82, 2008.

VERGIDIS, K.; TURNER, C.; TIWARI, A. Business process perspectives: Theoretical developments vs. real-world practice. International Journal of Production Economics, v. 114 , n. 1, p. 91-104, 2008.

VERNADAT, F. Enterprise Modeling and Integration: Principles and Applications. Springer, 1996.

WHITE, T. E.; FISCHER, L. New tools for new times: the workflow paradigm : the impact of information technology on business process reengineering. Future Strategies, 1994.

YI, J. S.; KANG, Y. A.; STASKO, J.; JACKO, J. Toward a deeper understanding of the role of interaction in information visualization. IEEE transactions on visualization and computer graphics, v. 13, n. 6, p. 1224-31, 2007.

ZACHMAN, J. A. A framework for information systems architecture. IBM Los Angeles Scientific Center, 1986. 



\section{Apêndice A - Definições de termos relevantes para modelagem de PDP}

\begin{tabular}{|c|c|c|}
\hline Termo & Definição & Fonte \\
\hline Abordagem & $\begin{array}{l}\text { "Abordagens estruturadas têm por objetivo proporcionar } \\
\text { uma dinâmica de projeto aos conceitos de modelagem" } \\
\text { "Uma abordagem é organizada em fases metodológicas, e } \\
\text { as fases organizadas em tarefas." }\end{array}$ & $\begin{array}{l}\text { (DOUMEINGTS et al., 1995, } \\
\text { pág 2) } \\
\text { (VERNADAT, 1996, pág 32) }\end{array}$ \\
\hline Arquitetura & $\begin{array}{l}\text { "O termo arquitetura se refere a um conjunto organizado de } \\
\text { elementos claramente relacionados um com o outro, que } \\
\text { juntos formam um todo definido pela sua finalidade." } \\
\text { "Estabelece um conjunto de regras, objetivos, princípios, } \\
\text { estratégias e modelos para os processos." }\end{array}$ & $\begin{array}{l}\text { (JESTON; NELIS, 2006, pág } \\
\text { 83) }\end{array}$ \\
\hline Atividade & $\begin{array}{l}\text { "Atividades ocorrem dentro de um processo ou } \\
\text { subprocesso. Elas são normalmente realizadas por } \\
\text { unidades (uma pessoa ou um departamento). Uma } \\
\text { atividade é normalmente documentada em uma instrução. A } \\
\text { instrução documentará as tarefas a serem executadas para } \\
\text { concluir uma atividade." } \\
\text { "Uma atividade realiza uma tarefa como um conjunto } \\
\text { parcialmente ordenado de operações básicas, executadas } \\
\text { para desempenhar as coisas a serem feitas em uma } \\
\text { empresa." }\end{array}$ & $\begin{array}{l}\text { (HARRINGTON et al., 1997, } \\
\text { pág 2) }\end{array}$ \\
\hline Atributos & $\begin{array}{l}\text { "Um atributo descreve uma característica ou propriedade de } \\
\text { uma entidade ou relacionamento (ex. a cor de um carro, o } \\
\text { nome de uma pessoa, a data de compra do carro pela } \\
\text { pessoa)." }\end{array}$ & (VERNADAT, 1996, pág 202) \\
\hline $\begin{array}{l}\text { Blocos de } \\
\text { Construção } \\
\text { (ou objetos) }\end{array}$ & $\begin{array}{l}\text { "Em geral, um modelo é um arranjo organizado de blocos } \\
\text { de construção. Um bloco de construção é um componente } \\
\text { de um modelo definido como uma instância de um ou mais } \\
\text { construtos. Por ex. um sobprograma em um programa de } \\
\text { computador é um bloco de construção. Um tipo de entidade } \\
\text { definida por um usuário também é um bloco de construção } \\
\text { em um esquema de relacionamento de entidades." } \\
\text { "Blocos de construção são equivalentes a palavras ou } \\
\text { expressões básicas da linguagem." }\end{array}$ & (VERNADAT, 1996, pág 71) \\
\hline Construtos & $\begin{array}{l}\text { "Um construto de modelagem é um elemento básico de } \\
\text { uma linguagem de modelagem definido por sua sintaxe e } \\
\text { semântica. Eles podem ser símbolos gráficos, declarações } \\
\text { textuais, ou expressões matemáticas e lógicas" } \\
\text { "É um elemento primitivo de uma linguagem de modelagem, } \\
\text { possuidor de uma semântica bem definida." }\end{array}$ & (AMARAL, 2002, pág 107) \\
\hline Ferramenta & $\begin{array}{l}\text { "Nível mais baixo de abstração; auxiliam na execução de } \\
\text { uma tarefa. Definidas como pacotes de software } \\
\text { computacional para oferecer suporte a uma ou mais } \\
\text { técnicas." } \\
\text { "Algo tangível, como um template ou um programa de } \\
\text { software, usado na desempenho de uma atividade para } \\
\text { produzir um produto ou resultado." }\end{array}$ & $\begin{array}{l}\text { (PALVIA; NOSEK, } 1993 \text { apud } \\
\text { KETTINGER et al., 1997) }\end{array}$ \\
\hline Framework & $\begin{array}{l}\text { "Uma abordagem genérica que pode ser aplicada para } \\
\text { modelar qualquer situação dentro de seu escopo, mas que } \\
\text { fornece apenas uma ideia geral." } \\
\text { "O termo framework se refere a uma coleção de elementos } \\
\text { reunidos para algum propósito" } \\
\text { "Framework é mais geral que arquitetura; várias } \\
\text { arquiteturas podem compor um framework." } \\
\text { "É uma coleção de princípios, formalismos de modelagem, } \\
\text { ferramentas e metodologias de modelagem, que sejam } \\
\text { relevantes para um dado domínio de aplicação da } \\
\text { modelagem." }\end{array}$ & $\begin{array}{l}\text { (BROWNING, TYSON R. et } \\
\text { al., 2006) } \\
\text { (O’DONOVAN et al., 2005) } \\
\text { (VERNADAT, 1996, pág 32) }\end{array}$ \\
\hline $\begin{array}{l}\text { Linguagem de } \\
\text { modelagem }\end{array}$ & $\begin{array}{l}\text { "Uma linguagem de modelagem fornece uma sintaxe e } \\
\text { semântica apropriadas para especificar precisamente os } \\
\text { requisitos de processos de negócios, com uma gramática } \\
\text { para expressar seus objetos e dependências." }\end{array}$ & (LU; SADIQ, 2007, pág 83). \\
\hline
\end{tabular}




\begin{tabular}{lll}
\hline Termo & Definição & Fonte \\
\hline Modelo & "Um modelo é uma representação útil de algum assunto. É & (VERNADAT, 1996, pág 70) \\
& $\begin{array}{l}\text { uma abstração mais ou menos formal da realidade (ou } \\
\text { universo, ou discurso) expressa por meio de algum } \\
\text { formalismo (ou linguagem) definido por construtos de }\end{array}$ & \\
& $\begin{array}{l}\text { modelagem para o propósito do usuário." } \\
\text { "Modelos são apoiados por formalismos matemáticos, }\end{array}$ & (DOUMEINGTS et al., 1995, \\
& linguagens e ou ferramentas gráficas." & pág 2) \\
\hline Modelagem de & "Modelagem de empresas é um termo genérico que & (AMICE, 1993; CEN, 1994; \\
empresa & $\begin{array}{l}\text { abrange o conjunto de atividades, métodos e ferramentas } \\
\text { relacionadas com o desenvolvimento de modelos para os }\end{array}$ & Petrie, 1992 apud \\
& Vários aspectos de uma empresa" & \\
\hline $\begin{array}{l}\text { Modelagem de } \\
\text { processo }\end{array}$ & "Modelagem de processos está relacionada com os & JESTON; NELIS, 2006, pág \\
& métodos usados para identificar e conceitualizar (retrato & 311) \\
& atual) processos de negócio e processos futuros (retrato &
\end{tabular}

futuro). O núcleo desses métodos são as técnicas de modelagem de processo."

"Um processo de modelagem é o conjunto de atividades a serem seguidas para criar um ou mais modelos de algo

(VERNADAT, 1996, pág 84) (definido pelo seu universo de discurso), para um determinado propósito (ex. representação, comunicação, análise, design ou síntese, tomada de decisão ou controle)."

\begin{tabular}{lll}
\hline Método & "Abordagens e técnicas que apoiam e permitem ações de & JESTON; NELIS, 2006, pág \\
& processo consistentes." & 310) \\
\hline Métodos de & "Um formalismo ou método de modelagem é um conjunto & (AMARAL, 2002, pág 107) \\
Modelagem & de elementos (constructs e regras de sintaxe) capaz de & \\
(ou formalismos & representar uma parte da realidade, relativa a um
\end{tabular}

(ou formalismos representar uma parte da realidade, relativa a um

de modelagem) subconjunto do domínio do processo/sistema que está sendo modelado. Um formalismo pode ser aplicado isoladamente para modelar a empresa, e também como parte integrante de um framework ou arquitetura de modelagem. Os métodos ou formalismos podem ser baseados em três tipos de linguagem: matemática (lógica), natural ou gráfica."

"Um formalismo de modelagem é um meio para representar peças de conhecimento que devem ser transmitidas de maneira inequívoca. Ele permite a construção de modelos de acordo com conceitos associados"

\begin{tabular}{ll}
\hline Metodologia & "Representam o maior nível de abstração para \\
& conceituação de métodos de solução de problemas. São \\
& uma coleção de métodos de solução de problemas \\
& orientados por um conjunto de princípios e uma filosofia \\
& comum." \\
& "É o conjunto de passos necessários para desenvolver um \\
& modelo de empresa, ou seja, construir uma representação \\
& de parte ou do todo de uma empresa, baseando-se em um \\
& único formalismo ou em um framework de modelagem. A \\
& metodologia pode fazer parte do framework de \\
& modelagem." \\
& "Uma metodologia é um conjunto de métodos, modelos e \\
& ferramentas a ser utilizado de maneira estruturada para \\
& resolver um problema. Uma abordagem é organizada em \\
& fases metodológicas, e as fases organizadas em tarefas. \\
& Fases, tarefas, métodos e uso de modelos devem ser \\
& documentados como parte de uma metodologia." \\
\hline "Uma organização é qualquer grupo, corporação, divisão, \\
departamento, planta ou escritório." \\
\hline "Processo (ou processo de negócio) é definido como um \\
conjunto de atividades parcialmente ordenadas, ligadas por \\
relações de precedência, execução do que é iniciado por \\
algum evento e resultará em resultado final observável ou \\
quantificável. Um processo pode ser organizado em sub- \\
processos e empregar atividades." \\
"Um processo é um conjunto de atividades lógico, \\
relacionado e sequencial (conectado) que toma uma \\
entrada de um fornecedor, adiciona valor a ela e produz \\
uma saída para um consumidor"
\end{tabular}

(DOUMEINGTS et al., 1995, pág 2)

(CHECKLAND, 1999)

(KETTINGER et al., 1997)

(AMARAL, 2002, pág 107)

(VERNADAT, 1996, pág 32)

(HARRINGTON et al., 1997, pág 4) (VERNADAT, 1996, pág 83)

(HARRINGTON et al., 1997, pág 1) 


\begin{tabular}{|c|c|c|}
\hline Termo & Definição & Fonte \\
\hline & $\begin{array}{l}\text { "Uma ordenação específica das atividades de trabalho no } \\
\text { tempo e no espaço, com um começo, um fim, e inputs e } \\
\text { outputs claramente identificados" } \\
\text { "Um conjunto de atividades estruturadas e medidas } \\
\text { destinadas a resultar num produto especificado para um } \\
\text { determinado cliente ou mercado" } \\
\text { "Uma rede de relações e compromissos entre } \\
\text { consumidores e fornecedores que orientam atividades de } \\
\text { trabalho a produzir resultados de valor." }\end{array}$ & $\begin{array}{l}\text { (DAVENPORT, T. H., 1994, } \\
\text { pág 7) }\end{array}$ \\
\hline Recursos & $\begin{array}{l}\text { Recursos podem ser equipamentos, serviços, suprimentos, } \\
\text { commodities, materiais (entre outros) que servem para a } \\
\text { execução das atividades de um processo. }\end{array}$ & (HARRINGTON et al., 1997) \\
\hline Sistema & $\begin{array}{l}\text { "Um sistema pode ser representado por vários tipos de } \\
\text { modelos baseados em vários pontos de vista." } \\
\text { "Um sistema é uma reunião de componentes (hardware, } \\
\text { software, procedimentos, ações humanas e outros } \\
\text { recursos) unidos por alguma forma de interação } \\
\text { regulamentada para formar um todo organizado. É um } \\
\text { grupo de processos relacionados que podem ou não estar } \\
\text { conectados." }\end{array}$ & $\begin{array}{l}\text { (DOUMEINGTS et al., 1995, } \\
\text { pág 2) } \\
\text { (HARRINGTON et al., 1997, } \\
\text { pág 3) }\end{array}$ \\
\hline $\begin{array}{l}\text { Sintaxe de } \\
\text { linguagem }\end{array}$ & $\begin{array}{l}\text { "Sintaxe de linguagem proporciona uma gramática para } \\
\text { especificar objetos e suas dependências em um processo } \\
\text { de negócio, frequentemente representado por um modelo } \\
\text { de processo com uma linguagem específica." }\end{array}$ & (LU; SADIQ, 2007, pág 84). \\
\hline $\begin{array}{l}\text { Semântica de } \\
\text { linguagem }\end{array}$ & $\begin{array}{l}\text { "Semântica (de uma linguagem) define uma interpretação } \\
\text { consistente do modelo de processo para refletir a lógica de } \\
\text { processo implícita." }\end{array}$ & (LU; SADIQ, 2007, pág 84). \\
\hline Subprocesso & $\begin{array}{l}\text { "Um subprocesso é a porção de um processo maior que } \\
\text { cumpre um objetivo específico no suporte do processo } \\
\text { maior." }\end{array}$ & $\begin{array}{l}\text { (HARRINGTON et al., 1997, } \\
\text { pág 2) }\end{array}$ \\
\hline Tarefa & $\begin{array}{l}\text { "Tarefas são elementos individuais ou subgrupos de uma } \\
\text { atividade. Normalmente, tarefas estão relacionadas a como } \\
\text { um item deve realizar uma atribuição específica." }\end{array}$ & $\begin{array}{l}\text { (HARRINGTON et al., 1997, } \\
\text { pág 2) }\end{array}$ \\
\hline Técnica & $\begin{array}{l}\text { "Um nível de abstração abaixo da metodologia. Pode ser } \\
\text { entendida como um procedimento ou conjunto de passos } \\
\text { específicos para obter um resultado desejado. É um } \\
\text { conjunto de procedimentos precisamente descritos para } \\
\text { obter uma tarefa padrão." } \\
\text { "Um procedimento sistemático definido empregado por um } \\
\text { recurso humano para realizar uma atividade a fim de } \\
\text { produzir um produto ou resultado ou entregar um serviço, e } \\
\text { que pode empregar uma ou mais ferramentas." }\end{array}$ & $\begin{array}{l}\text { (HACKATHORN; KARIMI, } \\
1988 \text { apud KETTINGER et } \\
\text { al., 1997) }\end{array}$ \\
\hline $\begin{array}{l}\text { Vista de um } \\
\text { modelo }\end{array}$ & $\begin{array}{l}\text { "Ao passo que um modelo de processo inclui todos os } \\
\text { atributos ou suposições subjacentes consideradas } \\
\text { suficientes para descrevê-lo, uma vista é um arranjo de } \\
\text { símbolos, uma tabela, ou outra representação escolhida } \\
\text { para mostrar um subconjunto selecionado desses atributos } \\
\text { ou suposições." }\end{array}$ & (BROWNING, 2008) \\
\hline Workflow & $\begin{array}{l}\text { "Facilitação computadorizada ou automação de um } \\
\text { processo de negócio, em todo ou em parte, durante o qual } \\
\text { documentos, informações ou tarefas são passadas de um } \\
\text { participante para outro para ação, de acordo com um } \\
\text { conjunto de procedimentos." }\end{array}$ & $\begin{array}{l}\text { (WHITE; FISCHER, } 1994 \\
\text { apud AGUILARSAVEN, 2004) }\end{array}$ \\
\hline
\end{tabular}





\section{Apêndice B - Protocolo da revisão bibliográfica sistemática}

\section{Definição do problema e objetivo}

As revisões sobre métodos de modelagem de PDP já existentes na literatura não esgotam o tema e podem estar desatualizadas. Dessa forma, esta revisão bibliográfica tem como objetivo identificar de forma sistemática os métodos que são utilizados na modelagem dos processos de desenvolvimento de produtos. A questão que orientou a RBS foi, portanto: Quais os métodos são utilizados na modelagem de processos de desenvolvimento de produtos?.

\section{Seleção das fontes primárias:}

\subsection{Bases de dados}

As bases de dados escolhidas para realização das buscas foram ISI Web of Science e SciVerse Scopus, pela sua abrangência e qualidade (Tabela 1). Foram considerados artigos e conferências.

Tabela 1 - Bases de dados selecionadas para realização das buscas

\begin{tabular}{lll}
\hline Base de Dados & Instituição & Website \\
\hline ISI Web of Science & Thomson Reuters & http://apps.isiknowledge.com/ \\
SciVerse Scopus & Elsevier & http://www.scopus.com/home.url \\
\hline
\end{tabular}

Os critérios de inclusão das fontes foram: estarem indexadas a uma das bases de dados selecionada para essa RBS; serem de livre acesso ou assinadas pela Universidade de São Paulo ou rede de periódicos CAPES; e apresentarem trabalhos completos na área de estudo no idioma inglês.

\subsection{Lista preliminar de artigos}

A lista preliminar de artigos foi definida a partir de uma revisão bibliográfica simples e a partir da indicação de especialistas. A revisão bibliográfica simples foi realizada no Google Scholar, pelas palavras chave: business process modeling e product development process modeling, e os artigos foram selecionados por afinidade com o tema e número de citações. Esta lista preliminar (tabela 2) serviu como ponto de partida para a definição das strings para realização das buscas. 


\begin{tabular}{|c|c|c|c|c|}
\hline $\mathbf{N}$ & Ano & Autor (es) & Periódico & Referência \\
\hline 1 & 2004 & $\begin{array}{l}\text { Aguilar- } \\
\text { Savén, } \\
\text { R.S. }\end{array}$ & $\begin{array}{l}\text { International } \\
\text { journal of } \\
\text { production } \\
\text { economics }\end{array}$ & $\begin{array}{l}\text { AGUILAR-SAVÉN, R.S.; Business process } \\
\text { modelling: Review and framework. International } \\
\text { journal of production economics, v.90, p.129-149, } \\
2004 \text {. }\end{array}$ \\
\hline 2 & 2004 & $\begin{array}{l}\text { Benedictis, } \\
\text { C. C.; } \\
\text { Amaral, D. } \\
\text { C.; } \\
\text { Rozenfeld } \\
\text { H. }\end{array}$ & $\begin{array}{l}\text { Product: } \\
\text { Management \& } \\
\text { Development }\end{array}$ & $\begin{array}{l}\text { BENEDICTIS, C. C.; AMARAL, D. C.; ROZENFELD } \\
\text { H. Evaluation of the main existing methods and tools } \\
\text { for product development process modeling. Product: } \\
\text { Management \& Development, v.2, n.2, p.19-28, } \\
2004 \text {. }\end{array}$ \\
\hline 3 & 2008 & $\begin{array}{l}\text { Chen D.; } \\
\text { Doumeingt } \\
\text { s G.; } \\
\text { Vernadat F. }\end{array}$ & $\begin{array}{l}\text { Computers in } \\
\text { Industry. }\end{array}$ & $\begin{array}{l}\text { CHEN D.; DOUMEINGTS G.; VERNADAT F. } \\
\text { Architectures for enterprise integration and } \\
\text { interoperability: Past, present and future. Computers } \\
\text { in Industry. v.59, i.7, p.647-659, } 2008 \text {. }\end{array}$ \\
\hline 4 & 2000 & $\begin{array}{l}\text { Hommes, } \\
\text { B. J.; } \\
\text { Reijswoud, } \\
\text { V. }\end{array}$ & $\begin{array}{l}\text { International } \\
\text { Conference on } \\
\text { System } \\
\text { Sciences }\end{array}$ & $\begin{array}{l}\text { HOMMES, B. J.; REIJSWOUD, V. Assessing the } \\
\text { quality of business process modelling techniques. } \\
\text { Proceedings of the } 33 \text { rd Annual Hawaii International } \\
\text { Conference on System Sciences, } 2000 \text {. }\end{array}$ \\
\hline 5 & 2002 & Kalpic B. & $\begin{array}{l}\text { Computers in } \\
\text { Industry }\end{array}$ & $\begin{array}{l}\text { KALPIC B. Business process modelling in industry: } \\
\text { the powerful tool in enterprise management. } \\
\text { Computers in Industry, v.47, i.3, p.299-318, } 2002 .\end{array}$ \\
\hline 6 & 1997 & $\begin{array}{l}\text { Kettinger } \\
\text { W. J.; Teng } \\
\text { J.T. C.; } \\
\text { Guha S. }\end{array}$ & MIS Quarterly & $\begin{array}{l}\text { KETTINGER W. J.; TENG J. T. C.; GUHA S. } \\
\text { Business Process Change: A Study of } \\
\text { Methodologies, Techniques, and Tools. MIS } \\
\text { Quarterly, v.2, i.1, p.55, } 1997 .\end{array}$ \\
\hline 7 & 2007 & $\begin{array}{l}\text { Lu R.; } \\
\text { Sadiq S. }\end{array}$ & $\begin{array}{l}\text { Business } \\
\text { Information } \\
\text { Systems }\end{array}$ & $\begin{array}{l}\text { LU R.; SADIQ S. A survey of comparative business } \\
\text { process modeling approaches. In: Business } \\
\text { Information Systems. Springer, p.82-94, } 2007 .\end{array}$ \\
\hline 8 & 1998 & Phalp, K.T. & $\begin{array}{l}\text { Information and } \\
\text { Software } \\
\text { Technology }\end{array}$ & $\begin{array}{l}\text { PHALP, K.T.; CAP framework for business process } \\
\text { modelling. Information and Software Technology, } \\
\text { v.40 (13), p. } 731-744,1998 .\end{array}$ \\
\hline 9 & 2000 & $\begin{array}{l}\text { Phalp, K., } \\
\text { Shepperd, } \\
\text { M. }\end{array}$ & $\begin{array}{l}\text { Journal of } \\
\text { Systems and } \\
\text { Software }\end{array}$ & $\begin{array}{l}\text { PHALP, K., SHEPPERD, M. Quantitative analysis of } \\
\text { static models of processes. Journal of Systems and } \\
\text { Software, v.52(2-3), p.105-112, } 2000 .\end{array}$ \\
\hline $\begin{array}{l}1 \\
0\end{array}$ & 2008 & $\begin{array}{l}\text { Siller H.R.; } \\
\text { Estruch A.; } \\
\text { Vila C.; } \\
\text { Abellan } \\
\text { J.V.; } \\
\text { Romero F. }\end{array}$ & $\begin{array}{l}\text { Journal of } \\
\text { Intelligent } \\
\text { Manufacturing }\end{array}$ & $\begin{array}{l}\text { SILLER H.R.; ESTRUCH A.; VILA C.; ABELLAN J.V.; } \\
\text { ROMERO F. Modeling workflow activities for } \\
\text { collaborative process planning with product lifecycle } \\
\text { management tools. Journal of Intelligent } \\
\text { Manufacturing, v.19, i.6, p.689-700, } 2008 \text {. }\end{array}$ \\
\hline $\begin{array}{l}1 \\
1\end{array}$ & 1999 & $\begin{array}{l}\text { Smith R. } \\
\text { P., Morrow } \\
\text { J. A. }\end{array}$ & Design Studies & $\begin{array}{l}\text { SMITH R. P., MORROW J. A. Product development } \\
\text { process modeling. Design Studies, v.20, i.3, p.237- } \\
261,1999 .\end{array}$ \\
\hline $\begin{array}{l}1 \\
2\end{array}$ & 2002 & $\begin{array}{l}\text { Vernadat, } \\
\text { F. }\end{array}$ & $\begin{array}{l}\text { Journal of } \\
\text { Production } \\
\text { Research }\end{array}$ & $\begin{array}{l}\text { VERNADAT, F. UEML: Towards a unified enterprise } \\
\text { modelling language. International Journal of } \\
\text { Production Research, v.40, i.17, p.4309-4321, } 2002 .\end{array}$ \\
\hline $\begin{array}{l}1 \\
3\end{array}$ & 2002 & $\begin{array}{l}\text { Vernadat, } \\
\text { F. B. }\end{array}$ & $\begin{array}{l}\text { Annual Reviews } \\
\text { in Control }\end{array}$ & $\begin{array}{l}\text { VERNADAT, F. B. Enterprise modeling and } \\
\text { integration (EMI): current status and research } \\
\text { perspectives. Annual Reviews in Control, v. 26, i.1, } \\
\text { p.15-25, 2002. }\end{array}$ \\
\hline $\begin{array}{l}1 \\
4\end{array}$ & 1995 & Zelm M. & $\begin{array}{l}\text { Computers in } \\
\text { Industry }\end{array}$ & $\begin{array}{l}\text { ZELM M. The CIMOSA business modelling process. } \\
\text { Computers in Industry, v.27, i.2, p.123-142, } 1995 .\end{array}$ \\
\hline
\end{tabular}

Tabela 2. Lista preliminar de artigos selecionados

\section{Construção das strings de busca}


O processo de construção das strings foi iterativo, em ciclos de elaboração, teste e refinamento. Os passos seguidos em cada iteração estão na tabela 3.

\begin{tabular}{l|l}
\hline Passo & Descrição \\
\hline 1 & Transcrição das palavras-chave dos artigos selecionados na busca preliminar; \\
\hline 2 & Seleção dos termos relevantes para a pesquisa, dentro dessas palavras-chave; \\
\hline 3 & $\begin{array}{l}\text { Busca de sinônimos para os termos relevantes na base de dados WordNet (disponível } \\
\text { em: http://wordnetweb.princeton.edu/perl/webwn); }\end{array}$ \\
\hline 4 & $\begin{array}{l}\text { Definição dos limitadores, expressões que garantem o foco das buscas, feita com o } \\
\text { auxílio de um especialista; }\end{array}$ \\
\hline 5 & $\begin{array}{l}\text { Elaboração das strings, combinando os termos relevantes com os limitadores, de acordo } \\
\text { com as regras de cada base de dados; }\end{array}$ \\
\hline 6 & Teste da string nas bases de dados; \\
\hline 7 & Refinamento dos termos relevantes, limitadores e strings. \\
\hline
\end{tabular}

Tabela 3 - Passos seguidos em cada iteração para elaboração das strings de busca

A Tabela 4 traz os termos relevantes e os limitadores levantados para a construção das strings de busca. A construção das strings foi baseada no padrão proposto pela ISI Web of Science, e pela SciVerse Scopus, pela amplitude dessas base da dados. As palavras definidas nos grupos foram conectadas por operadores lógicos "AND", "OR", conforme o padrão indicado para buscas booleanas. A busca foi realizada considerando os campos "título", "resumo" e "palavras-chave". Foram realizadas três iterações para elaboração das strings. As strings definitivas estão na Tabela 5.

\begin{tabular}{ll}
\hline Grupo Tema & Conjunto de palavras \\
\hline Termos & $\begin{array}{l}\text { formalism, framework, model, modeling, modelling, notation, structure, workflow, } \\
\text { Relevantes } \\
\text { informations, models, language, languages, visualization, scenarios, representation, }\end{array}$ \\
\hline Limitadores & $\begin{array}{l}\text { product development process, concurrent engineering design, new product } \\
\text { development, product life cycle management }\end{array}$ \\
\hline
\end{tabular}

Tabela 4 - Conjuntos de termos relevantes e limitadores a serem utilizados nas strings

\begin{tabular}{|c|c|c|}
\hline ID & String & Base de Dados \\
\hline Busca 1 & $\begin{array}{l}\text { TS=(formalism OR framework OR model OR modeling OR } \\
\text { modelling OR notation OR structure OR workflow OR workflows } \\
\text { OR models OR language or languages) AND TS=("product } \\
\text { development process" OR "concurrent engineering" OR "new } \\
\text { product development" OR "engineering design" OR "product life } \\
\text { cycle management") }\end{array}$ & Web of Science \\
\hline Busca 1 & $\begin{array}{l}\text { TITLE-ABS-KEY-AUTH((formalism OR framework OR model OR } \\
\text { modeling OR modelling OR notation OR structure OR workflow } \\
\text { OR workflows OR models OR language or languages) AND } \\
\text { ("product development process" OR "concurrent engineering" OR } \\
\text { "new product development" OR "engineering design" OR "product } \\
\text { life cycle management") }\end{array}$ & Scopus \\
\hline Busca 2 & $\begin{array}{l}\text { TS=(formalism OR framework OR model OR modeling OR } \\
\text { modelling OR notation OR structure OR workflow OR workflows } \\
\text { OR models OR language or languages) AND TS=("product } \\
\text { development process" OR "concurrent engineering design" OR } \\
\text { "new product development" OR "product life cycle management") }\end{array}$ & Web of Science \\
\hline Busca 2 & TITLE-ABS-KEY-AUTH((formalism OR framework OR model OR & Scopus \\
\hline
\end{tabular}




\begin{tabular}{lll}
\hline ID & String & Base de Dados \\
\hline & modeling OR modelling OR notation OR structure OR workflow & \\
& OR workflows OR models) AND ("product development process" & \\
& OR "concurrent engineering design" OR "new product & \\
& development" OR "product life cycle management")) & \\
\hline Busca 3 & TS=(formalism OR framework OR model OR modeling OR & Web of Science \\
(refinada) & modelling OR notation OR structure OR workflow OR workflows & \\
& OR models OR language or languages OR scenarios OR & \\
& representation OR visualization OR "information management") & \\
& AND TS=("product development process" OR "concurrent & \\
& engineering design" OR "new product development" OR "product & \\
& life cycle management") & \\
\hline Busca 3 & TITLE-ABS-KEY-AUTH((formalism OR framework OR model OR & Scopus \\
(refinada) & modeling OR modelling OR notation OR structure OR workflow & \\
& OR workflows OR models OR scenarios OR representation OR & \\
& visualisation OR "information management") AND ("product & \\
& development process" OR "concurrent engineering design" OR & \\
& "new product development" OR "product life cycle management")) & \\
\hline
\end{tabular}

Tabela 5. Construção das strings de busca

\section{Definição dos critérios de inclusão dos artigos}

\subsection{Critérios de inclusão:}

Cl1 - Descrição ou aplicação de frameworks, métodos, técnicas de modelagem para o processo de desenvolvimento de produtos.

Cl2 - Descrição ou aplicação de novos modelos para o processo de desenvolvimento de produtos.

\subsection{Critérios de exclusão:}

CE1 - Descrição ou aplicação de modelos que não representem o processo (exemplo: modelos de gestão de dados; frameworks de melhores práticas; sistemas de gestão; aplicação de novas tecnologias de informação e comunicação (TICS) no PDP).

CE2 - Descrição ou aplicação de métodos, técnicas e ferramentas de apoio pontual à tomada de decisão no processo de desenvolvimento de produtos.

Fazem parte do escopo dessa revisão apenas modelos que considerem o processo de desenvolvimento de produto como um todo. Modelos que auxiliem na tomada de decisão apenas em relação à seleção de ideias de novos produtos ou seleção de requisitos, por exemplo, não serão considerados. 
CE3 - Descrição ou aplicação de modelos de avaliação do processo de desenvolvimento de produtos.

Modelos que avaliem o desempenho ou a qualidade do processo de desenvolvimento de produtos como um todo não fazem parte do escopo desta revisão. Fazem parte do escopo modelos que ajudem na avaliação das variáveis que surgem durante o processo de desenvolvimento, apoiando a tomada de decisão em relação ao produto.

\section{Método e ferramentas para a condução das buscas e análise dos resultados}

Envolve a definição das etapas de busca, a definição dos filtros, as ferramentas para armazenamento dos dados, entre outros. As etapas realizadas na revisão bibliográfica sistemática desta pesquisa estão detalhadas na tabela 6. .

\begin{tabular}{l|l}
\hline Etapa & Descrição \\
\hline 1 & Definição das strings (foram realizadas três iterações); \\
\hline 2 & Realização da busca em cada base de dados listada na Tabela ; \\
\hline 3 & Cruzamento dos resultados a fim de eliminar duplicatas; \\
\hline 4 & Exportação os resultados da busca para a planilha de filtros; \\
\hline 5 & $\begin{array}{l}\text { Aplicação do Filtro 1: leitura do título, palavras chave e resumo do artigo. Aplicação dos } \\
\text { critérios de inclusão e exclusão de artigos e anotação A (aprovado) e R (reprovado); }\end{array}$ \\
\hline 6 & $\begin{array}{l}\text { Filtro 2: leitura parcial do artigo, incluindo a introdução, resultados e conclusão. Aplicação } \\
\text { dos critérios de inclusão e exclusão de artigos e anotação A (aprovado), R (reprovado) e I } \\
\text { (indisponível); }\end{array}$ \\
\hline 7 & Filtro 3: leitura completa dos artigos. Anotação A (aprovado) e R (reprovado); \\
\hline 8 & $\begin{array}{l}\text { Extração dos dados para a planilha de síntese por meio da leitura em profundidade dos } \\
\text { artigos selecionados; }\end{array}$ \\
\hline 9 & $\begin{array}{l}\text { Catalogação dos artigos: os artigos foram catalogados e armazenados em um software } \\
\text { para gestão de referências bibliográficas. O software adotado é o Mendeley@ (disponível } \\
\text { em: http://www.mendeley.com/). Todos os artigos que passaram no filtro 2 também foram } \\
\text { armazenados no Mendeley@ para consulta futura. }\end{array}$ \\
\hline
\end{tabular}

Tabela 6 - Etapas realizadas na revisão bibliográfica sistemática 



\section{Apêndice C - Tabela síntese dos métodos de modelagem de PDP}

Composto pelas tabelas:

- C1 - Métodos de modelagem por tipo de processo e descrição

- C2 - Métodos de modelagem: variáveis chave e atributos

- C3 - Métodos de modelagem: características

- C4 - Métodos de modelagem: vantagens e desvantagens para o usuário

- C5 - Métodos de modelagem: vantagens e desvantagens para o modelador

- C6 - Métodos de modelagem: propósitos 



\section{Apêndice C1 - Métodos de modelagem por tipo de processo e descrição}

\begin{tabular}{|c|c|c|c|}
\hline Referências & Processo & $\begin{array}{l}\text { Nome do } \\
\text { Método/Técnica }\end{array}$ & Descrição \\
\hline $\begin{array}{l}\text { (Smith, R. P.; } \\
\text { Morrow, J. A., } \\
\text { 1999) } \\
\text { (Browning, T. } \\
\text { R.; Fricke, E.; } \\
\text { Negele, H., } \\
\text { 2006) }\end{array}$ & PDP & $\begin{array}{l}\text { Agendamento de módulos } \\
\text { (Module scheduling) }\end{array}$ & $\begin{array}{l}\text { Um conjunto de fases/estágios sequenciais ou iterativos, } \\
\text { normalmente com critérios para transição de estágios. } \\
\text { Esse modelo considera os efeitos da coordenação de } \\
\text { módulos no desenvolvimento de software. }\end{array}$ \\
\hline $\begin{array}{l}\text { (Smith, R. P.; } \\
\text { Morrow, J. A., } \\
\text { 1999) }\end{array}$ & PDP & $\begin{array}{l}\text { Análise de áreas } \\
\text { interrelacionadas de decisão } \\
\text { (Analysis of interconnected } \\
\text { decision areas - AIDA) }\end{array}$ & \\
\hline $\begin{array}{l}\text { (Browning T.R., } \\
\text { 2008) }\end{array}$ & PDP & $\begin{array}{l}\text { Cadeia extendida de } \\
\text { processos orientados a } \\
\text { eventos (Extended Event- } \\
\text { driven Process Chain - EPC) }\end{array}$ & $\begin{array}{l}\text { A "super visão" fornecida pelo método ARIS, inclui } \\
\text { funções, eventos, itens de informação e produtos, e } \\
\text { unidades organizacionais. Técnica baseada em gráficos. }\end{array}$ \\
\hline $\begin{array}{l}\text { (Browning T.R., } \\
\text { 2008) }\end{array}$ & PDP & $\begin{array}{l}\text { Diagrama de atividades em } \\
\text { arcos (Activity-on-Arc } \\
\text { Diagram) }\end{array}$ & $\begin{array}{l}\text { Círculos representam eventos, assim como o início ou } \\
\text { término de uma atividade. Flechas (arcos) representam } \\
\text { atividades e são proporcionais em comprimento à } \\
\text { duração da atividade, que é dada entre parenteses } \\
\text { depois do nome da atividade. Linhas pontilhadas } \\
\text { conectam eventos dependentes onde não está implicado } \\
\text { pelas atividades atuais. Técnica baseada em gráficos }\end{array}$ \\
\hline $\begin{array}{l}\text { (Browning T.R., } \\
\text { 2008) } \\
\text { (Browning, T. } \\
\text { R.; Fricke, E.; } \\
\text { Negele, H., } \\
\text { 2006) }\end{array}$ & PDP & $\begin{array}{l}\text { Diagrama de Entrada-Tarefa- } \\
\text { Validação-Saída (Entry-Task- } \\
\text { Validation-Exit (ETVX) } \\
\text { Diagram) }\end{array}$ & $\begin{array}{l}\text { Técnica baseada em gráficos. Conjunto de atividades, } \\
\text { cada uma demandando entradas e produzindo saídas. } \\
\text { Talvez mais uma convenção do que um diagrama, criado } \\
\text { para garantir a inclusão de atributos de atividades } \\
\text { importantes. ETVX enfatiza os critérios de entrada, as } \\
\text { sub-tarefas a serem realizadas, os métodos de validação } \\
\text { de trabalho e os critérios de saída. }\end{array}$ \\
\hline $\begin{array}{l}\text { (Browning T.R., } \\
\text { 2008) } \\
\text { (Browning, T. } \\
\text { R.; Fricke, E.; } \\
\text { Negele, H., } \\
\text { 2006) }\end{array}$ & PDP & $\begin{array}{l}\text { Diagrama de estado (State } \\
\text { Diagram) }\end{array}$ & $\begin{array}{l}\text { A maioria dos diagramas de estado apenas mostram os } \\
\text { possíveis estados (ou nós) conectados por caminhos de } \\
\text { transição. Na modelagem de processos, eles podem } \\
\text { também mostrar as atividades intervenientes com um } \\
\text { tipo diferente de nó. }\end{array}$ \\
\hline $\begin{array}{l}\text { (Aguillar Savén, } \\
\text { R., 2004) } \\
\text { (Browning T.R., } \\
\text { 2010) }\end{array}$ & BPM/PDP & $\begin{array}{l}\text { Diagrama de fluxo de dados } \\
\text { (Data Flow Diagram - DFD) }\end{array}$ & Diagramas descritivos para análise estrutural. \\
\hline $\begin{array}{l}\text { (Browning T.R., } \\
\text { 2008) }\end{array}$ & PDP & $\begin{array}{l}\text { Diagrama de fluxo e estoque } \\
\text { (Stock-and-Flow Diagram) }\end{array}$ & $\begin{array}{l}\text { Ao invés de tratar um processo como uma rede de } \\
\text { atividades identificadas, o processo é modelado como } \\
\text { um estoque de trabalho genérico a ser realizado, o qual, } \\
\text { a uma certa taxa de fluxo, governada por uma taxa de } \\
\text { produtividade, resulta em trabalho completo. Técnica } \\
\text { baseada em gráficos }\end{array}$ \\
\hline
\end{tabular}




\begin{tabular}{|c|c|c|c|}
\hline Referências & Processo & $\begin{array}{l}\text { Nome do } \\
\text { Método/Técnica }\end{array}$ & Descrição \\
\hline $\begin{array}{l}\text { (Browning T.R., } \\
\text { 2008) } \\
\text { (Browning, T. } \\
\text { R.; Fricke, E.; } \\
\text { Negele, H., } \\
\text { 2006) }\end{array}$ & PDP & Diagrama SIPOC & $\begin{array}{l}\text { Conjunto de atividades, cada uma demandando entradas } \\
\text { e produzindo saídas. Para cada atividade, são descritas } \\
\text { as entradas, os fornecedores, as atividades constituintes, } \\
\text { as saídas e seus clientes. }\end{array}$ \\
\hline $\begin{array}{l}\text { (Smith, R. P.; } \\
\text { Morrow, J. A., } \\
\text { 1999) }\end{array}$ & PDP & $\begin{array}{l}\text { Entrega de produto (Product } \\
\text { release) }\end{array}$ & $\begin{array}{l}\text { Examina o relacionamento entre performance de } \\
\text { produto, entrega de produto e desenvolvimento. }\end{array}$ \\
\hline $\begin{array}{l}\text { (Smith, R. P.; } \\
\text { Morrow, J. A., } \\
\text { 1999) } \\
\text { (Browning, T. } \\
\text { R.; Fricke, E.; } \\
\text { Negele, H., } \\
\text { 2006) }\end{array}$ & PDP & $\begin{array}{l}\text { Estimativa de tempo de ciclos } \\
\text { iterativos (Iterative cycle time } \\
\text { estimation) }\end{array}$ & $\begin{array}{l}\text { Uma rede estruturada de atividades com dependências } \\
\text { substanciais e cíclicas }\end{array}$ \\
\hline $\begin{array}{l}\text { (Smith, R. P.; } \\
\text { Morrow, J. A., } \\
\text { 1999) } \\
\text { (Browning, T. } \\
\text { R.; Fricke, E.; } \\
\text { Negele, H., } \\
\text { 2006) }\end{array}$ & PDP & Feedbacks and Crossovers & $\begin{array}{l}\text { Uma rede estruturada de atividades com dependências } \\
\text { substanciais e cíclicas. Modelo de sequenciamento } \\
\text { baseado na matriz estrutural de projeto.. }\end{array}$ \\
\hline $\begin{array}{l}\text { (Aguillar Savén, } \\
\text { R., 2004) } \\
\text { (Browning, T. } \\
\text { R.; Fricke, E.; } \\
\text { Negele, H., } \\
\text { 2006) } \\
\text { (Browning T.R., } \\
2008 \text { ) }\end{array}$ & BPM / PDP & Fluxograma & $\begin{array}{l}\text { Técnica baseada em gráficos. Fluxo de atividades com } \\
\text { dependências nominais e acíclicas. Atividades em caixas } \\
\text { e relacionamentos em flechas, às vezes mostra nós de } \\
\text { ramificações usando losangos, frequentemente } \\
\text { ampliados de acordo com preferências locais e } \\
\text { convenções. }\end{array}$ \\
\hline $\begin{array}{l}\text { (O'Donovan, B; } \\
\text { Eckert, C; } \\
\text { Clarkson, J.; } \\
\text { Browning, T. } \\
\text { R.,2005) }\end{array}$ & PDP & Generic Design Model (GDM) & Estrutura formal para descrever o processo de projeto. \\
\hline $\begin{array}{l}\text { (Browning T.R., } \\
\text { 2008) } \\
\text { (Browning, T. } \\
\text { R.; Fricke, E.; } \\
\text { Negele, H., } \\
\text { 2006) }\end{array}$ & PDP & $\begin{array}{l}\text { Gráfico de entregas } \\
\text { (Milestone Chart) }\end{array}$ & $\begin{array}{l}\text { Técnica baseada em gráficos. Similar a um gráfico de } \\
\text { Gantt com a adição de símbolos representando eventos } \\
\text { principais (sobre ou dentro do gráfico) }\end{array}$ \\
\hline $\begin{array}{l}\text { Jun H.-B., Suh } \\
\text { H.-W. / } \\
\text { Aguillar } \\
\text { Savén, R. / } \\
\text { (Browning } \\
\text { T.R., 2008) }\end{array}$ & PDP / BPM & $\begin{array}{l}\text { Gráfico de Gantt (Gantt } \\
\text { Chart) }\end{array}$ & $\begin{array}{l}\text { Técnica baseada em gráficos para representação de } \\
\text { gestão de projetos. Descreve atividades e seus } \\
\text { relacionamentos temporais. Pode também indicar } \\
\text { relacionamentos de precedência e estado de atividades. } \\
\text { Às vezes pode representar atributos de atividades } \\
\text { adicionais. }\end{array}$ \\
\hline
\end{tabular}




\begin{tabular}{|c|c|c|c|}
\hline Referências & Processo & $\begin{array}{l}\text { Nome do } \\
\text { Método/Técnica }\end{array}$ & Descrição \\
\hline $\begin{array}{l}\text { (To C.K.M., Fung } \\
\text { H.-K., Harwood } \\
\text { R.J., Ho K.C., } \\
\text { 2009) } \\
\text { (Browning, T. } \\
\text { R.; Fricke, E.; } \\
\text { Negele, H., } \\
\text { 2006) } \\
\end{array}$ & PDP & $\begin{array}{l}\text { Gráfico de tarefas atividades } \\
\text { nos nós } \\
\text { (Activity-on-node task graph) }\end{array}$ & $\begin{array}{l}\text { Fluxo de atividades com dependências nominais e } \\
\text { acíclicas. Atividades são representadas por vértices e } \\
\text { dependências entre elas são representadas por } \\
\text { extremidades. Há dois tipos de extremidades, anteriores } \\
\text { e posteriores. A tarefa A é ligada à tarefa B por uma } \\
\text { extremidade posterior se B é uma tarefa sucessora } \\
\text { (filha) de A. De modo similar, se B pode potencialmente } \\
\text { fornecer alguma informação de resposta para A, B é } \\
\text { ligada a A por uma extremidade anterior. Naturalmente, } \\
\text { os dois subgraficos contendo todas as extremidades } \\
\text { anteriores e todas as extremidades posteriores devem } \\
\text { ser gráficos sem auto loops ou extremidades múltiplas. } \\
\text { Além disso, desde que dependências posteriores } \\
\text { impõem ordem sequencial, o subgrafico posterior não } \\
\text { deve conter ciclos. }\end{array}$ \\
\hline $\begin{array}{l}\text { (Jun H.-B., } \\
\text { Suh H.-W., } \\
2008) \\
\text { (Ko Y.-T., Kuo } \\
\text { P.-H., Yu C.- } \\
\text { W., 2010) } \\
\text { (Browning, T. } \\
\text { R.; Fricke, E.; } \\
\text { Negele, H., } \\
\text { 2006) }\end{array}$ & PDP & $\begin{array}{l}\text { Gráfico direto (Directed } \\
\text { graph) }\end{array}$ & $\begin{array}{l}\text { Técnica baseada em gráficos. Fluxo de atividades com } \\
\text { dependências nominais e acíclicas. Consiste em um } \\
\text { conjunto de nós, representando as atividades de } \\
\text { projeto, e um conjunto de linhas diretas conectando } \\
\text { esses nós. As linhas diretas ou ligações refletem a } \\
\text { dependência ou relacionamento entre as atividades } \\
\text { conectadas. }\end{array}$ \\
\hline $\begin{array}{l}\text { (Jun H.-B., } \\
\text { Suh H.-W., } \\
\text { 2008) } \\
\text { (O'Donovan, } \\
\text { B; Eckert, C; } \\
\text { Clarkson, J.; } \\
\text { Browning, T. } \\
\text { R., 2005) } \\
\text { (Aguillar } \\
\text { Savén, R., } \\
\text { 2004) } \\
\text { (Browning, T. } \\
\text { R.; Fricke, E.; } \\
\text { Negele, H., } \\
\text { 2006) } \\
\text { (Browning } \\
\text { T.R., 2008) }\end{array}$ & PDP / BPM & $\begin{array}{l}\text { IDEFO - Definição integrada } \\
\text { para modelagem de funções }\end{array}$ & $\begin{array}{l}\text { Técnica baseada em gráficos que enfatiza o fluxo de } \\
\text { entradas e saídas entre as atividades. Possui uma } \\
\text { hierarquia de diferentes níveis de atividades (funções). } \\
\text { As caixas com as atividades são organizadas } \\
\text { diagonalmente em uma página única. Dados de entrada } \\
\text { entram na esquerda de cada caixa, dados de saída saem } \\
\text { pela direita de cada caixa, dados de controle entram por } \\
\text { cima, entradas de mecanismos entram por baixo, } \\
\text { enquanto saídas de chamadas saem por baixo. } \\
\text { Hierarquias entre atividades e entregas também são } \\
\text { representadas. }\end{array}$ \\
\hline
\end{tabular}




\begin{tabular}{|c|c|c|c|}
\hline Referências & Processo & $\begin{array}{l}\text { Nome do } \\
\text { Método/Técnica }\end{array}$ & Descrição \\
\hline $\begin{array}{l}\text { (Jun H.-B., } \\
\text { Suh H.-W., } \\
\text { 2008) } \\
\text { (O'Donovan, } \\
\text { B; Eckert, C; } \\
\text { Clarkson, J.; } \\
\text { Browning, T. } \\
\text { R., 2005) } \\
\text { (Aguillar } \\
\text { Savén, R., } \\
\text { 2004) } \\
\text { (Browning, T. } \\
\text { R.; Fricke, E.; } \\
\text { Negele, H., } \\
\text { 2006) } \\
\text { (Browning } \\
\text { T.R., 2008) }\end{array}$ & PDP & $\begin{array}{l}\text { IDEF3 - Definição integrada } \\
\text { para modelagem de funções }\end{array}$ & $\begin{array}{l}\text { Técnica baseada em gráficos que mostra os aspectos } \\
\text { comportamentais de um sistema. Hierarquia de níveis } \\
\text { decompostos de atividades (funções) com vários tipos } \\
\text { de relacionamentos de entradas e saídas. }\end{array}$ \\
\hline $\begin{array}{l}\text { (Sonnemans } \\
\text { P.J.M., Geudens } \\
\text { W.H.J., } \\
\text { Brombacher } \\
\text { A.C., 2003) }\end{array}$ & PDP & $\begin{array}{l}\text { Liberação de tempo de uma } \\
\text { única atividade iterativa } \\
\text { incerta (Release time of a } \\
\text { single uncertain iterative } \\
\text { activity) }\end{array}$ & $\begin{array}{l}\text { Conceito quantitativo para modelar o tempo de entrega } \\
\text { de uma única atividade iterativa incerta, como uma } \\
\text { variável randômica para lidar com o aspecto } \\
\text { probabilístico de uma maneira simples. Para esse } \\
\text { modelo simples, a complexidade é estendida } \\
\text { sistematicamente para modelar configurações } \\
\text { fundamentalmente diferentes, que são por um lado } \\
\text { simples o suficiente para serem estudadas } \\
\text { analiticamente e por outro lado exibem suas } \\
\text { características de entrega fundamentalmente diferentes, } \\
\text { como experimentado na vida real. A partir da análise, } \\
\text { guias são formuladas para organizar ou reconfigurar uma } \\
\text { configuração de processo complexa. }\end{array}$ \\
\hline $\begin{array}{l}\text { (O'Donovan, B; } \\
\text { Eckert, C; } \\
\text { Clarkson, J.; } \\
\text { Browning, T. R., } \\
\text { 2005) } \\
\text { (Browning, T. } \\
\text { R.; Fricke, E.; } \\
\text { Negele, H., } \\
\text { 2006) } \\
\text { (Mellegard N., } \\
\text { Staron M., } \\
2010 \text { ) }\end{array}$ & PDP & $\begin{array}{l}\text { Linguagem universal de } \\
\text { modelagem (Universal } \\
\text { Modelling Language - UML) }\end{array}$ & $\begin{array}{l}\text { Descreve o processo de desenvolvimento e explora os } \\
\text { custos e esforços de utilizar diferentes notações de } \\
\text { modelagem e diferentes níveis de abstração para } \\
\text { especificar requisitos e projetar o produto. Atividades e } \\
\text { seus arranjos podem ser especificados com uma } \\
\text { linguagem padrão. }\end{array}$ \\
\hline $\begin{array}{l}\text { (Browning, T. } \\
\text { R.; Fricke, E.; } \\
\text { Negele, H., } \\
\text { 2006) } \\
\text { (Browning T.R., } \\
\text { 2008) }\end{array}$ & PDP & $\begin{array}{l}\text { Mapeamento da cadeia de } \\
\text { valor (Value Stream Mapping) }\end{array}$ & $\begin{array}{l}\text { Técnica baseada em gráficos. Um conjunto de atividades } \\
\text { que adicionam e não adicionam valor. Enfatiza o tempo } \\
\text { de ciclos assim como tempos de processos e tempos de } \\
\text { espera entre as atividades. Atividades de revisão são } \\
\text { mostradas em elipses ao invés de retângulos. } \\
\text { Intervenções são representadas por triângulos, símbolos } \\
\text { adicionais são comuns também. }\end{array}$ \\
\hline $\begin{array}{l}\text { (Browning, T. } \\
\text { R.; Fricke, E.; } \\
\text { Negele, H., } \\
\text { 2006) }\end{array}$ & PDP & Markov Models & $\begin{array}{l}\text { Um conjunto de estados alcançados através da execução } \\
\text { das atividades. }\end{array}$ \\
\hline
\end{tabular}




\begin{tabular}{|c|c|c|c|}
\hline Referências & Processo & $\begin{array}{l}\text { Nome do } \\
\text { Método/Técnica }\end{array}$ & Descrição \\
\hline $\begin{array}{l}\text { (Browning } \\
\text { T.R., 2010) }\end{array}$ & PDP & $\begin{array}{l}\text { Matriz de atribuição de } \\
\text { responsabilidades } \\
\text { (Responsibility Assignment } \\
\text { Matrix - RAM) } \\
\end{array}$ & $\begin{array}{l}\text { Uma tabela que mapeia atividades a unidades } \\
\text { organizacionais, que preenchem papéis ou possuem uma } \\
\text { resposabilidade para cada atividade. Usa } \\
\text { frequentemente o formato RACI (Responsible- } \\
\text { Accountable-Consult-Inform) }\end{array}$ \\
\hline $\begin{array}{l}\text { (Jun H.-B.; } \\
\text { Suh H.-W., } \\
\text { 2008) } \\
\text { (Browning, T. } \\
\text { R.; Fricke, E.; } \\
\text { Negele, H., } \\
\text { 2006) }\end{array}$ & PDP & $\begin{array}{l}\text { Matriz de incidêcia Atividade- } \\
\text { Atividade (Activity-Activity } \\
\text { Incidence Matrix) }\end{array}$ & $\begin{array}{l}\text { Técnica baseada em matrizes similar ao DSM baseado } \\
\text { em atividades, exceto pelo fato de que pode representar } \\
\text { relações de precedência entre as atividades. Uma rede } \\
\text { estruturada de atividades com dependências } \\
\text { substanciais e cíclicas }\end{array}$ \\
\hline $\begin{array}{l}\text { (Jun H.-B., } \\
\text { Suh H.-W., } \\
\text { 2008) } \\
\text { (Smith, R. P.; } \\
\text { Morrow, J. A., } \\
\text { 1999) } \\
\text { (Browning, T. } \\
\text { R.; Fricke, E.; } \\
\text { Negele, H., } \\
\text { 2006) }\end{array}$ & PDP & $\begin{array}{l}\text { Matriz de transformação de } \\
\text { trabalho (Work } \\
\text { transformation matrix) }\end{array}$ & $\begin{array}{l}\text { Técnica baseada em matrizes. Variação do DSM que } \\
\text { representa a força da dependência entre duas atividades } \\
\text { com elementos fora da diagonal da matriz, assim como o } \\
\text { tempo de execução de cada atividade com elementos da } \\
\text { diagonal da matriz. As entradas de fora da diagonal da } \\
\text { matriz são substituídas por fatores de retrabalho, e o } \\
\text { tempo de cada tarefa é estimado. }\end{array}$ \\
\hline $\begin{array}{l}\text { (Smith, R. P.; } \\
\text { Morrow, J. A., } \\
\text { 1999) } \\
\text { (Browning, T. } \\
\text { R.; Fricke, E.; } \\
\text { Negele, H., } \\
\text { 2006) }\end{array}$ & PDP & $\begin{array}{l}\text { Matriz de transformação de } \\
\text { trabalho de modelos } \\
\text { paralelos/seriais (Work } \\
\text { Transformation Matrix } \\
\text { (WTM) parallel/serial model) }\end{array}$ & $\begin{array}{l}\text { Conjuntos de tarefas que permite processamento } \\
\text { sequencial de tarefas iterativamente acopladas. Uma } \\
\text { rede estruturada de atividades com dependências } \\
\text { substanciais e cíclicas. }\end{array}$ \\
\hline $\begin{array}{l}\text { (Li X.J., Yuan } \\
\text { Y.P., 2011) } \\
\text { (Browning, T. } \\
\text { R.; Fricke, E.; } \\
\text { Negele, H., } \\
\text { 2006) }\end{array}$ & PDP & $\begin{array}{l}\text { Matriz estrutural de projeto } \\
\text { (Design structured Matrix - } \\
\text { DSM) }\end{array}$ & $\begin{array}{l}\text { É a mais representativa técnica baseada em matriz. É } \\
\text { uma matriz quadrada de } \mathrm{N} \text { atividades na sua diagonal, } \\
\text { onde marcas nas células fora da diagonal indicam as } \\
\text { relações de entrada e saída entre as atividades } \\
\text { (naconvenção utilizada, as respostas são mostradas } \\
\text { abaixo da diagonal). Normalmente usadas para modelar } \\
\text { sistemas complexos. Foi originalmente desenvolvida } \\
\text { para a análise de descrições paramétricas de desenhos e } \\
\text { recentemente foi aplicada para analisar atividades de } \\
\text { DP. }\end{array}$ \\
\hline $\begin{array}{l}\text { (Ko Y.-T., Kuo } \\
\text { P.-H., Yu C.-W., } \\
\text { 2010) } \\
\text { (Browning, T. } \\
\text { R.; Fricke, E.; } \\
\text { Negele, H., } \\
\text { 2006) }\end{array}$ & PDP & $\begin{array}{l}\text { Matriz estrutural de projeto } \\
\text { fuzzy (Fuzzy Design Structure } \\
\text { Matrix - FDSM) }\end{array}$ & $\begin{array}{l}\text { O FDSM é uma representação compacta da estrutura de } \\
\text { informação do fluxo de trabalho de projeto. É um plano } \\
\text { de projeto que mostra a ordem em que as atividades de } \\
\text { projeto devem ser executadas, e que atividades devem } \\
\text { ser verificadas. Método de avaliação fuzzy fornece um } \\
\text { método quantitativo para medir a força da dependência } \\
\text { entre atividades de projeto. }\end{array}$ \\
\hline $\begin{array}{l}\text { (Smith, R. P.; } \\
\text { Morrow, J. A., } \\
\text { 1999) } \\
\text { (Browning, T. } \\
\text { R.; Fricke, E.; } \\
\text { Negele, H., } \\
\text { 2006) }\end{array}$ & PDP & $\begin{array}{l}\text { Metas de estágio (Stage } \\
\text { targeting) }\end{array}$ & $\begin{array}{l}\text { Um conjunto de fases/estágios sequenciais ou iterativos, } \\
\text { normalmente com critérios para transição de estágios. } \\
\text { Diz respeito a como organizações alocam seus recursos } \\
\text { de desenvolvimento em estágios sequenciais. }\end{array}$ \\
\hline
\end{tabular}




\begin{tabular}{|c|c|c|c|}
\hline Referências & Processo & $\begin{array}{l}\text { Nome do } \\
\text { Método/Técnica }\end{array}$ & Descrição \\
\hline $\begin{array}{l}\text { (Jun H.-B., } \\
\text { Suh H.-W., } \\
\text { 2008) } \\
\text { (Browning, T. } \\
\text { R.; Fricke, E.; } \\
\text { Negele, H., } \\
2006 \text { ) }\end{array}$ & PDP & $\begin{array}{l}\text { Método de Diagrama de } \\
\text { Precedência (Precedence } \\
\text { Diagram Method - PDM) }\end{array}$ & $\begin{array}{l}\text { Técnica baseada em gráficos. Fluxo de atividades com } \\
\text { dependências nominais e acíclicas. }\end{array}$ \\
\hline (Liu H., 2011) & PDP & $\begin{array}{l}\text { Método do caminho crítico D } \\
\text { (D-Critical Path Method) }\end{array}$ & $\begin{array}{l}\text { Uma técnica matemática para programar um conjunto } \\
\text { de atividades de projeto. Uma ferramenta útil para a } \\
\text { gestão efetiva do projeto, que descreve explicitamente a } \\
\text { ordem de prioridade dos relacionamentos entre } \\
\text { diferentes atividades através de flechas ou nós. Os } \\
\text { elementos do sistema são frequentemente nomeados } \\
\text { nas linhas à esquerda da matriz e nas colunas acima da } \\
\text { matriz tembém. }\end{array}$ \\
\hline $\begin{array}{l}\text { (Jun H.-B., } \\
\text { Suh H.-W., } \\
\text { 2008) } \\
\text { (Browning, T. } \\
\text { R.; Fricke, E.; } \\
\text { Negele, H., } \\
\text { 2006) } \\
\text { (O'Donovan, } \\
\text { B; Eckert, C; } \\
\text { Clarkson, J.; } \\
\text { Browning, T. } \\
\text { R., 2005) } \\
\text { (Sonnemans } \\
\text { P.J.M., } \\
\text { Geudens } \\
\text { W.H.J., } \\
\text { Brombacher } \\
\text { A.C.,2003) }\end{array}$ & PDP & $\begin{array}{l}\text { Metodo do caminho crítico } \\
\text { (Critical Path Method - CPM) }\end{array}$ & $\begin{array}{l}\text { Técnica baseada em gráficos. Técnica baseada em } \\
\text { gráficos. Fluxo de atividades com dependências nominais } \\
\text { e acíclicas. Usado em gestão de projetos para analisar o } \\
\text { tempo de conclusão do projeto ou tempo de lançamento } \\
\text { do produto. }\end{array}$ \\
\hline $\begin{array}{l}\text { (O'Donovan, B; } \\
\text { Eckert, C; } \\
\text { Clarkson, J.; } \\
\text { Browning, T. R., } \\
\text { 2005) }\end{array}$ & PDP & $\begin{array}{l}\text { Minimally Long-tern } \\
\text { Organizational Support } \\
\text { (MILOS) }\end{array}$ & \\
\hline $\begin{array}{l}\text { (Browning, T. } \\
\text { R.; Fricke, E.; } \\
\text { Negele, H., } \\
\text { 2006) }\end{array}$ & PDP & $\begin{array}{l}\text { Modelagem de processos de } \\
\text { negócios (Business Process } \\
\text { Modeling) }\end{array}$ & $\begin{array}{l}\text { Um processo de negócio com atividades discretas, } \\
\text { orientadas a eventos, interfaces e questões de tempo. }\end{array}$ \\
\hline $\begin{array}{l}\text { (Smith, R. P.; } \\
\text { Morrow, J. A., } \\
\text { 1999) } \\
\text { (Browning, T. } \\
\text { R.; Fricke, E.; } \\
\text { Negele, H., } \\
\text { 2006) }\end{array}$ & PDP & Modelo de decomposição 1 & $\begin{array}{l}\text { Modelo de decomposição baseado na matriz estrutural } \\
\text { de projeto. Uma rede estruturada de atividades com } \\
\text { dependências substanciais e cíclicas }\end{array}$ \\
\hline $\begin{array}{l}\text { (Smith, R. P.; } \\
\text { Morrow, J. A., } \\
\text { 1999) } \\
\text { (Browning, T. } \\
\text { R.; Fricke, E.; } \\
\text { Negele, H., } \\
\text { 2006) }\end{array}$ & PDP & Modelo de decomposição 2 & $\begin{array}{l}\text { Modelo de decomposição baseado na matriz estrutural } \\
\text { de projeto. Uma rede estruturada de atividades com } \\
\text { dependências substanciais e cíclicas. }\end{array}$ \\
\hline
\end{tabular}




\begin{tabular}{|c|c|c|c|}
\hline Referências & Processo & $\begin{array}{l}\text { Nome do } \\
\text { Método/Técnica }\end{array}$ & Descrição \\
\hline $\begin{array}{l}\text { (Smith, R. P.; } \\
\text { Morrow, J. A., } \\
\text { 1999) } \\
\text { (Browning, T. } \\
\text { R.; Fricke, E.; } \\
\text { Negele, H., } \\
\text { 2006) }\end{array}$ & PDP & $\begin{array}{l}\text { Modelo de decomposição de } \\
\text { módulos de atividades } \\
\text { (Activity module } \\
\text { decomposition model) }\end{array}$ & $\begin{array}{l}\text { Uma rede estruturada de atividades com dependências } \\
\text { substanciais e cíclicas. As atividades de projeto são } \\
\text { consideradas similares à trabalhos de manufatura a } \\
\text { serem processados, e recursos de projeto (como } \\
\text { engenheiros) são considerados similares ao } \\
\text { equipamento de processamento de manufatura. }\end{array}$ \\
\hline $\begin{array}{l}\text { (Smith, R. P.; } \\
\text { Morrow, J. A., } \\
\text { 1999) } \\
\text { (Browning, T. } \\
\text { R.; Fricke, E.; } \\
\text { Negele, H., } \\
\text { 2006) }\end{array}$ & PDP & $\begin{array}{l}\text { Modelo de iterações } \\
\text { sequenciais (Sequential } \\
\text { Iteration Model) } \\
\end{array}$ & $\begin{array}{l}\text { Uma rede estruturada de atividades com dependências } \\
\text { substanciais e cíclicas }\end{array}$ \\
\hline $\begin{array}{l}\text { (Paul Bunch and } \\
\text { Gary Blau, } \\
\text { 2002) } \\
\text { (Browning, T. } \\
\text { R.; Fricke, E.; } \\
\text { Negele, H., } \\
\text { 2006) }\end{array}$ & PDP & $\begin{array}{l}\text { Modelo de planejamento de } \\
\text { simulação dinâmica (Dinamic } \\
\text { Simulation Planning model) }\end{array}$ & $\begin{array}{l}\text { Um conjunto de fases/estágios sequenciais ou iterativos } \\
\text { normalmente com critérios para transição de estágios. }\end{array}$ \\
\hline $\begin{array}{l}\text { (Smith, R. P.; } \\
\text { Morrow, J. A., } \\
\text { 1999) } \\
\text { (Browning, T. } \\
\text { R.; Fricke, E.; } \\
\text { Negele, H., } \\
\text { 2006) }\end{array}$ & PDP & $\begin{array}{l}\text { Modelo de redes de filas } \\
\text { (Queueing network model) }\end{array}$ & $\begin{array}{l}\text { Uma rede de atividades executadas e restringidas por } \\
\text { recursos limitados. Aplica mais recentes resultados } \\
\text { analíticos de redes de filas considerando aproximações } \\
\text { Brownianas e redes de fork-join para resolver o } \\
\text { problema de desenvolvimento de produtos, que é visto } \\
\text { como uma rede de filas. Os resultados do modelo } \\
\text { indicam a capacidade total disponível para qualquer } \\
\text { estrutura de rede, como também um tempo de ciclo de } \\
\text { uma dada taxa de produção e combinação de recursos. }\end{array}$ \\
\hline $\begin{array}{l}\text { (Paul Bunch and } \\
\text { Gary Blau, } \\
\text { 2002) } \\
\text { (Browning, T. } \\
\text { R.; Fricke, E.; } \\
\text { Negele, H., } \\
\text { 2006) }\end{array}$ & PDP & $\begin{array}{l}\text { Modelos de planejamento de } \\
\text { estado estático (Steady state } \\
\text { planning model) }\end{array}$ & $\begin{array}{l}\text { Um conjunto de fases/estágios sequenciais ou iterativos } \\
\text { normalmente com critérios para transição de estágios }\end{array}$ \\
\hline $\begin{array}{l}\text { (Browning, T. } \\
\text { R.; Fricke, E.; } \\
\text { Negele, H., } \\
\text { 2006) }\end{array}$ & PDP & $\begin{array}{l}\text { Modelos de teoria do } \\
\text { Controlee (Controle Theory } \\
\text { Models) }\end{array}$ & $\begin{array}{l}\text { Conjunto de atividades simultâneas que geram trabalho } \\
\text { umas para as outras. }\end{array}$ \\
\hline $\begin{array}{l}\text { (Browning T.R., } \\
\text { 2008) } \\
\text { (Barbalho, S. C. } \\
\text { M.; Amaral, D. } \\
\text { C.; Rozenfeld, } \\
\text { H., 2003) } \\
\text { (Phillips, C.; } \\
\text { Kemp, E., 2002) }\end{array}$ & PDP & Narrativa textual & $\begin{array}{l}\text { Documentação do processo que explica em palavras o } \\
\text { que deve ser feito e como. }\end{array}$ \\
\hline $\begin{array}{l}\text { (Jun H.-B.; Suh } \\
\text { H.-W., 2008) }\end{array}$ & PDP & New Modelling Framework & \\
\hline
\end{tabular}




\begin{tabular}{|c|c|c|c|}
\hline Referências & Processo & $\begin{array}{l}\text { Nome do } \\
\text { Método/Técnica }\end{array}$ & Descrição \\
\hline $\begin{array}{l}\text { (Smith, R. P.; } \\
\text { Morrow, J. A., } \\
\text { 1999) } \\
\text { (Browning, T. } \\
\text { R.; Fricke, E.; } \\
\text { Negele, H., } \\
\text { 2006) }\end{array}$ & PDP & $\begin{array}{l}\text { Programação paralela } \\
\text { (Parallel scheduling) } \\
\end{array}$ & $\begin{array}{l}\text { Duplas de atividades em pares, que podem ser } \\
\text { sobrepostas em alguma medida }\end{array}$ \\
\hline $\begin{array}{l}\text { (Browning, T. } \\
\text { R.; Fricke, E.; } \\
\text { Negele, H., } \\
\text { 2006) }\end{array}$ & PDP & Rede de compromissos & $\begin{array}{l}\text { Uma rede de compromissos implicados por } \\
\text { dependências entre atividades. }\end{array}$ \\
\hline $\begin{array}{l}\text { (Karniel A., } \\
\text { Reich Y., 2011) }\end{array}$ & PDP & $\begin{array}{l}\text { Rede de fluxo de trabalho } \\
\text { (Workflow net - WFnet) }\end{array}$ & $\begin{array}{l}\text { WFnets, sendo uma sub-classe de redes de Petri, } \\
\text { fornecem ferramentas formais para verificar } \\
\text { propriedades do processo. Bem elaboradas com } \\
\text { iterações regulares (RI), (WRI)-WF nets são uma sub- } \\
\text { classe de WF nets que permitem uma construção do } \\
\text { processo automatizada. }\end{array}$ \\
\hline $\begin{array}{l}\text { (Jun H.-B., } \\
\text { Suh H.-W., } \\
\text { 2008) } \\
\text { (O'Donovan, } \\
\text { B; Eckert, C; } \\
\text { Clarkson, J.; } \\
\text { Browning, T. } \\
\text { R., 2005) } \\
\text { (Browning, T. } \\
\text { R.; Fricke, E.; } \\
\text { Negele, H., } \\
\text { 2006) (Krause } \\
\text { F.-L.. Kind C., } \\
\text { Voigtsberger } \\
\text { J., 2004) }\end{array}$ & PDP & Rede de Petri & $\begin{array}{l}\text { Técnica baseada em gráficos que descreve fluxos de } \\
\text { informação em projetos de engenharia usando redes de } \\
\text { petri. Um sistema de eventos discretos de atividades } \\
\text { (transformações) e estados. O modelo do processo é } \\
\text { gerado dinamicamente no momento da simulação com } \\
\text { base no seu estado corrente em qualquer momento, ao } \\
\text { invés de ser gerado estaticamente. O conhecimento } \\
\text { corporativo de processo é explicitamente considerado, } \\
\text { integrando uma biblioteca de processos genéricos. }\end{array}$ \\
\hline $\begin{array}{l}\text { (Aguillar Savén, } \\
\text { R., 2004) } \\
\text { (Deng Q., Yang } \\
\text { L., 2011) } \\
\text { (Browning, T. } \\
\text { R.; Fricke, E.; } \\
\text { Negele, H., } \\
\text { 2006) }\end{array}$ & BPM / PDP & $\begin{array}{l}\text { Redes de Petri coloridas } \\
\text { (Coloured Petri Nets - CPNs) }\end{array}$ & $\begin{array}{l}\text { Linguagem orientada a gráficos para projetar, } \\
\text { especificar, simular e verificar sistemas. Um sistemas de } \\
\text { eventos discretos de atividades (transformações) e } \\
\text { estados. Uma CPN é uma extensão de ums rede de petri } \\
\text { clássica. Ela designa diferentes cores para símbolos de } \\
\text { lugares para representar coisas distintas. }\end{array}$ \\
\hline $\begin{array}{l}\text { (Jun H.-B., } \\
\text { Suh H.-W., } \\
\text { 2008) }\end{array}$ & PDP & $\begin{array}{l}\text { Roteiro de projeto (Design } \\
\text { roadmap) }\end{array}$ & $\begin{array}{l}\text { - Técnica baseada em gráficos proposta para descrever } \\
\text { processos de DP de larga escala e maduros, que } \\
\text { possuem numerosas tarefas. } \\
\text { - Desenvolvida em esforços para superar as limitações } \\
\text { de técnicas tradicionais de modelagem como CPM e } \\
\text { PERT. }\end{array}$ \\
\hline $\begin{array}{l}\text { (Jun H.-B.; } \\
\text { Suh H.-W., } \\
\text { 2008) }\end{array}$ & PDP & Signal Flow Graph & $\begin{array}{l}\text { - Técnica baseada em gráficos proposta para } \\
\text { representar iterações. } \\
\text { - Desenvolvida em esforços para superar as limitações } \\
\text { de técnicas tradicionais de modelagem como CPM e } \\
\text { PERT.. }\end{array}$ \\
\hline
\end{tabular}




\begin{tabular}{|c|c|c|c|}
\hline Referências & Processo & $\begin{array}{l}\text { Nome do } \\
\text { Método/Técnica }\end{array}$ & Descrição \\
\hline $\begin{array}{l}\text { (O'Donovan, B; } \\
\text { Eckert, C; } \\
\text { Clarkson, J.; } \\
\text { Browning, T. R., } \\
\text { 2005) } \\
\text { (Browning, T. } \\
\text { R.; Fricke, E.; } \\
\text { Negele, H., } \\
\text { 2006) }\end{array}$ & PDP & Signposting & $\begin{array}{l}\text { Modelo baseado em atividades que representa } \\
\text { informações de características de entradas e saídas. } \\
\text { Permite requisitos alternativos para entradas e } \\
\text { capacidades de saída dependedo da confiabilidade e } \\
\text { maturidade da informação. }\end{array}$ \\
\hline $\begin{array}{l}\text { (Smith, R. P.; } \\
\text { Morrow, J. A., } \\
\text { 1999) } \\
\text { (Browning, T. } \\
\text { R.; Fricke, E.; } \\
\text { Negele, H., } \\
\text { 2006) }\end{array}$ & PDP & $\begin{array}{l}\text { Sobreposição de estágios } \\
\text { (Stage overlapping) }\end{array}$ & $\begin{array}{l}\text { Duplas de atividades em pares, que podem ser } \\
\text { sobrepostas em alguma medida }\end{array}$ \\
\hline $\begin{array}{l}\text { (Browning T.R., } \\
\text { 2008) }\end{array}$ & PDP & $\begin{array}{l}\text { Tabela criar-ler-atualizar- } \\
\text { apagar (Create-Read-Update- } \\
\text { Delete - CRUD) }\end{array}$ & $\begin{array}{l}\text { Mostra efeitos de atividades nas entregas. Uma } \\
\text { atividade pode criar, usar, modificar e/ou apagar uma } \\
\text { entrega. Técnica baseada em matrizes }\end{array}$ \\
\hline $\begin{array}{l}\text { (Jun H.-B., } \\
\text { Suh H.-W., } \\
\text { 2008) } \\
\text { (Browning, T. } \\
\text { R.; Fricke, E.; } \\
\text { Negele, H., } \\
\text { 2006) } \\
\text { (O'Donovan, } \\
\text { B; Eckert, C; } \\
\text { Clarkson, J.; } \\
\text { Browning, T. } \\
\text { R., 2005) } \\
\text { (Sonnemans } \\
\text { P.J.M., } \\
\text { Geudens } \\
\text { W.H.J., } \\
\text { Brombacher } \\
\text { A.C., 2003) }\end{array}$ & PDP & $\begin{array}{l}\text { Técnica de avaliação e revisão } \\
\text { de projeto (Project Evaluation } \\
\text { and Review Technique - } \\
\text { PERT) }\end{array}$ & $\begin{array}{l}\text { Técnica baseada em gráficos. Fluxo de atividades com } \\
\text { dependências nominais e acíclicas. Usado em gestão de } \\
\text { projetos para analisar o tempo de conclusão do projeto } \\
\text { ou tempo de lançamento do produto. }\end{array}$ \\
\hline $\begin{array}{l}\text { (Jun H.-B., } \\
\text { Suh H.-W., } \\
\text { 2008) } \\
\text { (Browning, T. } \\
\text { R.; Fricke, E.; } \\
\text { Negele, H., } \\
\text { 2006) } \\
\text { (Browning } \\
\text { T.R., 2008) } \\
\end{array}$ & PDP & $\begin{array}{l}\text { Técnica de avaliação e revisão } \\
\text { gráfica (Graphical Evaluate } \\
\text { and Review Technique - } \\
\text { GERT) }\end{array}$ & $\begin{array}{l}\text { Técnica baseada em gráficos. Rede de atividades com } \\
\text { dependências cíclicas (looping). Extensão do PERT que } \\
\text { permite ramificações probabilísticas entre atividades } \\
\text { (nós). Arcos são nomeados com letras e tem } \\
\text { probabilidades associadas. Desenvolvida em esforços } \\
\text { para superar as limitações de técnicas tradicionais de } \\
\text { modelagem como CPM e PERT. }\end{array}$ \\
\hline $\begin{array}{l}\text { (Smith, R. P.; } \\
\text { Morrow, J. A., } \\
\text { 1999) } \\
\text { (Browning, T. } \\
\text { R.; Fricke, E.; } \\
\text { Negele, H., } \\
\text { 2006) }\end{array}$ & PDP & $\begin{array}{l}\text { Técnica de avaliação e revisão } \\
\text { gráfica (Q-GERT model) }\end{array}$ & $\begin{array}{l}\text { Rede de atividades com dependências cíclicas (looping) } \\
\text { Considera a necessidade de iteração assim como os } \\
\text { atrasos potenciais no desenvolvimento de produtos } \\
\text { causados por filas. }\end{array}$ \\
\hline
\end{tabular}




\begin{tabular}{|c|c|c|c|}
\hline Referências & Processo & $\begin{array}{l}\text { Nome do } \\
\text { Método/Técnica }\end{array}$ & Descrição \\
\hline $\begin{array}{l}\text { (Smith, R. P.; } \\
\text { Morrow, J. A., } \\
\text { 1999) } \\
\text { (Browning, T. } \\
\text { R.; Fricke, E.; } \\
\text { Negele, H., } \\
\text { 2006) }\end{array}$ & PDP & $\begin{array}{l}\text { Tempo de revisões de projeto } \\
\text { (Timing of design reviews) }\end{array}$ & $\begin{array}{l}\text { Assume a existência de dois tipos de atividades de } \\
\text { projeto: atividades de projeto de produto e atividades } \\
\text { de projeto de processo. Qualquer atividade de projeto } \\
\text { pode criar uma falha que só será descoberta na próxima } \\
\text { revisão de projeto. }\end{array}$ \\
\hline $\begin{array}{l}\text { (Li X.J., Yuan } \\
\text { Y.P., 2011) }\end{array}$ & PDP & $\begin{array}{l}\text { Teoria de redes complexas } \\
\text { (Complex Network theory) }\end{array}$ & $\begin{array}{l}\text { O relacionamento entre cada estrutura de tarefa do } \\
\text { evento é: nó representa os eventos provenientes de } \\
\text { uma tarefa; conexão representa a estrutura de tempo } \\
\text { entre esses eventos. }\end{array}$ \\
\hline
\end{tabular}




\section{Apêndice C2 - Métodos de modelagem: variáveis chave e atributos}

\begin{tabular}{|c|c|}
\hline Nome do Método/Técnica & Variáveis chave/Atributos \\
\hline $\begin{array}{l}\text { Agendamento de módulos (Module } \\
\text { scheduling) }\end{array}$ & $\begin{array}{l}\text { - Módulos and Atividades } \\
\text { - Tempo } \\
\text { - Milestones } \\
\text { - Estágios iterativos? } \\
\text { - Impedância de gates } \\
\text { - Principais pontos de decisão }\end{array}$ \\
\hline \multicolumn{2}{|l|}{$\begin{array}{l}\text { Análise de áreas interrelacionadas de } \\
\text { decisão (Analysis of interconnected } \\
\text { decision areas - AIDA) }\end{array}$} \\
\hline $\begin{array}{l}\text { Cadeia extendida de processos orientados } \\
\text { a eventos (Extended Event-driven Process } \\
\text { Chain - EPC) }\end{array}$ & $\begin{array}{l}\text { - Atividades } \\
\text { - Eventos } \\
\text { - Itens de informação } \\
\text { - Unidades organizacionais } \\
\text { - Processo: nome, filhos, Eventos, Unidades organizacionais, Entregas } \\
\text { - Atividade: nome, Entradas, Saídas, Fornecedores, Clientes, Unidade } \\
\text { organizacional responsável } \\
\text { - Entrega: nome, fornecedor, cliente, condições de fluxo, pais, filhos. }\end{array}$ \\
\hline $\begin{array}{l}\text { Diagrama de atividades em arcos (Activity- } \\
\text { on-Arc Diagram) }\end{array}$ & $\begin{array}{l}\text { - Atividades } \\
\text { - Tempo de duração } \\
\text { - Dependências entre atividades } \\
\text { - Nome do processo } \\
\text { - Filhos do processo } \\
\text { - Estados do processo } \\
\text { - Nome da atividade } \\
\text { - Fornecedores da atividade } \\
\text { - Clientes da atividade } \\
\text { - Durações de atividades }\end{array}$ \\
\hline $\begin{array}{l}\text { Diagrama de Entrada-Tarefa-Validação- } \\
\text { Saída (Entry-Task-Validation-Exit (ETVX) } \\
\text { Diagram) }\end{array}$ & $\begin{array}{l}\text { - Atividades } \\
\text { - Tarefas } \\
\text { - Critérios de entrada } \\
\text { - Validações } \\
\text { - Critérios de saída } \\
\text { - Entradas, Fornecedores } \\
\text { - Saídas, Clientes } \\
\text { - Sub-processos }\end{array}$ \\
\hline Diagrama de estado (State Diagram) & $\begin{array}{l}\text { - Fluxo de atividades } \\
\text { - Eventos } \\
\text { - Estados }\end{array}$ \\
\hline $\begin{array}{l}\text { Diagrama de fluxo de dados (Data Flow } \\
\text { Diagram - DFD) }\end{array}$ & Fluxo de dados \\
\hline $\begin{array}{l}\text { Diagrama de fluxo e estoque (Stock-and- } \\
\text { Flow Diagram) }\end{array}$ & $\begin{array}{l}\text { - Atividades (como estoque) } \\
\text { - Fluxo de trabalho } \\
\text { - Taxa de produtividade } \\
\text { - Resultados } \\
\end{array}$ \\
\hline Diagrama SIPOC & $\begin{array}{l}\text { - Atividades } \\
\text { - Entradas (Entregas) } \\
\text { - Fornecedores (sources) } \\
\text { - Processes } \\
\text { - Saídas (Entregas) } \\
\text { - Clientes (destinations) } \\
\text { - sub-processos }\end{array}$ \\
\hline Entrega de produto (Product release) & - Milestones \\
\hline
\end{tabular}




\begin{tabular}{|c|c|}
\hline Nome do Método/Técnica & Variáveis chave/Atributos \\
\hline $\begin{array}{l}\text { Estimativa de tempo de ciclos iterativos } \\
\text { (Iterative cycle time estimation) }\end{array}$ & $\begin{array}{l}\text { - Relacionamentos probabilísticos (OR, XOR) entre tarefas } \\
\text { - Forças de dependências } \\
\text { - Sequencia de atividades } \\
\text { - Estrutura de rede }\end{array}$ \\
\hline Feedbacks and Crossovers & $\begin{array}{l}\text { - Forças de dependências } \\
\text { - Sequencia de atividades } \\
\text { - Estrutura de rede }\end{array}$ \\
\hline Fluxograma & $\begin{array}{l}\text { - Fluxo de ações } \\
\text { - Duração de atividades estocástica } \\
\text { - Elasticidade tempo-custo } \\
\text { - Folgas/Tempos flutuantes } \\
\text { - Início e final cedo e tarde. } \\
\text { - Fluxo de atividades } \\
\text { - Relacionamentos entre atividades }\end{array}$ \\
\hline \multicolumn{2}{|l|}{ Generic Design Model (GDM) } \\
\hline Gráfico de entregas (Milestone Chart) & $\begin{array}{l}\text { - Atividades } \\
\text { - Tempo de duração } \\
\text { - Atividades status } \\
\text { - Eventos (milestones) } \\
\text { - Tipos de relacionamento entre atividades } \\
\text { - Tempos de início e término cedo }\end{array}$ \\
\hline Gráfico de Gantt (Gantt Chart) & $\begin{array}{l}\text { - Fluxo de atividades e duração } \\
\text { - Atividades } \\
\text { - Tempo de duração } \\
\text { - Atividades status }\end{array}$ \\
\hline $\begin{array}{l}\text { Gráfico de tarefas atividades nos nós } \\
\text { (Activity-on-node task graph) }\end{array}$ & $\begin{array}{l}\text { - Atividades } \\
\text { - Relacionamentos } \\
\text { - Duração de atividades estocástica } \\
\text { - Elasticidade tempo-custo } \\
\text { - Folgas/Tempos flutuantes } \\
\text { - Início e final cedo e tarde. }\end{array}$ \\
\hline Gráfico direto (Directed graph) & $\begin{array}{l}\text { - Duração de atividades estocástica } \\
\text { - Elasticidade tempo-custo } \\
\text { - Folgas/Tempos flutuantes } \\
\text { - Início e final cedo e tarde. }\end{array}$ \\
\hline $\begin{array}{l}\text { IDEFO - Definição integrada para } \\
\text { modelagem de funções }\end{array}$ & $\begin{array}{l}\text { - Atividades } \\
\text { - Funções } \\
\text { - Entradas } \\
\text { - Saídas } \\
\text { - Controle } \\
\text { - Mecanismos }\end{array}$ \\
\hline $\begin{array}{l}\text { IDEF3 - Definição integrada para } \\
\text { modelagem de funções }\end{array}$ & $\begin{array}{l}\text { - Relacionamentos de causa e efeito entre atividades } \\
\text { - Atvidades: Entradas, Controles, Saídas, Mecanismos (ICOMs) } \\
\text { - Ênfase em juntas de fluxo (And, Or, Xor, sincronizado ou asincronizado) }\end{array}$ \\
\hline $\begin{array}{l}\text { Liberação de tempo de uma única } \\
\text { atividade iterativa incerta (Release time of } \\
\text { a single uncertain iterative activity) }\end{array}$ & $\begin{array}{l}\text { - Processo sequencial } \\
\text { - Processo paralelo } \\
\text { - Estruturas de decisão (milestones) }\end{array}$ \\
\hline
\end{tabular}




\begin{tabular}{|c|c|}
\hline Nome do Método/Técnica & Variáveis chave/Atributos \\
\hline $\begin{array}{l}\text { Linguagem universal de modelagem } \\
\text { (Universal Modelling Language - UML) }\end{array}$ & $\begin{array}{l}\text { - Atividades } \\
\text { - Data Entregas } \\
\text { - Regras de produção } \\
\text { - Estrutura do projeto } \\
\text { - Estágios do projeto } \\
\text { - Entregas; } \\
\text { - Dependências do processo; } \\
\text { - Dependências do produto; } \\
\text { - Usuários; }\end{array}$ \\
\hline $\begin{array}{l}\text { Mapeamento da cadeia de valor (Value } \\
\text { Stream Mapping) }\end{array}$ & $\begin{array}{l}\text { - Atividades que adicionam valor } \\
\text { - Fluxo de informações } \\
\text { - Atividades } \\
\text { - Tempo de ciclos } \\
\text { - Tempos de processos } \\
\text { - Tempo de espera entre atividades }\end{array}$ \\
\hline Markov Models & $\begin{array}{l}\text { - Probabilidades de transição } \\
\text { - Durações de atividades }\end{array}$ \\
\hline \multicolumn{2}{|l|}{$\begin{array}{l}\text { Matriz de atribuição de responsabilidades } \\
\text { (Responsibility Assignment Matrix - RAM) }\end{array}$} \\
\hline $\begin{array}{l}\text { Matriz de incidêcia Atividade-Atividade } \\
\text { (Activity-Activity Incidence Matrix) }\end{array}$ & $\begin{array}{l}\text { - Forças de dependências } \\
\text { - Sequencia de atividades } \\
\text { - Estrutura de rede }\end{array}$ \\
\hline $\begin{array}{l}\text { Matriz de transformação de trabalho } \\
\text { (Work transformation matrix) }\end{array}$ & $\begin{array}{l}\text { - Forças de dependências } \\
\text { - Sequencia de atividades } \\
\text { - Estrutura de rede }\end{array}$ \\
\hline $\begin{array}{l}\text { Matriz de transformação de trabalho de } \\
\text { modelos paralelos/seriais (Work } \\
\text { Transformation Matrix (WTM) } \\
\text { parallel/serial model) }\end{array}$ & $\begin{array}{l}\text { - Conjuntos de tarefas } \\
\text { - Forças de dependências } \\
\text { - Sequencia de atividades } \\
\text { - Estrutura de rede } \\
\end{array}$ \\
\hline $\begin{array}{l}\text { Matriz estrutural de projeto (Design } \\
\text { structured Matrix - DSM) }\end{array}$ & $\begin{array}{l}\text { - Forças de dependências } \\
\text { - Sequencia de atividades } \\
\text { - Estrutura de rede } \\
\text { - Atividades } \\
\text { - Entregas } \\
\text { - Relacionamentos } \\
\text { - Frequentemente melhorado para incluir atributos adicionais como: } \\
\text { duração, organização responsável, propabilidade de retrabalho, impacto de } \\
\text { retrabalho, hierarquia entre processo/atividade (pai-filho), etc... }\end{array}$ \\
\hline $\begin{array}{l}\text { Matriz estrutural de projeto fuzzy (Fuzzy } \\
\text { Design Structure Matrix - FDSM) }\end{array}$ & $\begin{array}{l}\text { - Forças de dependências } \\
\text { - Sequencia de atividades } \\
\text { - Estrutura de rede }\end{array}$ \\
\hline Metas de estágio (Stage targeting) & $\begin{array}{l}\text { - Estágios sequenciais } \\
\text { - Recursos } \\
\text { - Estágios iterativos? } \\
\text { - Impedância de gates } \\
\text { - Principais pontos de decisão } \\
\text { - Principais milestones }\end{array}$ \\
\hline $\begin{array}{l}\text { Método de Diagrama de Precedência } \\
\text { (Precedence Diagram Method - PDM) }\end{array}$ & $\begin{array}{l}\text { - Duração de atividades estocástica } \\
\text { - Elasticidade tempo-custo } \\
\text { - Folgas/Tempos flutuantes } \\
\text { - Início e final cedo e tarde. }\end{array}$ \\
\hline $\begin{array}{l}\text { Método do caminho crítico D (D-Critical } \\
\text { Path Method) }\end{array}$ & \\
\hline
\end{tabular}




\begin{tabular}{|c|c|}
\hline Nome do Método/Técnica & Variáveis chave/Atributos \\
\hline $\begin{array}{l}\text { Metodo do caminho crítico } \\
\text { (Critical Path Method - CPM) }\end{array}$ & $\begin{array}{l}\text { - Duração de atividades estocástica } \\
\text { - Elasticidade tempo-custo } \\
\text { - Folgas/Tempos flutuantes } \\
\text { - Início e final cedo e tarde. }\end{array}$ \\
\hline $\begin{array}{l}\text { Minimally Long-tern Organizational } \\
\text { Support (MILOS) }\end{array}$ & - Atividades \\
\hline $\begin{array}{l}\text { Modelagem de processos de negócios } \\
\text { (Business Process Modeling) }\end{array}$ & $\begin{array}{l}\text { - Atividades como objetos com uma miríade de potenciais atributos } \\
\text { - Outros tipos de objetos - e.g., documentos }\end{array}$ \\
\hline Modelo de decomposição 1 & $\begin{array}{l}\text { - Precedência de tarefas } \\
\text { - Ciclos } \\
\text { - Incidência de recursos em atividades } \\
\text { - Forças de dependências } \\
\text { - Sequencia de atividades } \\
\text { - Estrutura de rede }\end{array}$ \\
\hline Modelo de decomposição 2 & $\begin{array}{l}\text { - Tarefas de projeto (design) } \\
\text { - Unidades organizacionais } \\
\text { - Forças de dependências } \\
\text { - Sequencia de atividades } \\
\text { - Estrutura de rede }\end{array}$ \\
\hline $\begin{array}{l}\text { Modelo de decomposição de módulos de } \\
\text { atividades (Activity module decomposition } \\
\text { model) }\end{array}$ & $\begin{array}{l}\text { - Módulos } \\
\text { - Atividades } \\
\text { - Forças de dependências } \\
\text { - Sequencia de atividades } \\
\text { - Estrutura de rede } \\
\end{array}$ \\
\hline $\begin{array}{l}\text { Modelo de iterações sequenciais } \\
\text { (Sequential Iteration Model) }\end{array}$ & $\begin{array}{l}\text { - Fluxo de tarefas } \\
\text { - Forças de dependências } \\
\text { - Sequencia de atividades } \\
\text { - Estrutura de rede }\end{array}$ \\
\hline $\begin{array}{l}\text { Modelo de planejamento de simulação } \\
\text { dinâmica (Dinamic Simulation Planning } \\
\text { model) }\end{array}$ & $\begin{array}{l}\text { - Recursos } \\
\text { - Estágios iterativos? } \\
\text { - Impedância de gates } \\
\text { - Principais pontos de decisão } \\
\text { - Principais milestones }\end{array}$ \\
\hline $\begin{array}{l}\text { Modelo de redes de filas (Queueing } \\
\text { network model) }\end{array}$ & $\begin{array}{l}\text { - Requisitos de recursos de atividades } \\
\text { - Prioridades de recursos e atribuições }\end{array}$ \\
\hline $\begin{array}{l}\text { Modelos de planejamento de estado } \\
\text { estático (Steady state planning model) }\end{array}$ & $\begin{array}{l}\text { - Milestones } \\
\text { - Estágios iterativos? } \\
\text { - Impedância de gates } \\
\text { - Principais pontos de decisão } \\
\text { - Principais milestones }\end{array}$ \\
\hline $\begin{array}{l}\text { Modelos de teoria do Controlee (Controle } \\
\text { Theory Models) }\end{array}$ & - Alocação de recursos e matrizes de transformação de trabalho \\
\hline Narrativa textual (Storyboard) & $\begin{array}{l}\text { - Atividades } \\
\text { - Eventos } \\
\text { - Entregas. }\end{array}$ \\
\hline \multicolumn{2}{|l|}{ New Modelling Framework } \\
\hline Programação paralela (Parallel scheduling) & $\begin{array}{l}\text { - Taxa de evolução da informação } \\
\text { - Sensibilidade da atividade às entradas } \\
\text { - Custos de retrabalho } \\
\text { - Frequencia de intercâmbio de informações } \\
\text { - Tarefas de projeto (design) }\end{array}$ \\
\hline Rede de compromissos & $\begin{array}{l}\text { - Atos de comunicação } \\
\text { - Estado de compromissos }\end{array}$ \\
\hline $\begin{array}{l}\text { Rede de fluxo de trabalho (Workflow net - } \\
\text { WFnet) }\end{array}$ & \\
\hline
\end{tabular}




\begin{tabular}{|c|c|}
\hline Nome do Método/Técnica & Variáveis chave/Atributos \\
\hline Rede de Petri & $\begin{array}{l}\text { - Atividades } \\
\text { - Locais } \\
\text { - Transições } \\
\text { - Arcos } \\
\text { - Símbolos } \\
\text { - Estados, transformações, arcos ponderados } \\
\text { - Gráficos de eventos } \\
\text { - Circuitos e loops }\end{array}$ \\
\hline $\begin{array}{l}\text { Redes de Petri coloridas (Coloured Petri } \\
\text { Nets - CPNs) }\end{array}$ & $\begin{array}{l}\text { - Estados, transformações, arcos ponderados } \\
\text { - Gráficos de eventos } \\
\text { - Circuitos e loops }\end{array}$ \\
\hline \multicolumn{2}{|l|}{ Roteiro de projeto (Design roadmap) } \\
\hline \multicolumn{2}{|l|}{ Signal Flow Graph } \\
\hline Signposting & $\begin{array}{l}\text { - Atividades } \\
\text { - Limitações de recursos } \\
\text { - Simultaneidade de atividades } \\
\text { - Efeito na curva de aprendizado/experiência } \\
\text { - Impact of tradding off quality against process duration/cost } \\
\text { - Níveis de confiança de entradas e saídas } \\
\text { - Possibilidade de atividades }\end{array}$ \\
\hline $\begin{array}{l}\text { Sobreposição de estágios (Stage } \\
\text { overlapping) }\end{array}$ & $\begin{array}{l}\text { - Taxa de evolução da informação } \\
\text { - Sensibilidade da atividade às entradas } \\
\text { - Custos de retrabalho } \\
\text { - Frequencia de intercâmbio de informações }\end{array}$ \\
\hline $\begin{array}{l}\text { Tabela criar-ler-atualizar-apagar (Create- } \\
\text { Read-Update-Delete - CRUD) }\end{array}$ & $\begin{array}{l}\text { - Atividades } \\
\text { - Entregas } \\
\text { - Efeitos das atividades nas entregas }\end{array}$ \\
\hline $\begin{array}{l}\text { Técnica de avaliação e revisão de projeto } \\
\text { (Project Evaluation and Review Technique } \\
\text { - PERT) }\end{array}$ & $\begin{array}{l}\text { - Duração de atividades estocástica } \\
\text { - Elasticidade tempo-custo } \\
\text { - Folgas/Tempos flutuantes } \\
\text { - Início e final cedo e tarde. }\end{array}$ \\
\hline $\begin{array}{l}\text { Técnica de avaliação e revisão gráfica } \\
\text { (Graphical Evaluate and Review Technique } \\
\text { - GERT) }\end{array}$ & $\begin{array}{l}\text { - Nós do tipo AND, OR, XOR } \\
\text { - Atividades } \\
\text { - Ramificações e loopings probabilísticos } \\
\text { - Entradas determinadas } \\
\text { - Saídas probabilísticas }\end{array}$ \\
\hline $\begin{array}{l}\text { Técnica de avaliação e revisão gráfica (Q- } \\
\text { GERT model) }\end{array}$ & $\begin{array}{l}\text { - Ramificações e loopings probabilísticos } \\
\text { - Nós do tipo AND, OR, XOR }\end{array}$ \\
\hline $\begin{array}{l}\text { Tempo de revisões de projeto (Timing of } \\
\text { design reviews) }\end{array}$ & $\begin{array}{l}\text { - Tempo } \\
\text { - Atividades } \\
\text { - Revisões de projeto } \\
\text { - Entrega do produto } \\
\text { - Milestones } \\
\end{array}$ \\
\hline $\begin{array}{l}\text { Teoria de redes complexas (Complex } \\
\text { Network theory) }\end{array}$ & $\begin{array}{l}\text { - Eventos } \\
\text { - Atividades } \\
\text { - Estrutura de tempo }\end{array}$ \\
\hline
\end{tabular}





\section{Apêndice C3 - Métodos de modelagem: características}

\begin{tabular}{|c|c|}
\hline Nome do Método/Técnica & Características \\
\hline $\begin{array}{l}\text { Agendamento de módulos } \\
\text { (Module scheduling) }\end{array}$ & $\begin{array}{l}\text { - Existe um número fixo total de módulos } \\
\text { - Um evento de coordenação ocorre após um certo número de módulos serem } \\
\text { concluídos, o que é outra variável de decisão. } \\
\text { - O tempo total de desenvolvimento é fixado com antecedência. } \\
\text { - Análise do modelo é apresentado com base nos resultados numéricos de } \\
\text { exemplos sobre muitos módulos idênticos. } \\
\text { - Os resultados dizem respeito a fenômenos como o tamanho da equipe ótima } \\
\text { como uma função do tempo disponível e o número ótimo de módulos que devem } \\
\text { ser completados antes de um evento de coordenação como uma função do número } \\
\text { total de módulos. } \\
\text { - Modelos de niveis mais baixos vão gerir dentro dos estágios } \\
\text { - Gates de decisão entre estágios }\end{array}$ \\
\hline $\begin{array}{l}\text { Análise de áreas interrelacionadas } \\
\text { de decisão (Analysis of } \\
\text { interconnected decision areas - } \\
\text { AIDA) }\end{array}$ & $\begin{array}{l}\text { AIDA assume que há um número de subproblemas dentro de cada problema de } \\
\text { criação, e cada subproblema tem uma variedade de soluções possíveis. Algumas das } \\
\text { sub soluções serão incompatíveis com soluções para outros subproblemas. Se nós } \\
\text { sabemos quais são essas incompatibilidades, então é possível encontrar conjuntos } \\
\text { viáveis de solução sem incompatibilidades conhecidas. }\end{array}$ \\
\hline $\begin{array}{l}\text { Cadeia extendida de processos } \\
\text { orientados a eventos (Extended } \\
\text { Event-driven Process Chain - EPC) }\end{array}$ & $\begin{array}{l}\text { Mais abrangente das representações nesta tabela, mas pode se tornar complicado } \\
\text { quando todos os objetos são incluídos de uma só vez. Pode ser usado para filtrar os } \\
\text { subconjuntos de objetos e mostrar apenas aqueles de interesse. }\end{array}$ \\
\hline $\begin{array}{l}\text { Diagrama de atividades em arcos } \\
\text { (Activity-on-Arc Diagram) }\end{array}$ & Atividades são transições entre estados, incluindo arcos e eventos fictícios. \\
\hline $\begin{array}{l}\text { Diagrama de Entrada-Tarefa- } \\
\text { Validação-Saída (Entry-Task- } \\
\text { Validation-Exit (ETVX) Diagram) }\end{array}$ & $\begin{array}{l}\text { - Enfatiza critérios de entrada, as sub-tarefas a serem realizadas, os métodos de } \\
\text { validação do trabalho (testes) e os critérios de saída. } \\
\text { - Tempo é frequentemente ignorado } \\
\text { - Links de entradas e saídas devem coincidir }\end{array}$ \\
\hline $\begin{array}{l}\text { Diagrama de estado (State } \\
\text { Diagram) }\end{array}$ & $\begin{array}{l}\text { Atividades são estágios (como em redes de Petri e UML). Aplicações em processos } \\
\text { de projeto requerem a possibilidade de estar em mais de um estado ao mesmo } \\
\text { tempo. }\end{array}$ \\
\hline $\begin{array}{l}\text { Diagrama de fluxo de dados (Data } \\
\text { Flow Diagram - DFD) }\end{array}$ & - Explica níveis lógicos e sub-camadas \\
\hline $\begin{array}{l}\text { Diagrama de fluxo e estoque } \\
\text { (Stock-and-Flow Diagram) }\end{array}$ & $\begin{array}{l}\text { Taxas mais altas dos três variáveis reguladoras de fluxo implicam em menor tempo } \\
\text { de conclusão do processo. Não identifica atividades discretas, entregas ou } \\
\text { relacionamentos de precedência. }\end{array}$ \\
\hline Diagrama SIPOC & $\begin{array}{l}\text { - Mais uma tabela que um diagrama. } \\
\text { - Tempo é frequentemente ignorado } \\
\text { - Links de entradas e saídas devem coincidir } \\
\text { As duas primeiras colunas possuem uma correspondência um para um com as } \\
\text { linhas, da mesma forma que as duas últimas colunas. O coluna do meio não se } \\
\text { relaciona com as outras colunas. }\end{array}$ \\
\hline $\begin{array}{l}\text { Entrega de produto (Product } \\
\text { release) }\end{array}$ & $\begin{array}{l}\text { - Assume-se que o desempenho do produto é uma função crescente do tempo de } \\
\text { desenvolvimento. } \\
\text { - Assume-se que o desempenho do produto tem uma forma Cobb-Douglas de } \\
\text { aumento, similar aos pressupostos comuns em economia para Funções de } \\
\text { produção. } \\
\text { - O modelo de demanda dos consumidores usa o modelo logit para sua forma } \\
\text { funcional. }\end{array}$ \\
\hline $\begin{array}{l}\text { Estimativa de tempo de ciclos } \\
\text { iterativos (Iterative cycle time } \\
\text { estimation) }\end{array}$ & $\begin{array}{l}\text { - Probabilidade de executar um ou mais caminhos OR/XOR é dependente do } \\
\text { número de iterações, e essas probabilidades são fixadas a priori. } \\
\text { - A duração de uma tarefa é fixa e determinada } \\
\text { - Rede de dependências é relativamente densa } \\
\text { - Dependências de respostas causam iterações/retrabalhos }\end{array}$ \\
\hline
\end{tabular}




\begin{tabular}{|c|c|}
\hline Nome do Método/Técnica & Características \\
\hline Feedbacks and Crossovers & $\begin{array}{l}\text { - Baseada na redução do número de respostas de informação, informação de } \\
\text { crossovers e comprimento de ciclos iterativos. } \\
\text { - Algoritmos genéticos são úteis para encontrar soluções ótimas para instâncias } \\
\text { grandes. } \\
\text { - Rede de dependências é relativamente densa } \\
\text { - Dependências de respostas causam iterações/retrabalhos }\end{array}$ \\
\hline Fluxograma & $\begin{array}{l}\text { - Não possui sub camadas } \\
\text { - Bom detalhamento } \\
\text { - Não proporciona visão geral } \\
\text { - Relacionamento de atividades término-para-início } \\
\text { - Tempos independentes de atividades } \\
\text { - Caminho crítico = duração do projeto } \\
\text { - Frequentemente melhorado para incluir atributos adicionais (como organização } \\
\text { responsável, swin lanes, etc.) }\end{array}$ \\
\hline Generic Design Model (GDM) & $\begin{array}{l}\text { - Define taxonomias genéricas de tarefas e outras entidades (requisitos, dados de } \\
\text { concepção, etc ..) }\end{array}$ \\
\hline $\begin{array}{l}\text { Gráfico de entregas (Milestone } \\
\text { Chart) }\end{array}$ & $\begin{array}{l}\text { - Frequentemente melhorado para incluir atributos adicionais: percent complete, } \\
\text { process/activity hierarchy (parent-children), etc. } \\
\text { - Relacionamentos de atividades além de F-to-S: F-to-F, S-to-S, and S-to-F. }\end{array}$ \\
\hline Gráfico de Gantt (Gantt Chart) & $\begin{array}{l}\text { - Refinamento da informação de projeto (pode representar o status aproximado de } \\
\text { conclusão de uma atividade) } \\
\text { - Relaciona atividades ao tempo } \\
\text { - Frequentemente melhorado para incluir atributos adicionais: percent complete, } \\
\text { process/activity hierarchy (parent-children), etc. }\end{array}$ \\
\hline $\begin{array}{l}\text { Gráfico de tarefas atividades nos } \\
\text { nós } \\
\text { (Activity-on-node task graph) }\end{array}$ & $\begin{array}{l}\text { - Modelagem } \\
\text { - Simulação } \\
\text { - Manipulação das iterações de processo } \\
\text { - Relacionamento de atividades término-para-início } \\
\text { - Tempos independentes de atividades } \\
\text { - Caminho crítico = duração do projeto }\end{array}$ \\
\hline Gráfico direto (Directed graph) & $\begin{array}{l}\text { - Relacionamento de atividades término-para-início } \\
\text { - Tempos independentes de atividades } \\
\text { - Caminho crítico = duração do projeto } \\
\text { - Iteração de respostas } \\
\text { - Iteração de negociação } \\
\text { - Analizar } \\
\text { - Sintetizar }\end{array}$ \\
\hline $\begin{array}{l}\text { IDEFO - Definição integrada para } \\
\text { modelagem de funções }\end{array}$ & $\begin{array}{l}\text { - Iteração de negociação } \\
\text { - Analizar } \\
\text { - Sintetizar } \\
\text { - Indica fluxos de informações e Recursos } \\
\text { - Indica precedência } \\
\text { - Estrutura hierárquica forte } \\
\text { - Baseado no SADT } \\
\text { - Sub-camadas } \\
\text { - Um dos mais populares } \\
\text { - Processos são hierarquias de redes } \\
\text { - Entradas e saídas merecem atenção explícita } \\
\text { - Tempo é frequentemente ignorado } \\
\text { - Distingue três tipos de entradas: dados, controles e mecanismos; e dois tipos de } \\
\text { sáidas: dados e chamadas }\end{array}$ \\
\hline
\end{tabular}




\begin{tabular}{|c|c|}
\hline Nome do Método/Técnica & Características \\
\hline $\begin{array}{l}\text { IDEF3 - Definição integrada para } \\
\text { modelagem de funções }\end{array}$ & $\begin{array}{l}\text { - Iteração de respostas } \\
\text { - Iteração de negociação } \\
\text { - Analizar } \\
\text { - Sintetizar } \\
\text { - Planejamento de incertezas e rotas alternativas } \\
\text { - Estrutura hierárquica forte } \\
\text { - Abordagens de modelagem relacionadas: descrição de transição de estado de } \\
\text { objetos e descrição de fluxo de processo. Este último indica precedências ambos os } \\
\text { temporais e baseada em informações de atividades, e podem incorporar recursos } \\
\text { como resultados aleatórios e iteração. } \\
\text { - Permite diferentes visões } \\
\text { - Sub-camadas } \\
\text { - Processos são hierarquias de redes } \\
\text { - Entradas e saídas merecem atenção explícita } \\
\text { - Tempo é frequentemente ignorado } \\
\text { - Enfatiza os fluxos sincronizados e assincrinizados (AND, OR, XOR) entre atividades. }\end{array}$ \\
\hline $\begin{array}{l}\text { Liberação de tempo de uma única } \\
\text { atividade iterativa incerta (Release } \\
\text { time of a single uncertain iterative } \\
\text { activity) }\end{array}$ & $\begin{array}{l}\text { Orgnizar processos incertos para a entrega rápida de um produto requer um } \\
\text { balanceamento entre a exploração dos pincípios da engenharia simultânea e o risco } \\
\text { de ultrapassar o tempo alvo. }\end{array}$ \\
\hline $\begin{array}{l}\text { Linguagem universal de } \\
\text { modelagem (Universal Modelling } \\
\text { Language - UML) }\end{array}$ & $\begin{array}{l}\text { - Assemelha-se a representação IDEF0, mas é complementado por outros } \\
\text { "esquemas" que indicam a organização, sistemas de apoio, interações, etc } \\
\text { - repositórios de processos padronizados são valiosos } \\
\text { - Processo "se desdobra" em função dos requisitos de informação e resultados } \\
\text { - Utilizado para modelos de especificação (para proporcionar a estrutura com os } \\
\text { requisitos e para servir como um meio de comunicação para os requisitos, funcional, } \\
\text { bem como não-funcional) }\end{array}$ \\
\hline $\begin{array}{l}\text { Mapeamento da cadeia de valor } \\
\text { (Value Stream Mapping) }\end{array}$ & $\begin{array}{l}\text { - Enfatizar a determinação de atividades que agregam valor } \\
\text { - Recentemente adaptado para os processos de modelagem do projeto, também } \\
\text { pode mostrar recursos adicionais do processo e enfatiza a identificação de fontes de } \\
\text { desperdício nos processos. }\end{array}$ \\
\hline Markov Models & $\begin{array}{l}\text { - Conclusão de atividade provoca a transição de estado. } \\
\text { - Estados de retrabalho }\end{array}$ \\
\hline \multicolumn{2}{|l|}{$\begin{array}{l}\text { Matriz de atribuição de } \\
\text { responsabilidades (Responsibility } \\
\text { Assignment Matrix - RAM) }\end{array}$} \\
\hline $\begin{array}{l}\text { Matriz de incidêcia Atividade- } \\
\text { Atividade (Activity-Activity } \\
\text { Incidence Matrix) }\end{array}$ & $\begin{array}{l}\text { - Iteração de respostas } \\
\text { - Iteração de negociação } \\
\text { - Analizar } \\
\text { - Sintetizar } \\
\text { - Rede de dependências é relativamente densa } \\
\text { - Dependências de respostas causam iterações/retrabalhos }\end{array}$ \\
\hline
\end{tabular}




\begin{tabular}{|c|c|}
\hline Nome do Método/Técnica & Características \\
\hline $\begin{array}{l}\text { Matriz de transformação de } \\
\text { trabalho (Work transformation } \\
\text { matrix) }\end{array}$ & $\begin{array}{l}\text { - Iteração de negociação } \\
\text { - Analizar } \\
\text { - Sintetizar } \\
\text { - Planejamento de incertezas e rotas alternativas } \\
\text { - Baseado em DSM } \\
\text { - Assume que retrabalho é uma função linear do trabalho na iteração } \\
\text { imediatamente anterior. } \\
\text { - Saída é o total de trabalho concluído. } \\
\text { - O trabalho total concluído é uma função forte dos auto-valores e auto-vetores da } \\
\text { matriz contendo as quantidades de retrabalho. } \\
\text { - Oa auto-vetores podem ser utilizados ára a decomposição do problema em grupos } \\
\text { de tarefas relativamente desconectados. } \\
\text { - Rede de dependências é relativamente densa } \\
\text { - Dependências de respostas causam iterações/retrabalhos }\end{array}$ \\
\hline $\begin{array}{l}\text { Matriz de transformação de } \\
\text { trabalho de modelos } \\
\text { paralelos/seriais (Work } \\
\text { Transformation Matrix (WTM) } \\
\text { parallel/serial model) }\end{array}$ & $\begin{array}{l}\text { - O tempo total de desenvolvimento e a quantidade total de esforços de engenharia } \\
\text { podem ser calculados baseados no modelo WTM. } \\
\text { - Rede de dependências é relativamente densa } \\
\text { - Dependências de respostas causam iterações/retrabalhos }\end{array}$ \\
\hline $\begin{array}{l}\text { Matriz estrutural de projeto } \\
\text { (Design structured Matrix - DSM) }\end{array}$ & $\begin{array}{l}\text { - Rede de dependências é relativamente densa } \\
\text { - Dependências de respostas causam iterações/retrabalhos } \\
\text { - Assume que cada tarefa de projeto pode ser modelada como tarefa de } \\
\text { processamento de informação, usando e criando informação. } \\
\text { - Indica a necessidade de iteração } \\
\text { - Tarefas da matriz podem ser re-sequenciadas, o que ajuda a identificar tarefas } \\
\text { cíclicas e acíclicas. } \\
\text { - Baseada em algebra de matriz e digrama de precedência de trabalho. } \\
\text { - Ligações entre atividades mostram o fluxo de informação correndo de uma } \\
\text { atividade a outra. } \\
\text { - Sequenciamento de atividades } \\
\text { - Mostra dependências, independências e interdependências entre atividades } \\
\text { - Destaca iterações e retrabalhos } \\
\text { - Pode representar indicadores chave de custo e risco de programação. } \\
\text { - Com a ajuda de simulação é possível quantificar o impacto de mudanças de } \\
\text { arquitetura no custo e riscos de programação } \\
\text { - Ferramenta para guiar a estrutura organizacional de projetos de produtos. } \\
\text { - Planejamento de processo } \\
\text { - Sobreposição das tarefas acopladas. } \\
\text { - Usa o conceito de probabilidade condicional de retrabalho e o impacto do método } \\
\text { de descrição de decomposição de retrabalho para superar as limitações das matrizes } \\
\text { de probabilidade de retrabalho e impacto de retrabalho. } \\
\text { - Iteração de negociação } \\
\text { - Analizar } \\
\text { - Sintetizar }\end{array}$ \\
\hline $\begin{array}{l}\text { Matriz estrutural de projeto fuzzy } \\
\text { (Fuzzy Design Structure Matrix - } \\
\text { FDSM) }\end{array}$ & $\begin{array}{l}\text { - Planejamento global e local do fluxo de trabalho } \\
\text { - Avalia a força da dependência entre atividades (baseado em fuzzy) } \\
\text { - Reduz julgamento subjetivo por meio de tecnica algébrica. } \\
\text { - Rede de dependências é relativamente densa } \\
\text { - Dependências de respostas causam iterações/retrabalhos }\end{array}$ \\
\hline
\end{tabular}




\begin{tabular}{|c|c|}
\hline Nome do Método/Técnica & Características \\
\hline Metas de estágio (Stage targeting) & $\begin{array}{l}\text { - Assume que há um conjunto limitado de recursos (profissionais de engenharia) } \\
\text { que são úteis ao projeto de desenvolvimento } \\
\text { - Modelos de niveis mais baixos vão gerir dentro dos estágios } \\
\text { - Gates de decisão entre estágios } \\
\text { - O desenvolvimento de produto é um processo em duas fases (pesquisa e } \\
\text { desenvolvimento). } \\
\text { - As empresas também decidem como definir objectivos técnicos de cada etapa. } \\
\text { - Incluiconceitos de teoria dos jogos }\end{array}$ \\
\hline $\begin{array}{l}\text { Método de Diagrama de } \\
\text { Precedência (Precedence Diagram } \\
\text { Method - PDM) }\end{array}$ & $\begin{array}{l}\text { - Relacionamento de atividades término-para-início } \\
\text { - Tempos independentes de atividades } \\
\text { - Caminho crítico = duração do projeto } \\
\text { - Analizar } \\
\text { - Sintetizar } \\
\text { - Sobreposição }\end{array}$ \\
\hline \multicolumn{2}{|l|}{$\begin{array}{l}\text { Método do caminho crítico D (D- } \\
\text { Critical Path Method) }\end{array}$} \\
\hline $\begin{array}{l}\text { Metodo do caminho crítico } \\
\text { (Critical Path Method - CPM) }\end{array}$ & $\begin{array}{l}\text { - Analizar } \\
\text { - Sintetizar } \\
\text { - Relacionamento de atividades término-para-início } \\
\text { - Tempos independentes de atividades } \\
\text { - Caminho crítico = duração do projeto }\end{array}$ \\
\hline $\begin{array}{l}\text { Minimally Long-tern } \\
\text { Organizational Support (MILOS) }\end{array}$ & $\begin{array}{l}\text { - Define atividades em termos de parâmetros de Entradas/Saídas. } \\
\text { - As atividades são dinamicamente reunidas no processo comparando entradas e } \\
\text { saídas. }\end{array}$ \\
\hline $\begin{array}{l}\text { Modelagem de processos de } \\
\text { negócios (Business Process } \\
\text { Modeling) }\end{array}$ & $\begin{array}{l}\text { - Generalizado, orientado ao objeto. } \\
\text { - Armazenament do modelo em base de dados } \\
\text { - Reutilização do modelo }\end{array}$ \\
\hline Modelo de decomposição 1 & $\begin{array}{l}\text { - Dois grupos de informações de matrizes ((Precedência de tarefase recursos de } \\
\text { atividades) são combinados para oferecer sugestões de como uma organização de } \\
\text { projeto deve ser decomposta, e quais iterações entre tarefas e pessoas são } \\
\text { desejáveis. } \\
\text { - Rede de dependências é relativamente densa } \\
\text { - Dependências de respostas causam iterações/retrabalhos }\end{array}$ \\
\hline Modelo de decomposição 2 & $\begin{array}{l}\text { - Amplia o DSM para incluir interações espaciais, de energia, informação e material } \\
\text { entre ps elements de projeto. Essas interações são usadas para identificar clusters } \\
\text { de elementos d eprojeto que devem ser abordados pelas unidades organizacionais. } \\
\text { - Rede de dependências é relativamente densa } \\
\text { - Dependências de respostas causam iterações/retrabalhos }\end{array}$ \\
\hline $\begin{array}{l}\text { Modelo de decomposição de } \\
\text { módulos de atividades (Activity } \\
\text { module decomposition model) }\end{array}$ & $\begin{array}{l}\text { - Rede de dependências é relativamente densa } \\
\text { - Dependências de respostas causam iterações/retrabalhos }\end{array}$ \\
\hline $\begin{array}{l}\text { Modelo de iterações sequenciais } \\
\text { (Sequential Iteration Model) }\end{array}$ & $\begin{array}{l}\text { - Baseado em DSM } \\
\text { - Tarefas são completadas uma por vez, com uma necessidade probabilística de } \\
\text { repetição de tarefas anteriores. } \\
\text { - A duração de uma tarefa é fixa e determinada } \\
\text { - A duração de qualquer ordem de tarefas pode ser calculada por meio da cadeia de } \\
\text { Markov. } \\
\text { - A ordem das tarefas pode ser mnipulada para minimizar o tempo esperado. } \\
\text { - Rede de dependências é relativamente densa } \\
\text { - Dependências de respostas causam iterações/retrabalhos }\end{array}$ \\
\hline
\end{tabular}




\begin{tabular}{|c|c|}
\hline Nome do Método/Técnica & Características \\
\hline $\begin{array}{l}\text { Modelo de planejamento de } \\
\text { simulação dinâmica (Dinamic } \\
\text { Simulation Planning model) }\end{array}$ & $\begin{array}{l}\text { - O fluxo de projetos através do processo é representada de forma recursiva. } \\
\text { - Os projetos podem entrar no processo NPD, em qualquer estágio de } \\
\text { desenvolvimento. } \\
\text { - Modelos de niveis mais baixos vão gerir dentro dos estágios } \\
\text { - Gates de decisão entre estágios }\end{array}$ \\
\hline $\begin{array}{l}\text { Modelo de redes de filas } \\
\text { (Queueing network model) }\end{array}$ & - Contenção de recursos e restrições \\
\hline $\begin{array}{l}\text { Modelos de planejamento de } \\
\text { estado estático (Steady state } \\
\text { planning model) }\end{array}$ & $\begin{array}{l}\text { - Modelos de niveis mais baixos vão gerir dentro dos estágios } \\
\text { - Gates de decisão entre estágios }\end{array}$ \\
\hline $\begin{array}{l}\text { Modelos de teoria do Controlee } \\
\text { (Controle Theory Models) }\end{array}$ & $\begin{array}{l}\text { - A estrutura do processo orienta a taxa de convergência } \\
\text { - Controle de loop fechado ótimo }\end{array}$ \\
\hline Narrativa textual (Storyboard) & $\begin{array}{l}\text { Diversos atributos de atividades e entregas podem ser incorporados, dependendo } \\
\text { das diretrizes seguidas }\end{array}$ \\
\hline New Modelling Framework & \\
\hline $\begin{array}{l}\text { Programação paralela (Parallel } \\
\text { scheduling) }\end{array}$ & $\begin{array}{l}\text { - Trabalhar com informações preliminares aumenta as chances de retrabalho } \\
\text { - Atividades variam em sensibilidade } \\
\text { - Atividades desenvolvem as saídas } \\
\text { - Número de tarefas de projeto (design) que devem ser completadas } \\
\text { - Explicita a ordem subjacente das tarefas de projeto (design). }\end{array}$ \\
\hline Rede de compromissos & - Proprietários de atividades devem se comprometer com as dependências. \\
\hline $\begin{array}{l}\text { Rede de fluxo de trabalho } \\
\text { (Workflow net - WFnet) }\end{array}$ & Implementação do processo \\
\hline Rede de Petri & $\begin{array}{l}\text { - Iteração de respostas } \\
\text { - Iteração de negociação } \\
\text { - Analizar } \\
\text { - Sintetizar } \\
\text { - Decompondo um processo em atividades, uma estrutura de eventos discretos é } \\
\text { criada. } \\
\text { - Pré-condições para as transformações a ocorrerem } \\
\text { - Muitas vezes assumem condições de estado estacionário } \\
\text { - Planejamento de incertezas e rotas alternativas } \\
\text { - Simulação estocástica }\end{array}$ \\
\hline $\begin{array}{l}\text { Redes de Petri coloridas (Coloured } \\
\text { Petri Nets - CPNs) }\end{array}$ & $\begin{array}{l}\text { - Redes de petri extendidas } \\
\text { - Símbolos são diferenciados por cores } \\
\text { - Decomposição hierárquica } \\
\text { - Pré-condições para as transformações a ocorrerem } \\
\text { - Muitas vezes assumem condições de estado estacionário } \\
\text { - Tem as características de expressão intuitiva de gráfico, das teorias matemáticas } \\
\text { rigorosas e facilidade para programar, as quais podem satisfazer as necessidades da } \\
\text { modelagem do processo de desenvolvimento de produtos. }\end{array}$ \\
\hline $\begin{array}{l}\text { Roteiro de projeto (Design } \\
\text { roadmap) }\end{array}$ & $\begin{array}{l}\text { - Iteração de respostas } \\
\text { - Iteração de negociação } \\
\text { - Analizar } \\
\text { - Sintetizar }\end{array}$ \\
\hline Signal Flow Graph & $\begin{array}{l}\text { - Iteração de respostas } \\
\text { - Iteração de negociação } \\
\text { - Analizar } \\
\text { - Sintetizar } \\
\text { - Planejamento de incertezas e rotas alternativas }\end{array}$ \\
\hline
\end{tabular}




\begin{tabular}{|c|c|}
\hline Nome do Método/Técnica & Características \\
\hline Signposting & $\begin{array}{l}\text { - Apresenta o conceito de "confiança" para descrever os níveis de crença do } \\
\text { designer na adequação dos valores dos parâmetros durante o processo. } \\
\text { - Codificação em cores de atividades de acordo com o que é possível e útil. } \\
\text { - Subsequentemente estendido para incluir dados probabilísticos. } \\
\text { - E / S varia em qualidade / maturidade e ativação, governados por atividades }\end{array}$ \\
\hline $\begin{array}{l}\text { Sobreposição de estágios (Stage } \\
\text { overlapping) }\end{array}$ & $\begin{array}{l}\text { - Trabalhar com informações preliminares aumenta as chances de retrabalho } \\
\text { - Atividades variam em sensibilidade } \\
\text { - Atividades desenvolvem as saídas }\end{array}$ \\
\hline $\begin{array}{l}\text { Tabela criar-ler-atualizar-apagar } \\
\text { (Create-Read-Update-Delete - } \\
\text { CRUD) }\end{array}$ & $\begin{array}{l}\text { Muitas vezes usado para banco de dados modelo e arquiteturas de sistemas de } \\
\text { informação. }\end{array}$ \\
\hline $\begin{array}{l}\text { Técnica de avaliação e revisão de } \\
\text { projeto (Project Evaluation and } \\
\text { Review Technique - PERT) }\end{array}$ & $\begin{array}{l}\text { - Analizar } \\
\text { - Sintetizar } \\
\text { - Planejamento de incertezas e rotas alternativas (A distribuição beta das atividades } \\
\text { é usada para capturar rotas alternativas) } \\
\text { - Relacionamento de atividades término-para-início } \\
\text { - Tempos independentes de atividades } \\
\text { - Exemplos do método de diagrama de precedência (PDM) } \\
\text { - Caminho crítico = duração do projeto }\end{array}$ \\
\hline $\begin{array}{l}\text { Técnica de avaliação e revisão } \\
\text { gráfica (Graphical Evaluate and } \\
\text { Review Technique - GERT) }\end{array}$ & $\begin{array}{l}\text { - Iteração de respostas } \\
\text { - Iteração de negociação } \\
\text { - Analizar } \\
\text { - Sintetizar } \\
\text { - Planejamento de incertezas e rotas alternativas } \\
\text { - Baseado no PERT } \\
\text { - Dependências entre atividades podem ser contigenciais e cíclicas }\end{array}$ \\
\hline $\begin{array}{l}\text { Técnica de avaliação e revisão } \\
\text { gráfica (Q-GERT model) }\end{array}$ & $\begin{array}{l}\text { - Extensão do GERT que permite atrasos de filas. } \\
\text { - Inclui recursos como rota probabilística de tarefas paa servidores, incluindo } \\
\text { iterações probabilísticas; ramificação e junção de tarefas; e múltiplos projetos } \\
\text { simultâneos com múltiplos grupos de desenvolvimento. } \\
\text { - Baseia-se na análise de simulação para fazer observações sobre o tempo e } \\
\text { variância esperada } \\
\text { - Dependências entre atividades podem ser contigenciais e cíclicas }\end{array}$ \\
\hline $\begin{array}{l}\text { Tempo de revisões de projeto } \\
\text { (Timing of design reviews) }\end{array}$ & $\begin{array}{l}\text { - As falhas são corrigidas por uma certa quantidade de retrabalho. } \\
\text { - Cada revisão do projeto libera uma quantidade de trabalho do projeto do produto } \\
\text { para o processo. } \\
\text { - É desejável ter revisões de projeto juntas de modo que as falhas sejam } \\
\text { descobertas rapidamente e de modo que os criadores de processo não sejam } \\
\text { privados dos trabalho. } \\
\text { - É desejável espaçar revisões de projeto de modo que a sobrecarga de conduzir as } \\
\text { revisões não é aumentada. } \\
\text { - O modelo é indicado de modo que um equilíbrio ideal pode ser encontrado entre } \\
\text { esses interesses conflitantes. }\end{array}$ \\
\hline $\begin{array}{l}\text { Teoria de redes complexas } \\
\text { (Complex Network theory) }\end{array}$ & $\begin{array}{l}\text { - Análise das características dos nós das atividades: grau, proximidade, } \\
\text { intermedialidade, eigenvector. } \\
\text { - Programação multi-tarefa de redes diretas: regras de programação baseadas na } \\
\text { importância do nó. }\end{array}$ \\
\hline
\end{tabular}





\section{Apêndice C4 - Métodos de modelagem: vantagens e desvantagens para o usuário}

\begin{tabular}{|c|c|c|}
\hline Nome do Método/Técnica & Vantagens para o usuário & Desvantagens para o usuário \\
\hline $\begin{array}{l}\text { Agendamento de módulos (Module } \\
\text { scheduling) }\end{array}$ & & $\begin{array}{l}\text { Os resultados deste modelo não deve ser } \\
\text { interpretados em sentido estritamente } \\
\text { numérico }\end{array}$ \\
\hline $\begin{array}{l}\text { Análise de áreas interrelacionadas } \\
\text { de decisão (Analysis of } \\
\text { interconnected decision areas - } \\
\text { AIDA) }\end{array}$ & $\begin{array}{l}\text { O formalismo AIDA descreve um } \\
\text { conjunto útil de conhecimento sobre o } \\
\text { projeto de processos, de que muitos } \\
\text { subcomponentes de decisões de design } \\
\text { estão inter-relacionados. }\end{array}$ & \\
\hline $\begin{array}{l}\text { Cadeia extendida de processos } \\
\text { orientados a eventos (Extended } \\
\text { Event-driven Process Chain - EPC) }\end{array}$ & $\begin{array}{l}\text { Possui a capacidade de enfatizar } \\
\text { entregas. }\end{array}$ & $\begin{array}{l}\text { Possui a capacidade de enfatizar } \\
\text { entregas, mas, quando o faz, o diagrama } \\
\text { fica confuso. Portanto, outros pontos de } \\
\text { vista diferentes podem ser necessárias } \\
\text { para enfatizar as características dos } \\
\text { produtos. }\end{array}$ \\
\hline \multicolumn{3}{|l|}{$\begin{array}{l}\text { Diagrama de atividades em arcos } \\
\text { (Activity-on-Arc Diagram) }\end{array}$} \\
\hline $\begin{array}{l}\text { Diagrama de Entrada-Tarefa- } \\
\text { Validação-Saída (Entry-Task- } \\
\text { Validation-Exit (ETVX) Diagram) }\end{array}$ & & $\begin{array}{l}\text { - Não representa atributos de objetos de } \\
\text { entrega. (Table VII p. 83) }\end{array}$ \\
\hline \multicolumn{3}{|l|}{ Diagrama de estado (State Diagram) } \\
\hline $\begin{array}{l}\text { Diagrama de fluxo de dados (Data } \\
\text { Flow Diagram - DFD) }\end{array}$ & Fácil de compreender & Apenas o fluxo de dados é mostrado \\
\hline \multicolumn{3}{|l|}{$\begin{array}{l}\text { Diagrama de fluxo e estoque (Stock- } \\
\text { and-Flow Diagram) }\end{array}$} \\
\hline \multicolumn{3}{|l|}{ Diagrama SIPOC } \\
\hline $\begin{array}{l}\text { Entrega de produto (Product } \\
\text { release) }\end{array}$ & $\begin{array}{l}\text { O modelo é capaz de indicar melhor } \\
\text { time-to-market e metas de desempenho } \\
\text { do produto, bem como mostrar as outras } \\
\text { relações, como a que estritamente } \\
\text { minimizando o tempo de colocação no } \\
\text { mercado não se conduz à estratégia } \\
\text { ótima de desenvolvimento a longo prazo } \\
\text { do produto. }\end{array}$ & $\begin{array}{l}\text { O modelo se baseia em dados que não } \\
\text { são estimáveis em prática, e assim os } \\
\text { resultados do modelo não podem ser } \\
\text { aplicados diretamente para permitir que } \\
\text { um gerente de projeto tome decisões de } \\
\text { desenvolvimento de produtos. }\end{array}$ \\
\hline $\begin{array}{l}\text { Estimativa de tempo de ciclos } \\
\text { iterativos (Iterative cycle time } \\
\text { estimation) }\end{array}$ & $\begin{array}{l}\text { Permite cálculo da distribuição de } \\
\text { probabilidade de o tempo total } \\
\text { necessário para completar o processo de } \\
\text { design. }\end{array}$ & $\begin{array}{l}\text { Sua utilidade para prática industrial ainda } \\
\text { precisa ser demonstrada. }\end{array}$ \\
\hline \multicolumn{3}{|l|}{ Feedbacks and Crossovers } \\
\hline Fluxograma & Habilidade de comunicação & $\begin{array}{l}\text { - Pode ficar muito grande } \\
\text { - Não representa atributos de objetos de } \\
\text { entrega. (Table VII p. 83) }\end{array}$ \\
\hline Generic Design Model (GDM) & $\begin{array}{l}\text { O processo de design é visto como um } \\
\text { processo de tomada de decisão eo } \\
\text { modelo capta isso. }\end{array}$ & \\
\hline $\begin{array}{l}\text { Gráfico de entregas (Milestone } \\
\text { Chart) }\end{array}$ & & \\
\hline
\end{tabular}




\begin{tabular}{|c|c|c|}
\hline Nome do Método/Técnica & Vantagens para o usuário & Desvantagens para o usuário \\
\hline Gráfico de Gantt (Gantt Chart) & $\begin{array}{l}\text { Representação de visão geral fácil e } \\
\text { controle de desempenho }\end{array}$ & $\begin{array}{l}\text { - Características iterativas não são } \\
\text { representadas } \\
\text { - Não auxilia na análise ou design } \\
\text { - Não representa atributos de objetos de } \\
\text { entrega. (Table VII p. 83) / } \\
\text { - Falha em captar iterações como loops } \\
\text { de respostas ou intercâmbio bidirecional } \\
\text { de informações entre atividades. } \\
\text { - Tem limitações para capturar } \\
\text { características cooperativas: não } \\
\text { representa rota detalhada ou } \\
\text { sincronização de informações em } \\
\text { ramificações e mesclagens. }\end{array}$ \\
\hline \multicolumn{3}{|l|}{$\begin{array}{l}\text { Gráfico de tarefas atividades nos } \\
\text { nós } \\
\text { (Activity-on-node task graph) }\end{array}$} \\
\hline Gráfico direto (Directed graph) & & $\begin{array}{l}\text { - Não permite sobreposição entre duas } \\
\text { atividades consecutivas } \\
\text { - Características iterativas não são } \\
\text { capturadas }\end{array}$ \\
\hline $\begin{array}{l}\text { IDEFO - Definição integrada para } \\
\text { modelagem de funções }\end{array}$ & $\begin{array}{l}\text { Mostra visão geral e detalhes de } \\
\text { Entradas, Saídas, Controle e } \\
\text { Mecanismos. }\end{array}$ & $\begin{array}{l}\text { - Não permite sobreposição entre duas } \\
\text { atividades consecutivas } \\
\text { - Tende a ser representado apenas como } \\
\text { uma sequencia de atividades } \\
\text { - Papéis não são representados } \\
\text { - Características iterativas não são } \\
\text { capturadas }\end{array}$ \\
\hline $\begin{array}{l}\text { IDEF3 - Definição integrada para } \\
\text { modelagem de funções }\end{array}$ & $\begin{array}{l}\text { Fácil de compreender aspectos } \\
\text { dinâmicos de uma forma estática. }\end{array}$ & $\begin{array}{l}\text { - Não permite sobreposição entre duas } \\
\text { atividades consecutivas } \\
\text { - Vários diagramas parciais para } \\
\text { descrever um processo } \\
\text { - Não representa atributos de objetos de } \\
\text { entrega. (Table VII p. 83)/ } \\
\text { - Características iterativas não são } \\
\text { capturadas }\end{array}$ \\
\hline \multicolumn{3}{|l|}{$\begin{array}{l}\text { Liberação de tempo de uma única } \\
\text { atividade iterativa incerta (Release } \\
\text { time of a single uncertain iterative } \\
\text { activity) }\end{array}$} \\
\hline \multicolumn{3}{|l|}{$\begin{array}{l}\text { Linguagem universal de modelagem } \\
\text { (Universal Modelling Language - } \\
\text { UML) }\end{array}$} \\
\hline \multicolumn{3}{|l|}{$\begin{array}{l}\text { Mapeamento da cadeia de valor } \\
\text { (Value Stream Mapping) }\end{array}$} \\
\hline \multicolumn{3}{|l|}{ Markov Models } \\
\hline $\begin{array}{l}\text { Matriz de atribuição de } \\
\text { responsabilidades (Responsibility } \\
\text { Assignment Matrix - RAM) }\end{array}$ & & \\
\hline
\end{tabular}




\begin{tabular}{|c|c|c|}
\hline Nome do Método/Técnica & Vantagens para o usuário & Desvantagens para o usuário \\
\hline $\begin{array}{l}\text { Matriz de incidêcia Atividade- } \\
\text { Atividade (Activity-Activity } \\
\text { Incidence Matrix) }\end{array}$ & $\begin{array}{l}\text { Proporciona manipulações simples e } \\
\text { poderodas para gestão do projeto de DP. }\end{array}$ & $\begin{array}{l}\text { Não fornece representação intuitiva do } \\
\text { PDP } \\
\text { - Características iterativas não são } \\
\text { capturadas }\end{array}$ \\
\hline $\begin{array}{l}\text { Matriz de transformação de } \\
\text { trabalho (Work transformation } \\
\text { matrix) }\end{array}$ & $\begin{array}{l}\text { - Proporciona manipulações simples e } \\
\text { poderodas para gestão do projeto de DP. } \\
\text { - É relativamente simples para coletar } \\
\text { dados de projetos reais de engenharia } \\
\text { - Os autovetores da WTM criados } \\
\text { correspondem bem com conhecidas } \\
\text { questões técnicas fortemente acopladas }\end{array}$ & $\begin{array}{l}\text { - Não proporciona representação } \\
\text { intuitiva do PDP } \\
\text { - Características iterativas não são } \\
\text { capturadas }\end{array}$ \\
\hline \multicolumn{3}{|l|}{$\begin{array}{l}\text { Matriz de transformação de } \\
\text { trabalho de modelos } \\
\text { paralelos/seriais (Work } \\
\text { Transformation Matrix (WTM) } \\
\text { parallel/serial model) }\end{array}$} \\
\hline $\begin{array}{l}\text { Matriz estrutural de projeto (Design } \\
\text { structured Matrix - DSM) }\end{array}$ & $\begin{array}{l}\text { - A premissa básica desse modelo, de } \\
\text { que tarefas de projeto são informações } \\
\text { previsíveis com entradas e saída } \\
\text { identificáveis é razoável (exceto no caso } \\
\text { de tecnologias realmente novas). } \\
\text { - Achar grupos de tarefas que requerem } \\
\text { fluxos cíclicos de informação é } \\
\text { relativamente fácil uma vez que os dados } \\
\text { da matriz existem. } \\
\text { - Simples a acessível. } \\
\text { - Fornece uma forma visual concisa para } \\
\text { representar processos. } \\
\text { - Fornece replanejamento do projeto } \\
\text { rápido } \\
\text { - Fornece fácil entendimento de como as } \\
\text { mudanças isoladas podem afetar todo o } \\
\text { processo. } \\
\text { - DSM supera as limitações de tamanho } \\
\text { e complexidade dos dígrafos; } \\
\text { - DSM é fácil de compreender e é capaz } \\
\text { de lidar com os processos como um todo. } \\
\text { - O formato da matriz é adequado para } \\
\text { programar e calcular utilizando } \\
\text { computadores. } \\
\text { •Melhora a compreensão da visibilidade } \\
\text { complexidade do projeto / sistema por } \\
\text { meio de fluxos de informação } \\
\text { - Assegura a comunicação eficiente e } \\
\text { eficaz entre gerentes de projetos e } \\
\text { designers de produtos, que podem } \\
\text { melhorar o entendimento do produto, } \\
\text { reduzir custos e encurtar o período de } \\
\text { desenvolvimento. } \\
\text { - Proporciona manipulações simples e } \\
\text { poderodas para gestão do projeto de DP. }\end{array}$ & $\begin{array}{l}\text { - Não fornece representação intuitiva do } \\
\text { PDP } \\
\text { - O método DSM como originalmente } \\
\text { proposto oferece poucos conselhos } \\
\text { sobre como lidar com e agendar tarefas } \\
\text { do projeto dentro dos grupos iterativos. } \\
\text { Recentes variações têm sido propostas } \\
\text { para suprir esta deficiência. } \\
\text { - Apenas relacionamentos de entradas e } \\
\text { saídas entre tarefas podem ser } \\
\text { visualizadas na matriz. } \\
\text { - Distribuição do tempo de não está } \\
\text { envolvida neste método. } \\
\text { - Características iterativas não são } \\
\text { capturadas } \\
\text { - Tem limitações para capturar } \\
\text { características cooperativas: não } \\
\text { representa rota detalhada ou } \\
\text { sincronização de informações em } \\
\text { ramificações e mesclagens. }\end{array}$ \\
\hline \multicolumn{3}{|l|}{$\begin{array}{l}\text { Matriz estrutural de projeto fuzzy } \\
\text { (Fuzzy Design Structure Matrix - } \\
\text { FDSM) }\end{array}$} \\
\hline Metas de estágio (Stage targeting) & & \\
\hline
\end{tabular}




\begin{tabular}{|c|c|c|}
\hline Nome do Método/Técnica & Vantagens para o usuário & Desvantagens para o usuário \\
\hline $\begin{array}{l}\text { Método de Diagrama de } \\
\text { Precedência (Precedence Diagram } \\
\text { Method - PDM) }\end{array}$ & & $\begin{array}{l}\text { Características iterativas não são } \\
\text { representadas, como loops de respostas } \\
\text { ou intercâmbio bidirecional de } \\
\text { informações entre atividade. }\end{array}$ \\
\hline $\begin{array}{l}\text { Método do caminho crítico D (D- } \\
\text { Critical Path Method) }\end{array}$ & $\begin{array}{l}\text { Assegura a comunicação eficiente e } \\
\text { eficaz entre gerentes de projetos e } \\
\text { designers de produtos, que podem } \\
\text { melhorar o entendimento do produto, } \\
\text { reduzir custos e encurtar } \\
\text { desenvolvimento período.. }\end{array}$ & $\begin{array}{l}\text { Desenvolvido para projetos complexos } \\
\text { mas razoavelmente rotineiros, com } \\
\text { incertezas mínimas nos tempos de } \\
\text { conclusão do projeto. }\end{array}$ \\
\hline $\begin{array}{l}\text { Metodo do caminho crítico } \\
\text { (Critical Path Method - CPM) }\end{array}$ & $\begin{array}{l}\text { Útil em situações onde as atividades são } \\
\text { mais previsíveis }\end{array}$ & $\begin{array}{l}\text { - Características iterativas não são } \\
\text { capturadas } \\
\text { - Não permite sobreposição entre duas } \\
\text { atividades consecutivas } \\
\text { - Falha em captar iterações como loops } \\
\text { de respostas ou intercâmbio bidirecional } \\
\text { de informações entre atividades. } \\
\text { - Não permite a representação de } \\
\text { características evolucionárias. } \\
\text { - Tem limitações para capturar } \\
\text { características cooperativas: não } \\
\text { representa rota detalhada ou } \\
\text { sincronização de informações em } \\
\text { ramificações e mesclagens. } \\
\text { - Não representa iteração probabilística } \\
\text { e e ramificações probabilísticas na rota } \\
\text { de atividades. }\end{array}$ \\
\hline \multicolumn{3}{|l|}{$\begin{array}{l}\text { Minimally Long-tern Organizational } \\
\text { Support (MILOS) }\end{array}$} \\
\hline \multicolumn{3}{|l|}{$\begin{array}{l}\text { Modelagem de processos de } \\
\text { negócios (Business Process } \\
\text { Modeling) }\end{array}$} \\
\hline \multicolumn{3}{|l|}{ Modelo de decomposição 1} \\
\hline \multicolumn{3}{|l|}{ Modelo de decomposição 2} \\
\hline \multicolumn{3}{|l|}{$\begin{array}{l}\text { Modelo de decomposição de } \\
\text { módulos de atividades (Activity } \\
\text { module decomposition model) }\end{array}$} \\
\hline $\begin{array}{l}\text { Modelo de iterações sequenciais } \\
\text { (Sequential Iteration Model) }\end{array}$ & $\begin{array}{l}\text { Completar tarefas curtas antes de tarefas } \\
\text { longas é desejável para diminuir o alto } \\
\text { número de probabilidade de repetição } \\
\text { que aparece como resposta ao } \\
\text { ordenamento ótimo. }\end{array}$ & $\begin{array}{l}\text { - Pressupostos irreais: Tarefas têm } \\
\text { durações fixas e constantes; e } \\
\text { probabilidades de repetição são } \\
\text { assumidas como conhecidas }\end{array}$ \\
\hline \multicolumn{3}{|l|}{$\begin{array}{l}\text { Modelo de planejamento de } \\
\text { simulação dinâmica (Dinamic } \\
\text { Simulation Planning model) }\end{array}$} \\
\hline $\begin{array}{l}\text { Modelo de redes de filas (Queueing } \\
\text { network model) }\end{array}$ & & \\
\hline
\end{tabular}




\begin{tabular}{|c|c|c|}
\hline Nome do Método/Técnica & Vantagens para o usuário & Desvantagens para o usuário \\
\hline $\begin{array}{l}\text { Modelos de planejamento de } \\
\text { estado estático (Steady state } \\
\text { planning model) }\end{array}$ & $\begin{array}{l}\text { - A ferramenta útil agregada para avaliar } \\
\text { as necessidades de recursos em uma } \\
\text { série de condições para atingir uma saída } \\
\text { dadas a partir de R \& D. } \\
\text { - Pode ser facilmente implementado em } \\
\text { uma planilha } \\
\text { - Seus conceitos são facilmente } \\
\text { comunicados } \\
\text { - Permite a facilidade avaliar o impacto } \\
\text { de parâmetros incertos, utilizando } \\
\text { padrão de simulação de Monte Carlo. }\end{array}$ & \\
\hline \multicolumn{3}{|l|}{$\begin{array}{l}\text { Modelos de teoria do Controlee } \\
\text { (Controle Theory Models) }\end{array}$} \\
\hline Narrativa textual (Storyboard) & $\begin{array}{l}\text { Ele tem a capacidade para incluir quase } \\
\text { qualquer atributo desejado. }\end{array}$ & $\begin{array}{l}\text { Quando muitos atributos são incluídos, } \\
\text { torna-se difícil organizar a narrativa de } \\
\text { uma forma que torne fácil para o usuário } \\
\text { encontrar um pedaço específico de } \\
\text { informação. Um bom mecanismo de } \\
\text { busca pode obter informações aos } \\
\text { usuários rapidamente, mas somente se } \\
\text { eles sabem exatamente o que procurar. }\end{array}$ \\
\hline \multicolumn{3}{|l|}{ New Modelling Framework } \\
\hline \multicolumn{3}{|l|}{$\begin{array}{l}\text { Programação paralela (Parallel } \\
\text { scheduling) }\end{array}$} \\
\hline \multicolumn{3}{|l|}{ Rede de compromissos } \\
\hline \multicolumn{3}{|l|}{$\begin{array}{l}\text { Rede de fluxo de trabalho } \\
\text { (Workflow net - WFnet) }\end{array}$} \\
\hline Rede de Petri & $\begin{array}{l}\text { - Movimentação de fluxos simultâneos e } \\
\text { iterativos } \\
\text { - Reforçar as capacidades dos modelos } \\
\text { de planejamento }\end{array}$ & $\begin{array}{l}\text { - Não permite sobreposição entre duas } \\
\text { atividades consecutivas } \\
\text { - Características iterativas não são } \\
\text { capturadas } \\
\text { - Falta de medidas úteis de tempo } \\
\text { - Ênfase na viabilidade como medida } \\
\text { Saídas de interesse. } \\
\text { - Não há ponderação para as conexões; } \\
\text { todas as conexões estão implícitas a ser } \\
\text { da mesma importância. } \\
\text { - A estrutura completa do projeto deve } \\
\text { ser feito com antecedência se o modelo } \\
\text { é de ter qualquer utilidade preditiva. }\end{array}$ \\
\hline $\begin{array}{l}\text { Redes de Petri coloridas (Coloured } \\
\text { Petri Nets - CPNs) }\end{array}$ & $\begin{array}{l}\text { Fácil de compreender como processos } \\
\text { individuais interagem uns com os outros. }\end{array}$ & Os modelos são excessivamente grandes \\
\hline $\begin{array}{l}\text { Roteiro de projeto (Design } \\
\text { roadmap) }\end{array}$ & & $\begin{array}{l}\text { - Não permite sobreposição entre duas } \\
\text { atividades consecutivas } \\
\text { - Características iterativas não são } \\
\text { capturadas }\end{array}$ \\
\hline
\end{tabular}




\begin{tabular}{|c|c|c|}
\hline Nome do Método/Técnica & Vantagens para o usuário & Desvantagens para o usuário \\
\hline Signal Flow Graph & & $\begin{array}{l}\text { - Não permite sobreposição entre duas } \\
\text { atividades consecutivas } \\
\text { - Características iterativas não são } \\
\text { capturadas }\end{array}$ \\
\hline \multicolumn{3}{|l|}{ Signposting } \\
\hline \multicolumn{3}{|l|}{$\begin{array}{l}\text { Sobreposição de estágios (Stage } \\
\text { overlapping) }\end{array}$} \\
\hline \multicolumn{3}{|l|}{$\begin{array}{l}\text { Tabela criar-ler-atualizar-apagar } \\
\text { (Create-Read-Update-Delete - } \\
\text { CRUD) }\end{array}$} \\
\hline $\begin{array}{l}\text { Técnica de avaliação e revisão de } \\
\text { projeto (Project Evaluation and } \\
\text { Review Technique - PERT) }\end{array}$ & $\begin{array}{l}\text { Útil em situações onde as atividades são } \\
\text { mais previsíveis. }\end{array}$ & $\begin{array}{l}\text { - Características iterativas não são } \\
\text { representadas } \\
\text { - Não permite sobreposição entre duas } \\
\text { atividades consecutivas } \\
\text { - Não permite looping. } \\
\text { - Características iterativas não são } \\
\text { capturadas } \\
\text { - Tem limitações para capturar } \\
\text { características cooperativas: não } \\
\text { representa rota detalhada ou } \\
\text { sincronização de informações em } \\
\text { ramificações e mesclagens. } \\
\text { - Não representa iteração probabilística } \\
\text { e e ramificações probabilísticas na rota } \\
\text { de atividades. }\end{array}$ \\
\hline $\begin{array}{l}\text { Técnica de avaliação e revisão } \\
\text { gráfica (Graphical Evaluate and } \\
\text { Review Technique - GERT) }\end{array}$ & & $\begin{array}{l}\text { - Características iterativas não são } \\
\text { representadas } \\
\text { - Não permite sobreposição entre duas } \\
\text { atividades consecutivas } \\
\text { - Não representa atributos de objetos de } \\
\text { entrega. (Table VII p. 83) }\end{array}$ \\
\hline \multicolumn{3}{|l|}{$\begin{array}{l}\text { Técnica de avaliação e revisão } \\
\text { gráfica (Q-GERT model) }\end{array}$} \\
\hline $\begin{array}{l}\text { Tempo de revisões de projeto } \\
\text { (Timing of design reviews) }\end{array}$ & & $\begin{array}{l}\text { É difícil imaginar uma situação em que o } \\
\text { resultado do modelo seria aplicada } \\
\text { diretamente. }\end{array}$ \\
\hline $\begin{array}{l}\text { Teoria de redes complexas } \\
\text { (Complex Network theory) }\end{array}$ & & \\
\hline
\end{tabular}




\section{Apêndice C5 - Métodos de modelagem: vantagens e desvantagens para o modelador}

\begin{tabular}{|c|c|c|}
\hline Nome do Método/Técnica & Vantagens para o modelador & $\begin{array}{l}\text { Desvantagens para o } \\
\text { modelador }\end{array}$ \\
\hline $\begin{array}{l}\text { Agendamento de módulos (Module } \\
\text { scheduling) }\end{array}$ & & $\begin{array}{l}\text { A dificuldade na obtenção de dados } \\
\text { específicos para um determinado } \\
\text { projeto vai limitar aplicabilidade direta } \\
\text { do modelo. }\end{array}$ \\
\hline $\begin{array}{l}\text { Análise de áreas interrelacionadas } \\
\text { de decisão (Analysis of } \\
\text { interconnected decision areas - } \\
\text { AIDA) }\end{array}$ & & $\begin{array}{l}\text { A falta de aplicação desses métodos na } \\
\text { literatura leva a crer que há dificuldades } \\
\text { em sua aplicabilidade. É possível que a } \\
\text { quantidade de conhecimento preditivo } \\
\text { sobre se subsolutions determinados são } \\
\text { incompatíveis excede a quantidade } \\
\text { normalmente disponíveis no momento } \\
\text { em que são tomadas decisões, ou a } \\
\text { recolha esta informação é proibitivo. } \\
\text { Alternativamente, o gráfico sugere que a } \\
\text { interacção de pares de soluções podem } \\
\text { ser incompatíveis, mas, na realidade, } \\
\text { pode ser triplos de soluções que são } \\
\text { incompatíveis, embora qualquer par } \\
\text { dentro do triplo seria satisfatório. }\end{array}$ \\
\hline $\begin{array}{l}\text { Cadeia extendida de processos } \\
\text { orientados a eventos (Extended } \\
\text { Event-driven Process Chain - EPC) }\end{array}$ & $\begin{array}{l}\text { Proporciona a capacidade de enfatizar } \\
\text { entregas }\end{array}$ & $\begin{array}{l}\text { Possui a capacidade de enfatizar } \\
\text { entregas, mas, quando o faz, o diagrama } \\
\text { fica confuso. Portanto, outros pontos de } \\
\text { vista diferentes podem ser necessárias } \\
\text { para enfatizar as características dos } \\
\text { produtos. }\end{array}$ \\
\hline \multicolumn{3}{|l|}{$\begin{array}{l}\text { Diagrama de atividades em arcos } \\
\text { (Activity-on-Arc Diagram) }\end{array}$} \\
\hline \multicolumn{3}{|l|}{$\begin{array}{l}\text { Diagrama de Entrada-Tarefa- } \\
\text { Validação-Saída (Entry-Task- } \\
\text { Validation-Exit (ETVX) Diagram) }\end{array}$} \\
\hline \multicolumn{3}{|l|}{ Diagrama de estado (State Diagram) } \\
\hline $\begin{array}{l}\text { Diagrama de fluxo de dados (Data } \\
\text { Flow Diagram - DFD) }\end{array}$ & Fácil de verificar e desenhar & \\
\hline \multicolumn{3}{|l|}{$\begin{array}{l}\text { Diagrama de fluxo e estoque (Stock- } \\
\text { and-Flow Diagram) }\end{array}$} \\
\hline \multicolumn{3}{|l|}{ Diagrama SIPOC } \\
\hline $\begin{array}{l}\text { Entrega de produto (Product } \\
\text { release) }\end{array}$ & $\begin{array}{l}\text { O modelo tem forte justificativa para } \\
\text { seus relacionamentos funcionais, o que } \\
\text { aumenta a credibilidade dos seus } \\
\text { resultados. }\end{array}$ & \\
\hline $\begin{array}{l}\text { Estimativa de tempo de ciclos } \\
\text { iterativos (Iterative cycle time } \\
\text { estimation) }\end{array}$ & & $\begin{array}{l}\text { - Pressupostos irreais: devemos assumir } \\
\text { que os tempos de tarefas e as } \\
\text { probabilidades de iteração são fixos e } \\
\text { conhecidos de antemão, como é a } \\
\text { estrutura de iteração tarefa. } \\
\text { - Não há exemplo apresentadas com } \\
\text { base em dados empíricos. }\end{array}$ \\
\hline
\end{tabular}




\begin{tabular}{|c|c|c|}
\hline Nome do Método/Técnica & Vantagens para o modelador & $\begin{array}{l}\text { Desvantagens para o } \\
\text { modelador }\end{array}$ \\
\hline Feedbacks and Crossovers & $\begin{array}{l}\text { O método de otimização é poderoso, e } \\
\text { poderia ser aplicado a outras Funções }\end{array}$ & $\begin{array}{l}\text { Não há nenhuma justificação empírica } \\
\text { ou de dados. }\end{array}$ \\
\hline Fluxograma & $\begin{array}{l}\text { - Flexível } \\
\text { - Rápido } \\
\text { - Simples }\end{array}$ & $\begin{array}{l}\text { - Não possui método disponível } \\
\text { - Há notações diversas }\end{array}$ \\
\hline Generic Design Model (GDM) & $\begin{array}{l}\text { A taxonomia é um meio de relacionar } \\
\text { atividades de uma instância específica } \\
\text { para um modelo de atividades genéricas } \\
\text { altamente detalhadas. } \\
\text { É realmente capaz de executar o projeto } \\
\text { sem a intervenção humana. }\end{array}$ & $\begin{array}{l}\text { A sua difícil de aplicar à totalidade do } \\
\text { processo de concepção, devido ao } \\
\text { volume de informação que seria } \\
\text { necessária e necessário. } \\
\text { É mais interessante para automação de } \\
\text { processos de apoio ao projeto. }\end{array}$ \\
\hline \multicolumn{3}{|l|}{$\begin{array}{l}\text { Gráfico de entregas (Milestone } \\
\text { Chart) }\end{array}$} \\
\hline Gráfico de Gantt (Gantt Chart) & Simples & $\begin{array}{l}\text { - Tem limitações para capturar } \\
\text { características cooperativas: não } \\
\text { representa rota detalhada ou } \\
\text { sincronização de informações em } \\
\text { ramificações e mesclagens. } \\
\text { - Nenhuma representação clara de } \\
\text { dependências } \\
\text { - Falha em captar iterações como loops } \\
\text { de respostas ou intercâmbio bidirecional } \\
\text { de informações entre atividades. } \\
\text { - Tem limitações para capturar } \\
\text { características cooperativas: não } \\
\text { representa rota detalhada ou } \\
\text { sincronização de informações em } \\
\text { ramificações e mesclagens. }\end{array}$ \\
\hline \multicolumn{3}{|l|}{$\begin{array}{l}\text { Gráfico de tarefas atividades nos } \\
\text { nós } \\
\text { (Activity-on-node task graph) }\end{array}$} \\
\hline Gráfico direto (Directed graph) & & $\begin{array}{l}\text { - Características iterativas não são } \\
\text { capturadas }\end{array}$ \\
\hline $\begin{array}{l}\text { IDEFO - Definição integrada para } \\
\text { modelagem de funções }\end{array}$ & $\begin{array}{l}\text { - Regras estritas } \\
\text { - Possível construir um software } \\
\text { - Mapeamento rápido }\end{array}$ & $\begin{array}{l}\text { - Características iterativas não são } \\
\text { capturadas }\end{array}$ \\
\hline $\begin{array}{l}\text { IDEF3 - Definição integrada para } \\
\text { modelagem de funções }\end{array}$ & $\begin{array}{l}\text { Regras e notação estritas } \\
\text { Possível construir um software }\end{array}$ & $\begin{array}{l}\text { - Necessita de muitos dados } \\
\text { - A modelagem é demorada, } \\
\text { principalmente para sistemas complexos } \\
\text { - Não permite a representação de } \\
\text { características evolucionárias. }\end{array}$ \\
\hline \multicolumn{3}{|l|}{$\begin{array}{l}\text { Liberação de tempo de uma única } \\
\text { atividade iterativa incerta (Release } \\
\text { time of a single uncertain iterative } \\
\text { activity) }\end{array}$} \\
\hline $\begin{array}{l}\text { Linguagem universal de modelagem } \\
\text { (Universal Modelling Language - } \\
\text { UML) }\end{array}$ & $\begin{array}{l}\text { Onde temporização e questões de } \\
\text { recursos não são críticas, a maioria dos } \\
\text { conceitos podem ser aplicados de forma } \\
\text { bastante direta }\end{array}$ & \\
\hline $\begin{array}{l}\text { Mapeamento da cadeia de valor } \\
\text { (Value Stream Mapping) }\end{array}$ & & \\
\hline
\end{tabular}




\begin{tabular}{|c|c|c|}
\hline Nome do Método/Técnica & Vantagens para o modelador & $\begin{array}{l}\text { Desvantagens para o } \\
\text { modelador }\end{array}$ \\
\hline \multicolumn{3}{|l|}{ Markov Models } \\
\hline $\begin{array}{l}\text { Graph with Results and Actions } \\
\text { Interrelated (GRAI) grid and GRAI } \\
\text { nets }\end{array}$ & $\begin{array}{l}\text { Strict rules } \\
\text { and notation } \\
\text { Possible } \\
\text { to build a software } \\
\end{array}$ & $\begin{array}{l}\text { Need lot of data } \\
\text { Time consuming } \\
\text { when modelling } \\
\text { Complexity }\end{array}$ \\
\hline \multicolumn{3}{|l|}{$\begin{array}{l}\text { Matriz de atribuição de } \\
\text { responsabilidades (Responsibility } \\
\text { Assignment Matrix - RAM) }\end{array}$} \\
\hline $\begin{array}{l}\text { Matriz de incidêcia Atividade- } \\
\text { Atividade (Activity-Activity Incidence } \\
\text { Matrix) }\end{array}$ & & $\begin{array}{l}\text { - Características iterativas não são } \\
\text { capturadas }\end{array}$ \\
\hline $\begin{array}{l}\text { Matriz de transformação de } \\
\text { trabalho (Work transformation } \\
\text { matrix) }\end{array}$ & $\begin{array}{l}\text { - O método seria aplicável em situações } \\
\text { em que as questões técnicas de tarefas } \\
\text { fortemente acopladas não são } \\
\text { conhecidas antecipadamente. }\end{array}$ & $\begin{array}{l}\text {-É difícil justificar a adequação estrita } \\
\text { desses pressupostos (criação linear de } \\
\text { retrabalho, medidas estáticas de } \\
\text { processo de retrabalho) } \\
\text { - Características iterativas não são } \\
\text { capturadas }\end{array}$ \\
\hline $\begin{array}{l}\text { Matriz de transformação de } \\
\text { trabalho de modelos } \\
\text { paralelos/seriais (Work } \\
\text { Transformation Matrix (WTM) } \\
\text { parallel/serial model) }\end{array}$ & $\begin{array}{l}\text { Os dados que são necessários para } \\
\text { implementar o modelo são mostrados } \\
\text { para ser possível a coleta e o resultado } \\
\text { do modelo parece coincidir com muitas } \\
\text { medidas de credibilidade. }\end{array}$ & $\begin{array}{l}\text { Os pressupostos são potencialmente } \\
\text { problemáticos (que não há alteração nos } \\
\text { parâmetros de modelo e do produto } \\
\text { durante o processo). }\end{array}$ \\
\hline $\begin{array}{l}\text { Matriz estrutural de projeto (Design } \\
\text { structured Matrix - DSM) }\end{array}$ & $\begin{array}{l}\text { - Viável mesmo para os processos de } \\
\text { design relativamente complexos com } \\
\text { mais de } 100 \text { Tarefas. } \\
\text { - Foram aplicados amplamente em } \\
\text { estudos de caso. } \\
\text { - DSM supera as limitações de tamanho } \\
\text { e complexidade dos dígrafos;; } \\
\text { - DSM é fácil de compreender e é capaz } \\
\text { de lidar com os processos como um } \\
\text { todo. } \\
\text { - O formato da matriz é adequado para } \\
\text { programar e calcular utilizando } \\
\text { computadores. } \\
\text { - Melhora a compreensão da visibilidade } \\
\text { complexidade do projeto / sistema por } \\
\text { meio de fluxos de informação } \\
\text { - Ele pode ser facilmente comunicar os } \\
\text { processos para os outros em uma única } \\
\text { visão. } \\
\text { - A pesquisa de tarefas no processo de } \\
\text { desenvolvimento de produto paralelo } \\
\text { pode optimizar o desenvolvimento do } \\
\text { produto }\end{array}$ & $\begin{array}{l}\text { - Apenas relacionamentos de entradas e } \\
\text { saídas entre tarefas podem ser } \\
\text { visualizadas na matriz. } \\
\text { - Características iterativas não são } \\
\text { capturadas } \\
\text { - Tem limitações para capturar } \\
\text { características cooperativas: não } \\
\text { representa rota detalhada ou } \\
\text { sincronização de informações em } \\
\text { ramificações e mesclagens. }\end{array}$ \\
\hline \multicolumn{3}{|l|}{$\begin{array}{l}\text { Matriz estrutural de projeto fuzzy } \\
\text { (Fuzzy Design Structure Matrix - } \\
\text { FDSM) }\end{array}$} \\
\hline Metas de estágio (Stage targeting) & Baseado em dados empíricos. & \\
\hline
\end{tabular}




\begin{tabular}{|c|c|c|}
\hline Nome do Método/Técnica & Vantagens para o modelador & $\begin{array}{l}\text { Desvantagens para o } \\
\text { modelador }\end{array}$ \\
\hline $\begin{array}{l}\text { Método de Diagrama de } \\
\text { Precedência (Precedence Diagram } \\
\text { Method - PDM) }\end{array}$ & & $\begin{array}{l}\text { Características iterativas não são } \\
\text { representadas, como loops de respostas } \\
\text { ou intercâmbio bidirecional de } \\
\text { informações entre atividade. }\end{array}$ \\
\hline \multicolumn{3}{|l|}{$\begin{array}{l}\text { Método do caminho crítico D (D- } \\
\text { Critical Path Method) }\end{array}$} \\
\hline $\begin{array}{l}\text { Metodo do caminho crítico } \\
\text { (Critical Path Method - CPM) }\end{array}$ & & $\begin{array}{l}\text { - Tem limitações para capturar } \\
\text { características cooperativas: não } \\
\text { representa rota detalhada ou } \\
\text { sincronização de informações em } \\
\text { ramificações e mesclagens. } \\
\text { - Não permite a representação de rotas } \\
\text { alternativas em ramificações } \\
\text { - Falha em captar iterações como loops } \\
\text { de respostas ou intercâmbio bidirecional } \\
\text { de informações entre atividades. } \\
\text { - Características iterativas não são } \\
\text { representadas. } \\
\text { - Não representa iteração probabilística } \\
\text { e e ramificações probabilísticas na rota } \\
\text { de atividades. }\end{array}$ \\
\hline \multicolumn{3}{|l|}{$\begin{array}{l}\text { Minimally Long-tern Organizational } \\
\text { Support (MILOS) }\end{array}$} \\
\hline \multicolumn{3}{|l|}{$\begin{array}{l}\text { Modelagem de processos de } \\
\text { negócios (Business Process } \\
\text { Modeling) }\end{array}$} \\
\hline Modelo de decomposição 1 & $\begin{array}{l}\text { É uma idéia útil a de que uma pessoa } \\
\text { deve estar ciente das interações entre } \\
\text { tarefas e entre as pessoas no momento } \\
\text { de decompor o processo e atribuir } \\
\text { tarefas. }\end{array}$ & $\begin{array}{l}\text { O modelo não é altamente formalizado e } \\
\text { as recomendações do modelo não são } \\
\text { baseadas em análises rigorosas. }\end{array}$ \\
\hline Modelo de decomposição 2 & $\begin{array}{l}\text { O modelo contém uma quantidade } \\
\text { razoável de estruturação de interações } \\
\text { entre elementos de projeto. }\end{array}$ & $\begin{array}{l}\text { A etapa de agrupamento permanece } \\
\text { informal }\end{array}$ \\
\hline $\begin{array}{l}\text { Modelo de decomposição de } \\
\text { módulos de atividades (Activity } \\
\text { module decomposition model) }\end{array}$ & & $\begin{array}{l}\text { A analogia com processos de manufatura } \\
\text { não é exatamente equivalente. Apenas } \\
\text { para uma instância onde a forma } \\
\text { funcional de governar equações de } \\
\text { projeto está disponível é possível } \\
\text { identificar decomposições que separam } \\
\text { sub-blocos substanciais do problema de } \\
\text { projeto. }\end{array}$ \\
\hline Object Oriented Methods & $\begin{array}{l}\text { Internal } \\
\text { consistency across } \\
\text { design, analysis } \\
\text { and programming } \\
\text { Possible to build } \\
\text { a software }\end{array}$ & $\begin{array}{l}\text { Need lot of data } \\
\text { Time consuming } \\
\text { when modelling } \\
\text { Complexity }\end{array}$ \\
\hline $\begin{array}{l}\text { Modelo de iterações sequenciais } \\
\text { (Sequential Iteration Model) }\end{array}$ & $\begin{array}{l}\text { A extensão permite a duração randômica } \\
\text { de tarefas assim como permite a } \\
\text { tentativa de realizar várias tarefas } \\
\text { simultaneamente. }\end{array}$ & $\begin{array}{l}\text { A limitação da extensão é uma } \\
\text { diminuição correspondente na } \\
\text { tratabilidade do modelo. }\end{array}$ \\
\hline
\end{tabular}




\begin{tabular}{|c|c|c|}
\hline Nome do Método/Técnica & Vantagens para o modelador & $\begin{array}{l}\text { Desvantagens para o } \\
\text { modelador }\end{array}$ \\
\hline \multicolumn{3}{|l|}{$\begin{array}{l}\text { Modelo de planejamento de } \\
\text { simulação dinâmica (Dinamic } \\
\text { Simulation Planning model) }\end{array}$} \\
\hline $\begin{array}{l}\text { Modelo de redes de filas (Queueing } \\
\text { network model) }\end{array}$ & & $\begin{array}{l}\text { Exige um conjunto de premissas válidas } \\
\text { que leva à dificuldades significativas na } \\
\text { aplicação dos modelos. }\end{array}$ \\
\hline $\begin{array}{l}\text { Modelos de planejamento de } \\
\text { estado estático (Steady state } \\
\text { planning model) }\end{array}$ & & $\begin{array}{l}\text { - Premissas simplificadoras: assume que } \\
\text { todas as vezes a cadeia de valor de P\&D } \\
\text { está balanceada em relação ao } \\
\text { progresso do trabalho e como resultado } \\
\text { não prevê flutuações nos requisitos ao } \\
\text { longo do tempo. } \\
\text { - Trata o fluxo de projetos como } \\
\text { contínuo através do processo, quando na } \\
\text { realidade não é. }\end{array}$ \\
\hline \multicolumn{3}{|l|}{$\begin{array}{l}\text { Modelos de teoria do Controlee } \\
\text { (Controle Theory Models) }\end{array}$} \\
\hline Narrativa textual (Storyboard) & $\begin{array}{l}\text { Ele tem a capacidade para incluir quase } \\
\text { qualquer atributo desejado. }\end{array}$ & $\begin{array}{l}\text { Quando muitos atributos são incluídos, } \\
\text { torna-se difícil organizar a narrativa de } \\
\text { uma forma que torne fácil para o usuário } \\
\text { encontrar um pedaço específico de } \\
\text { informação. Um bom mecanismo de } \\
\text { busca pode obter informações aos } \\
\text { usuários rapidamente, mas somente se } \\
\text { eles sabem exatamente o que procurar. }\end{array}$ \\
\hline \multicolumn{3}{|l|}{ New Modelling Framework } \\
\hline $\begin{array}{l}\text { Programação paralela (Parallel } \\
\text { scheduling) }\end{array}$ & & $\begin{array}{l}\text { O modelo é apresentado de uma forma } \\
\text { geral, mas a análise formal é restrita a } \\
\text { uma versão mais restrita com tarefas } \\
\text { identicas e repetição de tarefas limitada. } \\
\text { É improvável que possa ser aplicado a } \\
\text { projetos reais. }\end{array}$ \\
\hline \multicolumn{3}{|l|}{ Rede de compromissos } \\
\hline \multicolumn{3}{|l|}{$\begin{array}{l}\text { Rede de fluxo de trabalho } \\
\text { (Workflow net - WFnet) }\end{array}$} \\
\hline Rich Pictures & $\begin{array}{l}\text { Easy to illustrate } \\
\text { components as } \\
\text { clients, people, } \\
\text { Tarefas and } \\
\text { environment } \\
\end{array}$ & $\begin{array}{l}\text { Lack of a } \\
\text { particular notation }\end{array}$ \\
\hline Role Activity Diagram & $\begin{array}{l}\text { Include business } \\
\text { objects }\end{array}$ & \begin{tabular}{|l|} 
Different \\
notations
\end{tabular} \\
\hline Role Interaction Diagram & $\begin{array}{l}\text { Rigid notation } \\
\text { Complex processes } \\
\text { can be displayed } \\
\end{array}$ & $\begin{array}{l}\text { Difficult to edit na existing diagram } \\
\text { Hard to construct }\end{array}$ \\
\hline Rede de Petri & & $\begin{array}{l}\text { - Os proponentes não aplicaram a } \\
\text { técnica de modelagem a um problema } \\
\text { industrial. } \\
\text { - Características iterativas não são } \\
\text { capturadas }\end{array}$ \\
\hline
\end{tabular}




\begin{tabular}{|c|c|c|}
\hline Nome do Método/Técnica & Vantagens para o modelador & $\begin{array}{l}\text { Desvantagens para o } \\
\text { modelador }\end{array}$ \\
\hline $\begin{array}{l}\text { Redes de Petri coloridas (Coloured } \\
\text { Petri Nets - CPNs) }\end{array}$ & $\begin{array}{l}\text { - representação matemática formal } \\
\text { - sintaxe e semântica bem definidas } \\
\text { - Possível construir um software } \\
\text { - Conceitos de dados } \\
\text { - CPN pode descrever melhor os } \\
\text { modelos de processo, e o número de } \\
\text { lugar e de transição em modelos de } \\
\text { processo diminui. Isso torna o modelo de } \\
\text { processo mais simples. }\end{array}$ & A modelagem é demorada \\
\hline $\begin{array}{l}\text { Roteiro de projeto (Design } \\
\text { roadmap) }\end{array}$ & & $\begin{array}{l}\text { - Características iterativas não são } \\
\text { capturadas }\end{array}$ \\
\hline Signal Flow Graph & $\begin{array}{l}\text { Pode ser possível representar o } \\
\text { roteamento alternativo. No entanto, nós } \\
\text { adicionais ou estados são obrigatórios. }\end{array}$ & $\begin{array}{l}\text { - Características iterativas não são } \\
\text { capturadas }\end{array}$ \\
\hline Signposting & $\begin{array}{l}\text { A dissociação do valor e do significado } \\
\text { contextual da definição do projeto é de } \\
\text { grande valia na construção de classes } \\
\text { genéricas do modelo que podem ser } \\
\text { aplicados a uma série de projetos } \\
\text { futuros. }\end{array}$ & $\begin{array}{l}\text { Para incluir todos os aspectos do } \\
\text { processo de projeto listadas na } \\
\text { atributos-chave, o modelo torna-se } \\
\text { extremamente complexo e pode ser } \\
\text { caro. }\end{array}$ \\
\hline $\begin{array}{l}\text { Sobreposição de estágios (Stage } \\
\text { overlapping) }\end{array}$ & $\begin{array}{l}\text { Os resultados do modelo são baseados } \\
\text { em formas razoáveis de função de perda } \\
\text { de qualidade e expressões de mudanças } \\
\text { paramétricas. Os modelos são capazes } \\
\text { de calcular políticas de tempo de } \\
\text { desenvolvimento mínimo para dados } \\
\text { identificáveis. Ele também ilustra como } \\
\text { alguém deve tentar identificar } \\
\text { parâmetros que possam e devam ser } \\
\text { congelados cedo, de modo a diminuir o } \\
\text { tempo de desenvolvimento sem } \\
\text { sacrificar a qualidade do produto. }\end{array}$ & \\
\hline $\begin{array}{l}\text { Tabela criar-ler-atualizar-apagar } \\
\text { (Create-Read-Update-Delete - } \\
\text { CRUD) }\end{array}$ & & \\
\hline $\begin{array}{l}\text { Técnica de avaliação e revisão de } \\
\text { projeto (Project Evaluation and } \\
\text { Review Technique - PERT) }\end{array}$ & & $\begin{array}{l}\text { - Tem limitações para capturar } \\
\text { características cooperativas: não } \\
\text { representa rota detalhada ou } \\
\text { sincronização de informações em } \\
\text { ramificações e mesclagens. } \\
\text { - Não permite a representação de rotas } \\
\text { alternativas em ramificações. } \\
\text { - Características iterativas não são } \\
\text { representadas. } \\
\text { - Não permite looping, rotas alternativas } \\
\text { e probabilidade de ramificações. } \\
\text { - Características iterativas não são } \\
\text { capturadas } \\
\text { - Não representa iteração probabilística } \\
\text { e e ramificações probabilísticas na rota } \\
\text { de atividades. }\end{array}$ \\
\hline
\end{tabular}




\begin{tabular}{|c|c|c|}
\hline Nome do Método/Técnica & Vantagens para o modelador & $\begin{array}{l}\text { Desvantagens para o } \\
\text { modelador }\end{array}$ \\
\hline $\begin{array}{l}\text { Técnica de avaliação e revisão } \\
\text { gráfica (Graphical Evaluate and } \\
\text { Review Technique - GERT) }\end{array}$ & & $\begin{array}{l}\text { - Características iterativas não são } \\
\text { capturadas }\end{array}$ \\
\hline $\begin{array}{l}\text { Técnica de avaliação e revisão } \\
\text { gráfica (Q-GERT model) }\end{array}$ & & $\begin{array}{l}\text { - Na prática, é difícil imaginar que para } \\
\text { os próximos projetos será } \\
\text { suficientemente bem compreendido que } \\
\text { a caracterização probabilística será } \\
\text { preciso. } \\
\text { - A dependência de simulação como o } \\
\text { modo de análise significa que é difícil de } \\
\text { determinar a relação funcional entre as } \\
\text { variáveis. } \\
\text { - Cada instância da rede exige uma } \\
\text { codificação nova simulação, que pode } \\
\text { tornar-se proibitivo para situações } \\
\text { complexas. }\end{array}$ \\
\hline $\begin{array}{l}\text { Tempo de revisões de projeto } \\
\text { (Timing of design reviews) }\end{array}$ & $\begin{array}{l}\text { O modelo é tratável para situações } \\
\text { simples, como ter estratégias fixas e } \\
\text { apenas dois tipos de tarefa do projeto. } \\
\text { Extensões são possíveis, porém reduzem } \\
\text { tratabilidade. }\end{array}$ & $\begin{array}{l}\text { Os dados são difíceis de estimar para } \\
\text { qualquer instância específica, e alguns } \\
\text { dos pressupostos não refletem a } \\
\text { realidade do projeto. }\end{array}$ \\
\hline Workflow & $\begin{array}{l}\text { Possible build } \\
\text { a software } \\
\text { Data transfer } \\
\text { Easy to make } \\
\text { changes }\end{array}$ & $\begin{array}{l}\text { Lack of a } \\
\text { particular } \\
\text { notation } \\
\text { Many languages }\end{array}$ \\
\hline $\begin{array}{l}\text { Teoria de redes complexas } \\
\text { (Complex Network theory) }\end{array}$ & & \\
\hline
\end{tabular}





\section{Apêndice C6 - Métodos de modelagem: propósitos}

\begin{tabular}{|c|c|}
\hline Nome do Método/Técnica & Propósito \\
\hline Agendamento de módulos (Module scheduling) & $\begin{array}{l}\text { - Determinar o momento das revisões de projeto } \\
\text { - Caracteização de alto nível do processo de DP } \\
\text { - Avaliação de alocação de recursos entre estágios } \\
\text { - Tradeoffs e riscos do estágio }\end{array}$ \\
\hline \multicolumn{2}{|l|}{$\begin{array}{l}\text { Análise de áreas interrelacionadas de decisão } \\
\text { (Analysis of interconnected decision areas - AIDA) }\end{array}$} \\
\hline $\begin{array}{l}\text { Cadeia extendida de processos orientados a eventos } \\
\text { (Extended Event-driven Process Chain - EPC) }\end{array}$ & - Representa atributos de objetos de atividades \\
\hline $\begin{array}{l}\text { Diagrama de atividades em arcos (Activity-on-Arc } \\
\text { Diagram) }\end{array}$ & - Representa atributos de objetos de atividades \\
\hline $\begin{array}{l}\text { Diagrama de Entrada-Tarefa-Validação-Saída (Entry- } \\
\text { Task-Validation-Exit (ETVX) Diagram) }\end{array}$ & $\begin{array}{l}\text { - Representa atributos de objetos de atividades } \\
\text { - Descrição e documentação do processo }\end{array}$ \\
\hline Diagrama de estado (State Diagram) & - Representa atributos de objetos de atividades \\
\hline \multicolumn{2}{|l|}{$\begin{array}{l}\text { Diagrama de fluxo de dados (Data Flow Diagram - } \\
\text { DFD) }\end{array}$} \\
\hline $\begin{array}{l}\text { Diagrama de fluxo e estoque (Stock-and-Flow } \\
\text { Diagram) }\end{array}$ & - Representa atributos de objetos de atividades \\
\hline Diagrama SIPOC & $\begin{array}{l}\text { - Representa atributos de objetos de atividades } \\
\text { - Representa atributos de objetos de entregas } \\
\text { - Descrição e documentação do processo }\end{array}$ \\
\hline Entrega de produto (Product release) & Determinar o tempo de entrega do produto \\
\hline $\begin{array}{l}\text { Estimativa de tempo de ciclos iterativos (Iterative } \\
\text { cycle time estimation) }\end{array}$ & $\begin{array}{l}\text { - Sequenciamento de atividades e programação } \\
\text { - Gestão de iterações } \\
\text { - Representação concisa do processo }\end{array}$ \\
\hline Feedbacks and Crossovers & $\begin{array}{l}\text { - Sequenciamento de atividades } \\
\text { - Gestão de iterações } \\
\text { - Representação concisa do processo }\end{array}$ \\
\hline Fluxograma & $\begin{array}{l}\text { - Estimativa de tempo de conclusão } \\
\text { - Cálculo de folgas / tempo futuante } \\
\text { - Trade-offs de tempo e custo } \\
\text { - Minimização de custo e tempo } \\
\text { - Mapeamento do processo } \\
\text { - Representa atributos de objetos de atividades }\end{array}$ \\
\hline \multicolumn{2}{|l|}{ Generic Design Model (GDM) } \\
\hline Gráfico de entregas (Milestone Chart) & $\begin{array}{l}\text { - Representa atributos de objetos de atividades } \\
\text { - Análise de rede } \\
\text { - Criticidade de atividade }\end{array}$ \\
\hline Gráfico de Gantt (Gantt Chart) & - Representa atributos de objetos de atividades \\
\hline $\begin{array}{l}\text { Gráfico de tarefas atividades nos nós } \\
\text { (Activity-on-node task graph) }\end{array}$ & $\begin{array}{l}\text { - Proporcionar um mecanismo de aprendizado pelo qual empresas } \\
\text { podem continuamente melhorar seu planejamento e coordenação } \\
\text { de atividades. } \\
\text { - Estimativa de tempo de conclusão } \\
\text { - Cálculo de folgas / tempo futuante } \\
\text { - Trade-offs de tempo e custo } \\
\text { - Minimização de custo e tempo } \\
\text { - Mapeamento do processo }\end{array}$ \\
\hline Gráfico direto (Directed graph) & $\begin{array}{l}\text { - Estimativa de tempo de conclusão } \\
\text { - Cálculo de folgas / tempo futuante } \\
\text { - Trade-offs de tempo e custo } \\
\text { - Minimização de custo e tempo } \\
\text { - Mapeamento do processo }\end{array}$ \\
\hline
\end{tabular}




\begin{tabular}{|c|c|}
\hline Nome do Método/Técnica & Propósito \\
\hline $\begin{array}{l}\text { IDEFO - Definição integrada para modelagem de } \\
\text { funções }\end{array}$ & $\begin{array}{l}\text { - Modela o comportamento funcional dos sistemas de engenharia } \\
\text { - Mapeamento sofisticado de processos } \\
\text { - Representa atributos de objetos de atividades } \\
\text { - Representa atributos de objetos de entregas }\end{array}$ \\
\hline $\begin{array}{l}\text { IDEF3 - Definição integrada para modelagem de } \\
\text { funções }\end{array}$ & $\begin{array}{l}\text { - Captura o comportamento dinâmico de um processo } \\
\text { - Mapeamento sofisticado de processos } \\
\text { - Representa atributos de objetos de atividades }\end{array}$ \\
\hline $\begin{array}{l}\text { Liberação de tempo de uma única atividade iterativa } \\
\text { incerta (Release time of a single uncertain iterative } \\
\text { activity) }\end{array}$ & $\begin{array}{l}\text { - Compreender as estruturas de processo e suas (in) capacidades } \\
\text { sobre o tempo de liberação, com base numa análise objetiva } \\
\text { - Conceber um processo de configuração da rede, como um passo } \\
\text { para maximizar as propriedades da sua entrega. }\end{array}$ \\
\hline $\begin{array}{l}\text { Linguagem universal de modelagem (Universal } \\
\text { Modelling Language - UML) }\end{array}$ & $\begin{array}{l}\text { - Fornece uma linguagem genérica unificada para BPM } \\
\text { - Gestão do conhecimento } \\
\text { - Intercâmbio de dados de processo } \\
\text { - Descrição do espaço de processo } \\
\text { - Planejamento de processo } \\
\end{array}$ \\
\hline $\begin{array}{l}\text { Mapeamento da cadeia de valor (Value Stream } \\
\text { Mapping) }\end{array}$ & $\begin{array}{l}\text { - Mapeamento do processo } \\
\text { - Aplicação de princípios lean } \\
\text { - Redução de desperdícios } \\
\text { - Representa atributos de objetos de atividades }\end{array}$ \\
\hline Markov Models & $\begin{array}{l}\text { - Caracterização e minimização do tempo de projeto } \\
\text { - Sequenciamento de atividades }\end{array}$ \\
\hline \multicolumn{2}{|l|}{$\begin{array}{l}\text { Matriz de atribuição de responsabilidades } \\
\text { (Responsibility Assignment Matrix - RAM) }\end{array}$} \\
\hline $\begin{array}{l}\text { Matriz de incidêcia Atividade-Atividade (Activity- } \\
\text { Activity Incidence Matrix) }\end{array}$ & $\begin{array}{l}\text { - Modelar e gerenciar o processo de DP de maneira efetiva } \\
\text { - Sequenciamento de atividades } \\
\text { - Gestão de iterações } \\
\text { - Representação concisa do processo }\end{array}$ \\
\hline $\begin{array}{l}\text { Matriz de transformação de trabalho (Work } \\
\text { transformation matrix) }\end{array}$ & $\begin{array}{l}\text { - Modelar e gerenciar o processo de DP de maneira efetiva } \\
\text { - Decomposição de sistemas grandes } \\
\text { - Sequenciamento de atividades } \\
\text { - Gestão de iterações } \\
\text { - Representação concisa do processo }\end{array}$ \\
\hline $\begin{array}{l}\text { Matriz de transformação de trabalho de modelos } \\
\text { paralelos/seriais (Work Transformation Matrix } \\
\text { (WTM) parallel/serial model) }\end{array}$ & $\begin{array}{l}\text { - Determina a quantidade de paralelismo } \\
\text { - Sequenciamento de atividades } \\
\text { - Gestão de iterações } \\
\text { - Representação concisa do processo }\end{array}$ \\
\hline
\end{tabular}




\begin{tabular}{|c|c|}
\hline Nome do Método/Técnica & Propósito \\
\hline $\begin{array}{l}\text { Matriz estrutural de projeto (Design structured } \\
\text { Matrix - DSM) }\end{array}$ & $\begin{array}{l}\text { - Sequenciamento de atividades } \\
\text { - Gestão de iterações } \\
\text { - Representação concisa do processo } \\
\text { - Sequenciando e programando tarefas de projeto (design) } \\
\text { - Representar e analisar modelos de processo } \\
\text { - Representa atributos de objetos de atividades } \\
\text { - Representa atributos de objetos de entregas } \\
\text { - Coordenar tarefas dependentes, independentes, } \\
\text { interdependentes para o projeto como um todo em um ambiente } \\
\text { de engenharia simultânea } \\
\text { - Melhorar a gestão de projetos de desenvolvimento complexos } \\
\text { usando algoritmos de particionamento } \\
\text { - Minimizar iterações. } \\
\text { - Otimizar PDP. } \\
\text { - Estabelecer o modelo de processo de sobreposição de } \\
\text { acoplamento entre duas atividades no PDP. } \\
\text { - Simular e analisar o cronograma e custo do PDP } \\
\text { - Modelar o conhecimento do produto; depois, reordenar } \\
\text { algoritmos usados para o planejamento do processo }\end{array}$ \\
\hline $\begin{array}{l}\text { Matriz estrutural de projeto fuzzy (Fuzzy Design } \\
\text { Structure Matrix - FDSM) }\end{array}$ & $\begin{array}{l}\text { - Desenvolver um processo mais flexível e eficiente para o } \\
\text { desenvolvimento de novos produtos através do método de } \\
\text { planejamento proposto } \\
\text { - Reduzir o tempo de desenvolvimento de produto } \\
\text { - Sequenciamento de atividades } \\
\text { - Gestão de iterações } \\
\text { - Representação concisa do processo }\end{array}$ \\
\hline Metas de estágio (Stage targeting) & $\begin{array}{l}\text { - Determinar o momento das revisões de projeto } \\
\text { - Caracteização de alto nível do processo de DP } \\
\text { - Avaliação de alocação de recursos entre estágios } \\
\text { - Tradeoffs e riscos do estágio }\end{array}$ \\
\hline $\begin{array}{l}\text { Método de Diagrama de Precedência (Precedence } \\
\text { Diagram Method - PDM) }\end{array}$ & $\begin{array}{l}\text { - Estimativa de tempo de conclusão } \\
\text { - Cálculo de folgas / tempo futuante } \\
\text { - Trade-offs de tempo e custo } \\
\text { - Minimização de custo e tempo } \\
\text { - Mapeamento do processo }\end{array}$ \\
\hline $\begin{array}{l}\text { Método do caminho crítico D (D-Critical Path } \\
\text { Method) }\end{array}$ & $\begin{array}{l}\text { - Determinar o caminho crítico e outras partes relacionadas de } \\
\text { acordo com o processo otimizado } \\
\text { - Planejamento de processo }\end{array}$ \\
\hline $\begin{array}{l}\text { Metodo do caminho crítico } \\
\text { (Critical Path Method - CPM) }\end{array}$ & $\begin{array}{l}\text { - Estimativa de tempo de conclusão } \\
\text { - Cálculo de folgas / tempo futuante } \\
\text { - Trade-offs de tempo e custo } \\
\text { - Minimização de custo e tempo } \\
\text { - Mapeamento do processo }\end{array}$ \\
\hline Minimally Long-tern Organizational Support (MILOS) & $\begin{array}{l}\text { Procura integrar planejamento de projeto com sistemas de gestão } \\
\text { de workflow para a indústria de engenharia de software }\end{array}$ \\
\hline $\begin{array}{l}\text { Modelagem de processos de negócios (Business } \\
\text { Process Modeling) }\end{array}$ & $\begin{array}{l}\text { - Reengenharia } \\
\text { - Engenharia da organização } \\
\text { - Integração de TI } \\
\text { - Gestão de workflow }\end{array}$ \\
\hline Modelo de decomposição 1 & $\begin{array}{l}\text { - Decomposição de sistemas grandes } \\
\text { - Sequenciamento de atividades } \\
\text { - Gestão de iterações } \\
\text { - Representação concisa do processo }\end{array}$ \\
\hline
\end{tabular}




\begin{tabular}{|c|c|}
\hline Nome do Método/Técnica & Propósito \\
\hline Modelo de decomposição 2 & $\begin{array}{l}\text { - Decomposição de sistemas grandes } \\
\text { - Sequenciamento de atividades } \\
\text { - Gestão de iterações } \\
\text { - Representação concisa do processo }\end{array}$ \\
\hline $\begin{array}{l}\text { Modelo de decomposição de módulos de atividades } \\
\text { (Activity module decomposition model) }\end{array}$ & $\begin{array}{l}\text { - Decomposição de sistemas grandes } \\
\text { - Sequenciamento de atividades } \\
\text { - Gestão de iterações } \\
\text { - Representação concisa do processo }\end{array}$ \\
\hline $\begin{array}{l}\text { Modelo de iterações sequenciais (Sequential } \\
\text { Iteration Model) }\end{array}$ & $\begin{array}{l}\text { - Sequenciamento de atividades and scheduling } \\
\text { - Gestão de iterações } \\
\text { - Representação concisa do processo }\end{array}$ \\
\hline $\begin{array}{l}\text { Modelo de planejamento de simulação dinâmica } \\
\text { (Dinamic Simulation Planning model) }\end{array}$ & $\begin{array}{l}\text { - Tornar os métodos de estimativa de recursos do modelo de } \\
\text { estado estacionário mais realistas } \\
\text { - Pode ser usado para limitar o fluxo de projetos com base em } \\
\text { restrições de recursos para fornecer uma estimativa mais realista } \\
\text { do desempenho do pipeline. } \\
\text { - Caracteização de alto nível do processo de DP } \\
\text { - Avaliação de alocação de recursos entre estágios } \\
\text { - Tradeoffs e riscos do estágio }\end{array}$ \\
\hline Modelo de redes de filas (Queueing network model) & $\begin{array}{l}\text { - Examinar os efeitos de atrasos de filas no tempo do PDP } \\
\text { - Programar o projeto com restrições de recursos } \\
\text { - Alocação de recursos }\end{array}$ \\
\hline $\begin{array}{l}\text { Modelos de planejamento de estado estático } \\
\text { (Steady state planning model) }\end{array}$ & $\begin{array}{l}\text { Guiar a seleção de projetos, prever como um determinado } \\
\text { portfólio mai se comportar ao longo do tempo e ajudar a melhorar } \\
\text { os resultados. } \\
\text { - Caracteização de alto nível do processo de DP } \\
\text { - Avaliação de alocação de recursos entre estágios } \\
\text { - Tradeoffs e riscos do estágio }\end{array}$ \\
\hline $\begin{array}{l}\text { Modelos de teoria do Controlee (Controle Theory } \\
\text { Models) }\end{array}$ & $\begin{array}{l}\text { - Políticas de alocação de recursos } \\
\text { - Estimativa de tempo de conclusão } \\
\text { - Caracterizar estabilidade do processo }\end{array}$ \\
\hline Narrativa textual (Storyboard) & $\begin{array}{l}\text { - Representa atributos de objetos de atividades } \\
\text { - Representa atributos de objetos de entregas }\end{array}$ \\
\hline \multicolumn{2}{|l|}{ New Modelling Framework } \\
\hline Programação paralela (Parallel scheduling) & $\begin{array}{l}\text { - Determina a quantidade de paralelismo } \\
\text { - Otimiza o grau de sobreposição de atividades em relação ao } \\
\text { tempo, custo e/ou performance }\end{array}$ \\
\hline Rede de compromissos & - Gestão e adaptação do processo \\
\hline Rede de fluxo de trabalho (Workflow net - WFnet) & $\begin{array}{l}\text { A abordagem apresentada preenche uma lacuna identificada entre } \\
\text { a comunidade processo de planejamento (DSM) e da comunidade } \\
\text { processo de implementação (rede de Petri). }\end{array}$ \\
\hline Rede de Petri & $\begin{array}{l}\text { - Gráficos e simulação de sistemas de eventos discretos } \\
\text { - Processo de verificação para a acessibilidade, os impasses, } \\
\text { eficiência, etc. } \\
\text { - Modelagem de fluxo de trabalho } \\
\text { - Modelagem do processo de manufatura } \\
\text { - Modelagem e simulação do PDP }\end{array}$ \\
\hline Redes de Petri coloridas (Coloured Petri Nets - CPNs) & $\begin{array}{l}\text { - Processo de verificação para a acessibilidade, os impasses, } \\
\text { eficiência, etc. } \\
\text { - Modelagem de fluxo de trabalho } \\
\text { - Modelagem do processo de manufatura } \\
\text { - Racionalizar a alocação de recursos, para encurtar o tempo de } \\
\text { desenvolvimento de produtos e melhorar dua eficiência. }\end{array}$ \\
\hline Roteiro de projeto (Design roadmap) & \\
\hline
\end{tabular}




\begin{tabular}{|c|c|}
\hline Nome do Método/Técnica & Propósito \\
\hline \multicolumn{2}{|l|}{ Signal Flow Graph } \\
\hline Signposting & $\begin{array}{l}\text { - Proporciona uma compreensão fácil da estratégia geral do } \\
\text { trabalho de projeto } \\
\text { - Análise do processo de projeto } \\
\text { - Mapeamento da confiabilidade do projeto }\end{array}$ \\
\hline Sobreposição de estágios (Stage overlapping) & $\begin{array}{l}\text { - Determina a quantidade de paralelismo } \\
\text { - Otimiza o grau de sobreposição de atividades em relação ao } \\
\text { tempo, custo e/ou performance }\end{array}$ \\
\hline $\begin{array}{l}\text { Tabela criar-ler-atualizar-apagar (Create-Read- } \\
\text { Update-Delete - CRUD) }\end{array}$ & - Representa atributos de objetos de atividades \\
\hline $\begin{array}{l}\text { Técnica de avaliação e revisão de projeto (Project } \\
\text { Evaluation and Review Technique - PERT) }\end{array}$ & $\begin{array}{l}\text { - Estimativa de tempo de conclusão } \\
\text { - Cálculo de folgas / tempo futuante } \\
\text { - Trade-offs de tempo e custo } \\
\text { - Minimização de custo e tempo } \\
\text { - Mapeamento do processo }\end{array}$ \\
\hline $\begin{array}{l}\text { Técnica de avaliação e revisão gráfica (Graphical } \\
\text { Evaluate and Review Technique - GERT) }\end{array}$ & $\begin{array}{l}\text { - Análise de rede } \\
\text { - Representa atributos de objetos de atividades }\end{array}$ \\
\hline $\begin{array}{l}\text { Técnica de avaliação e revisão gráfica (Q-GERT } \\
\text { model) }\end{array}$ & $\begin{array}{l}\text { - Determinar os efeitos de atrasos estocásticos no tempo de } \\
\text { desenvolvimento de produtos. } \\
\text { - Análise de rede }\end{array}$ \\
\hline $\begin{array}{l}\text { Tempo de revisões de projeto (Timing of design } \\
\text { reviews) }\end{array}$ & Determinar o momento das revisões de projeto \\
\hline $\begin{array}{l}\text { Teoria de redes complexas (Complex Network } \\
\text { theory) }\end{array}$ & - Melhora o agendamento de recursos. \\
\hline
\end{tabular}





\section{Apêndice D - Artigo: Views of process models suitable for PD reference models purposes}

\section{Views of process models suitable for PD reference models purposes}

Carolina Román Amigo, Diego Rodrigues Iritani, Henrique Rozenfeld, Aldo Ometto.

Affiliation: University of São Paulo, São Carlos School of Engineering, Production Engineering Department.

\section{ABSTRACT}

Process modeling is a set of activities to be followed to create one or more models of a process for a certain purpose. Some views of process models are more suitable for a given purpose than others, and, at different detailing levels, PD process models serve to different purposes. Some literature reviews about product development process modeling and their purposes are available on the literature; however, they emphasize purposes regarding PD project planning and management. Therefore, this research aims to complement the available literature from a high-level perspective, exploring more extensively views of process models related to PD reference models purposes. To this end, a systematic literature review is conducted, followed by the elaboration of a comprehensive list of purposes suitable for PD reference models. Finally, a matrix relating views of process models to purposes of PD reference models is proposed. Among others, the resulting matrix can serve as the starting point for future efforts to develop new views of process models more suitable for PD reference models.

Keywords: product development, modeling, purpose.

\section{Introduction}

According to [Clark and Fujimoto, 1991], product development (PD) is the process by which an organization transforms market opportunities and technical possibilities into valuable information to commercial production. Unlike other business processes, which aim to obtain the same result repeatedly, product development process is intended to create something new once. Thus, product 
development is considered a business process with specific characteristics, because it involves creativity and innovation and is non-linear and iterative [Kline, 1985].

As well as other processes, it is possible and useful to build models for product development processes [Smith and Morrow, 1999]. PD process models can: help the development team to focus on value adding activities; provide current situation transparency and visibility to working force; help on commitments accomplish in a predictable, repeatable and consistent way; indicate best practices related to the process; help on failure prevention, based on previous processes; provide a common vocabulary to work and results discussion; provide a baseline to process management, helping on process improvement measures; provide a common approach to different projects in a same organization; allow potential process changes analysis; and help on learning and comprehension of complex processes, among others [Browning, Fricke, and Negele, 2006].

PD process models can be elaborated with different detailing levels. Reference models can give a high-level overview of the process, with generic guidelines and best practices that can be adapted to various contexts [Fettke, Loos, and Zwicker, 2006]. Once adapted to a specific organization, a reference model is termed as a standard model [Browning, Fricke, and Negele, 2006a], and can be the starting point to a PD project planning. At the most detailed level, PD models can help to manage and control development projects, giving information about resources allocation and tasks status [Browning and Ramasesh, 2007].

Reference models are especially useful for PD process, considering that it has a less structured and predictable character than other business processes. They can help on process structuring (showing main activities, milestones, desirable practices etc...) still maintaining the flexibility required by this kind of process. It's no coincidence that various reference models for product development have been proposed on the literature [Pahl and Beitz, 1988; Clark and Wheelwright, 1993; Urban and Hauser, 1993; Pugh and Clausing, 1996; Cooper, 2001, 2001,; Crawford and Di Benedetto, 2006; Ulrich and Eppinger, 2007].

At different detailing levels, PD process models serve to different purposes. There are some excellent previous researches on the literature about product development process modeling [Smith and Morrow, 1999; O'Donovan et al., 2005; Browning, Fricke, and Negele, 2006a; Browning, 2008; Hong-bae Jun and Suh, 2008], some of them focused on identifying and classifying PD models purposes 
[Browning and Ramasesh, 2007; Browning, 2010]. The aforementioned researches emphasize purposes regarding PD project planning and management. This research aims to complement the available literature, exploring more extensively views of process models related to PD reference models purposes, from a high-level perspective.

\section{PD process modeling main concepts}

According to [Vernadat, 1996], process modeling is an activity set to be followed to create one or more models of something for a certain purpose (e.g. representation, communication, analysis, design or synthesis, decision making and control). The result of a process modeling is a process model. The starting point to model a process is to choose a modeling framework, that can guide the definition of scope, concepts and methods used to modeling an enterprise [Vernadat, 1996].

A modeling framework will support the definition of the modeling methodology and modeling methods that will be employed to elaborate a model (Fig.1). A modeling methodology is a "collection of problem-solving methods governed by a set of principles and a common philosophy" [Kettinger, Teng, and Guha, 1997; Checkland, 1999]. A modeling methodology can employ different formalisms. A modeling formalism is a mean to represent pieces of knowledge that should be transmitted in an unequivocal way [Doumeingts, Vallespir, and Chen, 1995], and is based on a modeling language. A process modeling language provides appropriate syntax and semantics to precisely specify business process requirements [ $\mathrm{Lu}$ and Sadiq, 2007]. The semantic defines how the constructs (the most basic elements of a process model) will be represented, while the syntax refers to relationship logic between the constructs, so that the final result is coherent.

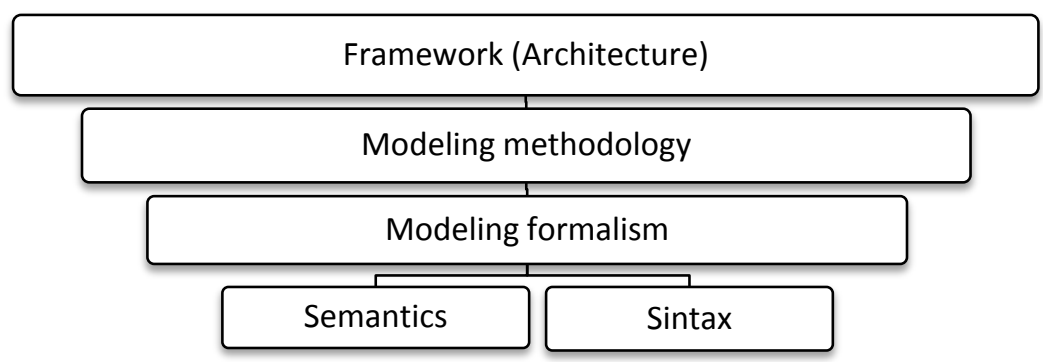

Fig.1 - Relationship among relevant terms in process modeling.

Understanding a process model in its totality can be difficult when dealing with complex processes [Browning, 2008]. Elaborating views of process models can be 
useful to simplify models comprehension, reducing its complexity and focusing, for example, on elements of interest for a given user. A view of a process model, according to [Browning, 2008] is a symbol arrangement, a table, or another chosen representation that shows a subset of the elements of a given model.

\section{PD reference models}

A PD reference model can be generic or specific. Generic reference models are business process representations containing best practices of their application field. Generally they are prescriptive (to-be), informing people about what work has to be done and how [Browning, Fricke, and Negele, 2006a]. They provide a generic set of guidelines, that can be adapted for different contexts [Fettke, Loos, and Zwicker, 2006]. Usually, generic reference models are developed by institutions or organizations (as PDMA and ISO ${ }^{27}$ ) or proposed by experts or researchers, as [Pahl and Beitz, 1988; Cooper, 2001, 2001,; Ulrich and Eppinger, 2007], among others.

Once a generic reference model is instantiated for a given context, it is termed as specific reference model, or standard model [Browning, 2010]. Standard models of this kind have also a prescriptive character. However, there are also descriptive standard models (as-is), that useful to represent the real process within an organization, exactly as it occurs [Browning, 2010]. This latter kind of model if often used to process analysis and improvement. Despite its origin, a standard model provides specific bases for planning the development of a particular product, which is termed as a project. Accordingly to [PMI, 2008], a project is a temporary endeavor, performed to create a product service or other kind of unique result (Fig. 2).

${ }^{27}$ PDMA: Product Development and Management Association ISO: International Organization for Standardization 


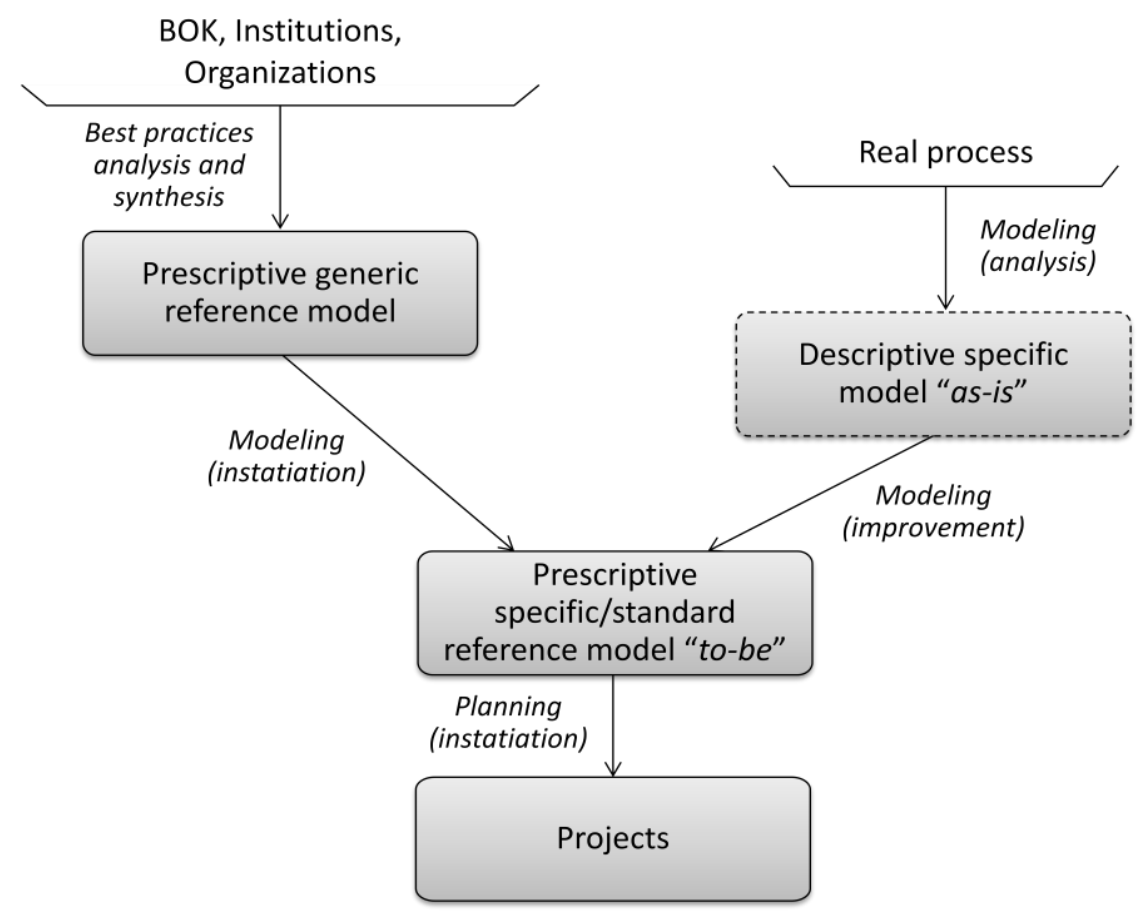

Fig. 2 - Relationship between generic and specific models.

\section{Previous literature reviews on PD modeling regarding its}

\section{purposes}

All these reviews give relevant information about a similar set of views of process models (e.g. event process chain, design structure matrix, flowcharts, among others), and relate them to a set of purposes. The provided information can vary in abstraction level or focus, but this fact contributes for a broader comprehension of each view.

Smith and Morrow [1999] group views of process models in five categories, regarding its purposes: sequencing and scheduling models, decomposition models, stochastic lead time models, design review timing models, and parallelism models. The views are then analyzed according four criteria: if it addresses an important managerial issue; if the decision making is based on information that is available and accurate; if the assumptions and simplifications of the model are reasonable; and if the model in computationally tractable. They conclude that all the analyzed views of process models meet the criterion of managerial importance; they focus in subjects of great significance in the product development process, as development lead time, development cost and product specifications. 
O'Donovan et al. [2005] describe views of process models focusing in its origins, main characteristics and purposes. They conclude that, despite the existence of a great variety of views, they tend to have a common nucleus, based on activities networks. They see in this fact the possibility of unifying some of these views into a new object oriented view. They identify a mismatch between the views of process models offered by literature and the simplistic views most used by the practical community. They also points out a gap regarding decision making supporting offered by the views of process models during the process.

None of the aforementioned reviews aims to structure information about views of process models starting from its purposes. In other words, they doesn't intend to elaborate a comprehensive list of purposes, treating the information to assure all the purposes are in the same detailing level, or don't aim to classify these purposes. The purposes are identified through the views of process models analysis, and are related to them as they are shown at the literature, as secondary information.

However, there are other researches in which the primordial focus relies on identifying and classifying process models purposes. Although it doesn't provide a list or a classification of PD models purposes, a paper from [Browning, Fricke, and Negele, 2006b] suggests general objectives of PD process models that can serve as a starting point (Table 1) to elaborate a taxonomy.

Table 1 - General objectives for a PD Process Model (Extracted from [Browning, Fricke, and Negele, 2006b])

\begin{tabular}{|l|l|}
\hline Objective & Explanation \\
\hline Elements & $\begin{array}{l}\text { Represent the variety of activity attributes required to support the spectrum of model } \\
\text { purposes }\end{array}$ \\
\hline Relationships & Represent meaningful and varied relationships between activities \\
\hline Maintenance & $\begin{array}{l}\text { Be quick and easy to change and update, where appropriate, by almost everyone in } \\
\text { the workforce (thus implying appropriate security features) }\end{array}$ \\
\hline $\begin{array}{l}\text { Computerizatio } \\
\mathrm{n}\end{array}$ & Enable computer-based model building, storage, analysis, and presentation \\
\hline Views & $\begin{array}{l}\text { Enable visualization and comprehension by varied users from different perspectives; } \\
\text { support varies but related views. }\end{array}$ \\
\hline Consistency & Provide a consistent representation of all relevant information in a formal structure \\
\hline Planning & $\begin{array}{l}\text { Support project planning, including process tailoring and activity selection, staffing, } \\
\text { resource loading, budgeting, and scheduling }\end{array}$ \\
\hline Empowerment & $\begin{array}{l}\text { Enable project visualization, communication, and informed decision making at all } \\
\text { levels }\end{array}$ \\
\hline Adaptation & Support process agility and adaptation \\
\hline Integration & $\begin{array}{l}\text { Integrate easily with other process models in other parts of the organization and with } \\
\text { other activity-based cost, schedule, and risk models in the organization }\end{array}$ \\
\hline $\begin{array}{l}\text { Simplicity and } \\
\text { Expandability }\end{array}$ & $\begin{array}{l}\text { Built of simple elements that can collectively model more complex processes; object- } \\
\text { oriented; holonic }\end{array}$ \\
\hline Improvement & Include allowances for improvement, particularly in the form of an improvement loop \\
\hline Error detection & $\begin{array}{l}\text { Automatically check for and flag integration problems and missing information, or } \\
\text { provide assistance in this regard }\end{array}$ \\
\hline
\end{tabular}


In another research, [Browning and Ramasesh, 2007] surveyed purposes of activity network-based process models. They propose a very complete list of PD process modeling purposes, stated as questions (e.g. what activities should be done?). These purposes are classified in four categories (Table 2). The categories are related to PD projects, and, although some purposes are the same, it's not trivial to identify among them which are suitable for PD reference models. For example, there are some purposes that can serve for reference models classified as "project visualization" (e.g. visualize information), and others classified as "project planning" (e.g. define standard activities).

Table 2 - Four Categories of Purposes for PD Process Modeling (extracted from [Browning and Ramasesh, 2007])

\begin{tabular}{|l|l|}
\hline PD project visualization & Actions, interactions, and commitments \\
\cline { 2 - 2 } & Customized "views" \\
\hline \multirow{5}{*}{ PD project planning } & Making commitments \\
\cline { 2 - 2 } & Choosing activities \\
\cline { 2 - 2 } & Structuring the process \\
\cline { 2 - 2 } & Estimating, optimizing, and improving key variables (time, cost, etc.) \\
\cline { 2 - 2 } & Allocating resources \\
\hline PD project execution and & Monitoring commitments \\
\cline { 2 - 2 } & Assessing progress \\
\cline { 2 - 2 } & Re-directing \\
\cline { 2 - 2 } & Re-planning \\
\hline \multirow{5}{*}{ PD project development } & Continuous improvement \\
\cline { 2 - 2 } & Organizational learning and knowledge management \\
\cline { 2 - 2 } & Training \\
\cline { 2 - 2 } & Metrics \\
\cline { 2 - 2 } & Compliance \\
\hline
\end{tabular}

Browning [2010] researches the alignment of the purposes and views of process models emphasizing project management. He considers the attributes that a model view is able to represent and the attributes that are useful to a given purpose to elaborate a matrix showing the alignment between models views and its purposes. This matrix is a high valuable contribution, but, as it relies only on information about attributes, does not consider other aspects important to a model's fitness for its purpose, such as the arrangement of the content on the view, intuitiveness and ease of use. The set of purposes selected for the matrix elaboration is classified according to types of process model users. Table 3 show the subset of purposes related to "process owner" that can be related to reference models, as they have a high level character. Accordingly to [Browning, 2010], process owners are responsible for documenting and maintaining standard processes for accomplishing work. 
Table 3 - Identified purposes of owners of process models (Extracted from [Browning, 2010])

\begin{tabular}{|l|l|}
\hline Purpose & Explanation \\
\hline $\begin{array}{l}\text { Define standard deliverables } \\
\text { and quality standards }\end{array}$ & $\begin{array}{l}\text { The process model can document the desired result(s) of each activity, } \\
\text { including its measures of effectiveness and their acceptable levels. }\end{array}$ \\
\hline $\begin{array}{l}\text { Define standard handoffs } \\
\text { and structure standard work } \\
\text { flows }\end{array}$ & $\begin{array}{l}\text { The process model can relate deliverables to activities via input-output } \\
\text { lists, resulting in a sequenced flow of work. }\end{array}$ \\
\hline $\begin{array}{l}\text { Define standard tools and } \\
\text { templates }\end{array}$ & $\begin{array}{l}\text { A set of standard tools, templates, facilities, etc. can be associated with } \\
\text { each activity. }\end{array}$ \\
\hline $\begin{array}{l}\text { Define standard staffing, } \\
\text { roles, responsibilities, and } \\
\text { skills }\end{array}$ & $\begin{array}{l}\text { A set of roles to be filled and/or responsibilities to be held can be specified } \\
\text { for each activity, along with the typical number of people, level of effort, } \\
\text { and required skills to ensure that the activity is performed effectively. }\end{array}$ \\
\hline $\begin{array}{l}\text { Visualize, understand, } \\
\text { analyze, and improve } \\
\text { processes }\end{array}$ & $\begin{array}{l}\text { Process owners desire ways to represent, examine, and improve } \\
\text { processes. }\end{array}$ \\
\hline $\begin{array}{l}\text { Identify "ripple effects" of } \\
\text { process changes }\end{array}$ & $\begin{array}{l}\text { When multiple projects use a standard process model, the owner of the } \\
\text { standard process faces a barrage of change requests, which he or she } \\
\text { must be able to evaluate quickly, especially in terms of their potential } \\
\text { effects on other, interdependent processes. }\end{array}$ \\
\hline $\begin{array}{l}\text { Organize knowledge about } \\
\text { work }\end{array}$ & $\begin{array}{l}\text { Process models can help structure the vast amount of information that } \\
\text { exists in a large company about what work to do and how to do it. }\end{array}$ \\
\hline $\begin{array}{l}\text { Define standard and } \\
\text { preferred activities }\end{array}$ & $\begin{array}{l}\text { The process model can document the work practices deemed appropriate } \\
\text { by the functional organizations. }\end{array}$ \\
\hline
\end{tabular}

Although these references emphasize purposes regarding PD project management, they are a valuable resource for determining PD reference models purposes and were consulted for the elaboration of the consolidated list on the results section.

\section{Methodology}

This research follows three phases, represented at Fig. 3. At this figure, the main activities of each phase are synthesized, and phases main deliverables are in gray. At the phase 1, a systematic literature review was conducted aiming to identify the views of process models that are used in product development process modeling. This systematic literature review resulted on a synthesis table with views of process models and its purposes. At the phase 2, the purposes part of this table was analyzed, condensed and compared to the purposes found on the literature (section $0)$. A final purposes list regarding reference PD models was obtained from this process. Then, at phase 3 , based on this final list, the information on the synthesis table was revised, and a matrix relating views of process models to this set of purposes was build. Some activities were performed iteratively. This is indicated at the figure by a circular arrow. 
Phase 1

Systematic literature review

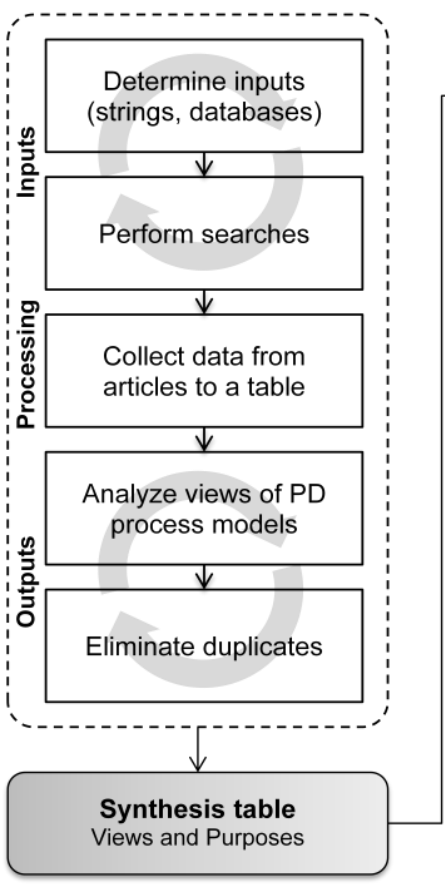

Phase 2

Purposes list

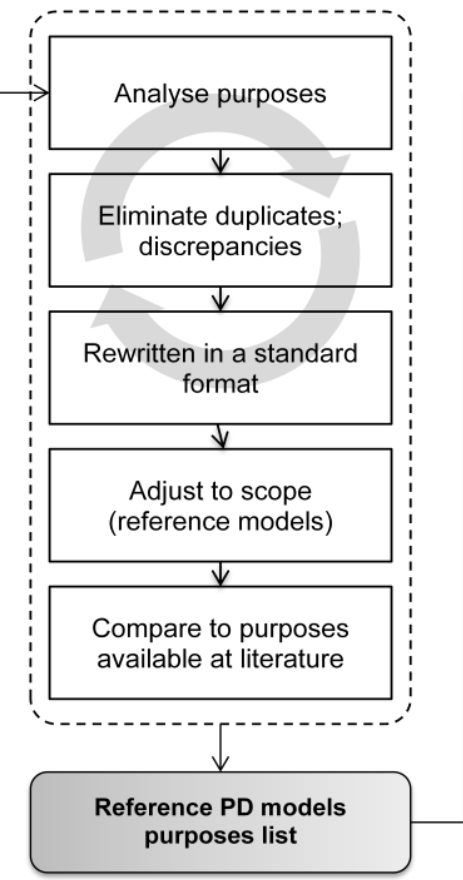

Phase 3

Matrix

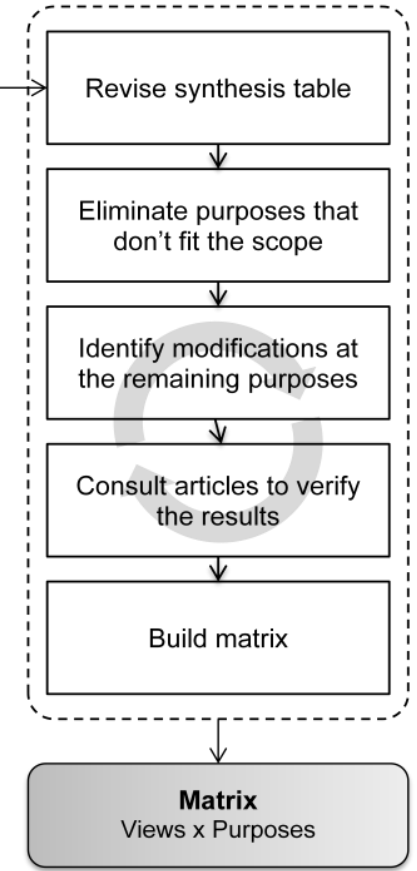

Fig. 3 - Methodology: main activities and deliverables of this research

\subsection{Phase 1: Systematic literature review}

This systematic literature review was conducted according to the roadmap proposed by [Conforto, Amaral, and Silva, 2011]. The roadmap was developed to guide systematic literature reviews in operations management, adapting and improving methods from other areas [Levy and Ellis, 2006; de Almeida Biolchini et al., 2007]. This roadmap has as main characteristics: the research strings tests and refinements; the iterative processing of the results, with more detailed selection filters at each iteration; and the references by references search. The roadmap is composed by 3 stages, described hereafter.

\section{Stage 1: Inputs}

In this phase, the systematic literature review was planned and its inputs defined. The resulting plan as the inputs selection criteria are shown below.

1. Objective definition: identify the views of process models that are used in product development process modeling.

2. Database definition: qualified experts, and ISI Web of Science (Thomson Reuters) and SciVerse Scopus (Elsevier) databases. Articles and conference proceedings available in English, free of charge, and authenticated by the researchers' institutions were considered. 
3. Strings definition: the keywords were selected from a preliminar list of articles identified by the qualified experts. Three iterations were then carried out for strings refinement.

4. Inclusion criteria definition: the established criteria for articles selection was "Proposition, description or application of modeling frameworks, methods, techniques or approaches or views for product development process models" and "Proposition, description or application of new views of process models for product development process".

5. Searching: searching the selected databases, eliminating duplicates, and exporting results to a table for filters application.

6. Filters with selection criteria application: 1st iteration with article's title, keywords and abstract reading; 2nd iteration with article's introduction, results and conclusion reading; 3rd iteration with article's full reading.

7. References by references search: were performed using the references of the selected articles.

8. Data extracting to synthesis table, obtained from deep reading of selected articles.

9. Articles cataloging and storing in bibliographic reference manager software.

\section{Stage 2: Processing}

This stage consists in systematic literature review searches conduction, as well results analysis and documentation. In this systematic literature review, the searches were conducted entering the strings on the databases defined on the previous phase, considering the fields "title", "abstract" and "keywords".

Searching using the chosen string produced 5646 articles (counting both databases). Of this total, 1394 articles were duplicates across the two databases (a $33 \%$ overlap). Thus, 4252 articles were iteratively subjected to the filters defined in the previous phase. During articles' full reading, it is normal to find citations to other relevant articles that did not appear on the searches. This indirect search for articles is named references by references search. In our systematic literature review, 36 articles were found through the references by references search. Finally, 101 articles were fully analyzed, 65 from the filters selection and 36 from the references by references search.

\section{Stage 3: Outputs}


Data extraction from the selected articles to a synthesis table then occurred, listing all the views of PD process models found and their purposes. The only information considered was what could be retrieved from the analyzed set of articles; no critical analysis occurred at this point. This table was refined iteratively, to eliminate duplicates (some author refers to the same modeling method with different names) and to assure that all the modeling methods selected are within the scope of this research.

\subsection{Phase 2: Elaboration of a purposes list suitable for reference models}

The raw data collected on the synthesis table resulting from the systematic literature review was the starting point to the elaboration reference model purposes list. This data was submitted to a critical analysis to refinement.

The critical analysis occurred in two steps. First, purposes assigned to each view according to what could be found on the articles selected by the systematic literature review were analyzed in order to find duplicates and eliminate discrepancies. Then they were rewritten in a standard format (verb followed by a substantive). These steps were repeated in three iterations, in order to result in a refined set of purposes (Fig. 3).

Then, the purposes list was adjusted to this research scope, selecting the purposes related to PD reference models. Purposes related to project management (e.g. estimate time completion, calculate slack/float time, allocate resources, among others), were eliminated. The level of detailing of the selected purposes was homogenized, avoiding purposes too generic as "organize knowledge" or visualizing process".

This set of purposes was compared to the purposes list already available on the literature (section 0 ). Some of them were rewritten, some decomposed and some excluded accordingly to a critical analysis.

\subsection{Phase 3: Matrix development relating views of PD process models to}

\section{its purposes}

The synthesis table obtained on phase 1 was revised accordingly to the new list of purposes obtained on phase 2. Some purposes were excluded (the ones pertaining to project management), others replaced, and further consult to the set of selected articles from the systematic literature review as realized to guarantee the correctness of information. Based on this revised synthesis table, the matrix was elaborated. 


\section{Synthesis and analysis of results}

A comprehensive list with purposes suitable for reference models is on Table 4. On the first column are the reference models purposes (with an ID), and at the second column are the explanations for these purposes. The related purposes identified on previous researches (section 0 ) were specified at the third column. It is important to point out that the major part of these related purposes are not equivalent to the purposes of the first column, considering that they were purposes identified for project management models. They only refer to similar issues that can be transposed from project management to reference process models. For example, the purpose "How and to what level should we decompose a process?" from project management scope, can be related to two reference models purposes, "Show activities hierarchy" and "Reduce complexity of design process".

The matrix relating views of PD process models to its purposes is on Table 5, and should be read using Table 4 as a legend for identifying the purposes. The views of PD process models found on the systematic literature review are listed on the matrix lines, and the purposes are on the columns. The names of views are followed by the main reference ${ }^{28}$. At the second line of the matrix is the total number of views that fulfills each purpose (A). At the last column is the total of purposes that can be fulfilled by each view (B). The lines and columns of the matrix were ordered in ascending order.

It is possible to observe that, accordingly to the literature, the five first purposes are supported by most views of PD process models. And that the views most suitable to reference models purposes are Extended event process chain diagram (EPC) [Scheer, Thomas, and Adam, 2005; Browning, 2008], and Business process modeling notation (BPMN) [Browning, Fricke, and Negele, 2006b; Arkin, 2002]. These two views are indeed very popular among the practical community, and there is a myriad of software tools available for supporting process modeling employing them. However, even these views doesn't attend to relevant purposes of reference PD process models, as "show process milestones or main deliverables", or "evaluate design process complexity".

\footnotetext{
${ }^{28}$ Further references were consulted, and can be obtained by contacting this paper authors.
} 


\section{Table 4 - PD reference models purposes}

\begin{tabular}{|c|c|c|}
\hline ID - Purpose & Explanation & Related purposes found on literature \\
\hline $\begin{array}{l}\text { P1-Define process activities } \\
\text { and its preferred sequence }\end{array}$ & $\begin{array}{l}\text { Define process preferred activities. Process or project activities linear ordering, } \\
\text { sequencing (not necessarily relying on input/outputs information). }\end{array}$ & $\begin{array}{l}\text { Define standard and preferred activities } \\
\text { [Browning, 2010] } \\
\text { What are the standard activities? When should } \\
\text { activities be done? [Browning and Ramasesh, } \\
\text { 2007] }\end{array}$ \\
\hline $\begin{array}{l}\text { P2-Visualize/ understand } \\
\text { design process }\end{array}$ & $\begin{array}{l}\text { Provide a concise representation of design process. Communicate or explain design } \\
\text { process. }\end{array}$ & $\begin{array}{l}\text { Visualize, understand, analyze, and improve } \\
\text { processes [Browning, 2010] } \\
\text { How can the workforce visualize and understanc } \\
\text { the project's planned process? [Browning and } \\
\text { Ramasesh, 2007] }\end{array}$ \\
\hline $\begin{array}{l}\text { P3-Identify } \\
\text { dependencies/precedence } \\
\text { between activities/functions }\end{array}$ & $\begin{array}{l}\text { Identify dependencies/precedence between activities for enabling concurrent engineering } \\
\text { (show parallelism, coupling, minimize overlapping), or allow network analysis. }\end{array}$ & $\begin{array}{l}\text { Which activities should be overlapped and by } \\
\text { how much? [Browning and Ramasesh, 2007] }\end{array}$ \\
\hline $\begin{array}{l}\text { P4-Show flow of data or } \\
\text { information }\end{array}$ & $\begin{array}{l}\text { Show how information enters and leaves the process (process or activities } \\
\text { inputs/outputs). Connect activities with deliverable and indicate cause and effect relations. }\end{array}$ & $\begin{array}{l}\text { Define standard handoffs and structure standaro } \\
\text { work flows [Browning, 2010] } \\
\text { How should we structure the information flow? } \\
\text { [Browning and Ramasesh, 2007] }\end{array}$ \\
\hline $\begin{array}{l}\text { P5-Identify and } \\
\text { organize/assign required } \\
\text { resources }\end{array}$ & $\begin{array}{l}\text { Assign general roles/responsibilities/skills to activities/deliverables; show organizational } \\
\text { units involved; show stakeholders. }\end{array}$ & $\begin{array}{l}\text { Define standard staffing, roles, responsibilities, } \\
\text { and skills [Browning, 2010] } \\
\text { Where and when should we allocate resources? } \\
\text { [Browning and Ramasesh, 2007] }\end{array}$ \\
\hline $\begin{array}{l}\text { P6-Improve/continuous } \\
\text { improve design process }\end{array}$ & Optimize product development process. Process reengineering. & $\begin{array}{l}\text { Visualize, understand, analyze, and improve } \\
\text { processes [Browning, 2010] }\end{array}$ \\
\hline $\begin{array}{l}\text { P7-Show process } \\
\text { milestones/main deliverables }\end{array}$ & $\begin{array}{l}\text { Highlighting important events of the process or project. Show preferred process point/time } \\
\text { for delivering a determined work package. }\end{array}$ & $\begin{array}{l}\text { Define standard deliverables and quality } \\
\text { standards [Browning, 2010] }\end{array}$ \\
\hline $\begin{array}{l}\text { P8-Show activities hierarchy } \\
\text { (parent/children) }\end{array}$ & $\begin{array}{l}\text { Show parent/children relationship, structure decomposition. Indicate hierarchical levels of } \\
\text { product development process (detailing level). }\end{array}$ & $\begin{array}{l}\text { How and to what level should we decompose a } \\
\text { process? [Browning and Ramasesh, 2007] }\end{array}$ \\
\hline $\begin{array}{l}\text { P9-Reduce complexity of } \\
\text { design process }\end{array}$ & Decomposing process models for reducing complexity. & $\begin{array}{l}\text { How and to what level should we decompose a } \\
\text { process? [Browning and Ramasesh, 2007] }\end{array}$ \\
\hline $\begin{array}{l}\text { P10-Organize knowledge } \\
\text { about work }\end{array}$ & $\begin{array}{l}\text { Documentation/register of design process data/information about what work to do and } \\
\text { how to do it. }\end{array}$ & $\begin{array}{l}\text { Organize knowledge about work [Browning, } \\
2010]\end{array}$ \\
\hline $\begin{array}{l}\text { P11-Evaluate design process } \\
\text { complexity }\end{array}$ & $\begin{array}{l}\text { Evaluate the level of complexity of development process, given, for example, by number } \\
\text { of activities, number of dependencies or number of resources required. }\end{array}$ & There were found no related purposes \\
\hline $\begin{array}{l}\text { P12-Determine the timing of } \\
\text { design reviews/gates }\end{array}$ & $\begin{array}{l}\text { Evaluate design reviews tradeoff (unnecessary reviews } \times \text { great amount of rework), for } \\
\text { determine optimal point/time for its realization. }\end{array}$ & There were found no related purposes \\
\hline $\begin{array}{l}\text { P13-Indicate standard } \\
\text { practices/tools }\end{array}$ & $\begin{array}{l}\text { Provide information about best practices and tools for product development, based on } \\
\text { consolidated literature, benchmarking and/or previous projects that were successful. }\end{array}$ & $\begin{array}{l}\text { Define standard tools and templates [Browning, } \\
\text { 2010] }\end{array}$ \\
\hline P14-Handle with changes & $\begin{array}{l}\text { Allow analysis of process modifications, provide alternative routing for process changing, } \\
\text { or allowing model updating. }\end{array}$ & $\begin{array}{l}\text { Identify "ripple effects" of process changes } \\
\text { [Browning, 2010] }\end{array}$ \\
\hline $\begin{array}{l}\text { P15-Interchange process } \\
\text { data }\end{array}$ & $\begin{array}{l}\text { Provide interchange between different computer systems through an integrated database } \\
\text { or common language. }\end{array}$ & There were found no related purposes \\
\hline
\end{tabular}




\section{2}

Table 5 - Matrix relating views of PD process models to PD reference models purposes

PD reference models purposes:

\begin{tabular}{|l|l|l|l|l|l|l|l|l|l|l|l|l|l|l|}
\hline P1 & P2 & P3 & P4 & P5 & P6 & P7 & P8 & P9 & P10 & P11 & P12 & P13 & P14 & P15 \\
\hline
\end{tabular}

View of PD process models [main references]

Event process chain diagram (EPC)[Scheer, Thomas, and Adam, 2005]

Business process modeling notation (BPMN)[Arkin, 2002]

Signposting[O'Donovan, Clarkson, and Eckert, 2003]

Design roadmap[HB Jun and Suh, 2008; Park and Cutkosky, 1999]

Design structure matrix (DSM)[Browning, 2001]

Work transformation matrix(WTM)[Smith and Morrow, 1999]

Value Stream Mapping[Mcmanus, 2005]

Entry-Task-Validation-Exit (ETVX) Diagram[Fricke et al., 2000]

Fuzzy DSM[Ko, Kuo, and Yu, 2010; Browning, Fricke, and Negele, 2006b]

Activity-on-Arc Diagram[Elmaghraby and Carolina, 1995]

Activity module decomposition model[Kusiak and Park, 1990]

Function Block Diagram[Park and Cutkosky, 1999]

Structured Analysis and Design Technique (SADT)[Ross, 1977]

Integration Definition for Function Modeling (IDEF0)[NIST, 1993]

Network of Commitments[Browning, Fricke, and Negele, 2006b]

SIPOC Diagram[Browning, 2008; Browning, Fricke, and Negele, 2006b]

Textual Narrative[Browning, 2008; Browning, 2010]

Q-GERT model[Taylor III and Moore, 1980]

Graphical Evaluate Review Technique (GERT)[Moore and Taylor III, 1977]

Coloured Petri Nets[Aguilarsaven, 2004; Deng and Yang, 2010]

Data Flow Diagram[Aguilarsaven, 2004; Browning, 2010]

Gantt Chart[Browning, 2008; Aguilarsaven, 2004; HB Jun and Suh, 2008]

D-Critical Path Method[Hang, 2011: Browning. Fricke, and Negele, 2006b

Integration Definition for Function Modeling (IDEF3)[Aguilarsaven, 2004]

Modeling the release time of a single uncertain iterative activity

[Sonnemans, Geudens, and Brombacher, 2003]

Sequential Iteration Model[Smith and Eppinger, 1997]

Markov Models[Smith and Eppinger, 1997]

Feedbacks and Crossovers[Smith and Morrow, 1999]

Flow Chart[Aguilarsaven, 2004; Browning, 2008]

A

\begin{tabular}{|c|c|c|c|c|c|c|c|c|c|c|c|c|c|c|c|}
\hline 39 & 33 & 33 & 29 & 27 & 15 & 10 & 9 & 9 & 8 & 6 & 6 & 4 & 5 & 2 & B \\
\hline $\mathrm{X}$ & $\mathrm{X}$ & $\mathrm{X}$ & $\mathrm{X}$ & $\mathrm{X}$ & $\bar{X}$ & & $\mathrm{X}$ & $\mathrm{X}$ & $\bar{X}$ & & $\bar{X}$ & $\bar{X}$ & $\mathrm{X}$ & & 12 \\
\hline $\bar{X}$ & $\bar{X}$ & $\mathrm{X}$ & $\bar{X}$ & $\bar{X}$ & $\bar{X}$ & & $\bar{X}$ & $\bar{X}$ & $\bar{X}$ & & & & $\bar{X}$ & $X$ & 11 \\
\hline $\bar{X}$ & $\bar{X}$ & $\bar{X}$ & $X$ & $\bar{X}$ & & & $\bar{X}$ & & & $X$ & & & $\bar{x}$ & & 8 \\
\hline $\bar{x}$ & $x$ & $\bar{x}$ & $\mathrm{X}$ & $\bar{x}$ & & & $\bar{x}$ & $X$ & $X$ & & & & & & 8 \\
\hline $\bar{X}$ & $\bar{X}$ & $\bar{X}$ & $\bar{X}$ & $\bar{X}$ & 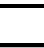 & & & $\bar{X}$ & $\bar{X}$ & & & & & & 7 \\
\hline $\bar{X}$ & $\bar{X}$ & $\bar{X}$ & $\mathrm{X}$ & $\bar{X}$ & $X$ & & & $X$ & & & & & & & 7 \\
\hline $\bar{X}$ & $\bar{X}$ & $\bar{X}$ & $\bar{X}$ & & $\bar{X}$ & & $\mathrm{X}$ & & & $X$ & & & & & 7 \\
\hline $\bar{X}$ & $\bar{X}$ & $\bar{X}$ & $X$ & $x$ & & & & & $X$ & & $x$ & & & & 7 \\
\hline $\bar{X}$ & $\bar{X}$ & $\bar{X}$ & $\bar{X}$ & $\bar{X}$ & $X$ & & & & & & & & & & 6 \\
\hline $\bar{X}$ & $\bar{X}$ & $\bar{x}$ & $X$ & & & $X$ & & & & $X$ & & & & & 6 \\
\hline $\bar{X}$ & $\mathrm{X}$ & $\bar{x}$ & & $X$ & $\bar{X}$ & & & $X$ & & & & & & & 6 \\
\hline$X$ & & $X$ & $X$ & $X$ & & & $X$ & $X$ & & & & & & & 6 \\
\hline $\bar{X}$ & $X$ & $\bar{X}$ & $\mathrm{X}$ & & $X$ & & $\bar{X}$ & & & & & & & & 6 \\
\hline $\bar{X}$ & $\bar{X}$ & $\bar{X}$ & $\mathrm{X}$ & & $\bar{X}$ & & $\bar{X}$ & & & & & & & & 6 \\
\hline $\bar{x}$ & $\bar{X}$ & $\bar{X}$ & $\mathrm{X}$ & $x$ & $\bar{X}$ & & & & & & & & & & 6 \\
\hline & $\bar{X}$ & $\bar{X}$ & & $\bar{X}$ & & $\mathrm{X}$ & & & $X$ & & & $\mathrm{X}$ & & & 6 \\
\hline$X$ & $\bar{X}$ & & $X$ & & T & & & & $\bar{X}$ & & & $\bar{X}$ & $X$ & & 6 \\
\hline $\bar{X}$ & & $\bar{X}$ & $\mathrm{X}$ & $X$ & & & & & & $X$ & & & & & 5 \\
\hline $\bar{X}$ & & $\bar{x}$ & $\bar{x}$ & $\bar{X}$ & & & & & & $\bar{x}$ & & & & & 5 \\
\hline$X$ & $X$ & $\mathrm{X}$ & & $\bar{X}$ & $\bar{X}$ & & & & & & & & & & 5 \\
\hline & $\mathrm{X}$ & & $\mathrm{X}$ & $\bar{X}$ & $\mathrm{X}$ & & & & $X$ & & & & & & 5 \\
\hline $\bar{x}$ & & $\mathrm{X}$ & & $x$ & & $x$ & & & & & $X$ & & & & 5 \\
\hline $\bar{X}$ & & $\bar{X}$ & $\bar{X}$ & $\bar{X}$ & $X$ & & & & & & & & & & 5 \\
\hline $\mathrm{X}$ & $X$ & $\bar{X}$ & $\mathrm{X}$ & & & & $X$ & & & & & & & & 5 \\
\hline$X$ & $X$ & $X$ & $X$ & & & & & $X$ & & & & & & & 5 \\
\hline $\mathrm{X}$ & $\mathrm{X}$ & $\mathrm{X}$ & & & $X$ & & & & & & & & & & 4 \\
\hline $\mathrm{X}$ & $\mathrm{X}$ & & $\mathrm{X}$ & $X$ & & & & & & & & & & & 4 \\
\hline $\mathrm{X}$ & $\bar{X}$ & & $\bar{X}$ & & & & & $X$ & & & & & & & 4 \\
\hline $\mathrm{X}$ & $\bar{X}$ & & $\bar{X}$ & & & & & & & & & & & $\bar{X}$ & 4 \\
\hline
\end{tabular}


PD reference models purposes:

\begin{tabular}{|l|l|l|l|l|l|l|l|l|l|l|l|l|l|l|}
\hline P1 & P2 & P3 & P4 & P5 & P6 & P7 & P8 & P9 & P10 & P11 & P12 & P13 & P14 & P15 \\
\hline
\end{tabular}

View of PD process models [main references]

\begin{tabular}{|l|l|l|l|l|l|l|l|l|l|l|l|l|l|l|l|l|} 
A & 39 & 33 & 33 & 29 & 27 & 15 & 10 & 9 & 9 & 8 & 6 & 6 & 4 & 5 & 2 & B \\
\hline
\end{tabular}

Iterative cycle time estimation[Smith and Morrow, 1999]

Activity-on-node task graph[Elmaghraby, 1995]

Activity-Activity Incidence Matrix[Kusiak et al., 1995]

Module scheduling[Smith and Morrow, 1999]

Stage targeting[Smith and Morrow, 1999]

Strategic information flows[Lewis and Cangshan, 1997

Analysis of interconnected decision areas (AIDA)[Smith and Morrow, 1999]

Petri Net[Krause and Kind, 2004; Aguilarsaven, 2004]

Project Evaluation Review Technique (PERT)[Park and Cutkosky, 1999]

Critical Path Method (CPM)[Elmaghraby, 1995; Park and Cutkosky, 1999]

Stage overlapping[Krishnan, Eppinger, and Whitney, 1997]

Digraph[HB Jun and Suh, 2008; Ko, Kuo, and Yu, 2010]

Queueing network model[Smith and Morrow, 1999]

Parallel scheduling[Smith and Morrow, 1999]

Timing of design reviews[Smith and Morrow, 1999]

Create-Read-Update-Delete (CRUD) Table[Browning, 2008]

Product release[Smith and Morrow, 1999]

Block Diagrams[Lee, Ong, and Khoo, 2004]

Signal Flow Graph[Eppinger, Nukala, and Whitney, 1997]

Stock-and-Flow Diagram[Browning, 2008; Browning, 2010]

Responsability Assignment Matrix [Browning, 2010; (U.S.), 2008]

\begin{tabular}{|c|c|c|c|c|c|c|c|c|c|c|c|c|c|c|c|}
\hline 39 & 33 & 33 & 29 & 27 & 15 & 10 & 9 & 9 & 8 & 6 & 6 & 4 & 5 & 2 & B \\
\hline $\mathrm{X}$ & $x$ & $\mathrm{X}$ & & $X$ & & & & & & & & & & & 4 \\
\hline $\bar{X}$ & $\bar{X}$ & $\mathrm{X}$ & & & $x$ & & & & & & & & & & 4 \\
\hline $\bar{X}$ & $\bar{X}$ & $\mathrm{X}$ & & & $X$ & & & & & & & & & & 4 \\
\hline $\bar{X}$ & $\bar{X}$ & & & $\mathrm{X}$ & & & & & & & $X$ & & & & 4 \\
\hline $\mathrm{X}$ & $\bar{X}$ & & & $\bar{X}$ & & & & & & & $\mathrm{X}$ & & & & 4 \\
\hline & $\bar{X}$ & & $\bar{X}$ & $\bar{X}$ & & $X$ & & & & & & & & & 4 \\
\hline & & $\mathrm{X}$ & & & & & & & & $\mathrm{X}$ & & $\mathrm{X}$ & $\mathrm{X}$ & & 4 \\
\hline$X$ & & $\mathrm{X}$ & $X$ & & & & & & & & & & & & 3 \\
\hline $\bar{X}$ & $X$ & & & & & $X$ & & & & & & & & & 3 \\
\hline $\bar{X}$ & $X$ & & & & & $\mathrm{X}$ & & & & & & & & & 3 \\
\hline $\bar{X}$ & & $X$ & $X$ & & & & & & & & & & & & 3 \\
\hline $\bar{x}$ & $X$ & $X$ & & & & & & & & & & & & & 3 \\
\hline $\mathrm{X}$ & & $X$ & & $X$ & & & & & & & & & & & 3 \\
\hline$X$ & & $X$ & $x$ & & & & & & & & & & & & 3 \\
\hline & & & & & & $X$ & & & & & $X$ & & & & 2 \\
\hline & & & $X$ & & & $\mathrm{X}$ & & & & & & & & & 2 \\
\hline & & & & & & $\mathrm{X}$ & & & & & & & & & 1 \\
\hline & & & & $X$ & & & & & & & & & & & 1 \\
\hline & & & & $\mathrm{X}$ & & & & & & & & & & & 1 \\
\hline & & & & & & $X$ & & & & & & & & & 1 \\
\hline & & & & $X$ & & & & & & & & & & & \\
\hline
\end{tabular}





\section{Conclusions and future researches}

Although the performed systematic literature review allows a comprehensive analysis of vies of PD process models and their purposes, it has limitations. The analyzed papers address the modeling methods from several perspectives and on varying levels of detail. Thus, the resulting set of purposes includes highly abstract purposes as "show flow of data and information" and less abstract ones as "define/show activities sequence." The same is true of the process views, where a Design roadmap model contrasts with a Gantt chart. Future research should classify the methods and purposes, identifying the groups that would help users with matrix comprehension and views selection.

Moreover, the literature describes some views better than others, implying that more details about purposes are available for some views than for others. This can produce a misconception about model views' appropriateness to their purposes. For example, a view poorly detailed in the literature can appear unsuitable for a purpose it can satisfy. This also turns infeasible to indicate the degree of purpose fulfillment for each view. The authors' critical analysis during the synthesis table refinement helped alleviate these problems, but further analyses and validation by experts and practitioners would be valuable.

Furthermore, some papers describe purposes of views of process models in combination with software tools or platforms, while others describe the purposes of views alone. Future studies should clarify which purposes flow from this combined use.

Despite these limitations, this study provides insights that can help researchers and practitioners interested in reference PD process modeling. The study's views list aggregates the majority of views found in the available literature reviews and provides additional ones. Although an exhaustive list is unfeasible, this research constitutes a comprehensive reference for future studies. The purposes list is also a valuable resource, as few studies have sought to identify PD reference models purposes.

This study's matrix can help PD reference process modelers select the best view for a given purpose. Future studies could give it more detail, showing the degree of purpose fulfillment provided by each view (i.e., partial or full), which was not possible with the methodology applied in this research. It could also serve as a basis for a view selection framework that combines process model purposes with other selection criteria, such as model change permissiveness. 
Finally, this research also indicated that despite their importance to PD reference models, some purposes-like "Determine the timing of design reviews/gates" and "indicate standard practices/tools"-are attended by only a few views. Moreover, it could serve as the starting point for future efforts to develop new views of PD process models more suitable for PD reference models.

\section{Acknowledgments}

The authors are grateful for the financial support provided by the Comissão de Aperfeiçoamento de Pessoal de Nível Superior (CAPES) and the Fundação de Amparo à Pesquisa do Estado de São Paulo (FAPESP).

\section{References}

P. M. I. (U.S.) (ed.), A guide to the project management body of knowledge (PMBOK® Guide), Project Management Institute, Inc, Newtown Square, Pa. :, 2008.

R. Aguilarsaven, Business process modelling: Review and framework, International Journal of Production Economics, 90 (2004), 129-149. doi:10.1016/S0925-5273(03)00102-6.

F. Aitsahlia, E. Johnson, and P. Will, Is Concurrent Engineering always a sensible proposition ?, IEEE Transactions on Engineering Management, 42 (1995), 166-170.

J. C. de Almeida Biolchini, P. G. Mian, A. C. C. Natali, T. U. Conte, and G. H. Travassos, Scientific research ontology to support systematic review in software engineering, Advanced Engineering Informatics, 21 (2007), 133-151. doi:10.1016/j.aei.2006.11.006.

A. Arkin, Business Process Modeling Language,. Ed. BPMI 2002.

T. R. Browning, Applying the Design Structure Matrix to System Decomposition and Integration Problems : A Review and New Directions, Engineering, 48 (2001), 292-306.

The Many Views of a Process : Toward a Process Architecture Framework for Product Development Processes, Systems Engineering, 12 (2008), 69-90. doi:10.1002/sys.

On the alignment of the purposes and views of process models in project management, Journal of Operations Management, 28 (2010), 316-332. doi:10.1016/j.jom.2009.11.007.

T. R. Browning, E. Fricke, and H. Negele, Key concepts in modeling product development processes, Systems Engineering, 9 (2006a), 104-128. doi:10.1002/sys.20047.

Key concepts in modeling product development processes, Systems Engineering, 9 (2006b), 104-128. doi:10.1002/sys.20047.

T. R. Browning, and R. V. Ramasesh, A survey of activity network-based process models for managing product development projects, PRODUCTION AND OPERATIONS MANAGEMENT, 16 (2007), 217-240.

P. Checkland, Systems thinking, systems practice, John Wiley, 1999.

K. B. Clark, and T. Fujimoto, Product development performance: strategy, organization, and management in the world auto industry, Harvard Business School Press, 1991.

K. B. Clark, and S. C. Wheelwright, Managing new product and process development: text and cases, Free Press, 1993.

E. C. Conforto, D. C. Amaral, and S. L. Da Silva, Roteiro para revisão bibliográfica sistemática : aplicação no desenvolvimento de produtos e gerenciamento de projetos, $8^{\circ}$ Congresso Brasileiro de Gestão de Desenvolvimento de Produto - CBGDP, Porto Alegre, 2011, pp. 1-12.

R. G. Cooper, Winning at New Products: Accelerating the Process from Idea to Launch, 3rd ed. vol. 2001; Perseus, Cambridge, Mass., 2001.

C. M. Crawford, and C. A. Di Benedetto, New products management,. Ed. McGraw-Hill/Irwin 8th ed. McGraw-Hill/Irwin, 2006.

Q. W. Deng, and L. P. Yang, Research on Product Development Resource Allocation Modeling Based on Hierarchical Colored Petri Net, Applied Mechanics and Materials, 44-47 (2010), 138-142. doi:10.4028/www.scientific.net/AMM.44-47.138.

G. Doumeingts, B. Vallespir, and D. Chen, Methodologies for designing CIM systems: A survey, Computers in Industry, (1995).

S. E. Elmaghraby, Activity nets : A guided tour through some recent developments, European Journal of Operational Research, (1995), 383-408. 
(1995).

S. E. Elmaghraby, and N. Carolina, Activity nets : A guided tour through some recent developments

S. D. Eppinger, M. V Nukala, and D. E. Whitney, Generalised models of design iteration using signal flow graphs, Research in Engineering Design, 9 (1997), 112-123.

P. Fettke, P. Loos, and J. Zwicker, Business Process Reference Models: Survey and Classification, 3rd International Conference on Business Process Management, Springer-Verlag Berlin, Nancy, FRANCE., 2006, pp. $469-483$.

E. Fricke, A. Schulz, P. Wehlitz, and H. Negele, A generic approach to implement information-based system development (2000).

L. Hang, The application research on process planning model of product development based on D-CPM Method, Msie 2011, (2011), 460-463. doi:10.1109/MSIE.2011.5707443.

HB Jun, and H. Suh, A modeling framework for product development process considering its characteristics, IEEE TRANSACTIONS ON ENGINEERING MANAGEMENT, 55 (2008), 103-119.

Hong-bae Jun, and H. Suh, A Modeling Framework for Product Development Process Considering its Characteristics, Engineering, 55 (2008), 103-119. doi:10.1109/TEM.2008.926322.

W. J. Kettinger, J. T. C. Teng, and S. Guha, Business Process Change: A Study of Methodologies, Techniques, and Tools, MIS Quarterly, 21 (1997), 55. doi:10.2307/249742.

S. J. Kline, Innovation is not a linear process., Research Management, 26 (1985), 36-45.

Y. Ko, P. Kuo, and C. Yu, Modelling Concurrent Workflow for New Product Development Management, Matrix, (2010), 474-479.

F. Krause, and C. Kind, Adaptive modelling and simulation of product development processes, CIRP Annals-Manufacturing, (2004).

V. Krishnan, S. D. Eppinger, and D. E. Whitney, A model-based framework to overlap product development activities, Management Science, 43 (1997), 437-451.

A. Kusiak, and K. Park, Concurrent Design: decomposition of design activities, Proceedings of the Rensselaer's 2nd International Conference on Computer Integrated Manufacturing, 1990, pp. 557-563.

A. Kusiak, J. R. Wang, D. W. He, and C. Feng, A Structured Approach for Analysis of Design Processes 18 (1995).

S. G. Lee, K. L. Ong, and L. P. Khoo, Control and Monitoring of Concurrent Design Tasks in a Dynamic Environment, Concurrent Engineering: Research and Applications, 12 (2004), 59-66. doi:10.1177/1063293X04041941.

Y. Levy, and T. J. Ellis, A Systems Approach to Conduct an Effective Literature Review in Support of Information Systems Research, Science Journal, 9 (2006).

W. Lewis, and L. Cangshan, The timely allocation of resources in the concurrent design of new products, Journal of Engineering Design, 8 (1997).

R. Lu, and S. Sadiq, A survey of comparative business process modeling approaches, Business Information Systems, Springer, 2007, pp. 82-94.

H. L. Mcmanus, Product Development Value Stream Mapping (PDVSM) Manual, Technology, (2005).

L. J. Moore, and B. W. Taylor III, Multiteam, multiproject research and development planning with

GERT, Management Science, 24 (1977), 401.

NIST, Integration Definition for Function Modeling (IDEF0) 1993.

B. D. O’Donovan, P. J. Clarkson, and C. Eckert, Signposting : modelling uncertainty in design processes, Proceedings of the 14th International Conference on Engineerng Design, Stockholm, Sweden, 2003, pp. 19-21.

O’Donovan, T. R. Browning, C. M. Eckert, and P. J. Clarkson, Design planning and modeling., Design process improvement: a review of current practice, Springer, 2005, pp. 60-87.

G. Pahl, and W. Beitz, Engineering Design, The Design Council, London, 1988.

H. Park, and M. R. Cutkosky, Framework for Modeling Dependencies in Collaborative Engineering Processes, Research in Engineering Design, (1999), 84-102.

PMI, Um Guia Do Conhecimento Em Gerenciamento de Projetos:, Project Management Institute, 2008.

S. Pugh, and D. Clausing, Creating Innovative Products Using Total Design: The Living Legacy of Stuart Pugh, 1st ed. Addison-Wesley Longman Publishing Co., Inc., Boston, MA, USA, 1996.

D. T. Ross, Structured Analysis ( SA ): A Language for - Communicating Ideas, IEEE Transactions on Software Engineering, SE-3 (1977), 16-34. $119-145$.

A. Scheer, O. Thomas, and O. Adam, Process Modeling Using Event-Driven Process Chains (2005),

R. P. Smith, and S. D. Eppinger, A predictive model of sequential iteration in engineering design, Management Science, 43 (1997), 1104-1120. 237-261.

R. P. Smith, and J. A. Morrow, Product development process modeling, Design Studies, 20 (1999),

P. Sonnemans, W. Geudens, and A. Brombacher, Organizing product releases in time-driven development processes: a probabilistic analysis, IMA Journal of Management Mathematics, 14 (2003), 337-356. 
B. W. Taylor III, and L. J. Moore, R \& D Project planning with Q-GERT network modeling and simulation, Management Science, 26 (1980), 44.

K. T. Ulrich, and S. D. Eppinger, Product Design and Development, 4th ed. McGraw-Hill Higher Education, 2007.

G. L. Urban, and J. R. Hauser, Design and marketing of new products, Prentice Hall, 1993. 1996.

F. Vernadat, Enterprise Modeling and Integration: Principles and Applications,, October, Springer, 


\section{Apêndice E - Questionário Perfil do Usuário}

\section{Perfil do usuário}

Este questionário tem por objetivo entender o perfil dos usuários que irão realizar o teste de usabilidade. Ele contém perguntas que vão ajudar o pesquisador a entender seu conhecimento e experiência nos temas relacionados com a pesquisa e identificar potenciais conflitos de interesse.

As informações fornecidas serão utilizadas apenas para o propósito de selecionar os usuários com perfil desejado no âmbito desta pesquisa e não serão divulgadas.

Você vai levar em torno de 10 minutos para respondê-lo. Não se esqueça de apertar o botão "enviar" ao término do questionário, para que suas respostas sejam recebidas pelo pesquisador.

Muito obrigada pela sua colaboração! 


\section{1/6 - Perfil do usuário}

Caracterização do participante

\section{Informações pessoais}

Nome completo: *

(obrigatório para que depois o pesquisador consiga entrar em contato com você)

Email: *

(obrigatório para que depois o pesquisador consiga entrar em contato com você)

Você tem disponibilidade para realizar um teste presencial (com $1 \mathrm{hr}$ de duração) nas dependências do departamento de Eng. de Produção da EESC em alguma data nos próximos dois meses? *

(Responder sim à esta questão não significa se comprometer com a realização do teste; se você se encaixar no perfil desejado, o pesquisador entrará em contato para saber sobre seu interesse e disponibilidade em realizá-lo)
Sim
Não

Qual a sua idade? *

(-) Menos de 30

30 a 34 anos

35 a 39 anos

() 40 a 45 anos

46 a 50 anos

Mais de 50 anos

Você ou qualquer membro próximo ou de sua família está envolvido com algum desses negócios ou indústrias? *

Empresas que desenvolvem/vendem softwares de modelagem de processos (Como ARPO, Intalio, Bizagi, Yed, etc...)

- Associaç̃̃es/organizaç̃óes relacionadas com modelagem de processos

Consultorias/empresas que assessoram empresas na modelagem de processos

Não se aplica

«Voltar Continuar » 
2/6 - Perfil do usuário

Caracterização do participante

\section{Formação educacional / profissional}

Qual seu grau de instrução? *

OBS 1: Considera-se ensino superior cursos de graduação, tecnólogo ou sequencial. OBS 2: Consideração pós-graduação cursos de especialização, MBA, mestrado, doutorado ou pósdoutorado.

Ensino superior incompleto (desistência/trancamento do curso)

Ensino superior em andamento

Ensino superior completo

Pós-graduação incompleto (desistência/trancamento do curso)

Pós-graduação em andamento

Pós-graduação completo

Indique seu curso de ensino superior: *

Ex: Engenharia de Produção

Indique o(s) seu(s) curso(s) de pós graduação, bem como o tipo: * Ex: Administração (Mestrado)

«Voltar Continuar » 
3/6 - Conhecimento e experiência

Dimensão: Conhecimento da tarefa

\section{Conhecimento e experiência sobre o Processo de Desenvolvimento de Produtos}

Já realizou algum curso/disciplina relacionada com o tema "Gestão do processo de desenvolvimento de produtos"? *

(2) Sim

○ Não

Assinale todas as disciplinas da lista a seguir que você cursou: *

(caso se aplique)

$\square$ SEP5782 - Processo de Desenvolvimento de Produto (Pós-graduação)

SEP0151 - Processo de Desenvolvimento do Produto (Graduação)

$\square$ Não se aplica

1 Outro:

Já participou profissionalmente de algum projeto de desenvolvimento de produto? * (selecione a opção que representa a sua experiência mais significativa)

( Sim, como gerente de produto (ou cargo hierarquicamente superior)

(1) Sim, como membro de equipe (ou cargo subordinado ao gerente de produto)

( Sim, como membro externo à organização (consultor ou especialista, entre outros)

() Nunca participei profissionalmente de um projeto de desenvolvimento de produto

Durante sua experiência profissional, fez uso de qualquer tipo de modelo de referência para processos? *

(caso se aplique)

○ Sim

ก Não

Não se aplica

Você está familiarizado com o Modelo de Referência para o Processo de Desenvolvimento de Produtos (Rozenfeld et. al, 2006)? *

(1) Sim

Não 
Como você adquiriu conhecimento sobre o Modelo de Referência para o Processo de Desenvolvimento de Produtos (Rozenfeld et. al, 2006)?*

(caso se aplique)

$\square$ Cursando uma disciplina que ensinava o Modelo de Referência para PDP (Rozenfeld et. al., 2006)

Pesquisando/Estudando por conta própria

Trabalhando em uma empresa que usava um modelo baseado no Modelo de Referência para PDP (Rozenfeld et. al., 2006)

$\square$ Não se aplica

$\square$ Outro:

Você participa ou já participou de alguma associação relacionada à área de Gestão do Processo de Desenvolvimento de Produto?*

Ex: PDMA, IGDP, etc..

Sim

Não

"Voltar Continuar» 
4/6 - Conhecimento e experiência

Dimensão: Conhecimento da tarefa

\section{Conhecimento e experiência sobre Modelagem de Processos}

Você já realizou alguma vez a modelagem de um processo? *

(O) Sim

ก Não

Como você avalia seu grau de familiaridade com o método de modelagem EPC (Eventdriven Process Chain)?

(http://en.wikipedia.org/wiki/Event-driven_process_chain)

- 1 - Nunca tomei contato, nem como usuário nem modelando um processo.

2 - Já li/ouvi um pouco sobre o método; tenho uma idéia geral de como funciona mas nunca usei.

3 - Fiz uma vez um trabalho acadêmico ou participei de um projeto onde usávamos um modelo/modelávamos um processo usando EPC

( 4 - Usei esporadicamente um modelo elaborado em EPC trabalhando em uma empresa ou realizando uma pesquisa

(1) 5 - Conheço profundamente o método, pois já pesquisei ou trabalhei rotineiramente modelando com EPC ou usando modelos modelados com EPC.

Selecione todos os métodos de modelagem com os quais você já teve contato: * (caso se aplique)

EPC (Event-driven Process Chain) e similares

BPMN (Business Process Modeling Notation) e similares

VSM (Value Stream Mapping) e similares

Fluxograma

IDEF (Integration definition for function modeling) e similares

SADT (Structured analysis and design technique) e similares

Não se aplica

Outro:

« Voltar Continuar » 


\section{5/6 - Conhecimento e experiência em sistemas computacionais}

Dimensão: Experiência computacional

Há quanto tempo utiliza computador? *

(1) Não utiliza

Entre 1 e 2 anos

- Entre 2 e 4 anos

(1) Entre 4 e 6 anos

(.) Mais de 6 anos

Em média, semanalmente, quanto tempo você utiliza o computador? *
(- Menos de 2 horas
Entre 2 e 10 horas
Entre 10 e 20 horas
Mais de 20 horas

Há quanto tempo utiliza a internet? *

Não utiliza

(1) Entre 1 e 2 anos

Entre 2 e 4 anos

Entre 4 e 6 anos

Mais de 6 anos

Quais das ferramentas a seguir que você utiliza? (Assinale todas as alternativas que se apliquem) *

$\square$ Navegador de internet (Ex. Internet Explorer, Chrome, Mozilla Firefox)

Gerenciador de e-mails (Ex. Outlook Express, Outlook)

Pacotes de escritório instalados no computador (Ex. Word, Excel, PowerPoint)

Pacotes de escritório "nas nuvens" (Ex. Google Docs)

Ferramentas de desenvolvimento gráfico (Ex. Corel Draw, Photoshop)

Software do tipo ERP (Ex. SAP R/3)

Software de gerenciamento de projetos (Ex. MSProject, dotProject)

Não se aplica

Outro 
6/6 - Experiência com softwares de modelagem de processos Dimensão: Experiência no sistema

Você utiliza ou utilizou alguma vez um software de modelagem de processos? *

(O) Sim

( Não

Sobre o uso de software para modelagem de processos escolha uma das alternativas: * (caso de aplique)

(1) Utilizo raramente, apenas quando exigido na minha organização.

Utilizo frequentemente, mas apenas para os principais projetos que conduzo na minha organização

Utilizo em todos os projetos que conduzo na minha vida profissional, de simples aos mais complexos

Não se aplica

Com quais softwares você está familiarizado? (Assinale todas as alternativas que se apliquem) *

$\square$ ARPO

$\square$ Visio

PowerPoint

$\square$ Bizagi

Intalio

$\square$ Yed

$\square$ ARIS

$\square$ Não se aplica

$\square$ Outro:

« Voltar Enviar 


\section{Apêndice F - Exemplo da apresentação do roteiro de tarefas para os usuários}

(exemplo das telas do questionário online)

\section{Roteiro de atividades}

Cada atividade será composta por três passos:

1) Realizar tarefa no modelo $A$

2) Realizar tarefa no modelo $B$

3) Responder a pergunta com escala comparativa.

Ao final de cada tarefa, você deve aguardar enquanto a tela é preparada para a próxima tarefa. Não use o mouse nem o teclado enquanto aguarda.

Assim que a nova tarefa aparecer na tela, comece a respondê-la imediatamente.

Todas as tarefas e perguntas deste roteiro são obrigatórias.

Obrigada pela sua colaboração e não se esqueça de assinar o Termo de Consentimento Livre e Esclarecido.

Obrigatório

Escreva seu nome completo: *

Continuar »

\section{Roteiro de atividades}

*Obrigatório

1/15 - Modelo A

Informe as três primeiras atividades da fase de "Projeto informacional". *

\section{Roteiro de atividades}

Por favor aguarde!

Aguarde a preparação das telas para a próxima atividade. Não use o mouse ou teclado.

"Voltar Continuar » 


\section{Roteiro de atividades}

*Obrigatório

1/15 - Modelo B

Informe as três primeiras atividades da fase de

"Lançamento". *

1

«Voltar Continuar

\section{Roteiro de atividades}

\section{Por favor aguarde!}

Aguarde a preparação das telas para a próxima atividade. Não use o mouse ou teclado.

«Voltar Continuar

\section{Roteiro de atividades}

*Obrigatório

1/15 - Comparação entre modelos

Posicione os protótipos avaliados na escala abaixo de acordo com a sua percepção em relação à facilidade para execução da tarefa: *

A escala é comparativa; posicione os protótipos na escala de acordo com a dificuldade relativa para realização das tarefas.

Muito difícil Difícil $\quad \begin{aligned} & \text { Conforme } \\ & \text { esperado }\end{aligned}$ Fácil Muito fácil

$\begin{array}{llllll}\text { Modelo A } & 0 & 0 & 0 & 0 & 0 \\ \text { Modelo B } & 0 & 0 & 0 & 0 & 0\end{array}$




\section{Apêndice G - Gabarito do roteiro de tarefas dos testes de usabilidade}

\begin{tabular}{|c|c|c|c|c|c|}
\hline & Propósitos dos usuários & Tarefa de leitura A & Resposta correta A & Tarefa de leitura B & Resposta Correta B \\
\hline & $\begin{array}{l}\text { Definir atividades padrão e } \\
\text { preferidas }\end{array}$ & $\begin{array}{l}\text { Informe as três primeiras atividades } \\
\text { da fase de "Projeto informacional". }\end{array}$ & $\begin{array}{l}\text { 1.3.1 - Atualizar Plano do Projeto } \\
\text { Informacional } \\
\text { 1.3.2 - Revisar e atualizar o escopo do } \\
\text { produto } \\
\text { 1.3.3 - Detalhar ciclo de vida do produto } \\
\text { e definir seus clientes }\end{array}$ & $\begin{array}{l}\text { Informe as três primeiras atividades da } \\
\text { fase de "Lançamento". }\end{array}$ & $\begin{array}{l}\text { 1.7.1 - Planejar lançamento } \\
\text { 1.7.2 - Desenvolver } \\
\text { processo de vendas } \\
\text { 1.7.3 - Desenvolver } \\
\text { processo de distribuição }\end{array}$ \\
\hline & $\begin{array}{l}\text { Definir/sugerir sequencia para } \\
\text { as atividades }\end{array}$ & $\begin{array}{l}\text { Você acaba de concluir a atividade } \\
\text { "Definir requisitos do produto" da } \\
\text { fase de "Projeto informacional". } \\
\text { Qual a próxima atividade a ser } \\
\text { realizada segundo o modelo? }\end{array}$ & $\begin{array}{l}\text { 1.3.6 - Definir especificações meta do } \\
\text { produto }\end{array}$ & $\begin{array}{l}\text { Você acaba de concluir a atividade } \\
\text { "Selecionar a concepção do produto" da } \\
\text { fase de "Projeto conceitual". Qual a } \\
\text { próxima atividade a ser realizada } \\
\text { segundo o modelo? }\end{array}$ & $\begin{array}{l}\text { 1.4.10 - Definir plano macro } \\
\text { de processos }\end{array}$ \\
\hline & $\begin{array}{l}\text { Mostrar relação hierárquica } \\
\text { entre atividades }\end{array}$ & $\begin{array}{l}\text { Informe as duas primeiras fases } \\
\text { que compõem a macrofase de } \\
\text { "Desenvolvimento". }\end{array}$ & $\begin{array}{l}\text { Projeto Informacional } \\
\text { Projeto Conceitual }\end{array}$ & $\begin{array}{l}\text { Informe as duas últimas fases que } \\
\text { compõem a macrofase de } \\
\text { "Desenvolvimento". }\end{array}$ & $\begin{array}{l}\text { Preparação da produção } \\
\text { Lançamento do produto }\end{array}$ \\
\hline & $\begin{array}{l}\text { Definir entregas ou milestones } \\
\text { padrão }\end{array}$ & $\begin{array}{l}\text { Informe as entregas de saída da } \\
\text { atividade "Detalhar ciclo de vida do } \\
\text { produto e definir seus clientes" da } \\
\text { fase de "Projeto informacional". }\end{array}$ & $\begin{array}{l}\text { Clientes de cada fase do ciclo de vida } \\
\text { do produto } \\
\text { Ciclo de vida do produto }\end{array}$ & $\begin{array}{l}\text { Informe as entregas de saída da } \\
\text { atividade "Promover marketing de } \\
\text { lançamento" da fase de "Lançamento". }\end{array}$ & $\begin{array}{l}\text { Plano de lançamento } \\
\text { (atualizado) } \\
\text { Marketing de lançamento }\end{array}$ \\
\hline & $\begin{array}{l}\text { Definir entregas ou milestones } \\
\text { padrão }\end{array}$ & $\begin{array}{l}\text { Informe a principal entrega da fase } \\
\text { "Projeto informacional". } \\
\end{array}$ & Especificações-meta do produto & $\begin{array}{l}\text { Informe a principal entrega da fase } \\
\text { "Lançamento". }\end{array}$ & Lançar produto no mercado \\
\hline & $\begin{array}{l}\text { Definir padrões de qualidade } \\
\text { para as entregas padrão }\end{array}$ & $\begin{array}{l}\text { Informe os padrões de qualidade } \\
\text { que o modelo fornece para a } \\
\text { entrega "Estrutura do produto } \\
\text { (BOM)" na fase de "Projeto } \\
\text { detalhado". }\end{array}$ & $\begin{array}{l}\text { As informações sobre itens (SSCs) } \\
\text { devem estar completas e atualizadas. A } \\
\text { estrutura deve mostrar o relacionamento } \\
\text { entre itens (SSCs). A estrutura deve } \\
\text { mostrar os documentos relacionados } \\
\text { com cada um dos itens (SSCs). }\end{array}$ & $\begin{array}{l}\text { Informe os padrões de qualidade que o } \\
\text { modelo fornece para a entrega } \\
\text { "Concepção escolhida para o produto" } \\
\text { na fase de "Projeto conceitual". }\end{array}$ & $\begin{array}{l}\text { A concepção escolhida deve } \\
\text { estar de acordo com as } \\
\text { especificações-meta do } \\
\text { produto. } \\
\text { A concepção escolhida deve } \\
\text { explorar adequadamente o } \\
\text { conceito de modularidade e } \\
\text { otimizar o uso de SSCs } \\
\text { quando possível. } \\
\text { A concepção escolhida deve } \\
\text { ter sido concebida prevendo } \\
\text { a estratégia de fim de vida } \\
\text { do produto. }\end{array}$ \\
\hline & $\begin{array}{l}\text { Identificar } \\
\text { dependência/precedência de }\end{array}$ & $\begin{array}{l}\text { Informe as entregas da atividade } \\
\text { "Promover marketing de }\end{array}$ & $\begin{array}{l}\text { Marketing de lançamento } \\
\text { Plano de lançamento (atualizado) }\end{array}$ & $\begin{array}{l}\text { Informe as entregas da atividade } \\
\text { "Detalhar ciclo de vida do produto e }\end{array}$ & $\begin{array}{l}\text { Clientes de cada fase do } \\
\text { ciclo de vida do produto }\end{array}$ \\
\hline
\end{tabular}


Propósitos dos usuários

atividades/funções via inputs e outputs

\section{Identificar}

8

dencia/precedencia de

atividades/funções via inputs e outputs

9 Definir ferramentas e templates padrão

10 Definir ferramentas e templates padrão

Relacionar papéis a atividades,

11 entregas e demais elementos do processo

Relacionar papéis a atividades,

12 às entregas e aos demais elementos do processo

Definir responsabilidades e

13 habilidades padrão para papéis e pessoal

\section{Tarefa de leitura A}

lançamento" que são entradas para a atividade "Lançar produto" na fase de "Lançamento".

\section{Informe as atividades que}

dependem das entregas da

seguinte atividade para serem

iniciadas: "1.4.2 - Modelar

funcionalmente o produto" da fase de "Projeto conceitual".

Informe as melhores práticas

sugeridas para a realização da

atividade "Detalhar ciclo de vida do

produto e definir seus clientes" da

fase de "Projeto informacional".

Você é um especialista em

"Abstração orientada". Informe as

atividades nas quais essa melhor

prática é empregada na fase de

"Projeto conceitual".

Informe as atividades da fase de

"Preparação da produção" com as

quais o "Gerente de qualidade" está

relacionado.

Informe as entregas com as quais o

"Gerente de design" está

relacionado na fase de "Projeto

conceitual" (tanto entregas de entrada quanto de saída).

Informe as melhores práticas de

que o "Gerente de suprimentos"

necessitará lançar mão na fase de

"Projeto conceitual".

Check-lists produto

1.4.6 - Analisar SSCs

Layout do produto

Análise make-or-buy

\section{Resposta correta A}

Tarefa de leitura B

Resposta Correta B

definir seus clientes" que são entradas para a atividade "Identificar os requisitos dos clientes do produto" na fase de

"Projeto informacional".

Informe as atividades que dependem

1.4.3 - Desenvolver princípios de

solução para as funções

das entregas da seguinte atividade para

serem iniciadas: "1.4.7 - Definir

ergonomia e estética" da fase de

"Projeto conceitual".

Matrizes de mapeamento

Estruturas do desdobramento do ciclo

Informe as melhores práticas sugeridas para a realização da atividade "Otimizar produção" da fase de "Preparação da produção" produção".

1.4.2 - Modelar funcionalmente o

1.4.3 - Desenvolver princípios de

solução para as funções

Você é um especialista em "QFD (Quality Function Deployment)". Informe as atividades nas quais essa melhor pratica é empregada na fase de "Projeto informacional".

Informe as atividades da fase de

1.6.3 - Receber e instalar recursos

"Projeto informacional" com as quais o

"Gerente de marketing" está relacionado.

Especificações-meta do produto

Informe as entregas com as quais o "Gerente de suprimentos" está

Requisitos dos clientes

Concepções para o produto

relacionado na fase de "Preparação da produção" (tanto entregas de entrada quanto de saída). Informe as melhores práticas sugeridas de que o "Gerente de vendas" necessitará lançar mão na fase de "Projeto detalhado".
Ciclo de vida do produto

1.4.8 - Definir fornecedores e parcerias de co-

desenvolvimento

1.4.9 - Selecionar a

concepção do produto

EVOP (Evoloutionary

Operation)

Lean Manufacturing

Metodologia de Superficie de Resposta

1.3.4 - Identificar os

requisitos dos clientes do

produto

1.3.5 - Definir requisitos do

produto

1.3.6 - Definir

especificações- meta do

produto

1.3.3 - Detalhar ciclo de vida

do produto e definir seus

clientes

1.3.4 - Identificar os

requisitos dos clientes do produto

nformação de fornecedores

Projetos dos recursos de

fabricação

Decisão make-or-buy

Recursos de fabricação

obtidos

Sistemas PLM (Product Lifecycle Management) 
Propósitos dos usuários

Definir responsabilidades e

14 habilidades padrão para papéis e pessoal

15 Avaliar a complexidade do processo de design
Tarefa de leitura A

Informe as responsabilidades

atribuídas ao papel de "Gerente de projetos" segundo o modelo.

Informe o número de papéis

envolvidos na fase de "Projeto

informacional".
Resposta correta A

Responsável por um projeto específico

de desenvolvimento e líder de um time

de desenvolvimento.

9

\section{Tarefa de leitura B}

Informe as responsabilidades atribuídas ao papel de "Time de planejamento estratégico de produto" segundo o modelo.

Informe o número de papéis envolvidos na fase de "Lançamento".
Resposta Correta B

Responsável pelo

desdobramento do

planejamento estratégico em

portifólio de produtos da empresa. 

Apêndice $H$ - Sequência preferencial de ações necessárias (estratégia ideal) para cumprir cada tarefa

\begin{tabular}{|c|c|c|c|c|c|c|c|c|c|c|c|c|c|c|c|c|}
\hline $\begin{array}{l}\text { Protóti } \\
\text { po: }\end{array}$ & Novo & EPC & Novo & EPC & $\begin{array}{l}\text { Nov } \\
0\end{array}$ & EPC & Novo & EPC & Novo & EPC & Novo & EPC & Novo & EPC & Novo & EPC \\
\hline Tarefa & $1 / 15$ & $1 / 15$ & $2 / 15$ & $2 / 15$ & $3 / 15$ & $3 / 15$ & $4 / 15$ & $4 / 15$ & $5 / 15$ & $5 / 15$ & $6 / 15$ & $6 / 15$ & $7 / 15$ & $7 / 15$ & $8 / 15$ & $8 / 15$ \\
\hline \multirow[t]{4}{*}{$\begin{array}{l}\text { Descriç } \\
\text { ão das } \\
\text { ações }\end{array}$} & $\begin{array}{l}\text { Clique } \\
\text { em } \\
\text { projeto } \\
\text { informa } \\
\text { cional }\end{array}$ & $\begin{array}{l}\text { Clique } \\
\text { em } \\
\text { desenvol } \\
\text { vimento } \\
\text { (menu) }\end{array}$ & $\begin{array}{l}\text { Clique } \\
\text { em } \\
\text { projeto } \\
\text { informa } \\
\text { cional }\end{array}$ & $\begin{array}{l}\text { Clique } \\
\text { em } \\
\text { desenvol } \\
\text { vimento }\end{array}$ & $\begin{array}{l}\text { (Evid } \\
\text { ente } \\
\text { na } \\
\text { prim } \\
\text { eira } \\
\text { tela) }\end{array}$ & $\begin{array}{l}\text { Clique } \\
\text { em } \\
\text { desenvol } \\
\text { vimento }\end{array}$ & $\begin{array}{l}\text { Clique } \\
\text { em } \\
\text { Projeto } \\
\text { informa } \\
\text { cional }\end{array}$ & $\begin{array}{l}\text { Clique } \\
\text { em } \\
\text { desenvol } \\
\text { vimento } \\
\text { (menu) }\end{array}$ & $\begin{array}{l}\text { Clique } \\
\text { em } \\
\text { desenvol } \\
\text { vimento }\end{array}$ & $\begin{array}{l}\text { Clique } \\
\text { em } \\
\text { desenvol } \\
\text { vimento }\end{array}$ & $\begin{array}{l}\text { Pass } \\
\text { aro } \\
\text { mous } \\
\text { e } \\
\text { sobre } \\
\text { o } \\
\text { icone } \\
\text { de } \\
\text { listas }\end{array}$ & $\begin{array}{l}\text { Clique } \\
\text { em } \\
\text { desenvol } \\
\text { vimento }\end{array}$ & $\begin{array}{l}\text { Clique } \\
\text { em } \\
\text { lança } \\
\text { mento }\end{array}$ & $\begin{array}{l}\text { Clique } \\
\text { em } \\
\text { desenvol } \\
\text { vimento } \\
\text { (menu) }\end{array}$ & $\begin{array}{l}\text { Passar } \\
\text { o mouse } \\
\text { sobre o } \\
\text { icone de } \\
\text { listas }\end{array}$ & $\begin{array}{l}\text { Clique } \\
\text { em } \\
\text { desenvol } \\
\text { vimento }\end{array}$ \\
\hline & $\begin{array}{l}\text { Rolar a } \\
\text { tela } \\
\text { para } \\
\text { procura } \\
r\end{array}$ & $\begin{array}{l}\text { Clique } \\
\text { em } \\
\text { Lançame } \\
\text { nto } \\
\text { (menu) }\end{array}$ & $\begin{array}{l}\text { Rolar a } \\
\text { tela } \\
\text { para } \\
\text { procura } \\
r\end{array}$ & $\begin{array}{l}\text { Clique } \\
\text { em } \\
\text { projeto } \\
\text { conceitua } \\
\text { I }\end{array}$ & & $\begin{array}{l}\text { Rolar a } \\
\text { tela para } \\
\text { procurar }\end{array}$ & $\begin{array}{l}\text { Rolar a } \\
\text { tela } \\
\text { para } \\
\text { procura } \\
\text { r }\end{array}$ & $\begin{array}{l}\text { Clique } \\
\text { em } \\
\text { lançamen } \\
\text { to (menu) }\end{array}$ & & $\begin{array}{l}\text { Rolar a } \\
\text { tela para } \\
\text { procurar }\end{array}$ & $\begin{array}{l}\text { Cliqu } \\
\text { e em } \\
\text { lista } \\
\text { de } \\
\text { entre } \\
\text { gas }\end{array}$ & $\begin{array}{l}\text { Clique } \\
\text { em } \\
\text { projeto } \\
\text { conceitua } \\
\text { I }\end{array}$ & $\begin{array}{l}\text { Rolar } \\
\text { a tela } \\
\text { para } \\
\text { procur } \\
\text { ar }\end{array}$ & $\begin{array}{l}\text { Clique } \\
\text { em } \\
\text { projeto } \\
\text { informaci } \\
\text { onal } \\
\text { (menu) }\end{array}$ & $\begin{array}{l}\text { Clique } \\
\text { em lista } \\
\text { de } \\
\text { atividad } \\
\text { es }\end{array}$ & $\begin{array}{l}\text { Clique } \\
\text { em } \\
\text { projeto } \\
\text { conceitua } \\
\text { I }\end{array}$ \\
\hline & & $\begin{array}{l}\text { Ler no } \\
\text { menu }\end{array}$ & & $\begin{array}{l}\text { Rolar a } \\
\text { tela para } \\
\text { procurar }\end{array}$ & & & & $\begin{array}{l}\text { Clique } \\
\text { em } \\
\text { "Promove } \\
\text { r } \\
\text { marketin } \\
\text { g de } \\
\text { lançamen } \\
\text { to" } \\
\text { (menu) }\end{array}$ & & $\begin{array}{l}\text { (não é } \\
\text { possivel } \\
\text { encontrar } \\
\text { a } \\
\text { resposta } \\
\text { exata, } \\
\text { apenas o } \\
\text { objetivo } \\
\text { da fase) }\end{array}$ & $\begin{array}{l}\text { Rolar } \\
\text { a tela } \\
\text { para } \\
\text { procu } \\
\text { rar }\end{array}$ & $\begin{array}{l}\text { Rolar a } \\
\text { tela para } \\
\text { procurar }\end{array}$ & & $\begin{array}{l}\text { Clique } \\
\text { em } \\
\text { "Detalhar } \\
\text { ciclo de } \\
\text { vida do } \\
\text { produto e } \\
\text { definir } \\
\text { seus } \\
\text { clientes" } \\
\text { (menu) }\end{array}$ & $\begin{array}{l}\text { Rolar a } \\
\text { tela para } \\
\text { procurar }\end{array}$ & $\begin{array}{l}\text { Rolar a } \\
\text { tela para } \\
\text { procurar }\end{array}$ \\
\hline & & & & & & & & & & & $\begin{array}{l}\text { Cliqu } \\
\text { e em } \\
\text { "Estr } \\
\text { utura } \\
\text { do } \\
\text { produ } \\
\text { to } \\
\text { (BO }\end{array}$ & $\begin{array}{l}\text { Clique } \\
\text { em } \\
\text { "Concepç } \\
\text { ão } \\
\text { escolhida } \\
\text { para o } \\
\text { produto" }\end{array}$ & & $\begin{array}{l}\text { Clique } \\
\text { em "ciclo } \\
\text { de vida } \\
\text { do } \\
\text { produto" }\end{array}$ & $\begin{array}{l}\text { Clique } \\
\text { em } \\
\text { "Modela } \\
r \\
\text { funciona } \\
\text { Imente o } \\
\text { produto" }\end{array}$ & \\
\hline
\end{tabular}




\begin{tabular}{|c|c|c|c|c|c|c|c|c|c|c|c|c|c|c|c|c|}
\hline $\begin{array}{l}\text { Protóti } \\
\text { po: }\end{array}$ & Novo & EPC & Novo & EPC & $\begin{array}{l}\text { Nov } \\
0\end{array}$ & EPC & Novo & EPC & Novo & EPC & Novo & EPC & Novo & EPC & Novo & EPC \\
\hline & & & & & & & & & & & M)" & & & & & \\
\hline & & & & & & & & & & & $\begin{array}{l}\text { Rolar } \\
\text { a tela } \\
\text { para } \\
\text { procu } \\
\text { rar }\end{array}$ & & & $\begin{array}{l}\text { Clique } \\
\text { em voltar }\end{array}$ & $\begin{array}{l}\text { Clique } \\
\text { em } \\
\text { "Requisi } \\
\text { tos } \\
\text { funciona } \\
\text { is, } \\
\text { função } \\
\text { global, } \\
\text { lista de } \\
\text { funções } \\
\text { do } \\
\text { produto" }\end{array}$ & \\
\hline & & & & & & & & & & & & & & $\begin{array}{l}\text { Clique } \\
\text { em } \\
\text { "Clientes } \\
\text { de cada } \\
\text { fase do } \\
\text { ciclo de } \\
\text { vida do } \\
\text { produto" }\end{array}$ & & \\
\hline $\begin{array}{l}\text { Nro de } \\
\text { ações }\end{array}$ & 2 & 3 & 2 & 3 & 0 & 2 & 2 & 3 & 1 & 2 & 5 & 4 & 2 & 6 & 5 & 3 \\
\hline $\begin{array}{l}\text { Memori } \\
\text { zação }\end{array}$ & NÃO & NẪO & NAिO & NÃO & NÃO & NAिO & NĀO & NĀO & NẪO & NÃO & NAिO & NÃO & NÃO & $\overline{N A \tilde{O}}$ & NẪO & NÃO \\
\hline $\begin{array}{l}\text { Busca } \\
\text { cega }\end{array}$ & NÃO & NÃO & NÂO & NẪO & NẪO & NAिO & NÃO & NÃO & NÃO & NÂO & NÃO & NÃO & NÃO & NÂO & NÂO & NÃO \\
\hline Busca & NĀO & NĀO & SIM & SIM & NĀO & NÁO & SIM & SIM & NĀO & NĀO & NĀO & SIM & SIM & NÁO & NĀO & SIM \\
\hline
\end{tabular}




\begin{tabular}{|c|c|c|c|c|c|c|c|c|c|c|c|c|c|c|}
\hline $\begin{array}{l}\text { Protótipo } \\
\text { : }\end{array}$ & Novo & EPC & Novo & EPC & Novo & EPC & Novo & EPC & Novo & EPC & Novo & EPC & Novo & EPC \\
\hline Tarefa & $9 / 15$ & $9 / 15$ & $10 / 15$ & $10 / 15$ & $11 / 15$ & $11 / 15$ & $12 / 15$ & $12 / 15$ & $13 / 15$ & $13 / 15$ & $14 / 15$ & $14 / 15$ & $15 / 15$ & $15 / 15$ \\
\hline \multirow[t]{5}{*}{$\begin{array}{l}\text { Descriçã } \\
\text { o das } \\
\text { ações }\end{array}$} & $\begin{array}{l}\text { Clique } \\
\text { em } \\
\text { projeto } \\
\text { informaci } \\
\text { onal }\end{array}$ & $\begin{array}{l}\text { Clique em } \\
\text { desenvolvim } \\
\text { ento (menu) }\end{array}$ & $\begin{array}{l}\text { Clique } \\
\text { em } \\
\text { projeto } \\
\text { conceit } \\
\text { ual }\end{array}$ & $\begin{array}{l}\text { Clique em } \\
\text { desenvolvi } \\
\text { mento } \\
\text { (menu) }\end{array}$ & $\begin{array}{l}\text { Clique } \\
\text { em } \\
\text { prepara } \\
\text { ção da } \\
\text { produçã } \\
\text { o }\end{array}$ & $\begin{array}{l}\text { Clique em } \\
\text { Estrutura } \\
\text { Organizaci } \\
\text { onal } \\
\text { (menu) }\end{array}$ & $\begin{array}{l}\text { Clique } \\
\text { em } \\
\text { projeto } \\
\text { conceit } \\
\text { ual }\end{array}$ & $\begin{array}{l}\text { Clique em } \\
\text { desenvolvi } \\
\text { mento }\end{array}$ & $\begin{array}{l}\text { Clique } \\
\text { em } \\
\text { projeto } \\
\text { conceitu } \\
\text { al }\end{array}$ & $\begin{array}{l}\text { Clique em } \\
\text { Estrutura } \\
\text { organizaci } \\
\text { onal } \\
\text { (menu) }\end{array}$ & $\begin{array}{l}\text { Pass } \\
\text { ar o } \\
\text { mous } \\
\text { e } \\
\text { sobre } \\
\text { o } \\
\text { icone } \\
\text { de } \\
\text { listas }\end{array}$ & $\begin{array}{l}\text { Clique em } \\
\text { desenvolvi } \\
\text { mento }\end{array}$ & $\begin{array}{l}\text { Clique } \\
\text { em } \\
\text { projeto } \\
\text { informaci } \\
\text { onal }\end{array}$ & $\begin{array}{l}\text { Clique em } \\
\text { desenvolvi } \\
\text { mento }\end{array}$ \\
\hline & $\begin{array}{l}\text { Rolar a } \\
\text { tela para } \\
\text { procurar }\end{array}$ & $\begin{array}{l}\text { Clique em } \\
\text { preparação } \\
\text { da produção } \\
\text { (menu) }\end{array}$ & $\begin{array}{l}\text { Passar } \\
\text { o } \\
\text { mouse } \\
\text { sobre o } \\
\text { icone } \\
\text { de } \\
\text { listas } \\
\end{array}$ & $\begin{array}{l}\text { Clique em } \\
\text { projeto } \\
\text { informacion } \\
\text { al (menu) }\end{array}$ & $\begin{array}{l}\text { Passar } \\
0 \\
\text { mouse } \\
\text { sobre o } \\
\text { icone } \\
\text { de listas }\end{array}$ & $\begin{array}{l}\text { Clique em } \\
\text { Marketing } \\
\text { (menu }\end{array}$ & $\begin{array}{l}\text { Passar } \\
\text { o } \\
\text { mouse } \\
\text { sobre } \\
\text { o icone } \\
\text { de } \\
\text { listas } \\
\end{array}$ & $\begin{array}{l}\text { Rolar a tela } \\
\text { para } \\
\text { procurar }\end{array}$ & $\begin{array}{l}\text { Passar o } \\
\text { mouse } \\
\text { sobre o } \\
\text { icone de } \\
\text { listas }\end{array}$ & $\begin{array}{l}\text { Clique em } \\
\text { áreas da } \\
\text { empresa } \\
\text { (menu) }\end{array}$ & $\begin{array}{l}\text { Cliqu } \\
\text { e em } \\
\text { lista } \\
\text { de } \\
\text { papéi } \\
\mathrm{s}\end{array}$ & $\begin{array}{l}\text { Clique em } \\
\text { projeto } \\
\text { informacion } \\
\text { al }\end{array}$ & $\begin{array}{l}\text { Rolar a } \\
\text { tela para } \\
\text { procurar }\end{array}$ & $\begin{array}{l}\text { Clique em } \\
\text { Lançament } \\
\text { o }\end{array}$ \\
\hline & & $\begin{array}{l}\text { Clique em } \\
\text { "Otimizar } \\
\text { produção"( } \\
\text { menu) }\end{array}$ & $\begin{array}{l}\text { Clique } \\
\text { em lista } \\
\text { de } \\
\text { melhor } \\
\text { es } \\
\text { práticas }\end{array}$ & $\begin{array}{l}\text { Clique em } \\
1.3 .1 \\
\text { (menu) }\end{array}$ & $\begin{array}{l}\text { Clique } \\
\text { em lista } \\
\text { de } \\
\text { papéis }\end{array}$ & $\begin{array}{l}\text { Clique em } \\
\text { Gerente } \\
\text { de } \\
\text { marketing } \\
\text { (menu) }\end{array}$ & $\begin{array}{l}\text { Clique } \\
\text { em } \\
\text { lista de } \\
\text { papéis }\end{array}$ & $\begin{array}{l}\text { Clique em } \\
\text { preparação } \\
\text { da } \\
\text { produção }\end{array}$ & $\begin{array}{l}\text { Clique } \\
\text { em lista } \\
\text { de } \\
\text { papéis }\end{array}$ & $\begin{array}{l}\text { Clique em } \\
\text { Vendas } \\
\text { (menu) }\end{array}$ & $\begin{array}{l}\text { Cliqu } \\
\text { e em } \\
\text { geren } \\
\text { te de } \\
\text { projet } \\
\text { os }\end{array}$ & $\begin{array}{l}\text { Rolar a tela } \\
\text { para } \\
\text { procurar }\end{array}$ & & $\begin{array}{l}\text { Rolar a tela } \\
\text { para } \\
\text { procurar }\end{array}$ \\
\hline & & & $\begin{array}{l}\text { Clique } \\
\text { em } \\
\text { "Abstra } \\
\text { ção } \\
\text { orienta } \\
\text { da" }\end{array}$ & $\begin{array}{l}\text { Clique em } \\
1.3 .2 \\
\text { (menu) }\end{array}$ & $\begin{array}{l}\text { Clique } \\
\text { em } \\
\text { "Gerent } \\
\text { e de } \\
\text { qualida } \\
\text { de" }\end{array}$ & $\begin{array}{l}\text { Clique em } \\
\text { Gerente } \\
\text { de } \\
\text { marketing } \\
\text { (tela) }\end{array}$ & $\begin{array}{l}\text { Clique } \\
\text { em } \\
\text { "Geren } \\
\text { te de } \\
\text { design }\end{array}$ & $\begin{array}{l}\text { Rolar a tela } \\
\text { para } \\
\text { procurar }\end{array}$ & $\begin{array}{l}\text { Clique } \\
\text { em } \\
\text { Gerente } \\
\text { de } \\
\text { suprime } \\
\text { ntos }\end{array}$ & $\begin{array}{l}\text { Clique em } \\
\text { Gerente } \\
\text { de vendas } \\
\text { (menu) }\end{array}$ & $\begin{array}{l}\text { Rolar } \\
\text { a tela } \\
\text { para } \\
\text { procu } \\
\text { rar }\end{array}$ & $\begin{array}{l}\text { Clique em } \\
\text { Time de } \\
\text { planejament } \\
0 \\
\text { estratégico } \\
\text { do produto }\end{array}$ & & \\
\hline & & & & $\begin{array}{l}\text { Clique em } \\
1.3 .3 \\
\text { (menu) }\end{array}$ & & & & $\begin{array}{l}\text { Clique em } \\
\text { "Gerente de } \\
\text { suprimentos }\end{array}$ & & $\begin{array}{l}\text { Clique em } \\
\text { Sistemas } \\
\text { PLM }\end{array}$ & & & & \\
\hline
\end{tabular}




\begin{tabular}{|c|c|c|c|c|c|c|c|c|c|c|c|c|c|c|}
\hline $\begin{array}{l}\text { Protótipo } \\
:\end{array}$ & Novo & EPC & Novo & EPC & Novo & EPC & Novo & EPC & Novo & EPC & Novo & EPC & Novo & EPC \\
\hline & & & & $\begin{array}{l}\text { Clique em } \\
1.3 .4 \\
\text { (menu) }\end{array}$ & & & & $\begin{array}{l}\text { Clique em } \\
\text { "Obter } \\
\text { recursos de } \\
\text { fabricação" }\end{array}$ & & & & & & \\
\hline & & & & $\begin{array}{l}\text { Clique em } \\
\text { QFD }\end{array}$ & & & & & & & & & & \\
\hline $\begin{array}{l}\text { Nro de } \\
\text { ações }\end{array}$ & 2 & 3 & 4 & 7 & 4 & 4 & 4 & 6 & 4 & 5 & 4 & 4 & 2 & 3 \\
\hline $\begin{array}{l}\text { Memoriza } \\
\text { ção }\end{array}$ & NÂO & NẪO & NÃO & NẪO & NÃO & NÃO & NÃO & NÃO & NÃO & NẪ & NÃO & NÃO & SIM & SIM \\
\hline $\begin{array}{l}\text { Busca } \\
\text { cega }\end{array}$ & NÃO & NÃO & NÃO & SIM & NÃO & NÃO & NÃO & NÃO & NÃO & NÃO & NÃO & SIM & NÃO & NÃO \\
\hline Busca & SIM & NẪO & NÃO & SIM & NÃO & NÃO & NÃO & SIM & NẪO & NẪO & NÃO & SIM & SIM & SIM \\
\hline
\end{tabular}




\title{
Apêndice I - Termo de consentimento livre e esclarecido
}

\section{TERMO DE CONSENTIMENTO LIVRE E ESCLARECIDO}

Você está sendo convidado para participar da pesquisa para comparar duas formas de visualização do modelo de referência para o Processo de Desenvolvimento de Produtos. Você foi selecionado por ser aluno de pós-graduação do curso de Engenharia de Produção da Escola de Engenharia de São Carlos, Universidade de São Paulo, e sua participação não é obrigatória. A qualquer momento você pode desistir e retirar o seu consentimento. Sua recusa não trará nenhum prejuízo em sua relação com o pesquisador ou com a instituição. O objetivo deste estudo é propor novas vistas para modelos de referencia de PDP que atendam melhor aos propósitos de modelos de referência de PDP em comparação com as vistas existentes, a partir da perspectiva de interação com o usuário. A sua participação nesta pesquisa consistirá em realizar um conjunto de tarefas e responder questões comparando dois modelos. Não há riscos relacionados à sua participação na pesquisa. As informações obtidas através dessa pesquisa serão confidenciais e asseguramos o sigilo sobre a sua participação. Os dados não serão divulgados de forma a possibilitar sua identificação.

Neste termo consta o telefone e o endereço institucional do pesquisador principal para que você possa tirar dúvidas sobre o projeto e sua participação, agora ou a qualquer momento.

\author{
Pesquisador (mestranda): Carolina Román Amigo \\ Orientador: Prof. Henrique Rozenfeld \\ Escola de Engenharia de São Carlos - EESC/USP \\ Departamento de Engenharia de Produção \\ Av. Trabalhador São-Carlense, 400 - Centro, CEP: 13566-590, São Carlos/SP - Brasil \\ Telefone: +551633739394_E-mail: carolamigo@gmail.com
}

Declaro que entendi os objetivos de minha participação na pesquisa e concordo em participar.

Sujeito da pesquisa 



\section{Apêndice $\mathrm{J}$ - Legenda dos ícones do protótipo $\mathrm{A}$}

Legenda: Áreas

Sul- Gestão de

Legenda: Atividades

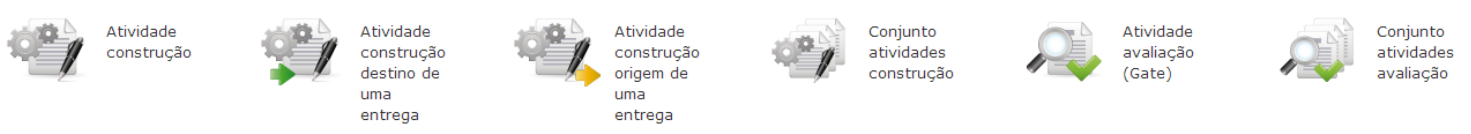

Legenda: Entregas

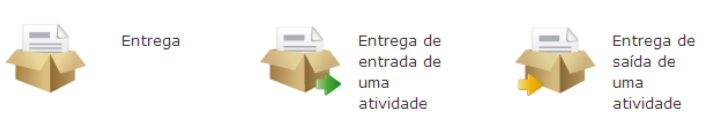

Legenda: Indicador de desempenho

Indicador de

Legenda: Melhores Práticas

$2 \begin{aligned} & \text { Melhor } \\ & \text { prática }\end{aligned}$

Legenda: Papéis
Minbros da

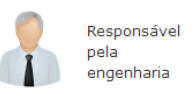
$8=$
is
?ी
Planejamento
Time de
Pof avaliação
$20 \begin{aligned} & \text { Time de } \\ & \text { acompanhamento } \\ & \text { de produto }\end{aligned}$
1 custos de
1 Gerente de
1 Gerente de
1 Gerente de
$3=$
1 aerente de
1) $\begin{aligned} & \text { Gerente de } \\ & \text { suprimentos }\end{aligned}$
1 Gerente de 



\title{
Apêndice K - Relatório do percurso cognitivo para os protótipos A e B
}

\author{
Relatório do percurso cognitivo para o protótipo A
}

\begin{tabular}{|c|c|c|c|c|}
\hline & Tarefa de leitura A & Tarefa de leitura B & $\begin{array}{l}\text { O usuário } \\
\text { sabe o que } \\
\text { fazer? }\end{array}$ & $\begin{array}{l}\text { O usuário } \\
\text { saberá } \\
\text { como fazer? }\end{array}$ \\
\hline 1 & $\begin{array}{l}\text { Informe as três primeiras } \\
\text { atividades da fase de "Projeto } \\
\text { informacional". }\end{array}$ & $\begin{array}{l}\text { Informe as três primeiras } \\
\text { atividades da fase de } \\
\text { "Lançamento". }\end{array}$ & Sim & Sim \\
\hline 2 & $\begin{array}{l}\text { Você acaba de concluir a } \\
\text { atividade "Definir requisitos do } \\
\text { produto" da fase de "Projeto } \\
\text { informacional". Qual a próxima } \\
\text { atividade a ser realizada } \\
\text { segundo o modelo? }\end{array}$ & $\begin{array}{l}\text { Você acaba de concluir a } \\
\text { atividade "Selecionar a } \\
\text { concepção do produto" da } \\
\text { fase de "Projeto conceitual". } \\
\text { Qual a próxima atividade a } \\
\text { ser realizada segundo o } \\
\text { modelo? }\end{array}$ & Sim & Sim \\
\hline 3 & $\begin{array}{l}\text { Informe as duas primeiras } \\
\text { fases que compõem a } \\
\text { macrofase de } \\
\text { "Desenvolvimento". }\end{array}$ & $\begin{array}{l}\text { Informe as duas últimas } \\
\text { fases que compõem a } \\
\text { macrofase de } \\
\text { "Desenvolvimento". }\end{array}$ & Sim & Sim \\
\hline 4 & $\begin{array}{l}\text { Informe as entregas de saída } \\
\text { da atividade "Detalhar ciclo de } \\
\text { vida do produto e definir seus } \\
\text { clientes" da fase de "Projeto } \\
\text { informacional". }\end{array}$ & $\begin{array}{l}\text { Informe as entregas de saída } \\
\text { da atividade "Promover } \\
\text { marketing de lançamento" da } \\
\text { fase de "Lançamento". }\end{array}$ & Sim & Sim \\
\hline 5 & $\begin{array}{l}\text { Informe a principal entrega da } \\
\text { fase "Projeto informacional". }\end{array}$ & $\begin{array}{l}\text { Informe a principal entrega } \\
\text { da fase "Lançamento". }\end{array}$ & Sim & Sim \\
\hline 6 & $\begin{array}{l}\text { Informe os padrões de } \\
\text { qualidade que o modelo } \\
\text { fornece para a entrega } \\
\text { "Estrutura do produto (BOM)" } \\
\text { na fase de "Projeto detalhado". }\end{array}$ & $\begin{array}{l}\text { Informe os padrões de } \\
\text { qualidade que o modelo } \\
\text { fornece para a entrega } \\
\text { "Concepção escolhida para o } \\
\text { produto" na fase de "Projeto } \\
\text { conceitual". }\end{array}$ & Sim & Sim \\
\hline 7 & $\begin{array}{l}\text { Informe as entregas da } \\
\text { atividade "Promover marketing } \\
\text { de lançamento" que são } \\
\text { entradas para a atividade } \\
\text { "Lançar produto" na fase de } \\
\text { "Lançamento". }\end{array}$ & $\begin{array}{l}\text { Informe as entregas da } \\
\text { atividade "Detalhar ciclo de } \\
\text { vida do produto e definir } \\
\text { seus clientes" que são } \\
\text { entradas para a atividade } \\
\text { "Identificar os requisitos dos } \\
\text { clientes do produto" na fase } \\
\text { de "Projeto informacional". }\end{array}$ & Sim & $\begin{array}{l}\text { Símbolos de } \\
\text { atividade de } \\
\text { origem e } \\
\text { destino, } \\
\text { (idem } \\
\text { entregas) } \\
\text { estão } \\
\text { confusos. }\end{array}$ \\
\hline 8 & $\begin{array}{l}\text { Informe as atividades que } \\
\text { dependem das entregas da } \\
\text { seguinte atividade para serem } \\
\text { iniciadas: "1.4.2 - Modelar } \\
\text { funcionalmente o produto" da } \\
\text { fase de "Projeto conceitual". }\end{array}$ & $\begin{array}{l}\text { Informe as atividades que } \\
\text { dependem das entregas da } \\
\text { seguinte atividade para } \\
\text { serem iniciadas: "1.4.7- } \\
\text { Definir ergonomia e estética" } \\
\text { da fase de "Projeto } \\
\text { conceitual". }\end{array}$ & Sim & $\begin{array}{l}\text { Falta de } \\
\text { botões para } \\
\text { navegar } \\
\text { entre } \\
\text { atividades. }\end{array}$ \\
\hline 9 & $\begin{array}{l}\text { Informe as melhores práticas } \\
\text { sugeridas para a realização da } \\
\text { atividade "Detalhar ciclo de } \\
\text { vida do produto e definir seus } \\
\text { clientes" da fase de "Projeto } \\
\text { informacional". }\end{array}$ & $\begin{array}{l}\text { Informe as melhores práticas } \\
\text { sugeridas para a realização } \\
\text { da atividade "Otimizar } \\
\text { produção" da fase de } \\
\text { "Preparação da produção". }\end{array}$ & Sim & Sim \\
\hline 10 & $\begin{array}{l}\text { Você é um especialista em } \\
\text { "Abstração orientada". Informe }\end{array}$ & $\begin{array}{l}\text { Você é um especialista em } \\
\text { "QFD (Quality Function }\end{array}$ & Sim & Sim \\
\hline
\end{tabular}




\begin{tabular}{|c|c|c|c|c|}
\hline & Tarefa de leitura A & Tarefa de leitura B & $\begin{array}{l}\text { O usuário } \\
\text { sabe o que } \\
\text { fazer? }\end{array}$ & $\begin{array}{l}\text { O usuário } \\
\text { saberá } \\
\text { como fazer? }\end{array}$ \\
\hline & $\begin{array}{l}\text { as atividades nas quais essa } \\
\text { melhor prática é empregada } \\
\text { na fase de "Projeto } \\
\text { conceitual". }\end{array}$ & $\begin{array}{l}\text { Deployment)". Informe as } \\
\text { atividades nas quais essa } \\
\text { melhor pratica é empregada } \\
\text { na fase de "Projeto } \\
\text { informacional". }\end{array}$ & & \\
\hline 11 & $\begin{array}{l}\text { Informe as atividades da fase } \\
\text { de "Preparação da produção" } \\
\text { com as quais o "Gerente de } \\
\text { qualidade" está relacionado. }\end{array}$ & $\begin{array}{l}\text { Informe as atividades da fase } \\
\text { de "Projeto informacional" } \\
\text { com as quais o "Gerente de } \\
\text { marketing" está relacionado. }\end{array}$ & Sim & $\begin{array}{l}\text { Falta de } \\
\text { botões para } \\
\text { navegar } \\
\text { entre papéis. }\end{array}$ \\
\hline 12 & $\begin{array}{l}\text { Informe as entregas com as } \\
\text { quais o "Gerente de design" } \\
\text { está relacionado na fase de } \\
\text { "Projeto conceitual" (tanto } \\
\text { entregas de entrada quanto de } \\
\text { saída). }\end{array}$ & $\begin{array}{l}\text { Informe as entregas com as } \\
\text { quais o "Gerente de } \\
\text { suprimentos" está } \\
\text { relacionado na fase de } \\
\text { "Preparação da produção" } \\
\text { (tanto entregas de entrada } \\
\text { quanto de saída). }\end{array}$ & Sim & $\begin{array}{l}\text { Excesso de } \\
\text { elementos } \\
\text { da órbita }\end{array}$ \\
\hline 13 & $\begin{array}{l}\text { Informe as melhores práticas } \\
\text { de que o "Gerente de } \\
\text { suprimentos" necessitará } \\
\text { lançar mão na fase de "Projeto } \\
\text { conceitual". }\end{array}$ & $\begin{array}{l}\text { Informe as melhores práticas } \\
\text { sugeridas de que o "Gerente } \\
\text { de vendas" necessitará } \\
\text { lançar mão na fase de } \\
\text { "Projeto detalhado". }\end{array}$ & Sim & $\begin{array}{l}\text { O menu } \\
\text { alfabético } \\
\text { não leva } \\
\text { sempre para } \\
\text { a mesma } \\
\text { fase. }\end{array}$ \\
\hline 14 & $\begin{array}{l}\text { Informe as responsabilidades } \\
\text { atribuídas ao papel de } \\
\text { "Gerente de projetos" segundo } \\
\text { o modelo. }\end{array}$ & $\begin{array}{l}\text { Informe as responsabilidades } \\
\text { atribuídas ao papel de "Time } \\
\text { de planejamento estratégico } \\
\text { de produto" segundo o } \\
\text { modelo. }\end{array}$ & Sim & Sim \\
\hline 15 & $\begin{array}{l}\text { Informe o número de papéis } \\
\text { envolvidos na fase de "Projeto } \\
\text { informacional". }\end{array}$ & $\begin{array}{l}\text { Informe o número de papéis } \\
\text { envolvidos na fase de } \\
\text { "Lançamento". }\end{array}$ & Sim & Sim \\
\hline
\end{tabular}

Sugestões de mudanças no protótipo A:

- Inserção de uma ferramenta de filtros nas telas das órbitas, pois em algumas situações o número de elementos apresentados é tão grande que alguns ícones se sobrepõem e dificultam a leitura.

- Ajustes nos ícones de atividade de origem e de destino, que poderiam causar confusão nos usuários.

- Ajustes nos links das listas alfabéticas de elementos do modelo, que não deixavam claro para qual fase do modelo estavam direcionando o usuário (optou-se por sempre levar ao começo do processo).

- Inserção de botões em algumas das vistas que permitissem a navegação entre fases ou entre elementos. 


\begin{tabular}{|c|c|c|c|c|}
\hline & Tarefa de leitura A & Tarefa de leitura B & $\begin{array}{l}\text { O usuário } \\
\text { sabe o que } \\
\text { fazer? }\end{array}$ & $\begin{array}{l}\text { O usuário } \\
\text { saberá } \\
\text { como fazer? }\end{array}$ \\
\hline 1 & $\begin{array}{l}\text { Informe as três primeiras } \\
\text { atividades da fase de "Projeto } \\
\text { informacional". }\end{array}$ & $\begin{array}{l}\text { Informe as três primeiras } \\
\text { atividades da fase de } \\
\text { "Lançamento". }\end{array}$ & Sim & Sim \\
\hline 2 & $\begin{array}{l}\text { Você acaba de concluir a } \\
\text { atividade "Definir requisitos do } \\
\text { produto" da fase de "Projeto } \\
\text { informacional". Qual a próxima } \\
\text { atividade a ser realizada } \\
\text { segundo o modelo? }\end{array}$ & $\begin{array}{l}\text { Você acaba de concluir a } \\
\text { atividade "Selecionar a } \\
\text { concepção do produto" da } \\
\text { fase de "Projeto conceitual". } \\
\text { Qual a próxima atividade a } \\
\text { ser realizada segundo o } \\
\text { modelo? }\end{array}$ & Sim & Sim \\
\hline 3 & $\begin{array}{l}\text { Informe as duas primeiras } \\
\text { fases que compõem a } \\
\text { macrofase de } \\
\text { "Desenvolvimento". }\end{array}$ & $\begin{array}{l}\text { Informe as duas últimas } \\
\text { fases que compõem a } \\
\text { macrofase de } \\
\text { "Desenvolvimento". }\end{array}$ & Sim & Sim \\
\hline 4 & $\begin{array}{l}\text { Informe as entregas de saída } \\
\text { da atividade "Detalhar ciclo de } \\
\text { vida do produto e definir seus } \\
\text { clientes" da fase de "Projeto } \\
\text { informacional". }\end{array}$ & $\begin{array}{l}\text { Informe as entregas de saída } \\
\text { da atividade "Promover } \\
\text { marketing de lançamento" da } \\
\text { fase de "Lançamento". }\end{array}$ & Sim & Sim \\
\hline 5 & $\begin{array}{l}\text { Informe a principal entrega da } \\
\text { fase "Projeto informacional". }\end{array}$ & $\begin{array}{l}\text { Informe a principal entrega } \\
\text { da fase "Lançamento". }\end{array}$ & Sim & Sim \\
\hline 6 & $\begin{array}{l}\text { Informe os padrões de } \\
\text { qualidade que o modelo } \\
\text { fornece para a entrega } \\
\text { "Estrutura do produto (BOM)" } \\
\text { na fase de "Projeto detalhado". }\end{array}$ & $\begin{array}{l}\text { Informe os padrões de } \\
\text { qualidade que o modelo } \\
\text { fornece para a entrega } \\
\text { "Concepção escolhida para o } \\
\text { produto" na fase de "Projeto } \\
\text { conceitual". }\end{array}$ & Sim & Sim \\
\hline 7 & $\begin{array}{l}\text { Informe as entregas da } \\
\text { atividade "Promover marketing } \\
\text { de lançamento" que são } \\
\text { entradas para a atividade } \\
\text { "Lançar produto" na fase de } \\
\text { "Lançamento". }\end{array}$ & $\begin{array}{l}\text { Informe as entregas da } \\
\text { atividade "Detalhar ciclo de } \\
\text { vida do produto e definir } \\
\text { seus clientes" que são } \\
\text { entradas para a atividade } \\
\text { "Identificar os requisitos dos } \\
\text { clientes do produto" na fase } \\
\text { de "Projeto informacional". }\end{array}$ & Sim & Sim \\
\hline 8 & $\begin{array}{l}\text { Informe as atividades que } \\
\text { dependem das entregas da } \\
\text { seguinte atividade para serem } \\
\text { iniciadas: "1.4.2 - Modelar } \\
\text { funcionalmente o produto" da } \\
\text { fase de "Projeto conceitual". }\end{array}$ & $\begin{array}{l}\text { Informe as atividades que } \\
\text { dependem das entregas da } \\
\text { seguinte atividade para } \\
\text { serem iniciadas: "1.4.7 - } \\
\text { Definir ergonomia e estética" } \\
\text { da fase de "Projeto } \\
\text { conceitual". }\end{array}$ & Sim & Sim \\
\hline 9 & $\begin{array}{l}\text { Informe as melhores práticas } \\
\text { sugeridas para a realização da } \\
\text { atividade "Detalhar ciclo de } \\
\text { vida do produto e definir seus } \\
\text { clientes" da fase de "Projeto } \\
\text { informacional". }\end{array}$ & $\begin{array}{l}\text { Informe as melhores práticas } \\
\text { sugeridas para a realização } \\
\text { da atividade "Otimizar } \\
\text { produção" da fase de } \\
\text { "Preparação da produção". }\end{array}$ & Sim & Sim \\
\hline 10 & $\begin{array}{l}\text { Você é um especialista em } \\
\text { "Abstração orientada". Informe } \\
\text { as atividades nas quais essa } \\
\text { melhor prática é empregada } \\
\text { na fase de "Projeto } \\
\text { conceitual". }\end{array}$ & $\begin{array}{l}\text { Você é um especialista em } \\
\text { "QFD (Quality Function } \\
\text { Deployment)". Informe as } \\
\text { atividades nas quais essa } \\
\text { melhor pratica é empregada } \\
\text { na fase de "Projeto } \\
\text { informacional". }\end{array}$ & Sim & Sim \\
\hline 11 & $\begin{array}{l}\text { Informe as atividades da fase } \\
\text { de "Preparação da produção" }\end{array}$ & $\begin{array}{l}\text { Informe as atividades da fase } \\
\text { de "Projeto informacional" }\end{array}$ & Sim & Sim \\
\hline
\end{tabular}




\begin{tabular}{|c|c|c|c|c|}
\hline & Tarefa de leitura A & Tarefa de leitura B & $\begin{array}{l}\text { O usuário } \\
\text { sabe o que } \\
\text { fazer? }\end{array}$ & $\begin{array}{l}\text { O usuário } \\
\text { saberá } \\
\text { como fazer? }\end{array}$ \\
\hline & $\begin{array}{l}\text { com as quais o "Gerente de } \\
\text { qualidade" está relacionado. }\end{array}$ & $\begin{array}{l}\text { com as quais o "Gerente de } \\
\text { marketing" está relacionado. }\end{array}$ & & \\
\hline 12 & $\begin{array}{l}\text { Informe as entregas com as } \\
\text { quais o "Gerente de design" } \\
\text { está relacionado na fase de } \\
\text { "Projeto conceitual" (tanto } \\
\text { entregas de entrada quanto de } \\
\text { saída). }\end{array}$ & $\begin{array}{l}\text { Informe as entregas com as } \\
\text { quais o "Gerente de } \\
\text { suprimentos" está } \\
\text { relacionado na fase de } \\
\text { "Preparação da produção" } \\
\text { (tanto entregas de entrada } \\
\text { quanto de saída). }\end{array}$ & Sim & Sim \\
\hline 13 & $\begin{array}{l}\text { Informe as melhores práticas } \\
\text { de que o "Gerente de } \\
\text { suprimentos" necessitará } \\
\text { lançar mão na fase de "Projeto } \\
\text { conceitual". }\end{array}$ & $\begin{array}{l}\text { Informe as melhores práticas } \\
\text { sugeridas de que o "Gerente } \\
\text { de vendas" necessitará } \\
\text { lançar mão na fase de } \\
\text { "Projeto detalhado". }\end{array}$ & Sim & $\begin{array}{l}\text { Não há a } \\
\text { dimensão } \\
\text { organizacion } \\
\text { al no } \\
\text { protótipo }\end{array}$ \\
\hline 14 & $\begin{array}{l}\text { Informe as responsabilidades } \\
\text { atribuídas ao papel de } \\
\text { "Gerente de projetos" segundo } \\
\text { o modelo. }\end{array}$ & $\begin{array}{l}\text { Informe as responsabilidades } \\
\text { atribuídas ao papel de "Time } \\
\text { de planejamento estratégico } \\
\text { de produto" segundo o } \\
\text { modelo. }\end{array}$ & Sim & $\begin{array}{l}\text { Não há a } \\
\text { dimensão } \\
\text { organizacion } \\
\text { al no } \\
\text { protótipo }\end{array}$ \\
\hline 15 & $\begin{array}{l}\text { Informe o número de papéis } \\
\text { envolvidos na fase de "Projeto } \\
\text { informacional". }\end{array}$ & $\begin{array}{l}\text { Informe o número de papéis } \\
\text { envolvidos na fase de } \\
\text { "Lançamento". }\end{array}$ & Sim & Sim \\
\hline
\end{tabular}

Sugestões de mudanças no protótipo B:

- acrescentar a dimensão organização ao modelo, que havia sido modelado apenas com a dimensão de processos. $O$ acréscimo da dimensão organização facilita 0 acesso às informações relacionadas aos departamentos e aos papéis, como responsabilidades e melhores práticas utilizadas. 


\section{Apêndice $L$ - Estatistica descritiva e teste $t$ de student para métricas de eficiência}

Estatística Descritiva (número ações/tarefa)

\begin{tabular}{|c|c|c|c|c|c|c|c|c|c|c|c|c|c|c|c|c|c|c|c|c|c|c|c|c|c|c|}
\hline & $\begin{array}{l}1 \\
(\mathrm{~A})\end{array}$ & $\begin{array}{l}1 \\
(B)\end{array}$ & $\begin{array}{l}2 \\
(A)\end{array}$ & $\begin{array}{l}2 \\
(B)\end{array}$ & $\begin{array}{l}3 \\
(\mathrm{~A})\end{array}$ & $\begin{array}{l}3 \\
\text { (B) }\end{array}$ & $\begin{array}{l}4 \\
(\mathrm{~A})\end{array}$ & $\begin{array}{l}4 \\
(\mathrm{~B})\end{array}$ & $\begin{array}{l}6 \\
(A) \\
\end{array}$ & $\begin{array}{l}6 \\
(\mathrm{~B})\end{array}$ & $\begin{array}{l}7 \\
(\mathrm{~A})\end{array}$ & $\begin{array}{l}7 \\
(B)\end{array}$ & $\begin{array}{l}8 \\
(A)\end{array}$ & $8(\mathrm{~B})$ & $\begin{array}{l}9 \\
(A)\end{array}$ & \begin{tabular}{|l}
9 \\
$(\mathrm{~B})$
\end{tabular} & $\begin{array}{l}10 \\
(\mathrm{~A})\end{array}$ & $\begin{array}{l}10 \\
(\mathrm{~B})\end{array}$ & $\begin{array}{l}11 \\
(\mathrm{~A})\end{array}$ & $\begin{array}{l}11 \\
(\mathrm{~B})\end{array}$ & $\begin{array}{l}12 \\
(\mathrm{~A})\end{array}$ & $\begin{array}{l}12 \\
(\mathrm{~B}) \\
\end{array}$ & $\begin{array}{l}13 \\
(\mathrm{~A})\end{array}$ & $\begin{array}{l}13 \\
(\mathrm{~B})\end{array}$ & $\begin{array}{l}14 \\
(\mathrm{~A})\end{array}$ & $\begin{array}{l}14 \\
\text { (B) }\end{array}$ \\
\hline Média & 3 & 5 & 3 & 5 & 0 & 3 & 2 & 4 & 6 & 6 & 3 & 6 & 5 & 8 & 2 & 5 & 4 & 18 & 4 & 10 & 5 & 11 & 4 & 12 & 6 & 5 \\
\hline Erro padrão & 1 & 1 & 0 & 1 & 0 & 0 & 0 & 0 & 1 & 1 & 1 & 1 & 2 & 3 & 0 & 0 & 1 & 3 & 1 & 3 & 2 & 1 & 1 & 2 & 1 & 1 \\
\hline Mediana & 2 & 5 & 2 & 5 & 0 & 3 & 2 & 4 & 5 & 5 & 2 & 6 & 2 & 6 & 2 & 5 & 4 & 18 & 3 & 6 & 3 & 12 & 3 & 12 & 5 & 4 \\
\hline Modo & 2 & 5 & 2 & 5 & 0 & 2 & 2 & 4 & 4 & 5 & 2 & 5 & 2 & \#N/D & 2 & 5 & 2 & 18 & 3 & 6 & 2 & 12 & 2 & 6 & 5 & 4 \\
\hline Desvio padrão & 2 & 2 & 1 & 2 & 0 & 1 & 0 & 1 & 3 & 3 & 2 & 2 & 4 & 7 & 1 & 2 & 2 & 9 & 2 & 8 & 5 & 3 & 4 & 6 & 4 & 2 \\
\hline $\begin{array}{l}\text { Variância da } \\
\text { amostra }\end{array}$ & 4 & 5 & 2 & $\begin{array}{r}3 \\
-\end{array}$ & 0 & 2 & $\begin{array}{l}0 \\
-\end{array}$ & 1 & $\begin{array}{l}8 \\
-\end{array}$ & 11 & $\begin{array}{l}6 \\
-\end{array}$ & 5 & 18 & 45 & 0 & $\begin{array}{r}3 \\
-\end{array}$ & $\begin{array}{l}3 \\
-\end{array}$ & $\begin{array}{r}90 \\
-\end{array}$ & 6 & 71 & 30 & 10 & 13 & $\begin{array}{r}32 \\
-\end{array}$ & 14 & 6 \\
\hline Curtose & 5,51 & 0,70 & 4,77 & 0,14 & & 3,12 & 1,22 & 0,40 & 2,10 & 6,76 & 0,84 & 0,06 & 1,43 & 3,24 & 6,96 & 0,01 & 1,72 & 0,88 & 0,48 & 1,17 & 5,50 & 1,53 & 4,88 & 0,68 & 6,15 & 5,29 \\
\hline Assimetria & 2,42 & 1,26 & 2,28 & 0,19 & & 1,47 & 1,04 & 0,60 & 0,50 & 2,53 & 1,23 & 0,33 & 1,54 & 1,77 & 2,68 & 0,87 & 0,23 & 0,26 & 1,28 & 1,45 & 2,32 & 1,05 & 2,19 & 0,49 & 2,42 & 2,22 \\
\hline Intervalo & 6 & 6 & 4 & 6 & 0 & 5 & 1 & 3 & 6 & 10 & 5 & 7 & 10 & 18 & 2 & 5 & 4 & 28 & 7 & 25 & 15 & 10 & 12 & 17 & 11 & 7 \\
\hline Mínimo & 2 & 3 & 2 & 2 & 0 & 1 & 2 & 3 & 4 & 4 & 2 & 3 & 2 & 3 & 2 & 3 & 2 & 5 & 2 & 3 & 2 & 5 & 2 & 5 & 3 & 3 \\
\hline Máximo & 8 & 9 & 6 & 8 & 0 & 6 & 3 & 6 & 10 & 14 & 7 & 10 & 12 & 21 & 4 & 8 & 6 & 33 & 9 & 28 & 17 & 15 & 14 & 22 & 14 & 10 \\
\hline Soma & 31 & 55 & 26 & 51 & 0 & 33 & 23 & 42 & 51 & 49 & 24 & 44 & 27 & 50 & 29 & 62 & 32 & 160 & 41 & 100 & 35 & 77 & 48 & 131 & 40 & 33 \\
\hline Contagem & 11 & 11 & 10 & 10 & 12 & 12 & 10 & 10 & 8 & 8 & 7 & 7 & 6 & 6 & 13 & 13 & 9 & 9 & 10 & 10 & 7 & 7 & 11 & 11 & 7 & 7 \\
\hline
\end{tabular}


Teste t de student (número ações/tarefa)

\begin{tabular}{|c|c|c|c|c|c|c|c|c|c|c|c|c|c|c|c|c|c|c|c|c|c|c|c|c|c|}
\hline & $1(\mathrm{~A})$ & \begin{tabular}{|l}
1 \\
$(\mathrm{~B})$
\end{tabular} & $2(\mathrm{~A})$ & $\begin{array}{l}2 \\
(\mathrm{~B}) \\
\end{array}$ & $3(A)$ & \begin{tabular}{|l}
3 \\
$(\mathrm{~B})$ \\
\end{tabular} & $4(\mathrm{~A})$ & $\begin{array}{l}4 \\
(\mathrm{~B})\end{array}$ & $6(\mathrm{~A})$ & $\begin{array}{l}6 \\
(\mathrm{~B}) \\
\end{array}$ & $7(\mathrm{~A})$ & \begin{tabular}{|l}
7 \\
$(\mathrm{~B})$ \\
\end{tabular} & $8(\mathrm{~A})$ & \begin{tabular}{|l|}
8 \\
$(B)$ \\
\end{tabular} & $9(A)$ & \begin{tabular}{|l|}
9 \\
$(\mathrm{~B})$ \\
\end{tabular} & \begin{tabular}{|l|}
10 \\
$(\mathrm{~A})$ \\
\end{tabular} & \begin{tabular}{|l|}
10 \\
$(B)$ \\
\end{tabular} & $\begin{array}{l}1 \\
(\mathrm{~A}) \\
\end{array}$ & \begin{tabular}{|l|}
11 \\
$(\mathrm{~B})$ \\
\end{tabular} & $\begin{array}{l}12 \\
(\mathrm{~A}) \\
\end{array}$ & \begin{tabular}{|l|}
12 \\
$(\mathrm{~B})$ \\
\end{tabular} & $13(A)$ & $\begin{array}{l}13 \\
(B) \\
\end{array}$ & \begin{tabular}{|l|}
14 \\
$(\mathrm{~A})$ \\
\end{tabular} \\
\hline Média & 3 & 5 & 3 & 5 & 0 & 3 & 2 & 4 & 6 & 6 & 3 & 6 & 5 & 8 & 2 & 5 & 4 & 18 & 4 & 10 & 5 & 11 & 4 & 12 & 6 \\
\hline Variância & 4 & 5 & 2 & 3 & 0 & 2 & 0 & 1 & 8 & 11 & 6 & 5 & 18 & 45 & 0 & 3 & 3 & 90 & 6 & 71 & 30 & 10 & 13 & 32 & 14 \\
\hline $\begin{array}{l}\text { Observações } \\
\text { Correlacão de }\end{array}$ & 11 & 11 & 10 & 10 & 12 & 12 & 10 & 10 & 8 & 8 & 7 & 7 & 6 & 6 & 13 & 13 & 9 & 9 & 10 & 10 & 7 & 7 & 11 & 11 & 7 \\
\hline $\begin{array}{l}\text { Pearson } \\
\text { Hipótese da } \\
\text { diferença de }\end{array}$ & 0,00 & & $-0,12$ & & \#DIV/0! & & 0,10 & & 0,67 & & $-0,38$ & & $-0,07$ & & 0,22 & & $-0,35$ & & $-0,34$ & & 0,59 & & 0,20 & & $-0,27$ \\
\hline média & 0,00 & & 0,00 & & 0,00 & & 0,00 & & 0,00 & & 0,00 & & 0,00 & & 0,00 & & 0,00 & & 0,00 & & 0,00 & & 0,00 & & 0,00 \\
\hline gl & 10,00 & & 9,00 & & 11,00 & & 9,00 & & 7,00 & & 6,00 & & 5,00 & & 12,00 & & 8,00 & & 9,00 & & 6,00 & & 10,00 & & 6,00 \\
\hline $\begin{array}{l}\text { Stat } t \\
P(T<=t) \text { uni- }\end{array}$ & $-2,50$ & & $-3,34$ & & $-7,40$ & & $-6,04$ & & 0,28 & & $-1,92$ & & $-1,15$ & & $-5,34$ & & $-4,20$ & & $-1,97$ & & $-3,58$ & & $-4,08$ & & 0,53 \\
\hline $\begin{array}{l}\text { caudal } \\
\text { t crítico uni- }\end{array}$ & 0,02 & & 0,00 & & 0,00 & & 0,00 & & 0,39 & & 0,05 & & 0,15 & & 0,00 & & 0,00 & & 0,04 & & 0,01 & & 0,00 & & 0,31 \\
\hline caudal & 1,81 & & 1,83 & & 1,80 & & 1,83 & & 1,89 & & 1,94 & & 2,02 & & 1,78 & & 1,86 & & 1,83 & & 1,94 & & 1,81 & & 1,94 \\
\hline $\begin{array}{l}\mathrm{P}(\mathrm{T}<=\mathrm{t}) \text { bi- } \\
\text { caudal }\end{array}$ & 0,03 & & 0,01 & & 0,00 & & 0,00 & & 0,78 & & 0,10 & & 0,30 & & 0,00 & & 0,00 & & 0,08 & & 0,01 & & 0,00 & & 0,61 \\
\hline $\begin{array}{l}\text { t crítico bi- } \\
\text { caudal }\end{array}$ & 2,23 & & 2,26 & & 2,20 & & 2,26 & & 2,36 & & 2,45 & & 2,57 & & 2,18 & & 2,31 & & 2,26 & & 2,45 & & 2,23 & & 2,45 \\
\hline
\end{tabular}




\section{Estatística descritiva (segundos/tarefa)}

\begin{tabular}{|c|c|c|c|c|c|c|c|c|c|c|c|c|c|c|c|c|c|c|c|c|c|c|c|c|c|c|}
\hline & $1(\mathrm{~A})$ & $1(\mathrm{~B})$ & $2(A)$ & $2(B)$ & $\begin{array}{l}3 \\
(A)\end{array}$ & $3(\mathrm{~B})$ & $4(\mathrm{~A})$ & $4(B)$ & $6(\mathrm{~A})$ & $6(\mathrm{~B})$ & $7(A)$ & $7(B)$ & $8(A)$ & $8(\mathrm{~B})$ & $9(A)$ & $9(\mathrm{~B})$ & $\begin{array}{l}10 \\
(\mathrm{~A})\end{array}$ & $\begin{array}{l}10 \\
(B)\end{array}$ & \begin{tabular}{|l|}
11 \\
$(A)$ \\
\end{tabular} & $\begin{array}{l}11 \\
(\mathrm{~B})\end{array}$ & \begin{tabular}{|l}
12 \\
$(\mathrm{~A})$ \\
\end{tabular} & $\begin{array}{l}12 \\
\text { (B) }\end{array}$ & \begin{tabular}{|l|}
13 \\
$(A)$ \\
\end{tabular} & $\begin{array}{l}13 \\
\text { (B) }\end{array}$ & $\begin{array}{l}14 \\
(\mathrm{~A})\end{array}$ & $\begin{array}{l}14 \\
(B) \\
\end{array}$ \\
\hline Média & 15 & 29 & 18 & 37 & 8 & 16 & 17 & 30 & 45 & 51 & 49 & 69 & 49 & 62 & 16 & 32 & 26 & 87 & 26 & 54 & 51 & 101 & 34 & 68 & 33 & 24 \\
\hline Erro padrão & 3 & 6 & 3 & 6 & 1 & 3 & 2 & 4 & 6 & 17 & 9 & 16 & 12 & 9 & 2 & 6 & 3 & 9 & 3 & 10 & 18 & 15 & 6 & 10 & 11 & 7 \\
\hline Mediana & 14 & 23 & 15 & 35 & 8 & 13 & 15 & 27 & 46 & 30 & 47 & 60 & 37 & 63 & 13 & 28 & 25 & 88 & 22 & 42 & 32 & 92 & 27 & 67 & 31 & 15 \\
\hline Modo & $\# N / D$ & $\# N / D$ & $\# \mathrm{~N} / \mathrm{D}$ & $\# \mathrm{~N} / \mathrm{D}$ & 3 & \#N/D & $\# \mathrm{~N} / \mathrm{D}$ & \#N/D & \#N/D & $\# \mathrm{~N} / \mathrm{D}$ & \#N/D & $\# N / D$ & $\# N / D$ & \#N/D & \#N/D & $\# \mathrm{~N} / \mathrm{D}$ & \#N/D & \#N/D & \#N/D & 38 & $\# N / D$ & \#N/D & $\# N / D$ & $\# \mathrm{~N} / \mathrm{D}$ & \#N/D & $\# N / D$ \\
\hline $\begin{array}{l}\text { Desvio } \\
\text { padrão }\end{array}$ & 9 & 19 & 9 & 20 & 4 & 10 & 6 & 13 & 17 & 47 & 24 & 42 & 29 & 23 & 8 & 21 & 10 & 27 & 11 & 30 & 46 & 40 & 21 & 32 & 29 & 19 \\
\hline $\begin{array}{l}\text { Variância da } \\
\text { amostra }\end{array}$ & 87 & 344 & 76 & 382 & $\begin{array}{r}17 \\
-\end{array}$ & 103 & 40 & 162 & 289 & 2193 & 580 & 1743 & 858 & 508 & 64 & 426 & 102 & 723 & 118 & 926 & 2160 & 1576 & 430 & 1053 & 852 & 362 \\
\hline Curtose & 3,22 & 0,14 & 2,41 & 3,65 & 1,20 & $-0,10$ & $-0,69$ & 3,48 & $-1,71$ & 6,68 & $-1,99$ & 6,24 & $-1,80$ & $-0,38$ & 3,32 & 3,07 & $-0,88$ & $-0,99$ & $-0,71$ & 0,60 & 2,91 & $-1,14$ & 2,63 & 1,70 & 3,99 & $-0,06$ \\
\hline Assimetria & 1,46 & 1,08 & 1,55 & 1,44 & 0,41 & 0,84 & 0,57 & 1,51 & $-0,05$ & 2,54 & $-0,04$ & 2,45 & 0,85 & 0,26 & 1,60 & 1,61 & $-0,21$ & 0,24 & 0,86 & 1,36 & 1,73 & 0,55 & 1,47 & 0,90 & 1,88 & 1,29 \\
\hline Intervalo & 34 & 56 & 28 & 74 & 11 & 32 & 19 & 46 & 44 & 138 & 61 & 122 & 65 & 62 & 31 & 75 & 30 & 79 & 28 & 86 & 134 & 103 & 73 & 122 & 84 & 48 \\
\hline Mínimo & 4 & 10 & 10 & 10 & 3 & 3 & 8 & 14 & 22 & 26 & 18 & 40 & 24 & 34 & 6 & 11 & 9 & 53 & 16 & 25 & 11 & 55 & 11 & 19 & 10 & 9 \\
\hline Máximo & 38 & 66 & 38 & 84 & 14 & 35 & 27 & 60 & 66 & 164 & 79 & 162 & 89 & 96 & 37 & 86 & 39 & 132 & 44 & 111 & 145 & 158 & 84 & 141 & 94 & 57 \\
\hline Soma & 165 & 318 & 179 & 374 & 91 & 191 & 166 & 296 & 363 & 411 & 343 & 483 & 296 & 372 & 208 & 414 & 232 & 784 & 258 & 543 & 355 & 705 & 373 & 751 & 230 & 167 \\
\hline Contagem & 11 & 11 & 10 & 10 & 12 & 12 & 10 & 10 & 8 & 8 & 7 & 7 & 6 & 6 & 13 & 13 & 9 & 9 & 10 & 10 & 7 & 7 & 11 & 11 & 7 & 7 \\
\hline $\begin{array}{l}\text { Nível de } \\
\text { confiança } \\
95,0 \%\end{array}$ & 6 & 12 & 6 & 14 & 3 & 6 & 5 & 9 & 14 & 39 & 22 & 39 & 31 & 24 & 5 & 12 & 8 & 21 & 8 & 22 & 43 & 37 & 14 & 22 & 27 & 18 \\
\hline
\end{tabular}


Teste t de student (segundos/tarefa)

\begin{tabular}{|c|c|c|c|c|c|c|c|c|c|c|c|c|c|c|c|c|c|c|c|c|c|c|c|c|c|c|}
\hline & $1(\mathrm{~A})$ & $\begin{array}{l}1 \\
(\mathrm{~B}) \\
\end{array}$ & $2(A)$ & \begin{tabular}{|l|}
2 \\
$(\mathrm{~B})$ \\
\end{tabular} & $3(A)$ & $\begin{array}{l}3 \\
(\mathrm{~B}) \\
\end{array}$ & $4(\mathrm{~A})$ & \begin{tabular}{|l}
4 \\
$(\mathrm{~B})$ \\
\end{tabular} & $6(\mathrm{~A})$ & $6(\mathrm{~B})$ & $7(A)$ & $7(\mathrm{~B})$ & $8(A)$ & $\begin{array}{l}8 \\
(\mathrm{~B}) \\
\end{array}$ & $9(A)$ & \begin{tabular}{|l|}
9 \\
$(\mathrm{~B})$ \\
\end{tabular} & \begin{tabular}{|l|}
10 \\
$(\mathrm{~A})$ \\
\end{tabular} & \begin{tabular}{|l|}
10 \\
$(B)$ \\
\end{tabular} & \begin{tabular}{|l|}
11 \\
$(\mathrm{~A})$ \\
\end{tabular} & \begin{tabular}{|l}
11 \\
$(B)$ \\
\end{tabular} & $\begin{array}{l}12 \\
(\mathrm{~A}) \\
\end{array}$ & $\begin{array}{l}12 \\
(\mathrm{~B}) \\
\end{array}$ & $13(\mathrm{~A})$ & \begin{tabular}{|l|l}
13 \\
$(B)$
\end{tabular} & $\begin{array}{l}14 \\
(\mathrm{~A}) \\
\end{array}$ & $\begin{array}{l}14 \\
(\mathrm{~B}) \\
\end{array}$ \\
\hline Média & 15 & 29 & 18 & 37 & 8 & 16 & 17 & 30 & 45 & 51 & 49 & 69 & 49 & 62 & 16 & 32 & 26 & 87 & 26 & 54 & 51 & 101 & 34 & 68 & 33 & 24 \\
\hline Variância & 87 & 344 & 76 & 382 & 17 & 103 & 40 & 162 & 289 & 2193 & 580 & 1743 & 858 & 508 & 64 & 426 & 102 & 723 & 118 & 926 & 2160 & 1576 & 430 & 1053 & 852 & 362 \\
\hline $\begin{array}{l}\text { Observações } \\
\text { Correlação de }\end{array}$ & 11 & 11 & 10 & 10 & 12 & 12 & 10 & 10 & 8 & 8 & 7 & 7 & $\begin{array}{l}6 \\
-\end{array}$ & 6 & 13 & 13 & 9 & 9 & $\begin{array}{r}10 \\
-\end{array}$ & 10 & 7 & 7 & 11 & 11 & $\begin{array}{l}7 \\
-\end{array}$ & 7 \\
\hline $\begin{array}{l}\text { Pearson } \\
\text { Hipótese da } \\
\text { diferença de }\end{array}$ & 0,29 & & 0,30 & & 0,23 & & 0,21 & & 0,08 & & 0,60 & & 0,44 & & 0,11 & & 0,28 & & 0,48 & & $-0,38$ & & 0,50 & & 0,19 & \\
\hline média & 0,00 & & 0,00 & & 0,00 & & 0,00 & & 0,00 & & 0,00 & & 0,00 & & 0,00 & & 0,00 & & 0,00 & & 0,00 & & 0,00 & & 0,00 & \\
\hline gl & 10,00 & & 9,00 & & 11,00 & & 9,00 & & $\begin{array}{r}7,00 \\
-\end{array}$ & & 6,00 & & 5,00 & & 12,00 & & 8,00 & & 9,00 & & 6,00 & & 10,00 & & 6,00 & \\
\hline $\begin{array}{l}\text { Stat } t \\
P(T<=t) \text { uni- }\end{array}$ & $-2,54$ & & 3,28 & & $-2,88$ & & 3,16 & & 0,35 & & 1,59 & & 0,70 & & $-2,68$ & & 7,10 & & 2,44 & & $-1,85$ & & $-4,00$ & & 0,63 & \\
\hline $\begin{array}{l}\text { caudal } \\
\text { t crítico uni- }\end{array}$ & 0,01 & & 0,00 & & 0,01 & & 0,01 & & 0,37 & & 0,08 & & 0,26 & & 0,01 & & 0,00 & & 0,02 & & 0,06 & & 0,00 & & 0,28 & \\
\hline caudal & 1,81 & & 1,83 & & 1,80 & & 1,83 & & 1,89 & & 1,94 & & 2,02 & & 1,78 & & 1,86 & & 1,83 & & 1,94 & & 1,81 & & 1,94 & \\
\hline $\begin{array}{l}\mathrm{P}(\mathrm{T}<=\mathrm{t}) \mathrm{bi}- \\
\text { caudal }\end{array}$ & 0,03 & & 0,01 & & 0,01 & & 0,01 & & 0,74 & & 0,16 & & 0,51 & & 0,02 & & 0,00 & & 0,04 & & 0,11 & & 0,00 & & 0,55 & \\
\hline $\begin{array}{l}\text { t crítico bi- } \\
\text { caudal }\end{array}$ & 2,23 & & 2,26 & & 2,20 & & 2,26 & & 2,36 & & 2,45 & & 2,57 & & 2,18 & & 2,31 & & 2,26 & & 2,45 & & 2,23 & & 2,45 & \\
\hline
\end{tabular}

